NIST Technical Note 2055

\title{
Compartment Fire Experiments on Long-Span Composite-Beams with Simple Shear Connections Part 2: Test Results
}

Lisa Choe Selvarajah Ramesh Matthew Hoehler Mina Seif Matthew Bundy John Reilly Branko Glisic

This publication is available free of charge from: https://doi.org/10.6028/NIST.TN.2055 
NIST Technical Note 2055

\section{Compartment Fire Experiments on Long-Span Composite-Beams with Simple Shear Connections Part 2: Test Results}

Lisa Choe, Selvarajah Ramesh, Matthew Hoehler, Mina Seif, Matthew Bundy Fire Research Division Engineering Laboratory, NIST

John Reilly and Branko Glisic Princeton University

This publication is available free of charge from:

https://doi.org/10.6028/NIST.TN.2055

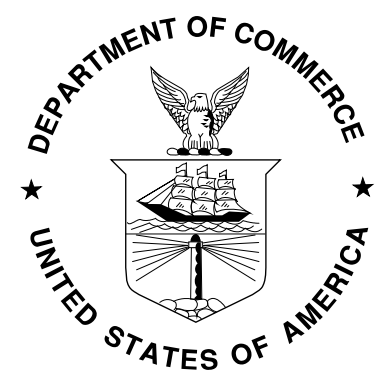

U.S. Department of Commerce Wilbur L. Ross, Jr., Secretary

National Institute of Standards and Technology Walter Copan, NIST Director and Undersecretary of Commerce for Standards and Technology 
This page intentionally left blank 
The policy of the National Institute of Standards and Technology is to use metric units in all its published materials. Because this report is intended for the U.S. building construction industry, in some cases U.S. customary units are used.

Certain commercial entities, equipment, products, or materials are identified in this document in order to describe a procedure or concept adequately. Such identification is not intended to imply recommendation or endorsement by the National Institute of Standards and Technology, nor is it intended to imply that the entities, products, materials, or equipment are necessarily the best available for the purpose.

The policy of the National Institute of Standards and Technology is to include statements of uncertainty with all NIST measurements. In this document, some measurements made by authors outside of NIST are presented, for which uncertainties were not reported and are unknown.

National Institute of Standards and Technology Technical Note 2055 Natl. Inst. Stand. Technol. Tech. Note 2055, 147 pages (November 2019) CODEN: NTNOEF

This publication is available free of charge from: https://doi.org/10.6028/NIST.TN.2055 
This page intentionally left blank 


\section{ABSTRACT}

This report presents the results of compartment fire experiments on four $12.8 \mathrm{~m}$ long composite floor beams with various end support conditions. Each specimen was constructed as a partiallycomposite beam, consisting of a lightweight concrete slab cast on $76 \mathrm{~mm}$ (3 in.) deep ribbed steel decking and a W18×35 steel beam acting compositely via $19 \mathrm{~mm}$ (3/4 in.) diameter steel headed stud anchors welded on the top flange. Test variables included two types of simple shear connections (shear-tab and welded-bolted double-angle connections) and the presence or absence of slab continuity over girders. Hydraulic actuators were used to apply gravity loads to the specimen under fire conditions. The natural gas-fueled burners were used to create a compartment fire with the maximum heat release rate of $4000 \mathrm{~kW}$. This study evaluated the characteristics of the fire loading and thermal and structural responses of the specimens. The test results indicated that the thermal restraint conditions significantly affected the behavior and failure modes of the specimens with simple shear connections. The specimens resisted gravity loads at large vertical displacements near midspan (approximately a ratio of the span length over 20) without collapse under fire loading. Various limit states and vulnerabilities to fires were observed, including local buckling of the steel beams near supports, flexural failure (yielding of steel beams and concrete fracture near restrained end supports), and connection failure (weld shear or bolt shear) during heating and cooling which could lead to partial or total collapse of the floor system.

Keywords: Compartment fire; Composite beam; Concrete slab; Simple shear connection; Experimental testing. 


\section{Preface}

This work was conducted as part of the project "Measurement of Structural Performance in Fire" under the National Institute of Standards and Technology (NIST) Engineering Laboratory's Fire Risk Reduction in Building Program. We thank William Baker (Skidmore, Owings \& Merrill), Craig Beyler (Jensen Hughes), Luke Bisby (University of Edinburgh), Ian Burgess (University of Sheffield), Charles Carter (AISC), Charles Clifton (University of Auckland), Michael Engelhardt (University of Texas), Graeme Flint (Arup), Nestor Iwankiw (Jensen Hughes), Kevin LaMalva (Simpson Gumpertz \& Heger), Roberto Leon (Virginia Tech.), and Amit Varma (Purdue University) for their expert consultation. We also thank the NIST colleagues including William Grosshandler, John Gross, Brian Story, Laurean DeLauter, Anthony Chakalis, Philip Deardorff, Marco Fernandez, Artur Chernovsky, Ana Sauca, Chao Zhang, Joseph Main, and Fahim Sadek for their significant contributions to design, construction, and execution of this test program. 


\section{TABLE OF CONTENTS}

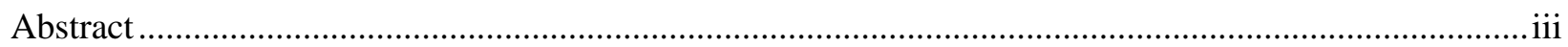

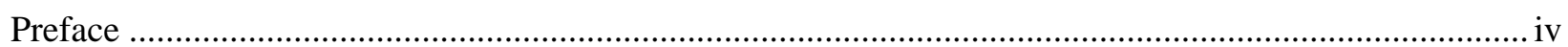

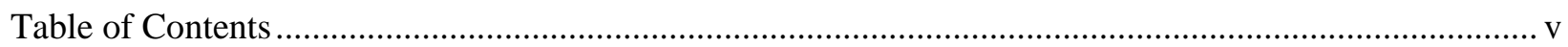

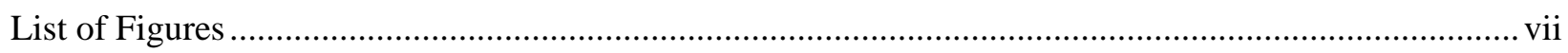

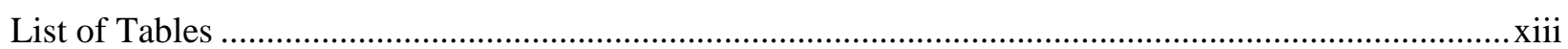

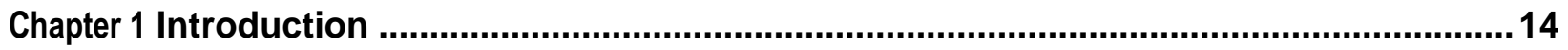

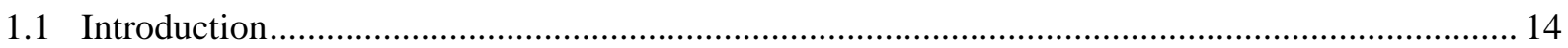

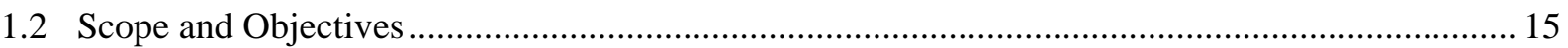

Chapter 2 Experimental Design ........................................................................................ 17

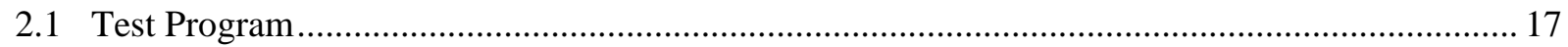

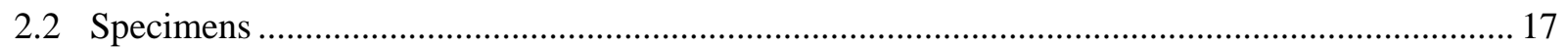

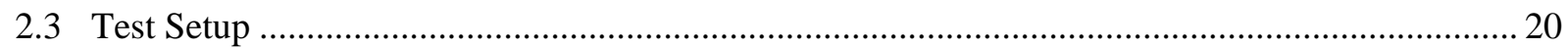

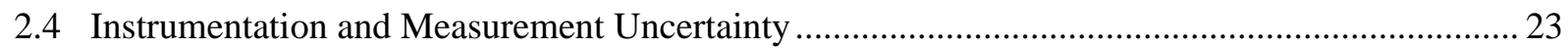

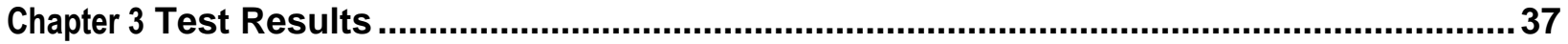

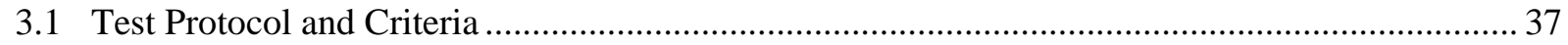

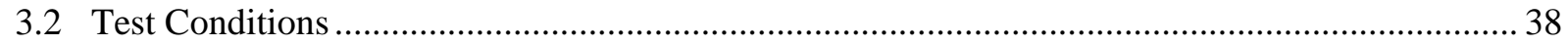

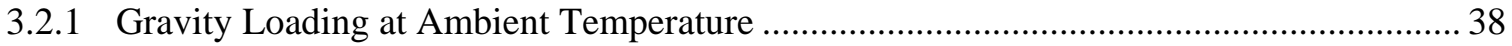

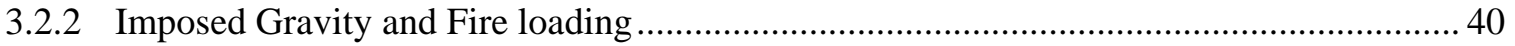

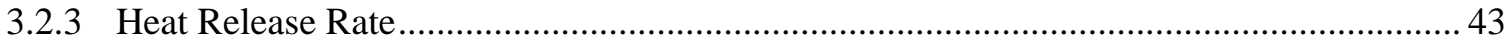

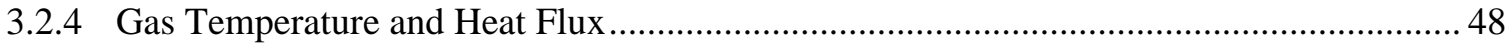

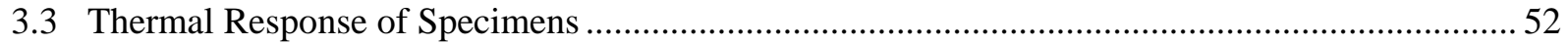

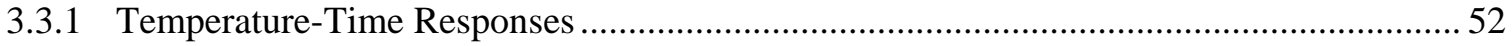

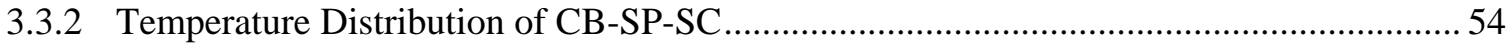

3.3.3 Challenges in Temperature Measurement of Steel Beams ................................................. 56

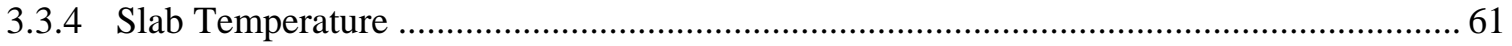

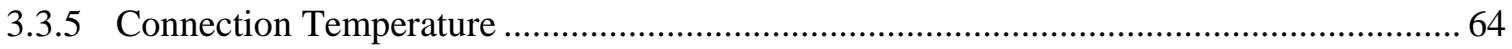

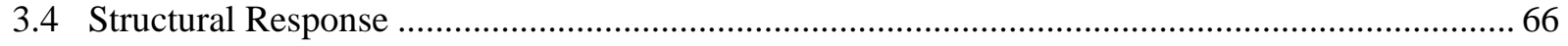

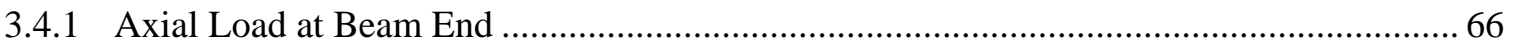

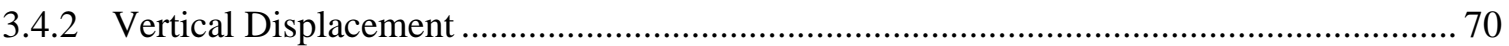




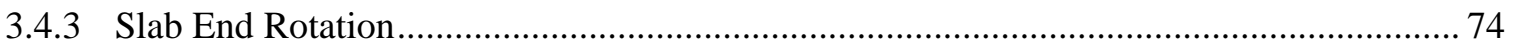

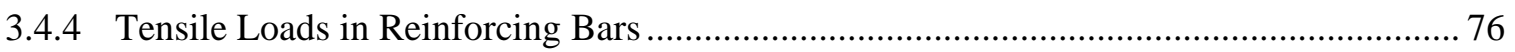

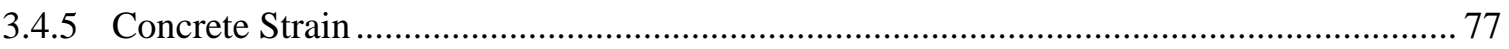

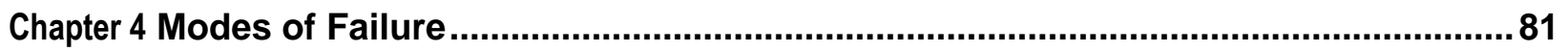

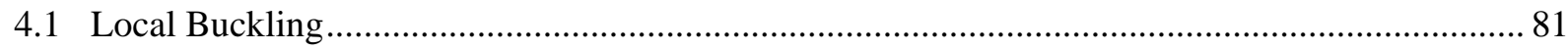

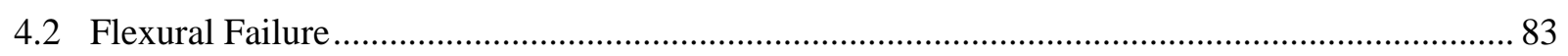

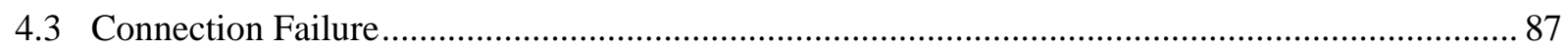

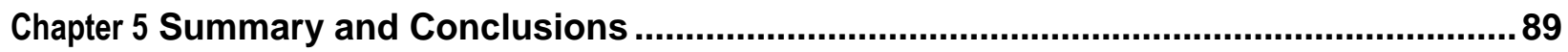

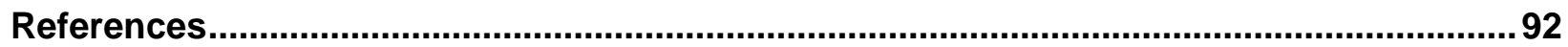

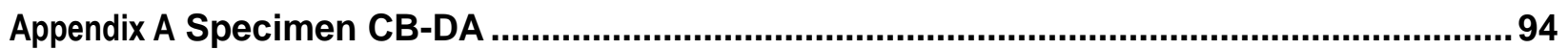

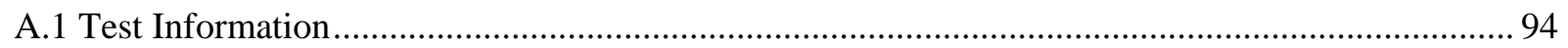

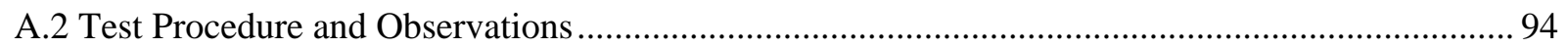

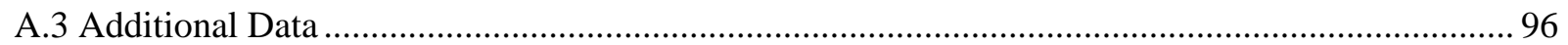

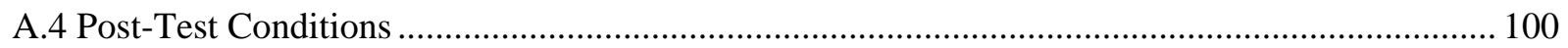

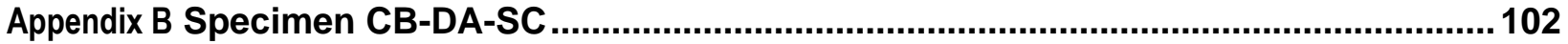

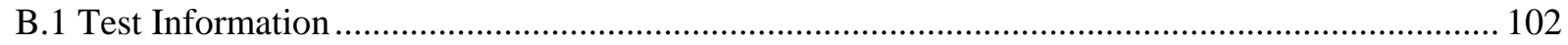

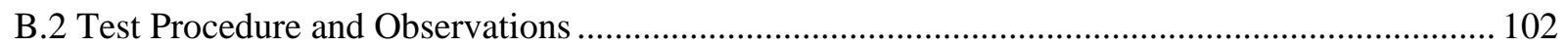

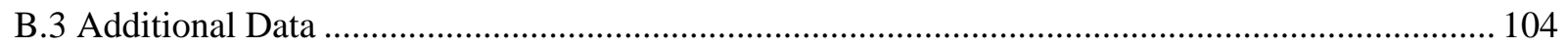

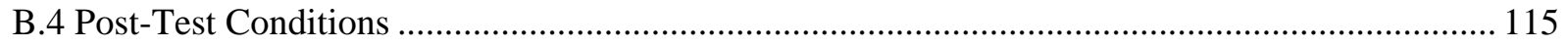

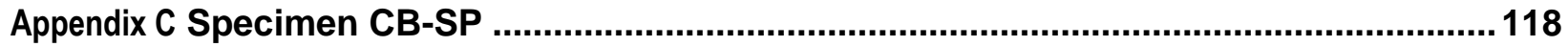

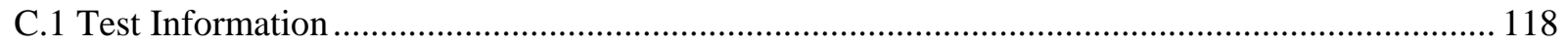

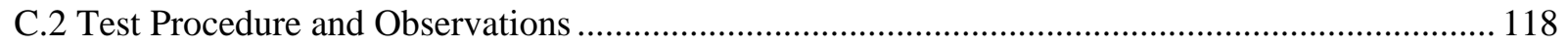

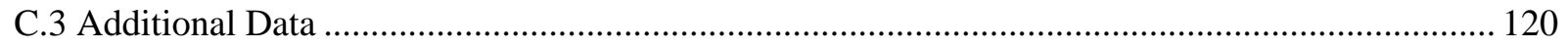

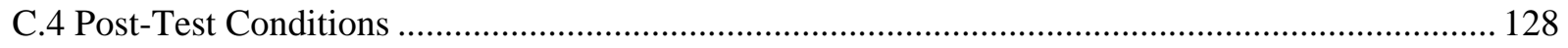

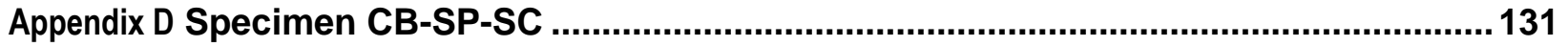

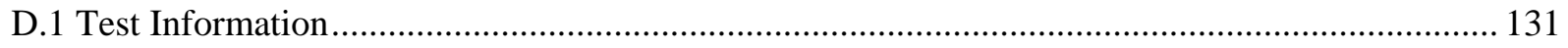

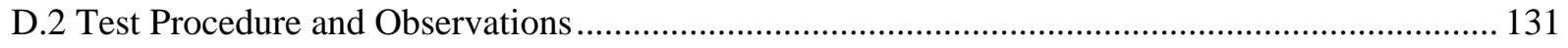

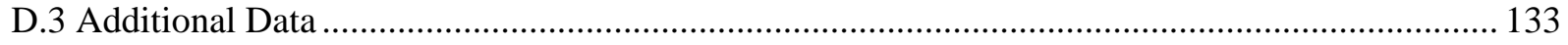

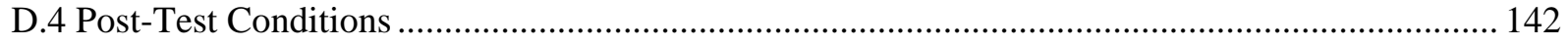




\section{LIST OF FIGURES}

Figure 1 The cross section of the specimens. Units $=\mathrm{mm}$. 18

Figure 2 Details of simple shear connections used the study: (a) double-angle, and (b) shear-tab (Ramesh et al. 2019).

Figure 3 Details of slab continuity used for the CB-DA-SC, and CB-SP-SC specimens (Ramesh et al. 2019).

Figure 4 (a) Scale drawing of test setup (front view), and (b) photograph of loading apparatus used for mechanical loading.

Figure 5 Photographs of (a) outside, and (b) inside of the test compartment.

Figure 6 (a) Top view, and (b) front view of the specimen with the instrument location of vertical displacements (VD2 through VD5) and end rotations (RotSlabWx; RotSlabWy; RotSlabEx; and RotSlabEy). Units are in inches $(1$ inch $=25.4 \mathrm{~mm})$.

Figure 7 Locations and labels of thermocouples mounted on the specimen: (a) section numbers $(x=1$ through 8), (b) glass-sheathed thermocouples in sections 1, 2, 7, and 8, (c) glass-sheathed thermocouples in sections 3, 4, 5, and 6, and (d) Inconel-sheathed thermocouples (STC1 through STC12). Units are in inches.

Figure 8 Locations and labels of thermocouples mounted on the specimen connections: (a) the west angle connection for CB-DA and CB-DA-SC, and (b) the west shear-tab connection for CB-SP and CBSP-SC. Units are in inches.

Figure 9 Thermocouples used for measurements of upper layer gas temperatures (TCC1 through TCC16) inside the test compartment and at ventilation openings (TCC17 through TCC24): (a) plan view, and (b) elevation view. Units are in inches.

Figure 10 Locations of plate thermometers (PT1 through PT3): (a) $5 \mathrm{~cm}$ from midspan of the specimen, and (b) $13 \mathrm{~cm}$ from exposed surface of the east wall. Units are in inches.

Figure 11 (a) Strain gauges mounted at west braced column (ColW1 through ColW8), (b) inclinometers mounted on loading trusses (RotLT1 through RotLT2), and (c) load cells mounted on \#4 reinforcing bars for specimens CB-DA-SC and CB-SP-SC. Units are in inches...... 35

Figure 12 Top view of the locations of Fiber Bragg Grating (FBG) sensors in CB-DA and CB-DA-SC

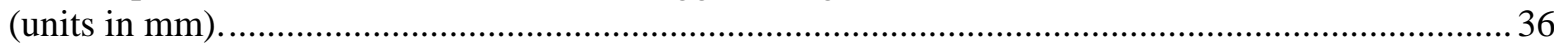

Figure 13 Side view of the locations of Fiber Bragg Grating (FBG) sensors in CB-DA and CB-DA-SC

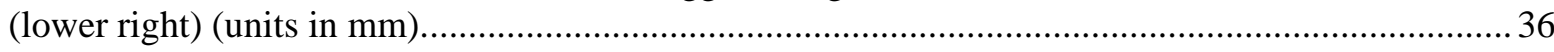

Figure 14 Average point load applied to (a) CB-DA, (b) CB-DA-SC, (c) CB-SP, and (d) CB-SP-SC at ambient temperatures. Error bars indicate the standard deviation of the six point loads distributed along the beam length.

Figure 15 Total mechanical load and HRRburner as a function of fire exposure time for the specimens

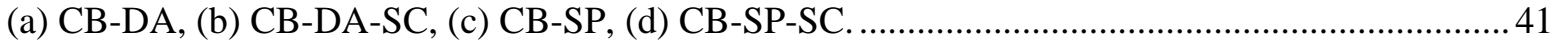

Figure 16 Distribution of point loads varying with fire exposure time for (a) CB-DA, (b) CB-DA-SC,

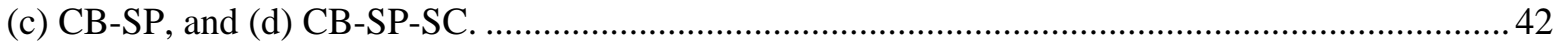

Figure 17 Heat release rates measured for (a) CB-DA, (b) CB-DA-SC, (c) CB-SP, and (d) CB-SP-SC... 44 
Figure 18 Snapshots of the video showing the test beam inside the compartment using a camera near vent openings at (a) $8 \mathrm{~min}$, (b) $12 \mathrm{~min}$, (c) $20 \mathrm{~min}$ from ignition. Specimen name: CB-DA-SC. .45

Figure 19 Snapshots of the video with the view from the east wall at (a) $12 \mathrm{~min}$, (b) $30 \mathrm{~min}$, and (c) 65 min from ignition. Specimen name: CB-DA-SC.

Figure 20 Snapshots of the video taken outside of the compartment at (a) $10 \mathrm{~min}$, and (b) $40 \mathrm{~min}$ from ignition. Specimen name: CB-DA-SC.

Figure 21 Upper layer gas temperature measured $81 \mathrm{~cm}$ below the exposed deck for (a) CB-DA, (b) CBDA-SC, (c) CB-SP, and (d) CB-SP-SC. Error bars indicate the standard deviation of readings from the eight thermocouples (TCC1 through TCC8) shown in Figure 9.

Figure 22 Gas temperature measured using thermocouple probes placed $2.5 \mathrm{~cm}, 23 \mathrm{~cm}$, and $81 \mathrm{~cm}$ below the exposed deck for (a) CB-DA, (b) CB-DA-SC, (c) CB-SP, and (d) CB-SP-SC. .50

Figure 23 Gas temperature measured using plate thermometers for (a) CB-SP, and (b) CB-SP-SC comparing with the heat release rates measured using oxygen calorimetry.

Figure 24 Calculated heat fluxes at locations of PT1 through PT3 shown in Figure 10: (a) CB-SP, and (b) CB-SP-SC

Figure 25 Temperature at various locations of the specimens for (a) CB-DA, (b) CB-DA-SC, (c) CB-SP, and (d) CB-SP-SC.

Figure 26 (a) Location of temperature measurements (units in inches. 1 inch $=25.4 \mathrm{~mm}$ ), and (b) average temperatures at various locations through the depth of CB-SP-SC.

Figure 27 Temperature distribution of CB-SP-SC along the longitudinal centerline at various times after the burner ignition. The burner was extinguished $73 \mathrm{~min}$ after ignition.

Figure 28 Photographs of thermocouples mounted to the steel beams with various insulation methods:

(a) high-temperature ceramic fabric and stainless-steel tubing for CB-DA-SC, (b) ceramic beads and fabric used to separate chromel and alumel wires for CB-SP (photo taken after test), (c) grooved SFRM coating for CB-SP-SC, and (d) Inconel-sheathed thermocouples. .58

Figure 29 Comparison of the bottom flange temperatures measured using glass-sheathed (TC) and Inconel-sheathed (STC) thermocouples for (a) CB-DA-SC, and (b) CB-SP. .59

Figure 30 Comparison of temperatures of (a) bottom flange, (b) middle web, and (c) top flange measured using glass-sheathed (TC) and Inconel-sheathed (STC) thermocouples for CB-SP-SC. Error bars indicate the maximum standard deviation of temperatures measured at multiple locations along the beam length.

Figure 31 Measured concrete temperatures in sections TC4 and TC5 shown in Figure 7 (directly above the W18×35 beam) for (a) CB-DA, (b) CB-DA-SC, (c) CB-SP, (d) CB-SP-SC..

Figure 32 Average temperatures on the north and south side of the concrete slab measured $45 \mathrm{~cm}$ to the east and west of the W18 335 beam for (a) CB-DA, (b) CB-DA-SC, (c) CB-SP, and (d) CB-SP-SC. Error bars indicate the maximum standard deviations of temperatures measured in eight sections (Figure 7) along the beam length.

Figure 33 Connection temperatures of (a) CB-DA, (b) CB-DA-SC, (c) CB-SP, and (d) CB-SP-SC measured using the thermocouples shown in Figure 8.

Figure 34 Measured axial strains developed in the braces of east and west columns for (a) CB-DA, (b) CB-DA-SC, (c) CB-SP, and (d) CB-SP-SC. Error bars indicate the maximum standard deviations of strains measured in the top and bottom diagonal braces shown in Figure 11a. 
Figure 35 Estimated thermally-induced axial loads at the ends of (a) CB-DA-SC, (b) CB-SP, and (c)

$\mathrm{CB}-\mathrm{SP}-\mathrm{SC}$ as a function of the bottom flange temperature. Error bars indicate the standard deviations of local buckling capacity.

Figure 36 Vertical displacement versus time relationship for specimens (a) CB-DA, (b) CB-DA-SC, (c) CB-SP, and (d) CB-SP-SC. 72

Figure 37 Deflected shapes of the speicmens: (a) CB-DA, (b) CB-DA-SC, (c) CB-SP, and (d) CB-SP-SC.

Figure 38 End rotations at the east and west ends as a function of the fire expsoure time for (a) CB-DA,

(b) CB-DA-SC, (c) CB-SP, and (d) CB-SP-SC.

Figure 39 Total tensile loads in the east and west reinforcing bars for the specimens (a) CB-DA-SC, and

(b) CB-SP-SC

Figure 40 Fiber Bragg Grating strain and applied load (NM + SM actuators) on CB-DA...................... 78

Figure 41 Fiber Bragg Grating strain and total applied zoom during concrete cracking for CB-DA test. . 79

Figure 42 CB-DA-SC test Fiber Bragg Grating strain...

Figure 43 Photographs of locally buckled ends of the W18 $\times 35$ steel beam: (a) CB-DA, (b) CB-DA-SC, and (c) fracture of bottom web toe of fillet (CB-DA-SC).

Figure 44 Photographs of locally buckled ends of the W18×35 steel beam: (a) CB-SP, and (b) CB-SP-SC.

Figure 45 Photographs of west end of (a) CB-DA-AMB after removal of concrete slab, and (b) CB-SP-SC after removal of SFRM and concrete slab. 84

Figure 46 Photographs of deflected shape of (a) CB-DA-AMB and (b) CB-DA-SC. 84

Figure 47 Photographs of deflected concrete slab of (a) CB-SP (side view), and (b) CB-SP-SC (top view).

Figure 48 Photographs of concrete cracks of (a) CB-DA-SC, and (b) CB-SP-SC near the west end after cool-down.

Figure 49 Photographs of beam-to-column connections after cool-down: (a) CB-DA (prying of angles at west end), (b) CB-DA-SC (weld fracture of east angle connection), (c) CB-SP (weld fracture of east shear tab), (d) CB-SP (weld fracture on a sacrificial plate connected to east column), (e) CB-SP-SC (east shear tab), and (e) CB-SP-SC (fracture of bolts used in east shear tab). 88

Figure 50 Actuator data of CB-DA: (a) loads, and (b) stroke lengths applied using six actuators (SW, NW, SM, NM, SE, and NE). Actuator stroke was not recorded after unloading. 96

Figure 51 Gas temperature data of CB-DA: (a) $81 \mathrm{~cm}$ below exposed steel decking and (b) above vent openings outside of the test compartment......

Figure 52 Concrete temperature along the longitudinal centerline of CB-DA: (a) sections TC1 and TC8, (b) sections TC2 and TC7, (c) sections TC3 and TC6, and (d) sections TC4 and TC5 .................. 97

Figure 53 Concrete temperature measured $45.7 \mathrm{~cm}$ from the north edge of CB-DA: (a) sections TC1 and TC8, (b) sections TC2 and TC7, (c) sections TC3 and TC6, and (d) sections TC4 and TC5............98

Figure 54 Concrete temperature measured $45.7 \mathrm{~cm}$ from the south edge of CB-DA: (a) sections TC1 and TC8, (b) sections TC2 and TC7, (c) sections TC3 and TC6, and (d) sections TC4 and TC5............99

Figure 55 Post-test images of CB-DA: (a) cracked SFRM near east connection, (b) west angle connection after SFRM was removed, (c) steel beam covered with SFRM that remained intact after test, and (d) 
fracture of weld between top of angle legs and a sacrificial plate attached to the flange of east column.

Figure 56 Actuator data of CB-DA-SC: (a) loads and (b) stroke lengths applied using six actuators (SW, NW, SM, NM, SE, and NE). Actuator stroke was not recorded after unloading. 104

Figure 57 (a) Rotations of three loading trusses placed on top of the concrete and (b) six-point loads during fire loading, where P1 through P6 are the point loads from east to west ends (CB-DA-SC).

Figure 58 Gas temperature data of CB-DA-SC: (a) $81 \mathrm{~cm}$ below exposed steel decking and (b) above vent openings outside of the test compartment. 105

Figure 59 Photograph of flames coming out from vent openings of the south compartment wall during fire loading (CB-DA-SC). 106

Figure 60 Concrete temperature along the longitudinal centerline of CB-DA-SC: (a) sections TC1 and TC8, (b) sections TC2 and TC7, (c) sections TC3 and TC6, and (d) sections TC4 and TC5 .......... 107

Figure 61 Concrete temperature measured $45.7 \mathrm{~cm}$ from the north edge of CB-DA-SC: (a) sections TC1 and TC8, (b) sections TC2 and TC7, (c) sections TC3 and TC6, and (d) sections TC4 and TC5 ... 108

Figure 62 Concrete temperature measured $45.7 \mathrm{~cm}$ from the south edge of CB-DA-SC: (a) sections TC1 and TC8, (b) sections TC2 and TC7, (c) sections TC3 and TC6, and (d) sections TC4 and TC5... 109

Figure 63 Temperatures of (a) exposed steel deck and (b) bottom flange temperature for CB-DA-SC. Discontinuity of data indicates dislodging of thermocouples.

Figure 64 Temperatures of (a) east and (b) west connection region for CB-DA-SC. Discontinuity of data indicates dislodging of thermocouples.

Figure 65 Tensile loads on No. 4 reinforcing bars anchored at (a) east and (b) west end (CB-DA-SC).. 111

Figure 66 Still image of a video viewing the outside of the test compartment at 40 min after the burner ignition (CB-DA-SC)

Figure 67 Still images of a video viewing the east connection region for CB-DA-SC. Time (min: sec) is recorded after the fire was ignited.

Figure 68 Still images of a video viewing top of the concrete near the east column for CB-DA-SC. Time (min: sec) is recorded after the fire was ignited.

Figure 69 Still images of a video viewing top of the concrete near the west column for CB-DA-SC. Time (min: sec) is recorded after the fire was ignited.

Figure 70 Photographs of (a) deflected shape of the steel beam covered with SFRM inside the test compartment, and (b) deformation of the concrete slab after cooling (CB-DA-SC)...

Figure 71 Photograph of concrete fracture and separation near the east column after the angle connection failed during cooling (CB-DA-SC). 116

Figure 72 Photograph of local web buckling of the steel beam connected to the west column after cooling (CB-DA-SC). 116

Figure 73 Photograph of shear studs at the west end after cooling (CB-DA-SC). 117

Figure 74 Actuator data of CB-SP: (a) loads and (b) stroke lengths applied using six actuators (SW, NW, SM, NM, SE, and NE). Actuator stroke was not recorded after unloading. 120

Figure 75 (a) Rotations of three loading trusses placed on top of the concrete and (b) six-point loads during fire loading, where P1 through P6 are the point loads from east to west ends (CB-SP)...... 120 
Figure 76 Gas temperature data of CB-SP: (a) $81 \mathrm{~cm}$ below exposed steel decking and (b) above vent openings outside of the test compartment.

Figure 77 Concrete temperature along the longitudinal centerline of CB-SP: (a) sections TC1 and TC8, (b) sections TC2 and TC7, (c) sections TC3 and TC6, and (d) sections TC4 and TC5.

Figure 78 Concrete temperature measured $45.7 \mathrm{~cm}$ from the north edge of CB-SP: (a) sections TC1 and TC8, (b) sections TC2 and TC7, (c) sections TC3 and TC6, and (d) sections TC4 and TC5.......... 123

Figure 79 Concrete temperature measured $45.7 \mathrm{~cm}$ from the south edge of CB-SP: (a) sections TC1 and TC8, (b) sections TC2 and TC7, (c) sections TC3 and TC6, and (d) sections TC4 and TC5.......... 124

Figure 80 Temperatures of (a) exposed steel deck and (b) bottom flange temperature for CB-SP. Discontinuity of data indicates dislodging of thermocouples.

Figure 81 Temperatures of (a) east and (b) west connection region for CB-SP. Discontinuity of data indicates dislodging of thermocouples.

Figure 82 Still images of a video viewing outside of the test compartment at (a) 20 min and (b) 64 min after the burner ignition (CB-SP).

Figure 83 Still images of a video viewing top of the concrete near the east column for CB-SP. Time (min: $\mathrm{sec})$ is recorded after the fire was ignited....

Figure 84 Photographs of the deflected shape of CB-SP: (a) front view and (b) perspective view..... 128

Figure 85 Photographs of CB-SP after cooling: (a) west connection region inside the test compartment and (b) east connection region after removal of the shear tab.

Figure 86 Photographs of CB-SP: (a) concrete slab at midspan after cut and (b) concrete slab and shear studs at west end.

Figure 87 Actuator data of CB-SP-SC: (a) loads and (b) stroke lengths applied using six actuators (SW, NW, SM, NM, SE, and NE). Actuator stroke was not recorded after unloading. 133

Figure 88 (a) Rotations of three loading trusses placed on top of the concrete and (b) six-point loads during fire loading, where P1 through P6 are the point loads from east to west ends (CB-SP-SC). 133

Figure 89 Gas temperature data of CB-SP-SC: (a) $81 \mathrm{~cm}$ below exposed steel decking and (b) above vent openings outside of the test compartment.

Figure 90 Concrete temperature along the longitudinal centerline of CB-SP-SC: (a) sections TC1 and TC8, (b) sections TC2 and TC7, (c) sections TC3 and TC6, and (d) sections TC4 and TC5.......... 135

Figure 91 Concrete temperature measured $45.7 \mathrm{~cm}$ from the north edge of CB-SP-SC: (a) sections TC1 and TC8, (b) sections TC2 and TC7, (c) sections TC3 and TC6, and (d) sections TC4 and TC5.... 136

Figure 92 Concrete temperature measured $45.7 \mathrm{~cm}$ from the south edge of CB-SP-SC: (a) sections TC1 and TC8, (b) sections TC2 and TC7, (c) sections TC3 and TC6, and (d) sections TC4 and TC5 ... 137

Figure 93 Temperatures of (a) exposed steel deck and (b) steel beam measured using Inconel sheathed thermocopules for CB-SP-SC. Discontinuity of data indicates dislodging of thermocouples.......... 138

Figure 94 Temperatures of steel beam measured using glass-sheathed thermocouples for CB-SP-SC: (a) sections TC1 and TC8, (b) sections TC2 and TC7, (c) sections TC3 and TC6, and (d) sections TC4 and TC5. Discontinuity of data indicates dislodging of thermocouples.

Figure 95 Temperatures of (a) east and (b) west connection region for CB-SP-SC. Discontinuity of data indicates dislodging of thermocouples. 140

Figure 96 Tensile loads on No. 4 reinforcing bars anchored at (a) east and (b) west end (CB-SP-SC)... 140 
Figure 97 Still images of a video viewing top of the concrete near the east column for CB-SP-SC. Time (min: sec) is recorded after the fire was ignited.

Figure 98 Photographs of CB-SP-SC after cooling: (a) deflected shape of the steel beam and (b) concrete slab after removal of loading frames.

Figure 99 Photographs of CB-SP-SC after cooling: (a) the west shear tab connected to the column and (b) east connection region where three bolts connecting the shear tab fractured.

Figure 100 Photographs of CB-SP-SC after cooling: (a) concrete fracture at east end and (b) cut section of the concrete slab at midspan above the steel beam. 


\section{LIST OF TABLES}

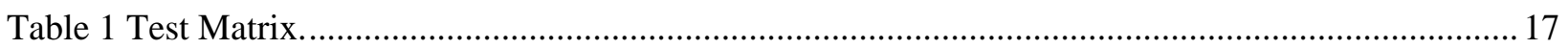

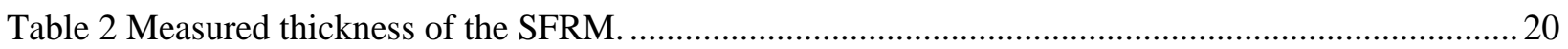

Table 3 Measured mechanical properties of steel components of composite beam specimens................. 20

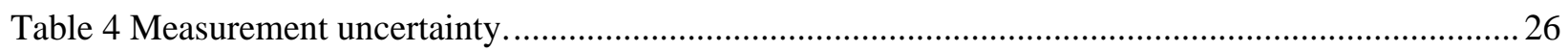

Table 5 Time-averaged values of the total mechanical load and point load maintained at ambient temperature; the values after \pm symbols indicate the standard deviation........................................ 38

Table 6 Time-averaged values of the total mechanical load, the initial and maintained HRRburner values and duration of the test fire; Values after \pm symbols indicate the standard deviation over time. ....... 41

Table 7 Thermocouple locations for Figure 22 and the average temperature while the burner heat release rate was set to $4000 \mathrm{~kW}$; the values after \pm symbols indicate the standard deviation. ...................... 50

Table 8 List of thermocouples used to estimate the average temperatures plotted in Figure 25.............. 53

Table 9 List of thermocouples used in Figure 25 and the mean and standard deviation of the measured temperatures at $60 \mathrm{~min}, 73 \mathrm{~min}$, and $258 \mathrm{~min}$ from the burner ignition. ..........................................54

Table 10 List of thermocouples used for temperature data plotted in Figure 30 for CB-SP-SC. .............. 59

Table 11 Thermocouples used in Figure 33 and the maximum average temperature of the beam-to-column connections with the test time.

Table 12 Strain gauges mounted on the column braces for estimation of axial loads plotted in Figure 34

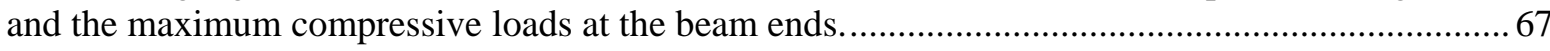

Table 13 List of displacement transducer channels used for vertical displacement measurements........... 70

Table 14 Test procedure and observations for CB-DA. Test time was recorded after the burner ignition and rounded to the nearest $1 \mathrm{~min}$.

Table 15 Test procedure and observations for CB-DA-SC. Test time was recorded after the burner ignition and rounded to the nearest 1 minute.

Table 16 Test procedure and observations for CB-SP. Test time was recorded after the burner ignition and rounded to the nearest $1 \mathrm{~min}$.

Table 17 Test procedure and observations for CB-SP-SC. Test time was recorded after the burner ignition and rounded to the nearest $1 \mathrm{~min}$. 


\section{Chapter 1 \\ INTRODUCTION}

\section{$1.1 \quad$ Introduction}

Composite floor beam assemblies, i.e., composite beams with end connections, are a common type of floor framing construction for multi-story steel buildings, which often require large column-free spaces. A typical length of composite beams used in commercial buildings ranges from $12 \mathrm{~m}$ to $15 \mathrm{~m}$ (SCI 2008). When exposed to fires, the behavior of composite floor beam assemblies becomes complex and difficult to predict using conventional design equations and methods for loading conditions at ambient temperatures. Temperatures of composite beams vary through the section depth and change over the duration of a fire, making it difficult to predict composite interaction between the concrete slabs and steel beams. Furthermore, thermal strains developed in long-span composite beams can introduce large forces and displacements that can be detrimental to some types of beam end connections (NIST 2008). Failure of these connections could trigger a partial or total collapse of a building.

In the United States, passive fire protection (construction measures that contain or slow the spread of fire or mitigate its impact that do not require active fire detection and suppression) is required for composite beam and floor assemblies as prescribed in national building codes, e.g., the International Building Code (IBC) (ICC 2018) and the Building Construction and Safety Code (NFPA 2018). Sprayed Fire-Resistive Materials (SFRM) are the most common insulation applied to exposed steel substrates of structural members and assemblies. Adequacy of insulating materials and associated installation details must be certified by standard fire testing, such as the American Society of Testing and Material (ASTM) E119 (ASTM 2019). The fire-resistance ratings, expressed in hours, for composite beam and floor assemblies installed with commercial insulation products can be found, for example, in the Underwriters Laboratory directory (http://productspec.ul.com/index.php).

However, the limiting criteria achieved during standard fire tests and structural responses of specimens (forces and displacements) generally remain proprietary information (ASCE 2018). The span of specimens subject to standard fire testing seldom exceeds $6 \mathrm{~m}$ due to size limitations of furnaces, and the beam end supports do not incorporate actual frame connections used in building constructions. Rather, the ends of specimens are either simply supported allowing free thermal expansion and rotation or fully fixed at the reaction frames. 
There has been renewed interest in the United States to develop performance-based design methods since the 9/11 World Trade Center disaster (ASCE 2018). Alternative engineering approaches have been established along with guidance and design references, e.g., Appendix 4 of the American National Standards Institute/American Institute of Steel Construction (ANSI/AISC) Specification for Structural Steel Buildings (AISC 2016) and the American Society of Civil Engineers (ASCE) Structural Fire Engineering (ASCE 2018). Simple calculation methods used for composite floor systems in fire, however, merely account for strength reduction in composite beams with idealized end supports at elevated temperatures. The suggested modeling approaches require rigorous validation against experimental data characterizing thermal restraints from surrounding frames and connections, which are not readily available. A significant need exists for experimental data providing the behavior and limit states of full-scale composite floor beam assemblies exposed to realistic fires, incorporating medium-to-long spans of floor beam assemblies commonly used in industry practice. Such information cannot be achieved by standard fire testing with furnaces.

The National Institute of Standards and Technology (NIST) has proposed the experimental research project on full-scale composite floor systems exposed to realistic, structurally significant fires. The purpose of this project is to produce the experimental data and technical information essential for both development and validation of computational models used for performancebased design of structures in fire. This research project consists of a series of fire experiments conducted at the National Fire Research Laboratory (NFRL) on long-span composite beam assemblies (Phase I) and composite floor assemblies constructed as part of a multi-bay steel framed building (Phase II), as well as possible future work on subassemblies. The Phase I experimental tests were completed in 2018, and the Phase II study is currently in progress.

This report presents the results of the Phase I fire experiments.

\section{$1.2 \quad$ Scope and Objectives}

A series of compartment fire experiments was conducted on $12.8 \mathrm{~m}$ long composite floor beam assemblies resisting mechanically-applied gravity loads. The objectives of this study were as follows:

1) to design a repeatable test fire that can be used for large-scale fire experiments to study the limit states of composite floor beam assemblies subjected to uncontrolled fires, 
2) to evaluate the performance and failure mechanisms of restrained composite beams with simple shear connections subjected to heating and cooling phases of a test fire, and

3) to assist development or validation of numerical models that predict the structural responses of composite beam and floor assemblies under realistic fire conditions.

For this test program, the composite beam specimens were constructed as a partially-composite floor beam assembly commonly designed for steel framed buildings in the United States. Test variables included two types of simple shear connections (i.e., shear-tab and double-angle connections) and the presence or absence of slab continuity over girders. The specimens were loaded to gravity loads (approximately $45 \%$ of the ambient capacity) applied using hydraulic actuators. For thermal loading, a $4000 \mathrm{~kW}$ compartment fire was produced using natural gas-fueled burners and resulted in the average upper layer gas temperature of approximately $1000{ }^{\circ} \mathrm{C}$ inside the test compartment. The Part 1 report (Ramesh et al. 2019) describes details of the experimental design, including design and construction of the composite beam specimens and reaction frames, design of a test fire, measurement systems, and the ambient capacity and behavior of the composite beam specimen.

This report (Part 2) presents the experimental test results of four $12.8 \mathrm{~m}$ long composite floor beam assemblies exposed to compartment fires, including (1) imposed gravity loading and fire conditions, (2) thermal (temperatures) and structural responses (displacements and forces) of the specimens, and (3) observed modes of failure of the specimens during fire loading and cooling. In addition, the challenges in temperature measurements as well as recommendations from this research are discussed. 


\section{Chapter 2 \\ EXPERIMENTAL DESIGN}

Design, construction, and condition of the test beams and experimental test setup are detailed in the companion report (Ramesh et al. 2019) and summarized herein.

\section{$2.1 \quad$ Test Program}

Table 1 shows the test matrix with investigated variables including two types of simple shear connections (welded-bolted double-angle versus shear-tab connections) and the presence or absence of slab continuity over the girders. The first specimen (CB-DA-AMB) was tested at ambient temperature to investigate the behavior, failure modes, and ultimate moment capacity (Mиа) as presented in Ramesh et al. (2019). The remaining four specimens were tested under combined mechanical and fire loading. The imposed flexural load $(M)$ on these specimens conformed to the ASCE 7 gravity load combination for extraordinary events $(1.2 \times$ dead load + $0.5 \times$ live load), equivalent to approximately $45 \%$ of $M_{u a}$.

Table 1 Test Matrix.

\begin{tabular}{lllllll}
\hline Test No. & Specimen name & Test date & $\begin{array}{l}\text { Simple shear } \\
\text { connections }\end{array}$ & $\begin{array}{l}\text { Slab end } \\
\text { continuity }\end{array}$ & $M / M_{u a}$ & $\begin{array}{l}\text { Fire } \\
\text { Load }\end{array}$ \\
\hline 1 & CB-DA-AMB & $09 / 21 / 2017$ & Double-angles & - & 1 & - \\
2 & CB-DA & $12 / 19 / 2017$ & Double-angles & - & 0.45 & $4000 \mathrm{~kW}$ \\
3 & CB-DA-SC & $01 / 12 / 2018$ & Double-angles & Included & 0.45 & $4000 \mathrm{~kW}$ \\
4 & CB-SP & $02 / 13 / 2018$ & Shear tab & - & 0.45 & $4000 \mathrm{~kW}$ \\
5 & CB-SP-SC & $03 / 06 / 2018$ & Shear tab & Included & 0.45 & $4000 \mathrm{~kW}$ \\
\hline
\end{tabular}

\section{$2.2 \quad$ Specimens}

All four specimens tested under fire conditions had an identical cross section (Figure 1). Each test beam consisted of a lightweight concrete slab on $76 \mathrm{~mm}$ deep, ribbed steel decking supported by a W18×35 steel beam. The steel deck was oriented perpendicular to the steel beam. The thickness of the topping concrete (over the top ribs) was $83 \mathrm{~mm}$ (3.25 in.). The slab width of the specimen was $1.83 \mathrm{~m}$ ( $6 \mathrm{ft}$.). Each W18×35 steel beam was partially-composite with the concrete slab using $19 \mathrm{~mm}$ (3/4 in.) steel headed stud anchors welded at the top flange. Shear studs were welded off- 
center to the deck ribs in 'strong' positions for a horizontal shear according to ANSI/AISC 360 and placed at a spacing of $305 \mathrm{~mm}$ (12 in.). The resulting composite action (i.e., the total shear strength provided by studs) was equivalent to $82 \%$ of the yield strength of the W18 $\times 35$ beam. For shrinkage reinforcement of the slab, $6 \times 6 \mathrm{~W} 1.4 \times \mathrm{W} 1.4$ welded wire fabric $(3.4 \mathrm{~mm}$ diameter plain steel wires in $150 \mathrm{~mm}$ grids) were placed at the mid-height of the topping concrete according to the ANSI/Steel Deck Institute (ANSI/SDI) C-2017 (SDI 2017) requirement (0.075\% of area of the concrete above the deck). The length of the steel beam, the center-to-center distance between the bolt lines on the beam web, and the distance between the centerlines of the two columns were $12.3 \mathrm{~m}, 12.2 \mathrm{~m}$, and $12.8 \mathrm{~m}$, respectively.

The specimens were coated with a commercially-available Sprayed Fire Resistive Material (SFRM) with the thickness required for the 2-hour fire-resistance rating according to the IBC code. The beam-to-column connection region were protected with the same SFRM material with the thickness required for the 3-hour rating of W12×106 steel columns. The manufacturer's specified minimum density of SFRM was $352 \mathrm{~kg} / \mathrm{m}^{3}$. Prior to each fire test, the SFRM thickness was measured in accordance with the ASTM E 605 standard (ASTM 2015). The average values and standard deviations are presented in Table 2.

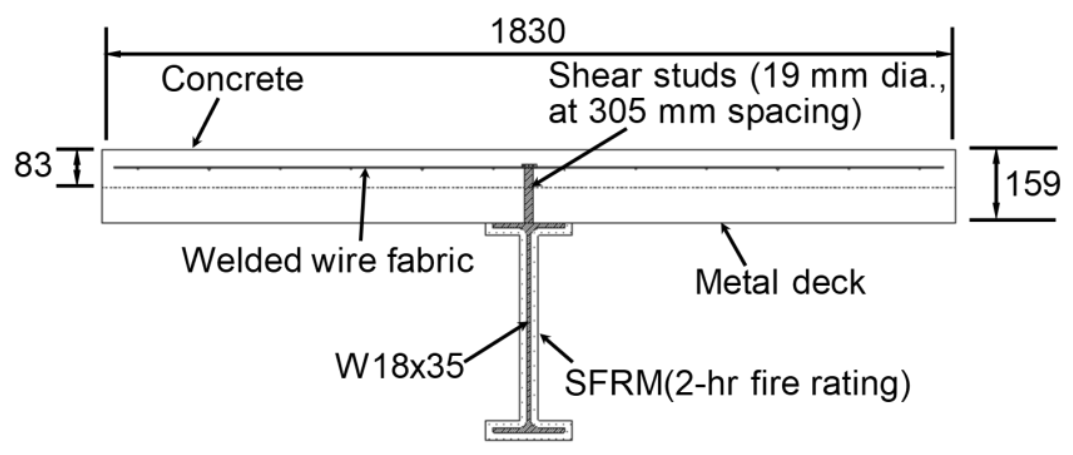

Figure 1 The cross section of the specimens. Units $=\mathbf{m m}$.

Figure 2 shows the simple shear connections used in this study, including the double-angle connection using structural steel angles (L5 $\times 3 \times 3 / 8)$ and the shear-tab connection using an $11 \mathrm{~mm}$ thick steel plate. The bottom flanges of the steel beams were coped only for the specimens with double-angle connections. The connections were bolted to the beam web using three $19 \mathrm{~mm}$ diameter high-strength structural steel bolts spaced $76 \mathrm{~mm}$ on center and welded to a $19 \mathrm{~mm}$ thick sacrificial plate attached to the column flanges using $8 \mathrm{~mm}$ fillet welds (E70XX electrodes). This sacrificial plate was replaced for each test. The use of these sacrificial plates helped to minimize damage to the column flange and allowed the reuse of the support columns. 


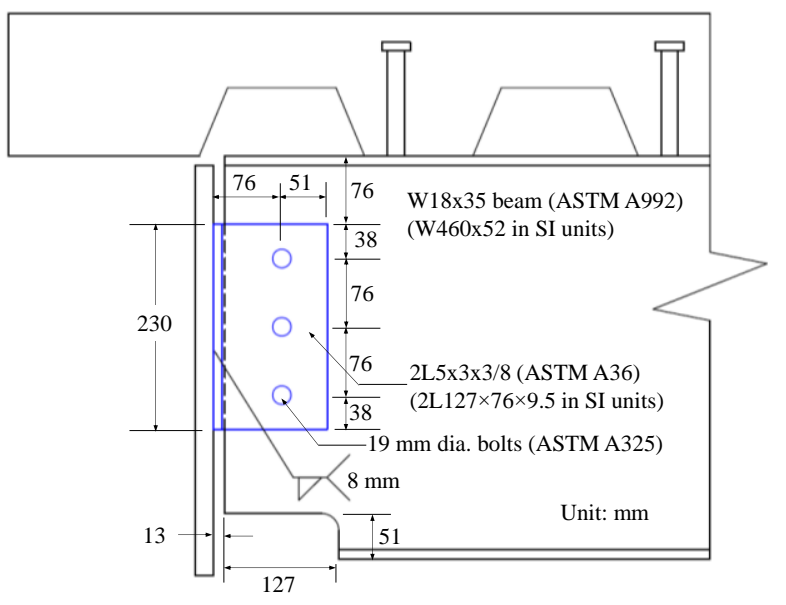

(a)

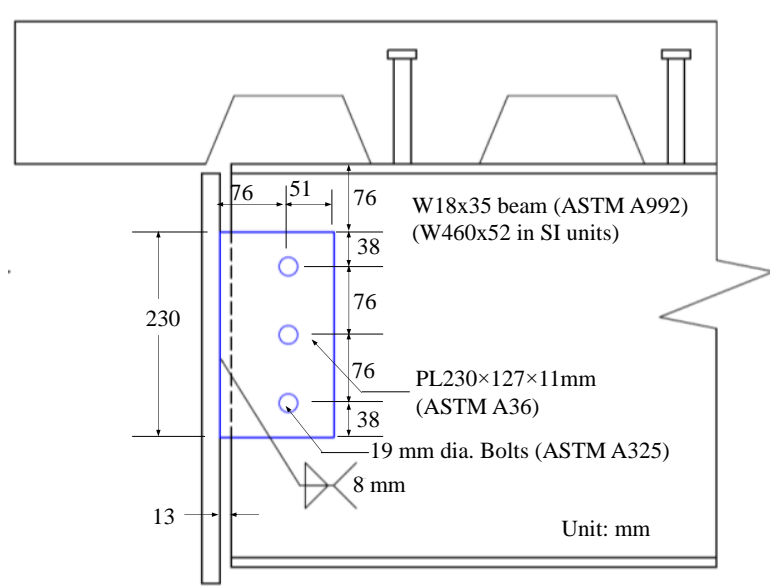

(b)

Figure 2 Details of simple shear connections used in the study: (a) double-angle, and (b) shear-tab (Ramesh et al. 2019).

Figure 3 shows details of the slab continuity used for the CB-DA-SC and CB-SP-SC specimens. To simulate a continuous slab over a support girder, both the embedded wire mesh and four $762 \mathrm{~mm}$ long No. 4 (12.7 mm diameter) reinforcing bars spaced $46 \mathrm{~cm}$ on average were anchored at the centerline of the columns.

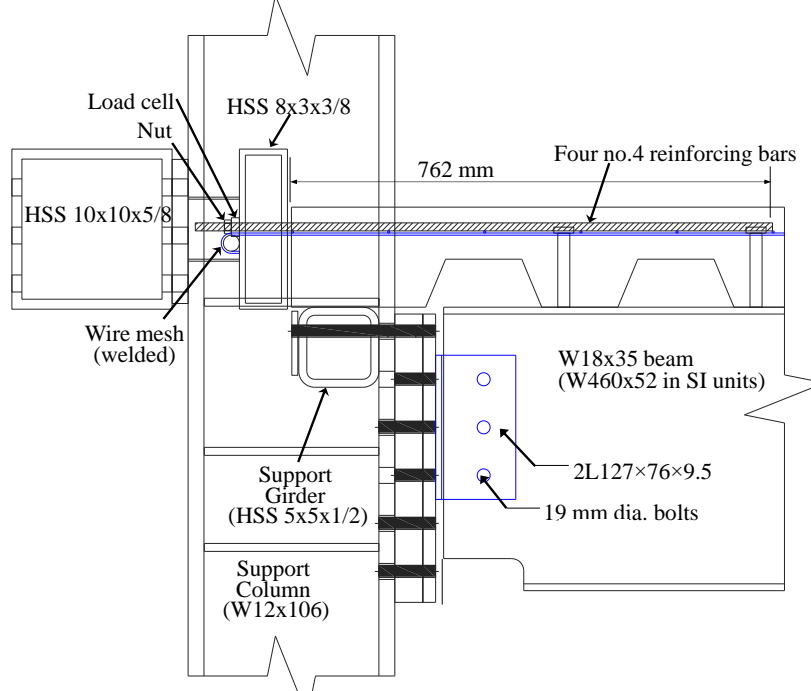

Figure 3 Details of slab continuity used for the CB-DA-SC, and CB-SP-SC specimens (Ramesh et al. 2019). The ASTM E8 standard (ASTM 2016) was used to measure the ambient mechanical properties of the steel components of the specimens as presented in Ramesh et al (2019). Table 3 shows a summary of the elastic modulus $(E)$, the yield stress measured at $0.2 \%$ strain $\left(F_{y}\right)$, the 
ultimate tensile stress $\left(F_{u}\right)$, and \% elongation $\left(\varepsilon_{u}\right)$ at break, measured at ambient temperature. The concrete mixture was designed to provide a lightweight aggregate concrete with a low propensity for thermally-induced spalling. Monofilament polypropylene microfibers of $2.37 \mathrm{~kg} / \mathrm{m}^{3}$ and an expanded slate lightweight aggregate with low water-retention characteristics and high desorption (Pour-Ghaz et al. 2012) were used. The mean 28-day concrete strength was 45.4 MPa. After curing of 6 months, internal relative humidity in the concrete dropped to about $80 \%$. The first fire specimen (CB-DA) was tested approximately 1 year after the concrete placement.

Table 2 Measured thickness of the SFRM.

\begin{tabular}{lccc}
\hline \multirow{2}{*}{$\begin{array}{l}\text { Specimen } \\
\text { name }\end{array}$} & \multicolumn{3}{c}{ Final average measured thickness $(\mathrm{mm})$} \\
\cline { 2 - 4 } & Steel beam & $\begin{array}{c}\text { Connection } \\
\text { elements }\end{array}$ & $\begin{array}{c}\text { Steel beam web near the edge } \\
\text { of connections }\end{array}$ \\
\hline CB-DA & $20 \pm 3$ & $28 \pm 7$ & $22 \pm 3$ \\
CB-DA-SC & $18 \pm 3$ & $26 \pm 3$ & $24 \pm 1$ \\
CB-SP & $19 \pm 3$ & $31 \pm 7$ & $24 \pm 5$ \\
CB-SP-SC & $19 \pm 4$ & $32 \pm 2$ & $24 \pm 4$ \\
\hline
\end{tabular}

Table 3 Measured mechanical properties of steel components of composite beam specimens.

\begin{tabular}{|c|c|c|c|c|c|}
\hline Steel Components & ASTM Designation & $E$ (MPa) & $F_{y}(\mathrm{MPa})$ & $F_{u}(\mathrm{MPa})$ & $\varepsilon_{u}(\%)$ \\
\hline $\mathrm{W} 18 \times 35$ & A992 & $2.03 \mathrm{E}+05$ & $3.60 \mathrm{E}+02$ & $4.70 \mathrm{E}+02$ & 18 \\
\hline shear tab & A36 & $2.06 \mathrm{E}+05$ & $3.48 \mathrm{E}+02$ & $4.86 \mathrm{E}+02$ & 20 \\
\hline L5 $53 \times 3 / 8$ angle & A36 & $1.97 \mathrm{E}+05$ & $3.79 \mathrm{E}+02$ & $5.11 \mathrm{E}+02$ & 17 \\
\hline structural steel bolts & $\mathrm{F} 3125$ (A325) & $2.06 \mathrm{E}+05$ & $9.02 \mathrm{E}+02$ & $9.61 \mathrm{E}+02$ & 6 \\
\hline \#4 reinforcing bar & A615 & $1.90 \mathrm{E}+05$ & $4.69 \mathrm{E}+02$ & 7.07E+02 & 11 \\
\hline shear stud & A29 & $2.06 \mathrm{E}+05$ & $4.08 \mathrm{E}+02$ & $5.05 \mathrm{E}+02$ & 5 \\
\hline welded wire fabric & A185 & $2.02 \mathrm{E}+05$ & $7.28 \mathrm{E}+02$ & $7.57 \mathrm{E}+02$ & 1 \\
\hline
\end{tabular}

\section{$2.3 \quad$ Test Setup}

Figure $4 \mathrm{a}$ show the front view of the test setup. The composite beam specimens were attached to the W12×106 columns via simple shear connections as in Table 1. Each specimen was mechanically loaded at six points using three loading beam assemblies. The north and south ends of each loading beam were connected to hydraulic actuators (mounted below the laboratory strong floor) via steel tension bars although they are not shown in this figure. Forces applied at the ends 
of the loading beams were transferred to the specimen via loading trusses which were pinconnected at midspan of the loading beams. Steel roller bearings were placed at the interface of the loading trusses and the concrete slab to minimize friction effects.

Figure $4 \mathrm{~b}$ shows a photograph of the top of the specimen. The sides of the concrete slab of the specimen were laterally braced at three points (spaced $4.3 \mathrm{~m}$ ), using the braces attached to the loading beam. These braces helped to prevent tilting of the concrete slab while the long-span specimen was loaded under fire condition. The loading beams were mechanically guided to move vertically together with the specimen and maintained level using displacement control of the connected actuators. Simultaneously, the total mechanical loads applied on the specimen remained nearly constant using force control of the actuators.

Figure 5a shows a photograph of the west side of the test setup. A set of brace modules was used to laterally brace the columns at the location of the beam-end connection, which simulated restraints to thermal elongation or contraction of the composite beam specimen. Prior to the fire experiment, the stiffness of the braced column was measured by applying a lateral load at the elevation where the beam-to-column connection was presumed to be located. The bending stiffness of the braced column was $190 \mathrm{kN} / \mathrm{mm}$ for a lateral force pushing the column away from the test compartment and $170 \mathrm{kN} / \mathrm{mm}$ for a lateral force pulling the column toward the test compartment.

The test compartment was approximately $380 \mathrm{~cm}$ in height, $1250 \mathrm{~cm}$ in length and $200 \mathrm{~cm}$ in width. Enclosing walls were constructed of sheet steel on steel studs protected by two layers of $25 \mathrm{~mm}$ thick ceramic fiber blanket on the fire-exposed side (Figure $5 \mathrm{~b}$ ). The side walls were placed outside of the concrete slab so that they were not loaded during the experiment (Figure 4b). The vent openings were on the $1250 \mathrm{~cm}$ long walls only, with a total area of about $5 \mathrm{~m}^{2}$. Three $1 \mathrm{~m} \times$ $1.5 \mathrm{~m}$ burners with a rating up to $4000 \mathrm{~kW}$ each were used to distribute the fire throughout the test compartment. Natural gas was used as the fuel because it allowed independent and nearinstantaneous control of heat release rate during the experiment. The design basis and development of the test fire conditions are detailed in the Part 1 report (Ramesh et al. 2019). 


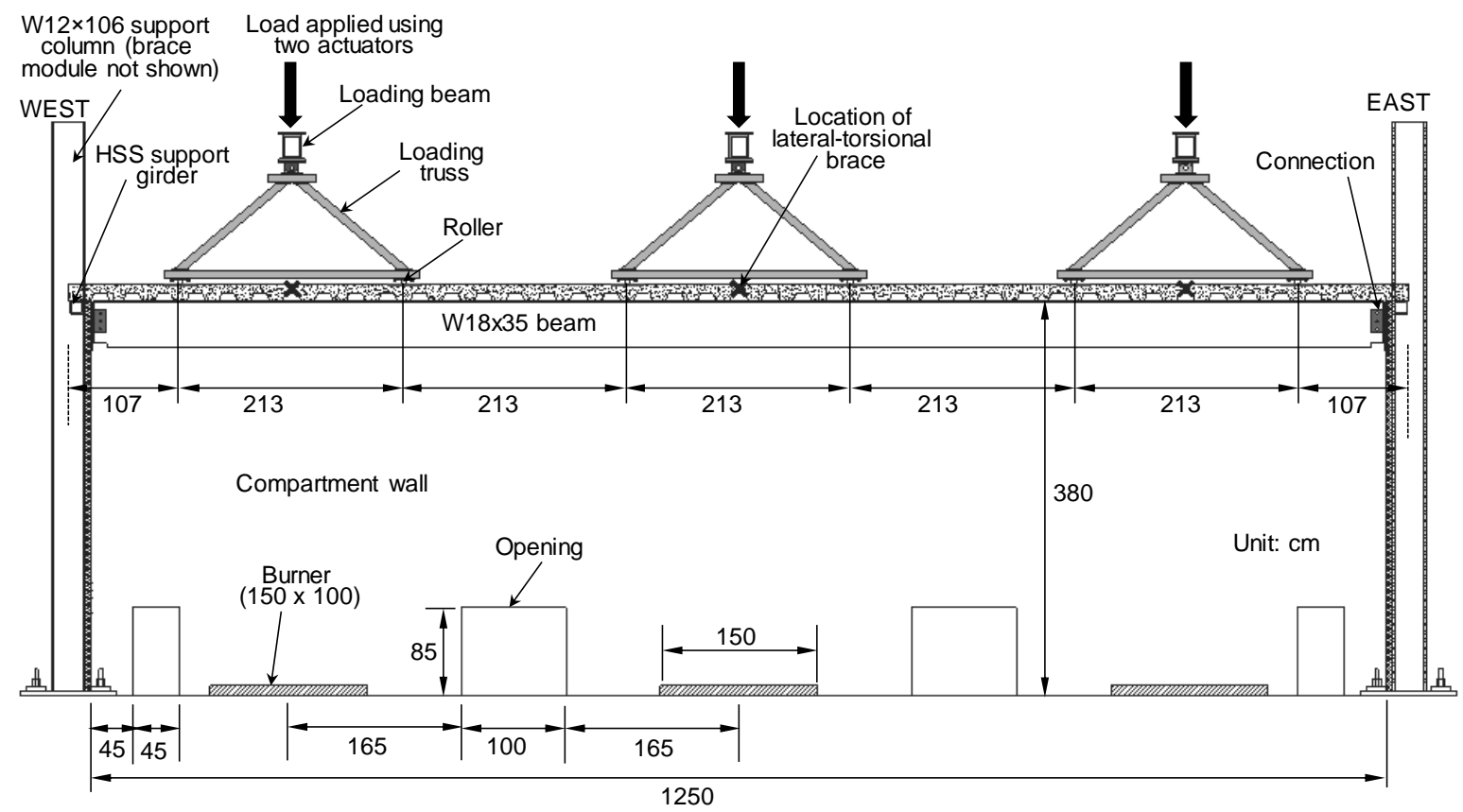

(a)

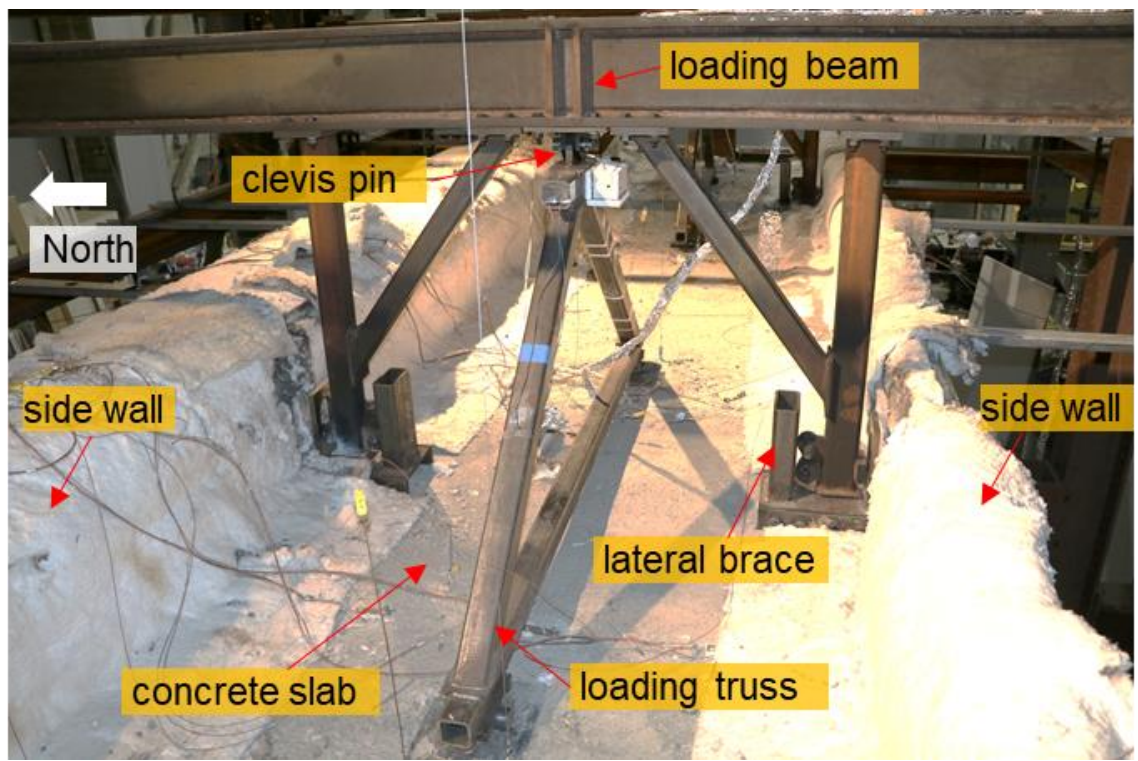

(b)

Figure 4 (a) Scale drawing of test setup (front view), and (b) photograph of loading apparatus used for mechanical loading. 


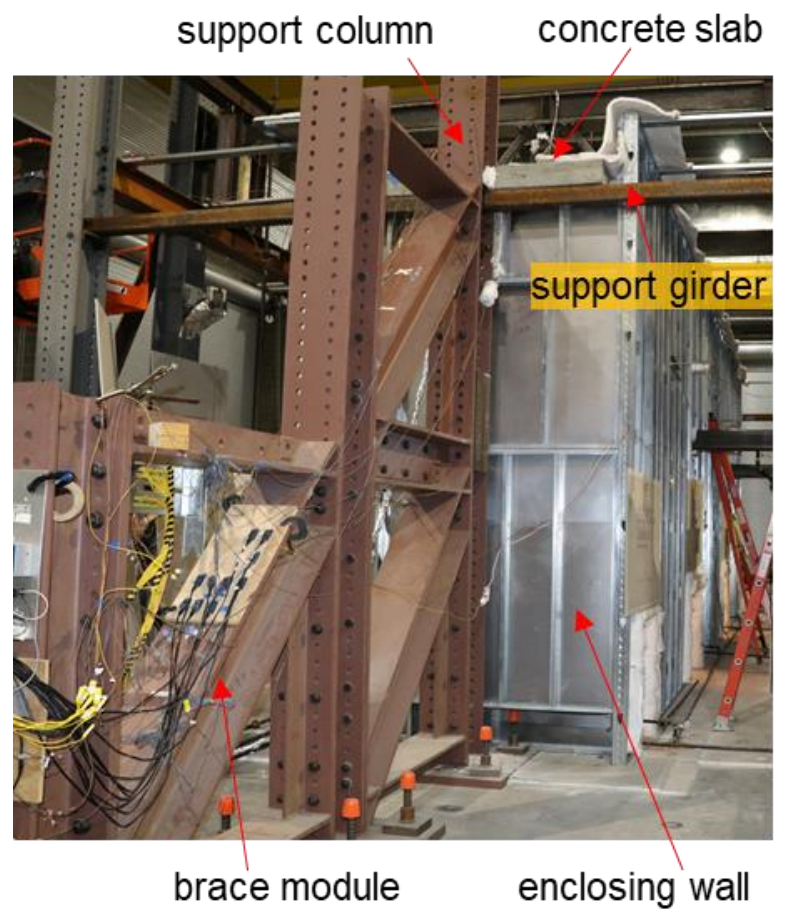

(a)

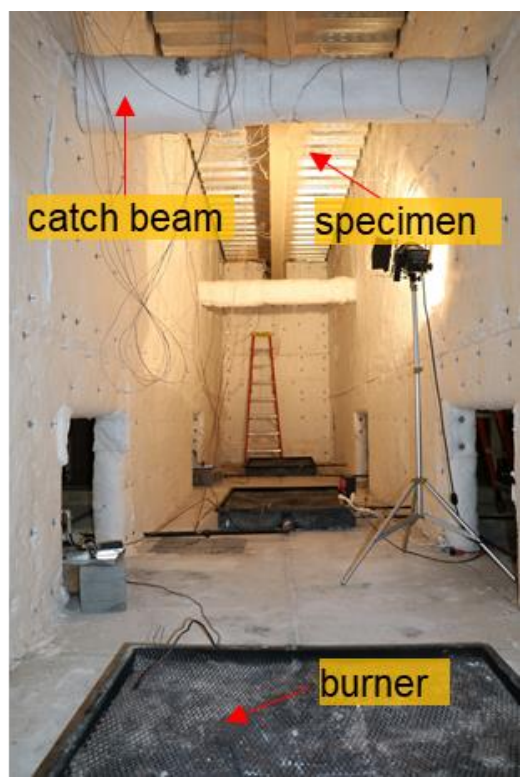

(b)

Figure 5 Photographs of (a) outside, and (b) inside of the test compartment.

\section{$2.4 \quad$ Instrumentation and Measurement Uncertainty}

Approximately 290 sensors were used to measure the test conditions as well as the thermal and structural response of the specimens. Temperature and displacement of the specimens were recorded up to approximately 3 hours after extinguishment of a fire. Details of instruments, data acquisition, and recording system are presented in the companion report (Ramesh et al. 2019).

Figure 6 shows the location of resistive-based transducers to measure vertical displacements and end rotations of the specimen. The vertical displacement of the specimen was measured at four locations along the beam length (VD1 through VD4). A measuring string of each transducer was attached to the top surface of steel bearing plates embedded into the concrete slab at the location of point loads. Two dual-axis inclinometers were mounted on the top of the concrete slab to measure the end rotations resulted from bending of the specimen (RotSlabEx and RotSlabWx) and tilting of the concrete slab at the same location (RotSlabEy and RotSlabWy). All these sensors were located outside of the fire compartment and thermocouples were used to monitor temperatures at the sensor locations. 
Temperatures of the specimens were measured using glass-sheathed type- $\mathrm{K}$ thermocouples mounted at eight locations along the length, sections TC1 through TC8 (Figure 7a). Figure 7b and Figure 7c show the locations of thermocouple beads across each of those eight sections. For the CB-DA-SC, CB-SP, and CB-SP-SC specimens, Inconel-sheathed type-K thermocouples were added to measure temperature of the steel beams, STC1 through STC12 (Figure 7d). Figure 8 shows the thermocouple layout in the west connection region; similar labels and locations of thermocouples were used for the east connection region.

Figure 9 shows location of thermocouples to measure the gas temperature inside the compartment and at ventilation openings. To characterize the average upper layer gas temperature, a total of eight Inconel-shielded type-K thermocouples were installed $81 \mathrm{~cm}$ below the steel deck of the specimens (TCC1 through TCC8); four at $23 \mathrm{~cm}$ below exposed steel decking (TCC10, TCC12, TCC14, and TCC16); four at $2.5 \mathrm{~cm}$ below exposed steel decking (TCC9, TCC11, TCC13, and TCC15); and eight glass-sheathed type- $\mathrm{K}$ thermocouples at the ventilation openings on the unexposed surface of the compartment (TCC17 through TCC24). Three plate thermometers (PT1 through PT3) were used in the testing of two specimens, CB-SP and CB-SP-SC, to measure the gas temperature and heat flux on the east wall: one at $86 \mathrm{~cm}$ below the steel deck, another at $6 \mathrm{~cm}$ below the bottom flange near mid span, and the other at $10 \mathrm{~cm}$ from the middle web of the steel beam near midspan (Figure 10).

Figure 11 shows the instrumentation layout for the columns and other loading frames. Strain gauges mounted on the brace modules of the column were used to measure the change in thermallyinduced axial loads at the beam ends (Figure 11a). The rotations of three loading trusses were measured using inclinometers (Figure 11b). For the specimens with slab continuity, CB-DA-SC and CB-SP-SC, tensile forces developed on the No.4 reinforcing bars were measured using through-hole load cells (Figure 11c). All these sensors were located outside of the fire compartment and thermocouples were added to monitor operating temperatures of these sensors.

The ends of the loading beams were connected to two, coupled hydraulic actuators (mounted in the basement) via high-strength tension bars. A total of six actuators were used to measure applied forces (LoadNE; LoadSE; LoadNM; LoadSM; LoadNW; LoadSW) and displacements (DispNE; DispSE; DispNM; DispSM; DispNW; DispSW).

Optical fiber sensors were used to measure strain in the concrete with both distributed (ambient only) and grating-based (ambient and elevated temperature) sensors. Information on the distributed fiber optic sensors (DFOS) are in the Part 1 report. Fiber Bragg Grating (FBG) strain sensors were embedded in the concrete deck in specimens CB-DA-AMB, CB-DA, and CB-DA-SC. These 
sensors measured an average change in strain over their gauge length. The FBG sensors have a measurement standard uncertainty of $\pm 3.1 \mu \varepsilon$. The FBGs in specimens CB-DA and CB-DA-SC, which were subjected to fire loading, had a gauge length of $25 \mathrm{~cm}$ and were encased in a polytetrafluoroethylene tube for protection at temperatures up to $300{ }^{\circ} \mathrm{C}$. Steel cylinders mechanically attached to the optical fiber marked the ends of the measurement region (gauge length) and transferred strain from the concrete to the sensor. Two sensors were installed in parallel in the concrete near the midspan of the beam to measure both axial strain and bending in the deck. The locations of the sensors are shown in Figure 12 and Figure 13.

Fire loading was characterized by a heat release from the burning produced by natural gas fueled burners. The heat release rate of the natural gas burners (HRRburner) used to control the fire was measured using fuel flow as described in Bryant at al. (2015). The resultant heat release rate in the $13.7 \mathrm{~m}$ by $15.2 \mathrm{~m}$ exhaust hood (HRR) was measured using oxygen consumption calorimetry (Bryant et al. 2004).

The uncertainty in measurements is summarized in Table 4. Refer to the Part 1 report (Ramesh et al. 2019) for details of the uncertainty components for each measurand. The component standard uncertainties, combined standard uncertainty, and total expanded uncertainty were estimated for each measurand. The component standard uncertainty was evaluated either as Type-A or Type-B uncertainties. As defined by Taylor and Kuyatt (1994), Type-A uncertainty was evaluated using statistical analysis of the measurements. Type-B uncertainty was estimated using scientific judgment based on past experience, manufacturer's specifications, and previous data. The combined standard uncertainty was calculated as the square root of the summations of the squares of each component standard uncertainty, referred to as root-sum-of-squares method. The expanded uncertainty was computed by multiplying the combined uncertainty by a coverage factor of 2 corresponding to an interval with approximately a level of confidence of $95 \%$.

The uncertainty components included resolution, bias, installation, repeatability and random errors. The resolution is the ability of the measurement instrument to exhibit changes in the data. Bias is resulted from calibration of the sensor and other known repeatable errors. The uncertainties due to resolution and bias were derived from instrument specifications (Type-B). Uncertainty due to installation method was estimated based on engineering judgment (Type-B). Random error, which is resulted from random, unpredictable variations in the measurement process and environment was estimated as Type-A using the standard deviations of the residuals from the mean value of the measurements under a steady-state period. It was estimated as Type-B in the absence of data for statistical analysis. 
Table 4 Measurement uncertainty.

\begin{tabular}{|c|c|c|c|c|}
\hline Measurement / Component & $\begin{array}{l}\text { Estimation } \\
\text { Method of } \\
\text { Uncertainty }\end{array}$ & $\begin{array}{c}\text { Component } \\
\text { Standard } \\
\text { Uncertainty }\end{array}$ & $\begin{array}{l}\text { Combined } \\
\text { Standard } \\
\text { Uncertainty }\end{array}$ & $\begin{array}{c}\text { Total } \\
\text { Expanded } \\
\text { Uncertainty } \\
(\mathrm{k}=2)\end{array}$ \\
\hline $\begin{array}{l}\text { Actuator Load } \\
\text { Resolution } \\
\text { Bias } \\
\text { Installation } \\
\text { Random }(\mathrm{N}=4000) \\
\end{array}$ & $\begin{array}{l}\text { Type B } \\
\text { Type B } \\
\text { Type B } \\
\text { Type A }\end{array}$ & $\begin{array}{c} \pm 0.1 \% \\
\pm 1 \% \\
\pm 2 \% \\
\pm 3 \% \\
\end{array}$ & $\pm 3.8 \%$ & $\pm 8 \%$ \\
\hline $\begin{array}{l}\text { Load Cells at Reinforcing Bars } \\
\text { Resolution } \\
\text { Bias } \\
\text { Installation } \\
\text { Random (estimate) } \\
\end{array}$ & $\begin{array}{l}\text { Type B } \\
\text { Type B } \\
\text { Type B } \\
\text { Type B } \\
\end{array}$ & $\begin{array}{c} \pm 0.1 \% \\
\pm 0.8 \% \\
\pm 5 \% \\
\pm 1 \% \\
\end{array}$ & $\pm 5.2 \%$ & $\pm 11 \%$ \\
\hline $\begin{array}{l}\text { Displacement (String Potentiometer) } \\
\text { Resolution } \\
\text { Bias (linearity) } \\
\text { Bias (repeatability) } \\
\text { Installation } \\
\text { Random }(\mathrm{N}=600) \\
\end{array}$ & $\begin{array}{l}\text { Type B } \\
\text { Type B } \\
\text { Type B } \\
\text { Type B } \\
\text { Type A }\end{array}$ & $\begin{array}{l} \pm 0.1 \% \\
\pm 0.2 \% \\
\pm 0.1 \% \\
\pm 2 \% \\
\pm 0.4 \%\end{array}$ & $\pm 2.1 \%$ & $\pm 5 \%$ \\
\hline $\begin{array}{l}\text { Rotation (Ambient, } 25^{\circ} \mathrm{C} \text { ) } \\
\text { Resolution } \\
\text { Bias } \\
\text { Installation } \\
\text { Random (estimate) }\end{array}$ & $\begin{array}{l}\text { Type B } \\
\text { Type B } \\
\text { Type B } \\
\text { Type B }\end{array}$ & $\begin{array}{c} \pm 0.3 \% \\
\pm 3 \% \\
\pm 1 \% \\
\pm 3 \%\end{array}$ & $\pm 4.4 \%$ & $\pm 9 \%$ \\
\hline $\begin{array}{l}\text { Strain } \\
\text { Resolution } \\
\text { Calibration } \\
\text { Installation } \\
\text { Random }(\mathrm{N}=600) \\
\end{array}$ & $\begin{array}{l}\text { Type B } \\
\text { Type B } \\
\text { Type B } \\
\text { Type A }\end{array}$ & $\begin{array}{l} \pm 0.1 \% \\
\pm 0.5 \% \\
\pm 1 \% \\
\pm 2 \% \\
\end{array}$ & $\pm 2.3 \%$ & $\pm 5 \%$ \\
\hline $\begin{array}{l}\text { Steel Temperature }{ }^{1} \\
\text { Resolution } \\
\text { Bias } \\
\text { Installation } \\
\text { Random }(\mathrm{N}=300), 700^{\circ} \mathrm{C}\end{array}$ & $\begin{array}{l}\text { Type B } \\
\text { Type B } \\
\text { Type B } \\
\text { Type A }\end{array}$ & $\begin{array}{c} \pm 0.1 \% \\
\pm 0.4 \% \\
\pm 2 \% \\
\pm 0.6 \%\end{array}$ & $\pm 2.2 \%$ & $\pm 5 \%$ \\
\hline $\begin{array}{l}\text { Concrete Temperature } \\
\text { Resolution } \\
\text { Bias } \\
\text { Installation } \\
\text { Random }(\mathrm{N}=300), 600^{\circ} \mathrm{C} \\
\end{array}$ & $\begin{array}{l}\text { Type B } \\
\text { Type B } \\
\text { Type B } \\
\text { Type A } \\
\end{array}$ & $\begin{array}{c} \pm 0.1 \% \\
\pm 0.4 \% \\
\pm 3 \% \\
\pm 1.2 \% \\
\end{array}$ & $\pm 3.1 \%$ & $\pm 7 \%$ \\
\hline $\begin{array}{l}\text { Steel Deck Temperature } \\
\text { Resolution } \\
\text { Bias } \\
\text { Installation } \\
\text { Random }(\mathrm{N}=300), 1000^{\circ} \mathrm{C} \\
\end{array}$ & $\begin{array}{l}\text { Type B } \\
\text { Type B } \\
\text { Type B } \\
\text { Type A }\end{array}$ & $\begin{array}{c} \pm 0.1 \% \\
\pm 0.4 \% \\
\pm 2 \% \\
\pm 1.3 \% \\
\end{array}$ & $\pm 2.4 \%$ & $\pm 5 \%$ \\
\hline $\begin{array}{l}\text { Gas Temperature } \\
\text { Resolution } \\
\text { Bias } \\
\text { Installation } \\
\text { Random }(\mathrm{N}=3000), 1000^{\circ} \mathrm{C}\end{array}$ & $\begin{array}{l}\text { Type B } \\
\text { Type B } \\
\text { Type B } \\
\text { Type A }\end{array}$ & $\begin{array}{c} \pm 0.1 \% \\
\pm 0.4 \% \\
\pm 1 \% \\
\pm 1.2 \%\end{array}$ & $\pm 1.6 \%$ & $\pm 4 \%$ \\
\hline $\begin{array}{l}\text { Temperature (Plate Thermometer) } \\
\text { Resolution } \\
\text { Bias } \\
\text { Installation } \\
\text { Random (estimate) } \\
\end{array}$ & $\begin{array}{l}\text { Type B } \\
\text { Type B } \\
\text { Type B } \\
\text { Type B }\end{array}$ & $\begin{array}{c} \pm 0.1 \% \\
\pm 0.8 \% \\
\pm 2 \% \\
\pm 0.5 \% \\
\end{array}$ & $\pm 2.2 \%$ & $\pm 5 \%$ \\
\hline
\end{tabular}

\footnotetext{
${ }^{1}$ Insulation failure and dislodging of thermocouples were not considered.
} 


\begin{tabular}{|c|c|c|c|c|}
\hline Measurement / Component & $\begin{array}{l}\text { Estimation } \\
\text { Method of } \\
\text { Uncertainty }\end{array}$ & $\begin{array}{l}\text { Component } \\
\text { Standard } \\
\text { Uncertainty }\end{array}$ & $\begin{array}{l}\text { Combined } \\
\text { Standard } \\
\text { Uncertainty }\end{array}$ & $\begin{array}{c}\text { Total } \\
\text { Expanded } \\
\text { Uncertainty } \\
(\mathrm{k}=2)\end{array}$ \\
\hline $\begin{array}{l}\text { Burner Heat Release Rate } \\
\text { Resolution } \\
\text { Bias } \\
\text { Random }\end{array}$ & $\begin{array}{l}\text { Type B } \\
\text { Type B } \\
\text { Type B }\end{array}$ & $\begin{array}{l} \pm 0.2 \% \\
\pm 0.6 \% \\
\pm 0.5 \%\end{array}$ & $\pm 0.8 \%$ & $\pm 2 \%$ \\
\hline $\begin{array}{l}\text { Calorimeter Heat Release Rate } \\
\text { Resolution } \\
\text { Bias } \\
\text { Random }\end{array}$ & $\begin{array}{l}\text { Type B } \\
\text { Type B } \\
\text { Type B }\end{array}$ & $\begin{array}{l} \pm 0.1 \% \\
\pm 4.5 \% \\
\pm 5.9 \%\end{array}$ & $\pm 7.4 \%$ & $\pm 15 \%$ \\
\hline $\begin{array}{l}\text { Dimensions, Larger than } 0.5 \mathrm{~m} \\
\text { Resolution } \\
\text { Bias } \\
\text { Random }\end{array}$ & $\begin{array}{l}\text { Type B } \\
\text { Type B } \\
\text { Type B }\end{array}$ & $\begin{array}{l} \pm 2 \mathrm{~mm} \\
\pm 2 \mathrm{~mm} \\
\pm 13 \mathrm{~mm}\end{array}$ & $\pm 13 \mathrm{~mm}$ & $\pm 27 \mathrm{~mm}$ \\
\hline $\begin{array}{l}\text { Dimensions, Smaller than } 0.5 \mathrm{~m} \\
\text { Resolution } \\
\text { Bias } \\
\text { Random }\end{array}$ & $\begin{array}{l}\text { Type B } \\
\text { Type B } \\
\text { Type B }\end{array}$ & $\begin{array}{l} \pm 2 \mathrm{~mm} \\
\pm 2 \mathrm{~mm} \\
\pm 3 \mathrm{~mm}\end{array}$ & $\pm 4 \mathrm{~mm}$ & $\pm 8 \mathrm{~mm}$ \\
\hline
\end{tabular}




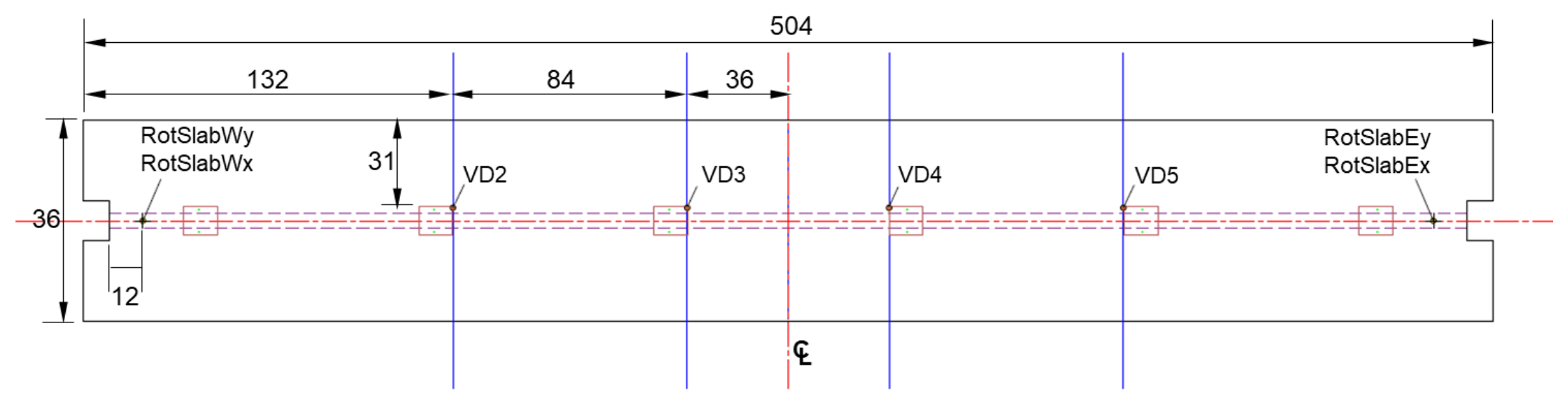

(a)

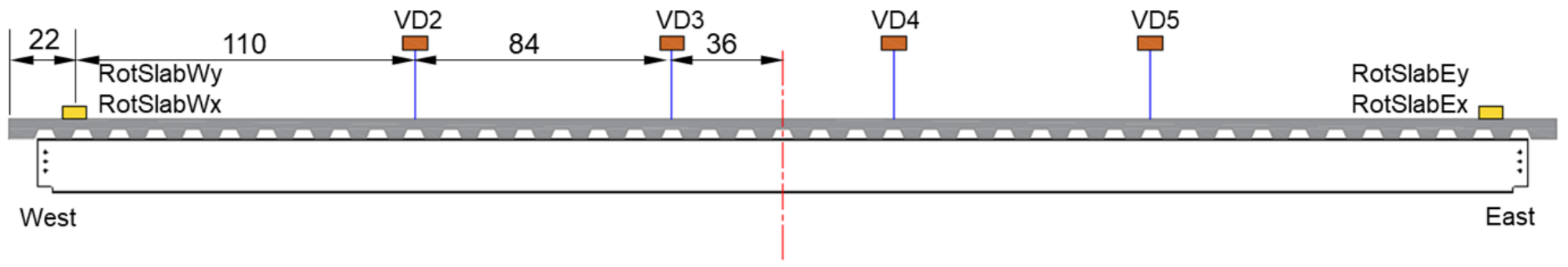

(b)

Figure 6 (a) Top view, and (b) front view of the specimen with the instrument location of vertical displacements (VD2 through VD5) and end rotations (RotSlabWx; RotSlabWy; RotSlabEx; and RotSlabEy). Units are in inches (1 inch = 25.4 mm). 


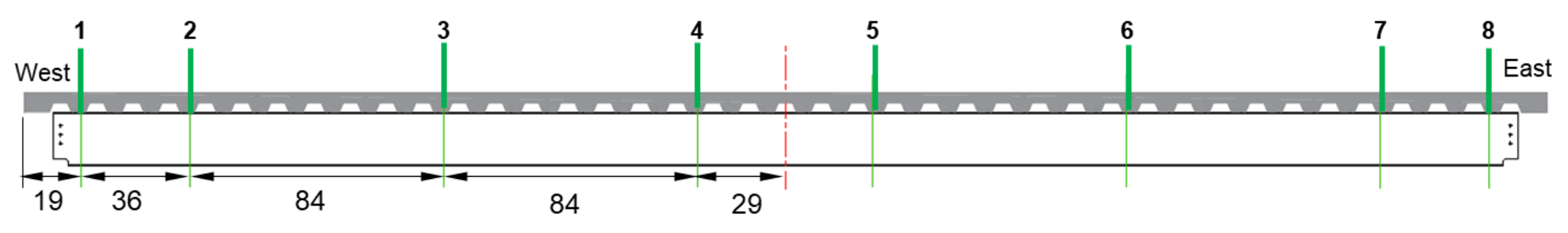

(a)

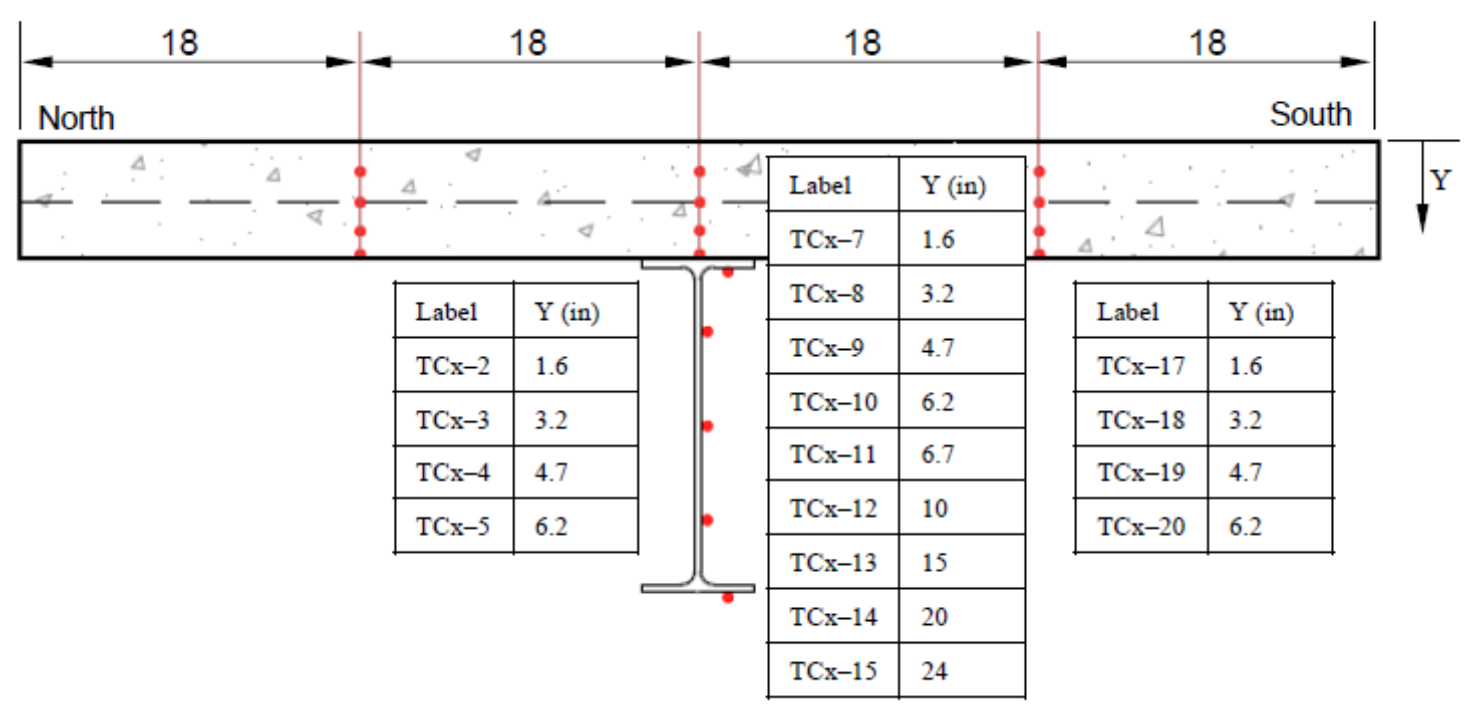

(b) 


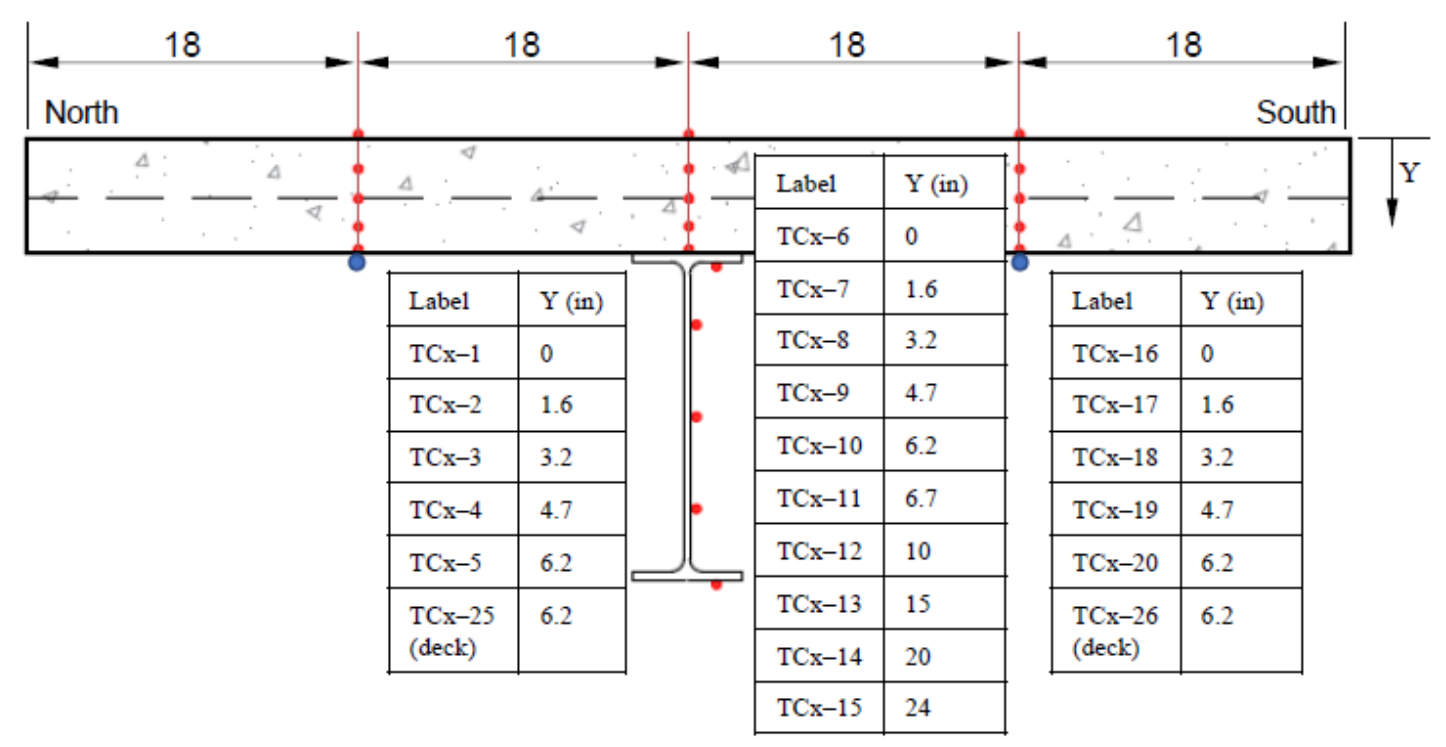

(c)

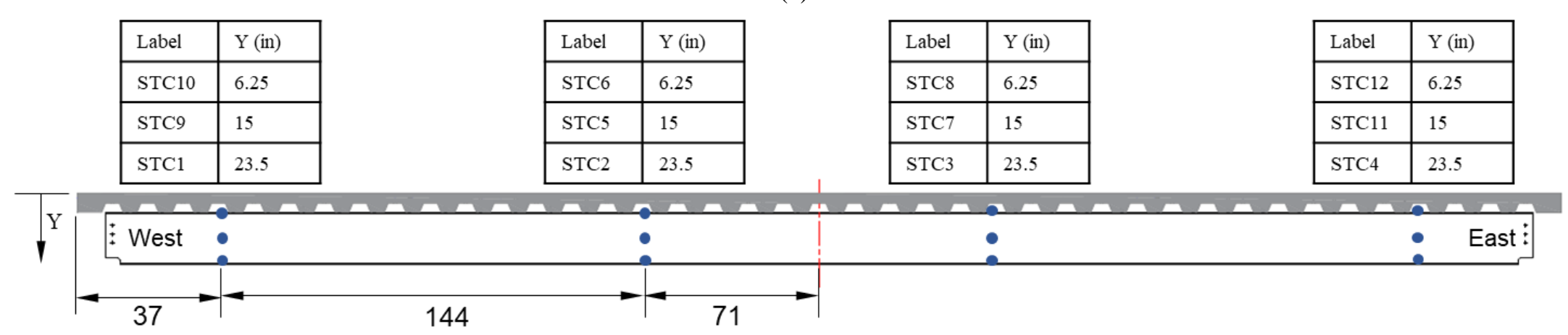

(d)

Figure 7 Locations and labels of thermocouples mounted on the specimen: (a) section numbers ( $x=1$ through 8), (b) glass-sheathed thermocouples in sections 1, 2, 7, and 8, (c) glass-sheathed thermocouples in sections 3, 4, 5, and 6, and (d) Inconel-sheathed thermocouples (STC1 through STC12). Units are in inches. 


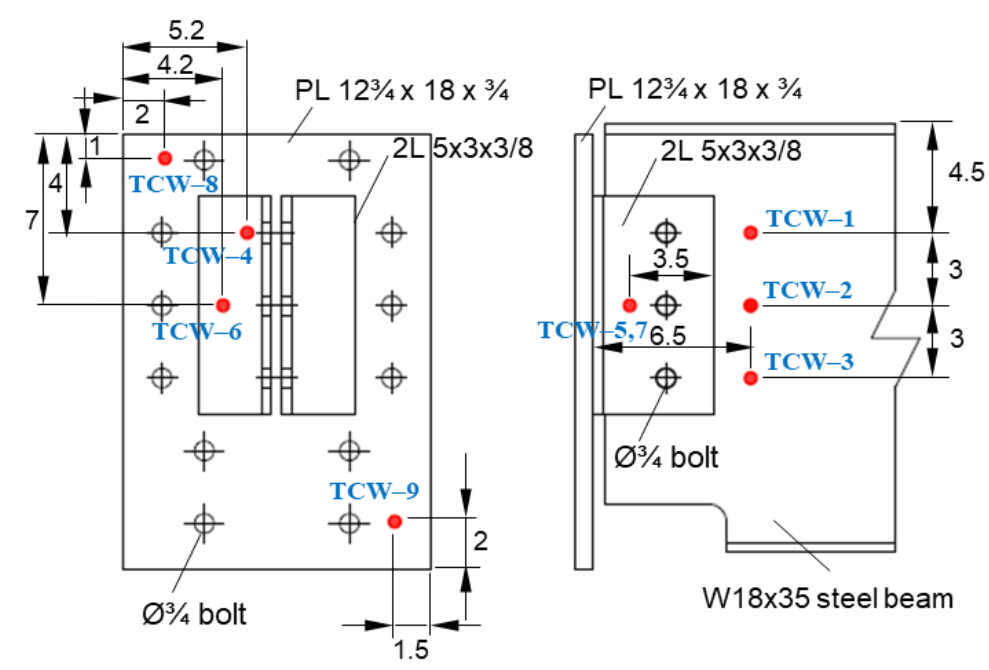

(a)

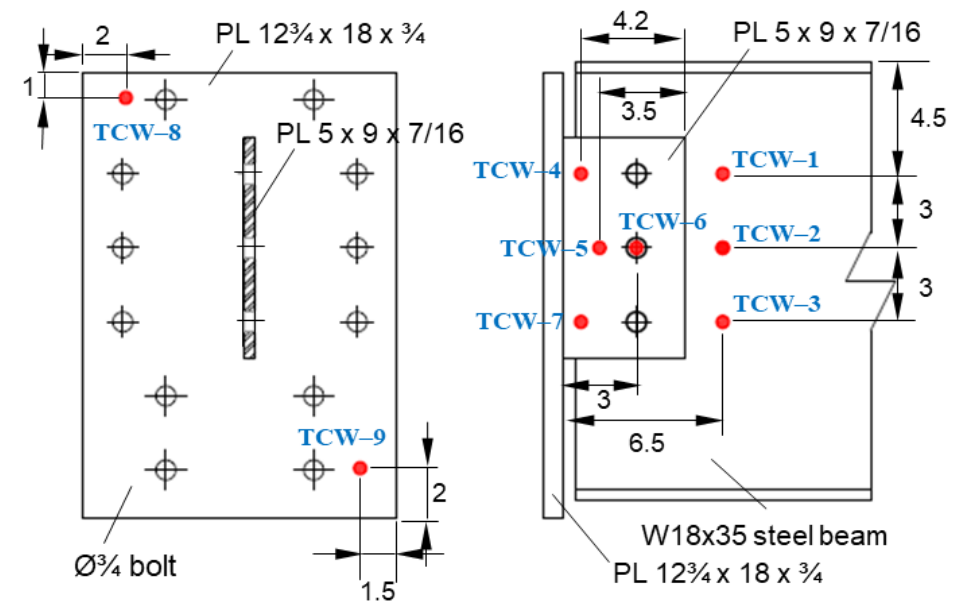

(b)

Figure 8 Locations and labels of thermocouples mounted on the specimen connections: (a) the west angle connection for CB-DA and CB-DA-SC, and (b) the west shear-tab connection for CB-SP and CB-SP-SC. Units are in inches. 


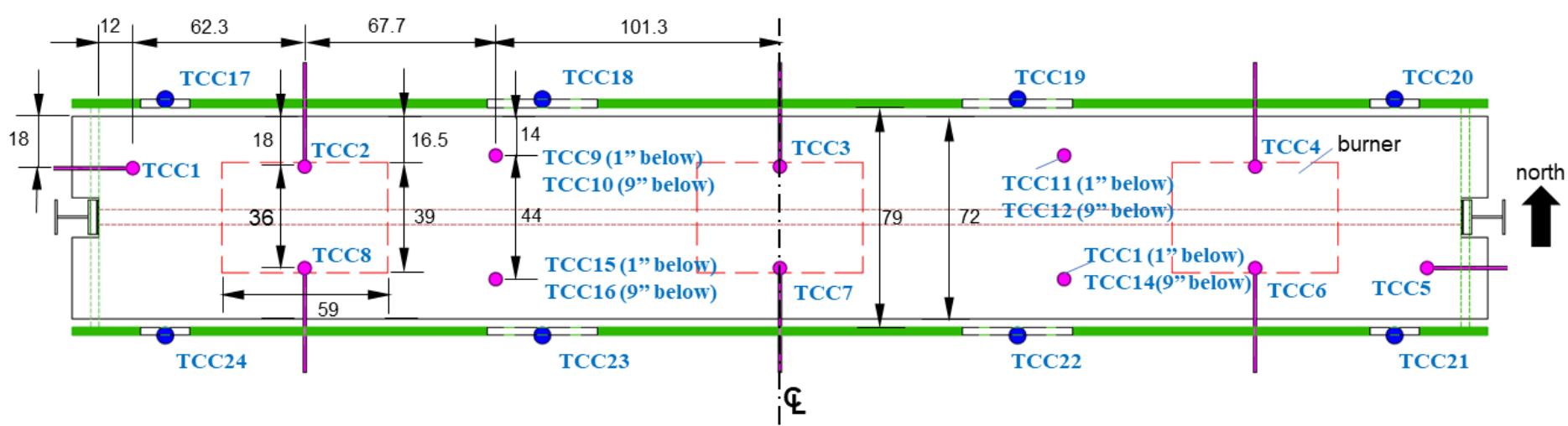

(a)

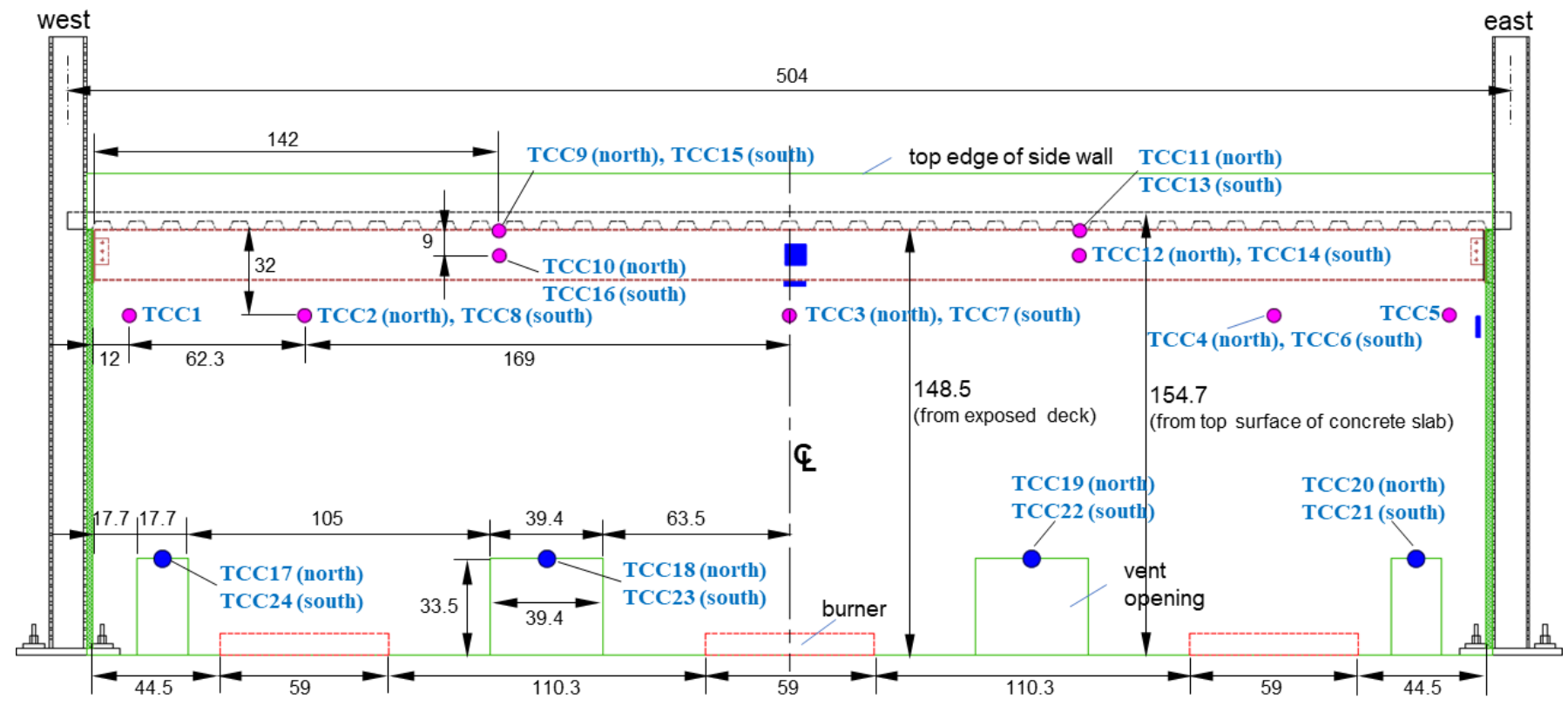

(b)

Figure 9 Thermocouples used for measurements of upper layer gas temperatures (TCC1 through TCC16) inside the test compartment and at ventilation openings (TCC17 through TCC24): (a) plan view, and (b) elevation view. Units are in inches. 


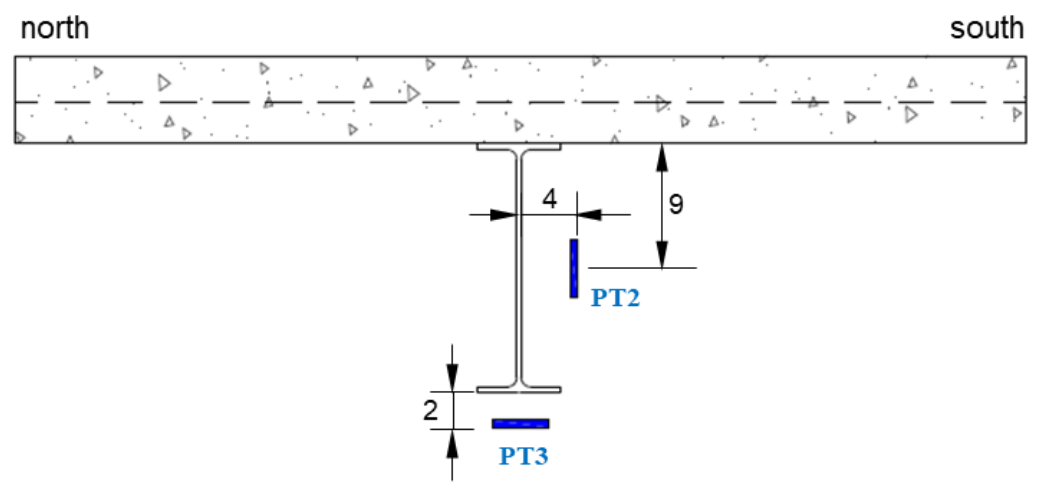

(a)

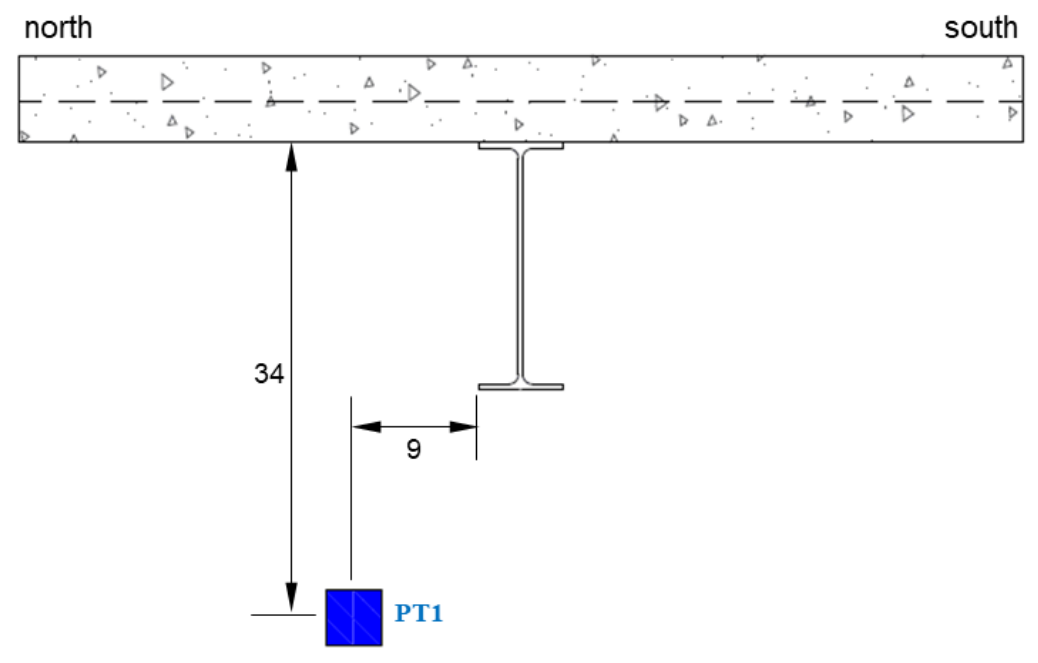

(b)

Figure 10 Locations of plate thermometers (PT1 through PT3): (a) $5 \mathrm{~cm}$ from midspan of the specimen, and (b) $13 \mathrm{~cm}$ from exposed surface of the east wall. Units are in inches. 


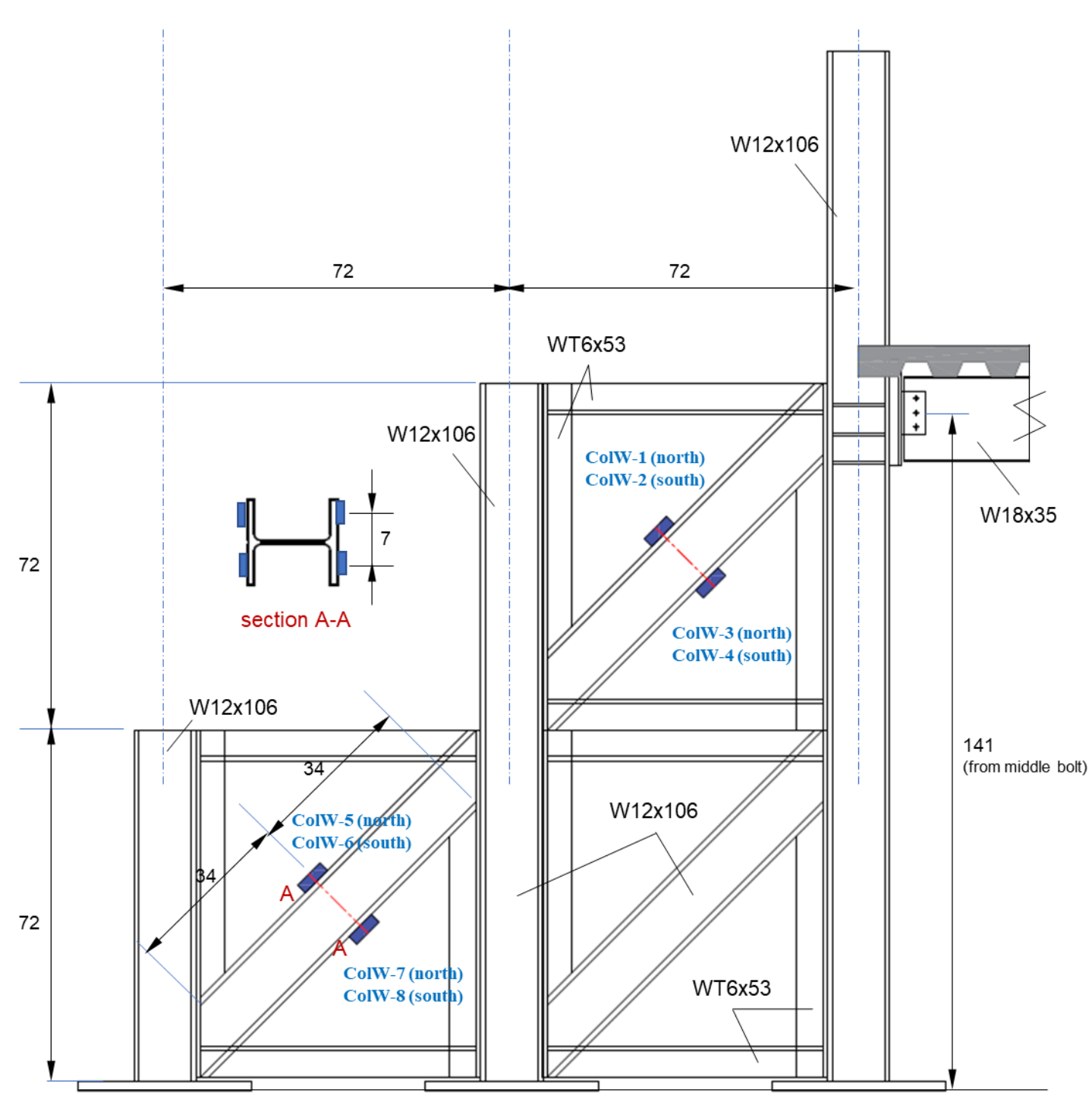

(a) 


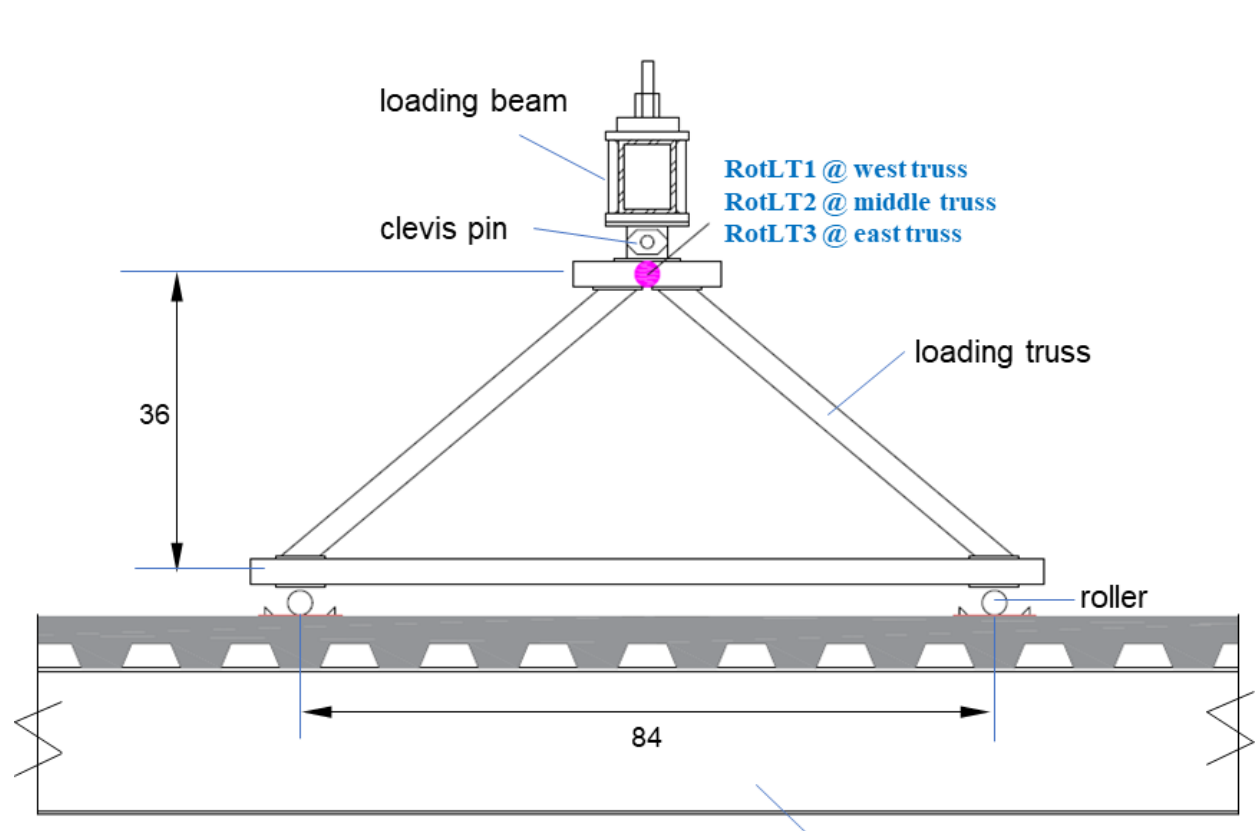

test beam

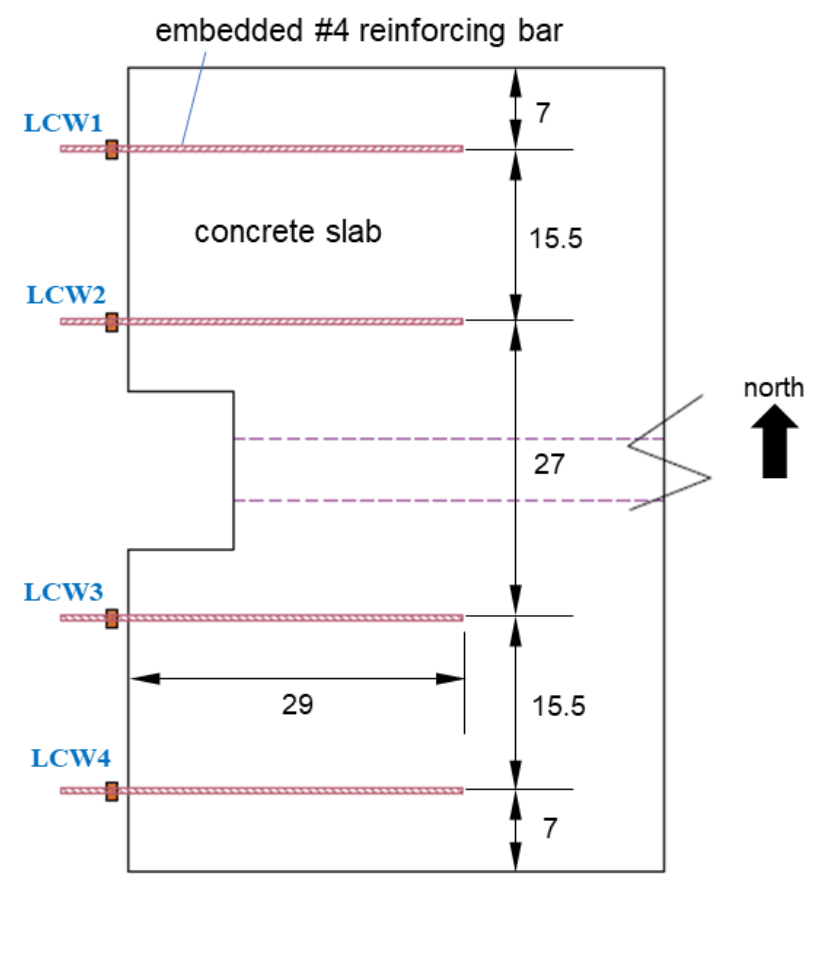

(c)

Figure 11 (a) Strain gauges mounted at west braced column (ColW1 through ColW8), (b) inclinometers mounted on loading trusses (RotLT1 through RotLT2), and (c) load cells mounted on \#4 reinforcing bars for specimens CB-DA-SC and CB-SP-SC. Units are in inches. 


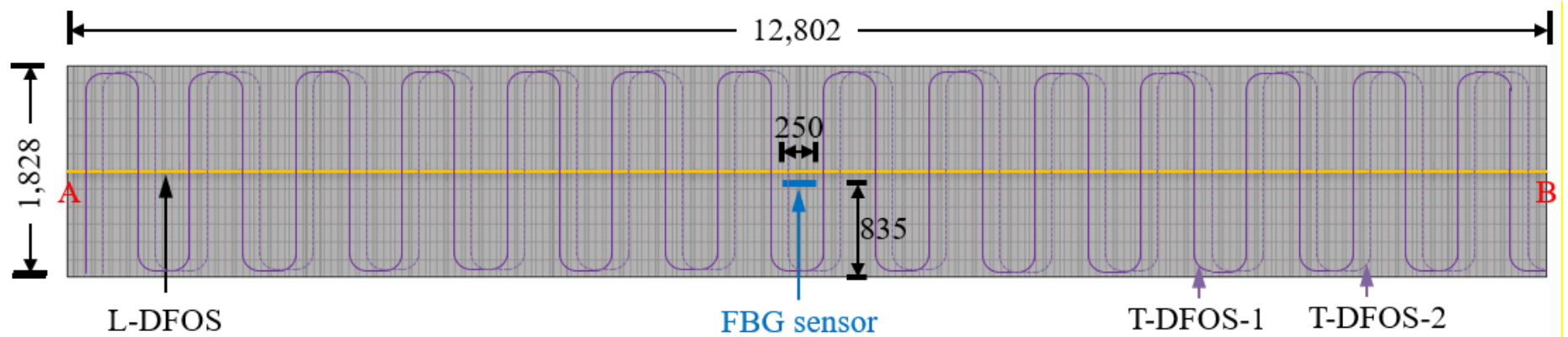

Figure 12 Top view of the locations of Fiber Bragg Grating (FBG) sensors in CB-DA and CB-DA-SC (units in mm).
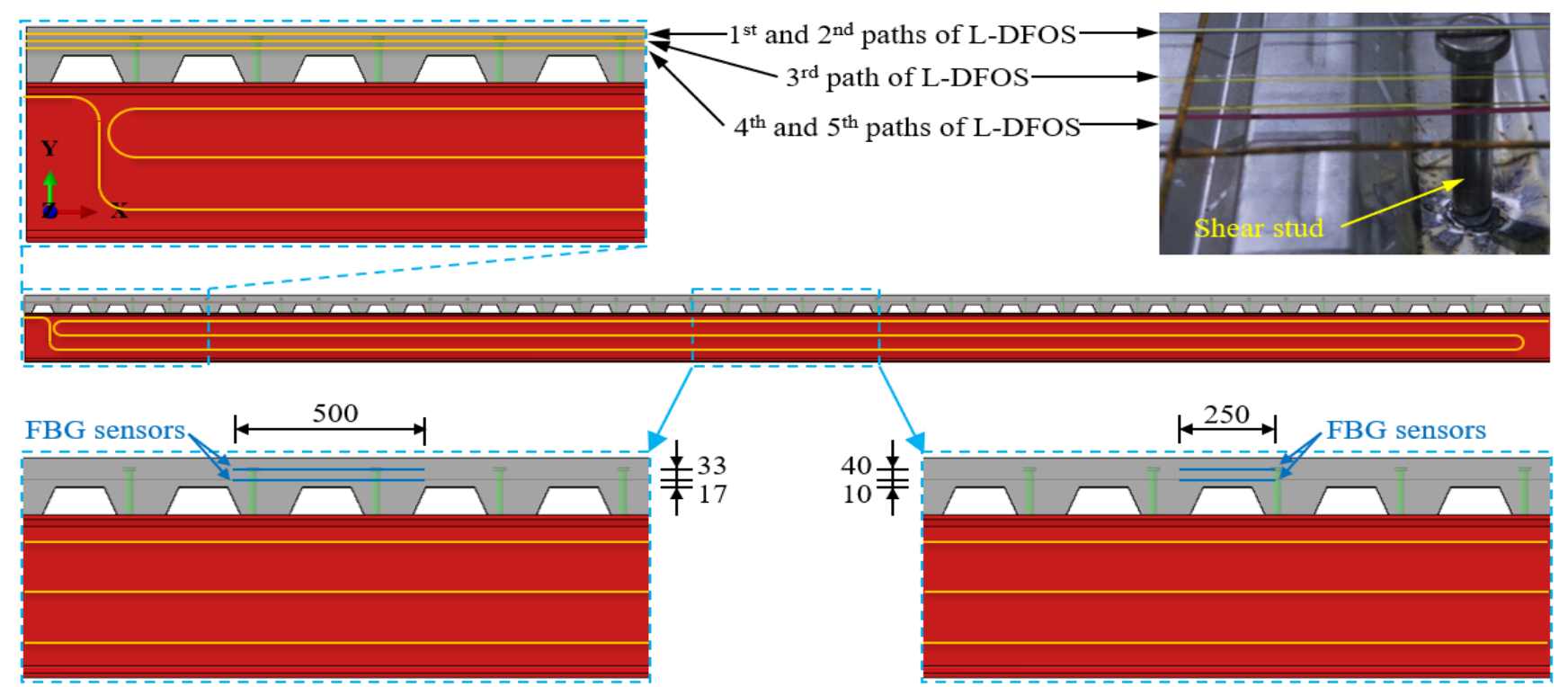

Figure 13 Side view of the locations of Fiber Bragg Grating (FBG) sensors in CB-DA and CB-DA-SC (lower right) (units in mm). 


\section{Chapter 3 \\ TEST RESULTS}

\subsection{Test Protocol and Criteria}

Compartment fire experiments on four specimens (CB-DA, CB-DA-SC, CB-SP, and CB-SP-SC) were conducted as follows:

1. A gravity load of $106 \mathrm{kN}$ was applied using hydraulic actuators at ambient temperature and held constant.

2. After ignition of a pilot flame on each burner, the heat release rate was initially set to or below $500 \mathrm{~kW}$ for about 5 min to verify the uniformity of natural gas flow to all burners. Subsequently, the heat release rate of the burners was linearly increased to $4000 \mathrm{~kW}$ over approximately 10 min and held constant until the mechanical loading was removed when either a preset load or displacement criterion was met (criteria provided below).

3. For specimens not exhibiting failure of beam-to-column connections in Step 2, a cooling phase (decay of the fire) was simulated by linearly decreasing the heat release rate of the burners over $30 \mathrm{~min}$.

In Step 2, the specimens were unloaded using two criteria as follows. For the first specimen tested in fire (CB-DA), a load limit was utilized such that the mechanical loading was automatically removed when the total applied load dropped below $90 \mathrm{kN} ; 85 \%$ of the total applied load at ambient temperatures in Step 1. For the remaining specimens (CB-DA-SC, CB-SP, and CB-SPSC), a displacement limit was employed instead. All six actuators were simultaneously depressurized when the vertical displacement of the specimen exceeded $630 \mathrm{~mm}$ (equivalent to $L / 20$, where $L$ is the nominal length of the specimen, $12.8 \mathrm{~m}$ ).

The test was terminated if one of the following criteria was met: 1) incipient collapse of the specimens caused by failure of beam-to-column connections, 2) significant flame leakage above the concrete slab, 3) the loss of exhaust hood flow, 4) significant damage to the fire compartment, 5) failure of data acquisition systems, or 6) the end of the 30-min decay period. Details of the testing procedure used in each experiment and associated events are summarized in Appendices A through D. 


\subsection{Test Conditions}

\subsubsection{Gravity Loading at Ambient Temperature}

A total gravity load corresponding to the ASCE 7 load combination for fire effects $(1.2 D L+0.5 L L$, where $D L=$ dead load and $L L=$ live load) was $210 \mathrm{kN}$. The calculated weight of the beam specimen and that of the loading fixtures placed on the specimen was $58 \mathrm{kN}$ and $46 \mathrm{kN}$, respectively. Based on the expanded uncertainty in dimensions of the tested specimens (Table 4), the expanded uncertainty (with a coverage factor of 2 ) was estimated to be $\pm 2 \%$. Hydraulic actuators were used to apply the remaining load $(106 \mathrm{kN})$ distributed at six points along the beam length.

Figure 14 shows the mean and standard deviation of point loads measured for each specimen at ambient temperature prior to the ignition of a fire. Table 5 shows the time-averaged values of the point load and those of the total mechanical load maintained from 15 min to 40 min in Figure 14.

Table 5 Time-averaged values of the total mechanical load and point load maintained at ambient temperature; the values after \pm symbols indicate the standard deviation.

\begin{tabular}{lllll}
\hline & CB-DA & CB-DA-SC & CB-SP & CB-SP-SC \\
\hline Total mechanical load $(\mathrm{kN})$ & $106.1 \pm 0.1$ & $106.5 \pm 0.1$ & $105.6 \pm 0.3$ & $106.4 \pm 0.1$ \\
Point load $(\mathrm{kN})$ & $17.7 \pm 0.4$ & $17.8 \pm 0.6$ & $17.6 \pm 0.5$ & $17.7 \pm 0.3$ \\
\hline
\end{tabular}




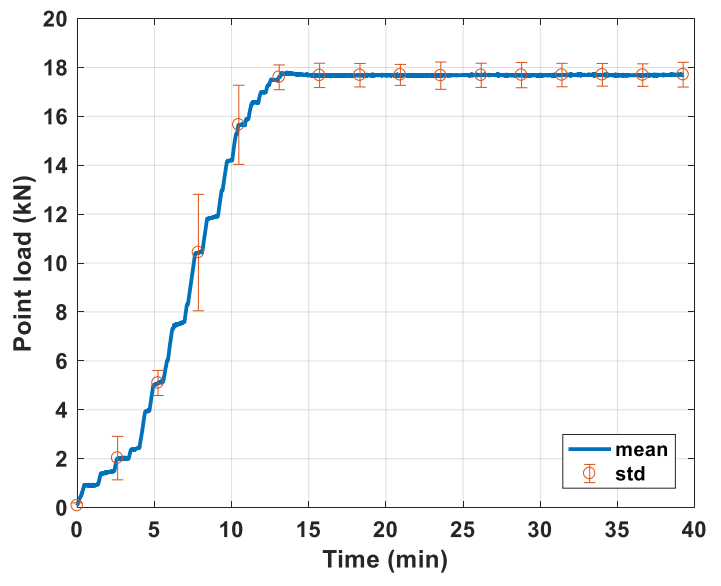

(a)

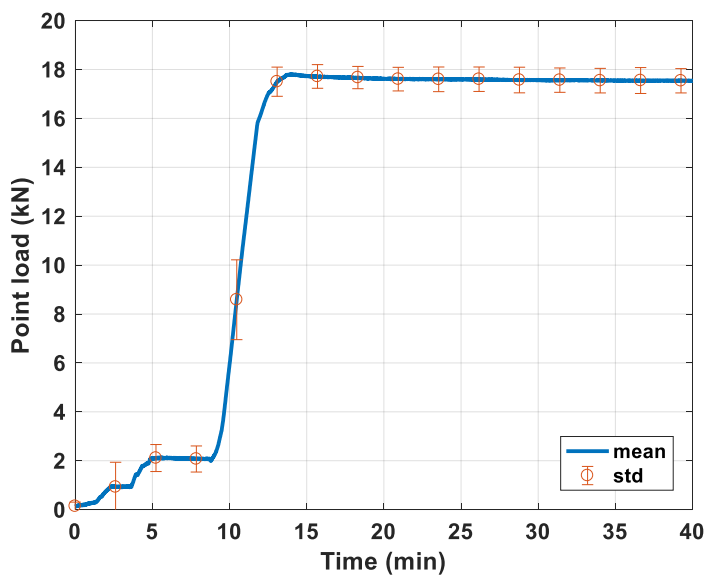

(c)

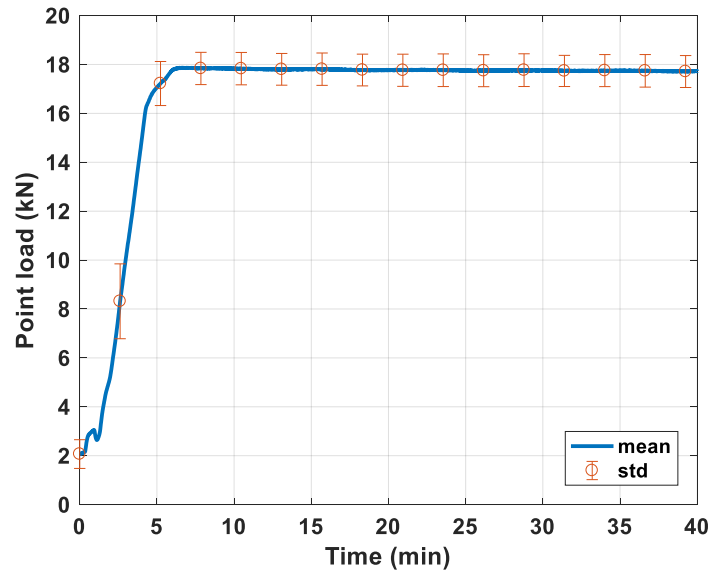

(b)

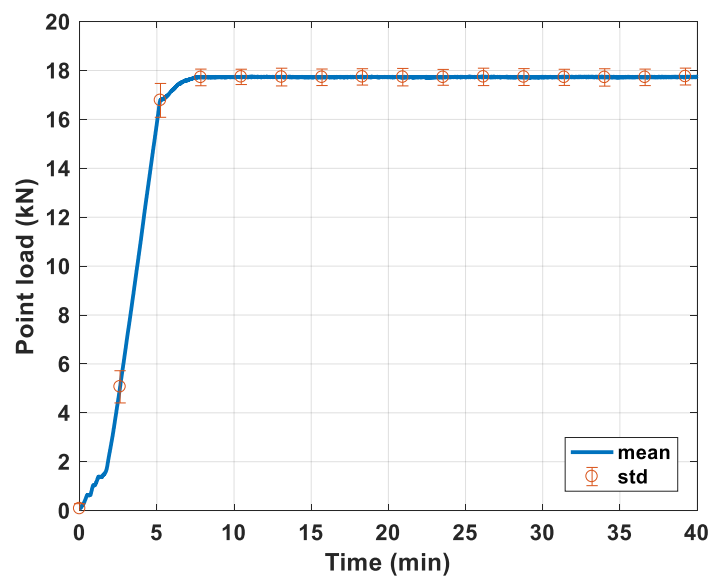

(d)

Figure 14 Average point load applied to (a) CB-DA, (b) CB-DA-SC, (c) CB-SP, and (d) CB-SP-SC at ambient temperatures. Error bars indicate the standard deviation of the six point loads distributed along the beam length. 


\subsubsection{Imposed Gravity and Fire loading}

While the total mechanical load of $106 \mathrm{kN}$ was maintained, the compartment fire was produced using three $1 \mathrm{~m} \times 1.5 \mathrm{~m}$ natural gas fueled burners on the floor (See Figure 5). Fire loading was applied using a similar protocol for all tested specimens, as presented in Section 3.1.

Figure 15 shows the total mechanical load and the total heat release rate of the burners (HRRburner) as a function of the test time recorded after the burner ignition. As shown, the CBDA specimen was automatically unloaded at $30 \mathrm{~min}$ because of the preset load limit programmed in actuators. This unloading appeared to be triggered by local buckling in the steel beam near the angle connections at both ends. The CB-DA-SC specimen was unloaded at $63 \mathrm{~min}$ as the actuator stroke exceeded the preset displacement limit $(630 \mathrm{~mm})$. For these two specimens, the 30-min decay of a fire was followed since no incipient collapse was exhibited after unloading. For the other two specimens (CB-SP and CB-SP-SC), both the mechanical and thermal loading was manually removed at $65 \mathrm{~min}$ and $73 \mathrm{~min}$, respectively, followed by failure of the east shear-tab connection.

Table 6 presents a summary of the time-averaged values of the total mechanical load and the initial and maintained HRRburner values for each test as well as duration of the test fires. For all specimens, the time-averaged value of total mechanical load was $106 \mathrm{kN}$ with the variation in the range of $1 \%$ to $3 \%$ over time. In the testing of CB-DA-SC and CB-SP, the applied loads fluctuated over time, caused by tuning issues of the electrohydraulic servo valve used in one of the six actuators (NE actuator). This servo valve was replaced before testing the last specimen (CB-SP$\mathrm{SC}$ ), and the load variations (over time) fell to approximately $1 \%$.

The total mechanical load imposed on the top of the concrete slab was distributed at six equally spaced points via three loading trusses (Figure 4). As the specimen bent downward in response to combined mechanical loading and heating, the rotation of the east and west loading trusses increased. This resulted in variations in applied loads which depended upon the fire exposure time. Figure 16 shows the magnitude of each of the six point loads at various fire exposure times, estimated using rotation of the loading trusses and forces applied using actuators. This variation was less than $4 \%$ until the fire exposure time reached $40 \mathrm{~min}$ and increased up to $15 \%$ at $60 \mathrm{~min}$. However, varied point loads had a small impact on the total gravity load including the self-weight of the specimen and the resulting maximum moment (at midspan). Given that the specimen was simply supported, the difference of the bending moment at midspan between $10 \mathrm{~min}$ and $60 \mathrm{~min}$ in fire was about $2 \%$. 


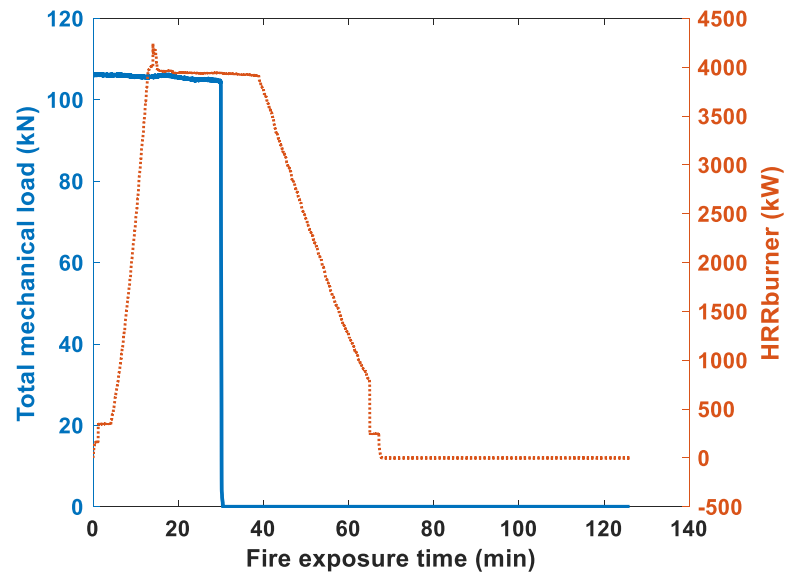

(a)

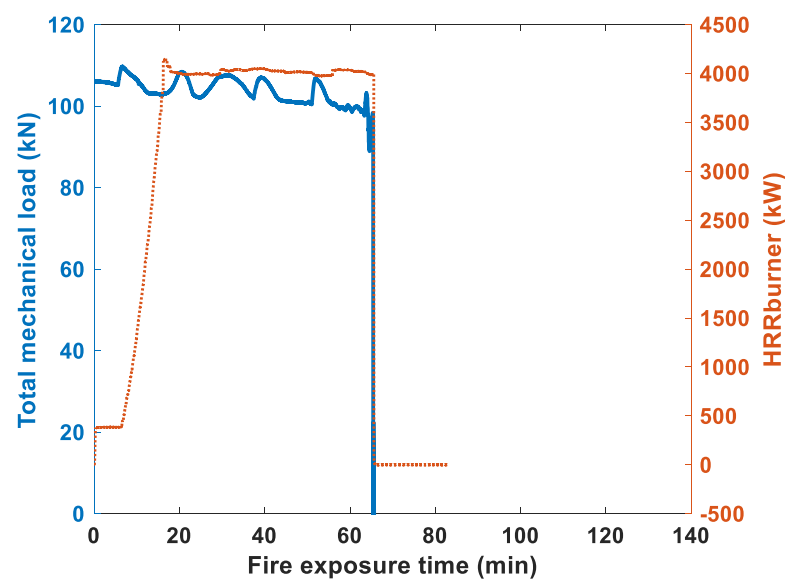

(c)

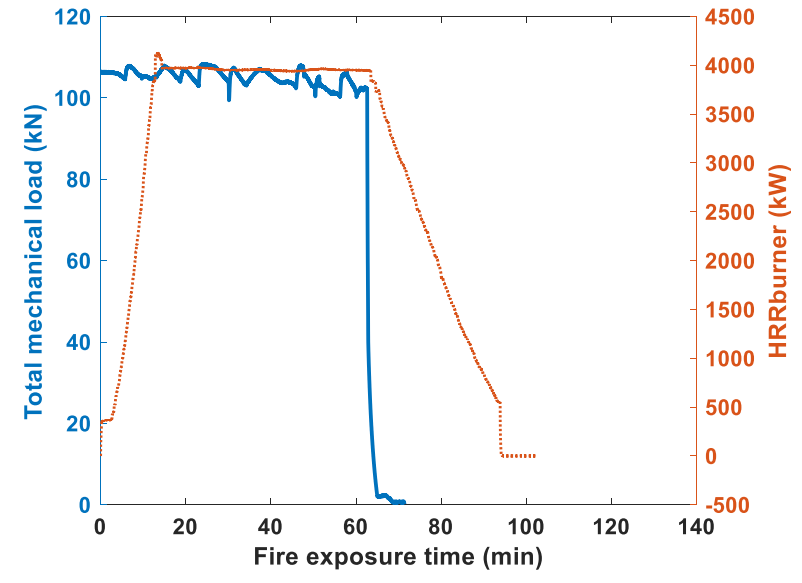

(b)

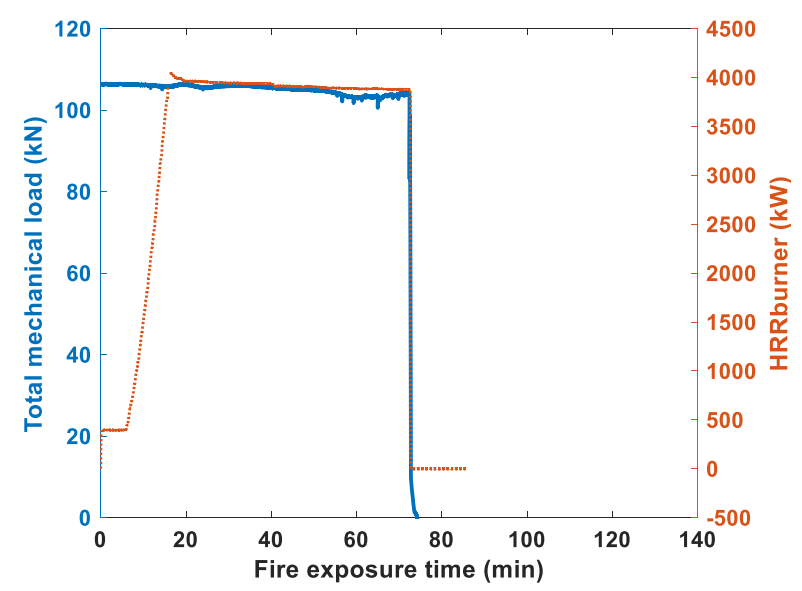

(d)

Figure 15 Total mechanical load and HRRburner as a function of fire exposure time for the specimens (a) CB-DA, (b) CB-DA-SC, (c) CB-SP, (d) CB-SP-SC.

Table 6 Time-averaged values of the total mechanical load, the initial and maintained HRRburner values and duration of the test fire; Values after \pm symbols indicate the standard deviation over time.

HRRburner (kW) Fire Duration (min)

\begin{tabular}{cccccccc}
\hline $\begin{array}{c}\text { Specimen } \\
\text { ID }\end{array}$ & $\begin{array}{c}\text { Total mechanical } \\
\text { load }(\mathrm{kN})\end{array}$ & Initial & Maintained & Growth & Maintained & Decay & Total \\
\hline CB-DA & $106 \pm 0.5$ & $347 \pm 2$ & $3950 \pm 40$ & 13 & 26 & 30 & 68 \\
CB-DA-SC & $105 \pm 2.0$ & $364 \pm 5$ & $3960 \pm 25$ & 13 & 52 & 30 & 94 \\
CB-SP & $104 \pm 3.1$ & $384 \pm 1$ & $4020 \pm 30$ & 15 & 50 & - & 65 \\
CB-SP-SC & $105 \pm 1.2$ & $395 \pm 1$ & $3920 \pm 30$ & 16 & 57 & - & 73 \\
\hline
\end{tabular}




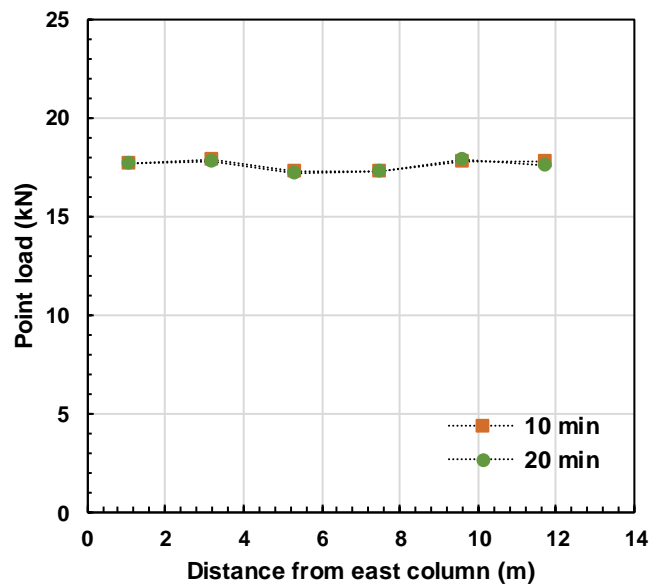

(a)

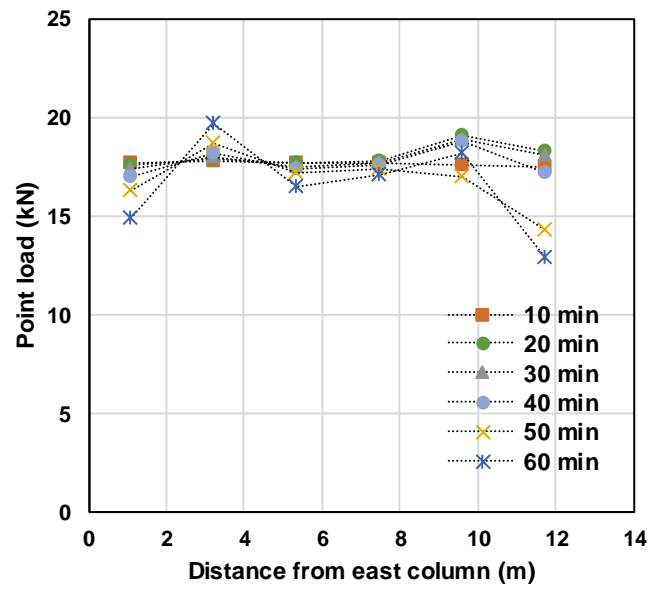

(c)

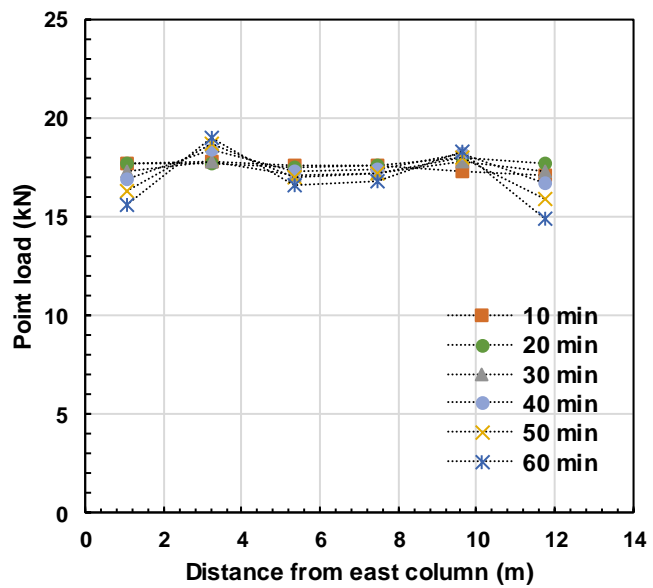

(b)

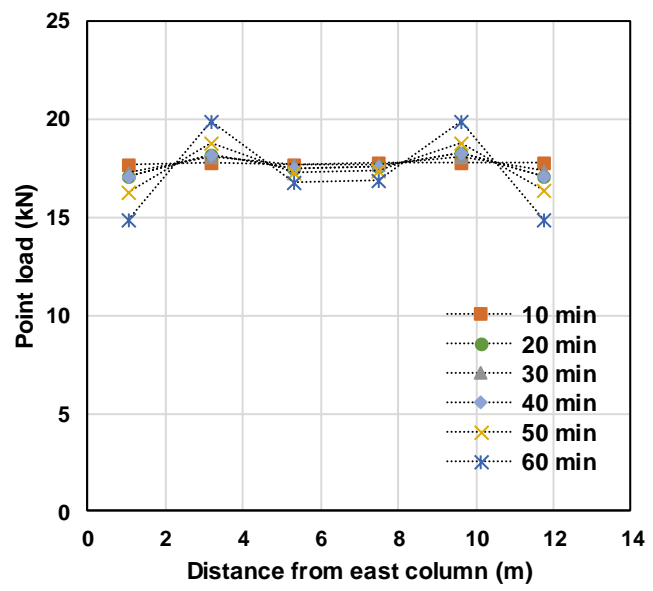

(d)

Figure 16 Distribution of point loads varying with fire exposure time for (a) CB-DA, (b) CB-DA-SC, (c) CB-SP, and (d) CB-SP-SC. 


\subsubsection{Heat Release Rate}

The heat release rate of the compartment fire, denoted as HRR, was measured at the $13.7 \mathrm{~m} \times$ $15.2 \mathrm{~m}$ exhaust hood using oxygen consumption calorimetry. This measurement represents a total burning under the hood, which can be affected by the fuel (natural gas) and ventilation conditions achieved during the test.

Figure 17 shows the measured HRR as a function of the test time recorded after the burner ignition, indicating that the HRR values matched very well with the HRRburner values during each experiment. In the growth stage of a fire, both HRR and HRRburner values increased at a similar rate. The average ramp rate of HRR was $360 \mathrm{~kW} / \mathrm{min}$, about $10 \%$ smaller than that of HRRburner. Some of this difference can be attributed to the overall response time of the oxygen calorimetry system including the mixing time of gases in the compartment. The variation in the ramp rates of HRR was $2 \%$ among the four specimens. While the HRRburner value was maintained around $4000 \mathrm{~kW}$, the HRR values also became steady with $3 \%$ variation over time. The time-averaged HRR value during this period was in the range of $3700 \mathrm{~kW}$ to $3900 \mathrm{~kW}$. The largest difference was observed during the testing of CB-DA-SC in which the time-averaged value of HRR was about $7.5 \%$ less than that of HRRburner. For other three tests, this difference remained below $3 \%$. Both CB-DA and CB-DA-SC specimens included a cooling phase controlled by linearly decreasing the value of HRRburner over $30 \mathrm{~min}$. The measured HRR value also decreased at a similar rate.

Figure 18 and Figure 19 show snapshots from the videos of the inside of the test compartment, and Figure 20 shows the outside view of the compartment recorded during the testing of CB-DA-SC. As shown, the exposed bottom surface of the specimen was only visible up to around 12 min after burner ignition (when the HRRburner was less than $3000 \mathrm{~kW}$ ) and became less visible afterwards. While the HRRburner value was fixed at around $4000 \mathrm{~kW}$ (from $20 \mathrm{~min}$ to $60 \mathrm{~min}$ ), turbulent diffusion flames were observed inside the compartment (Figure 18c and Figure 19b). After $40 \mathrm{~min}$, flames extended from the ventilation openings (Figure 20). The inside view of the compartment became clear again as the HRRburner ramped down during the decay phase (Figure 19c). The other three tests also exhibited similar fire characteristics although there was a slight difference in the time of occurrence for each event described above. 


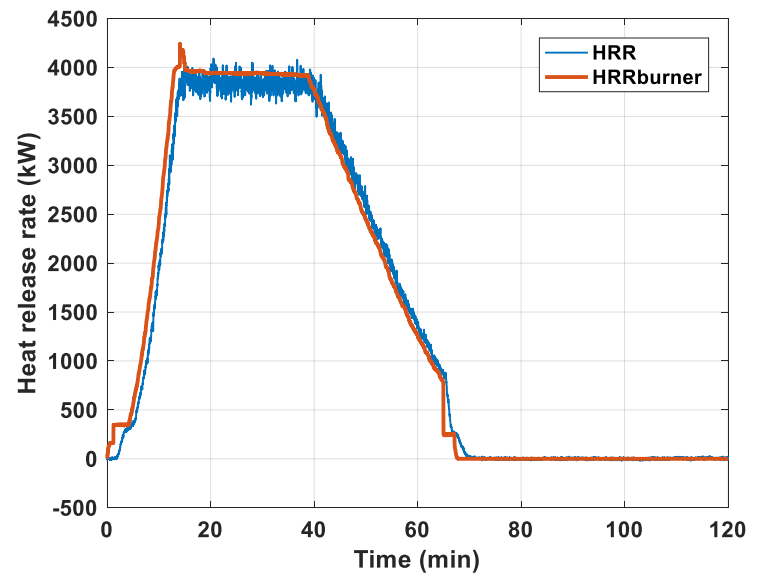

(a)

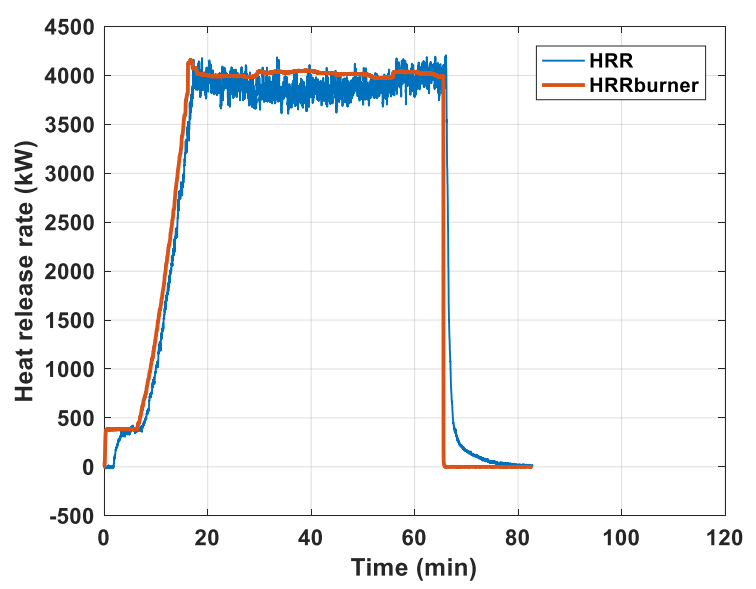

(c)

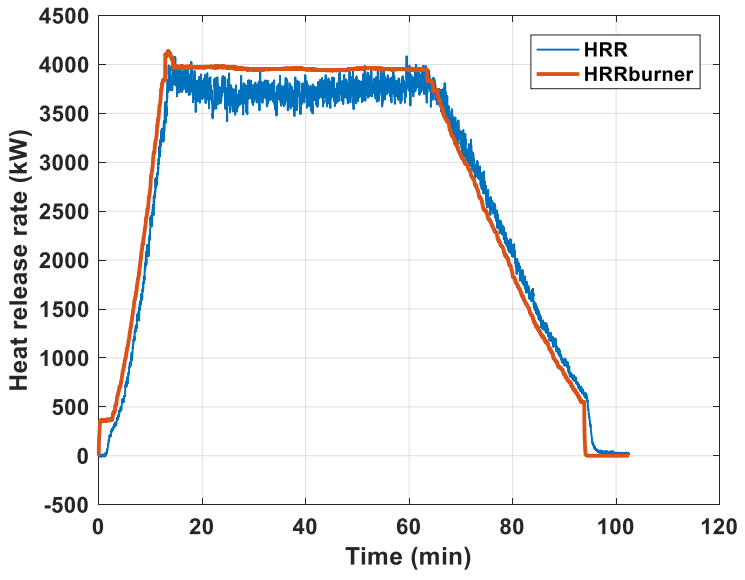

(b)

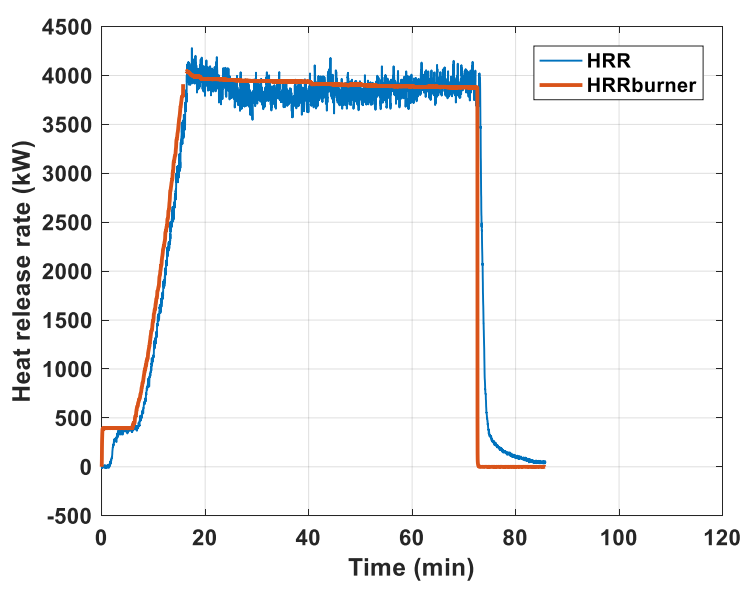

(d)

Figure 17 Heat release rates measured for (a) CB-DA, (b) CB-DA-SC, (c) CB-SP, and (d) CB-SP-SC. 


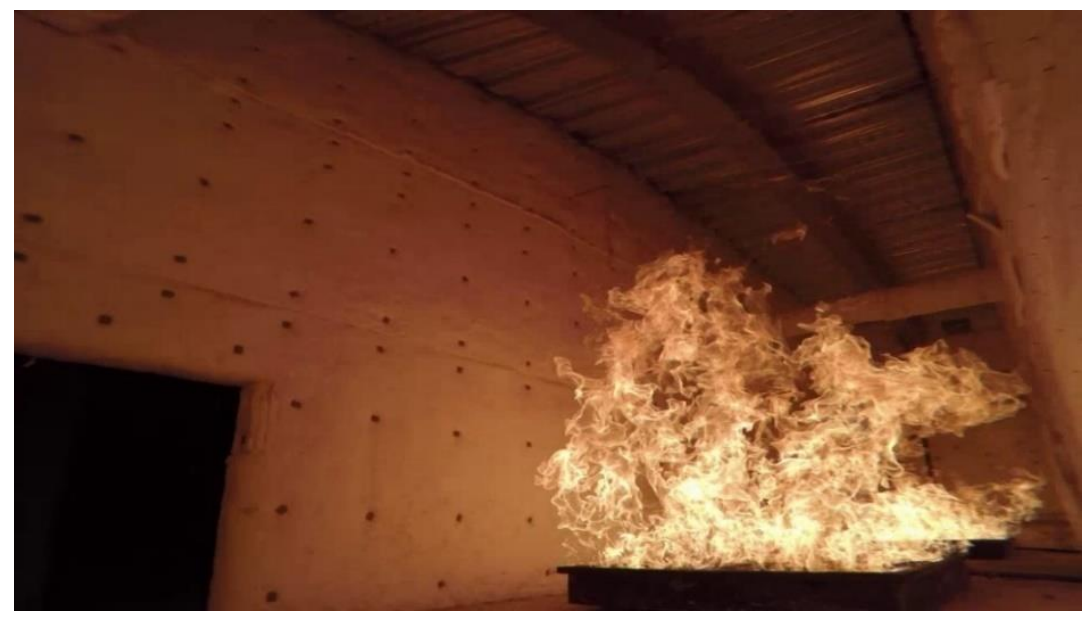

(a)

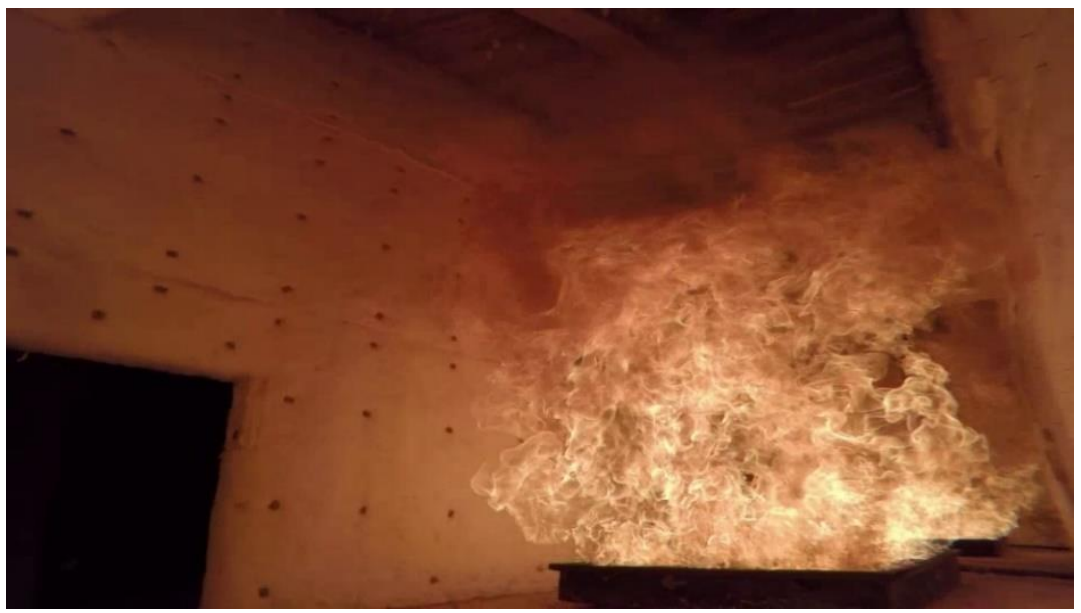

(b)

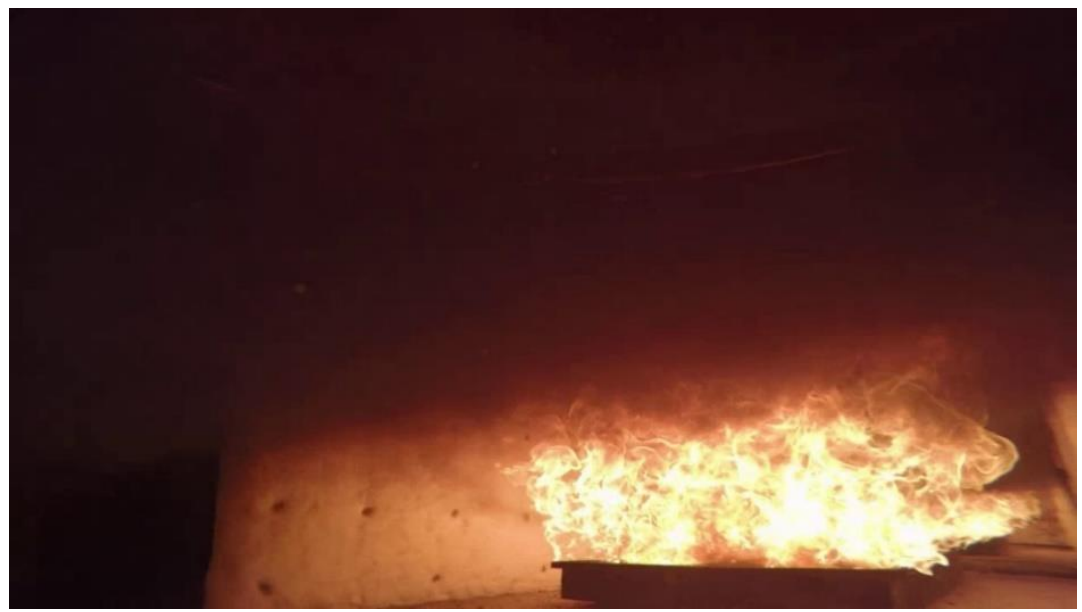

(c)

Figure 18 Snapshots of the video showing the test beam inside the compartment using a camera near vent openings at (a) $8 \mathrm{~min}$, (b) $12 \mathrm{~min}$, (c) $20 \mathrm{~min}$ from ignition. Specimen name: CB-DA-SC. 


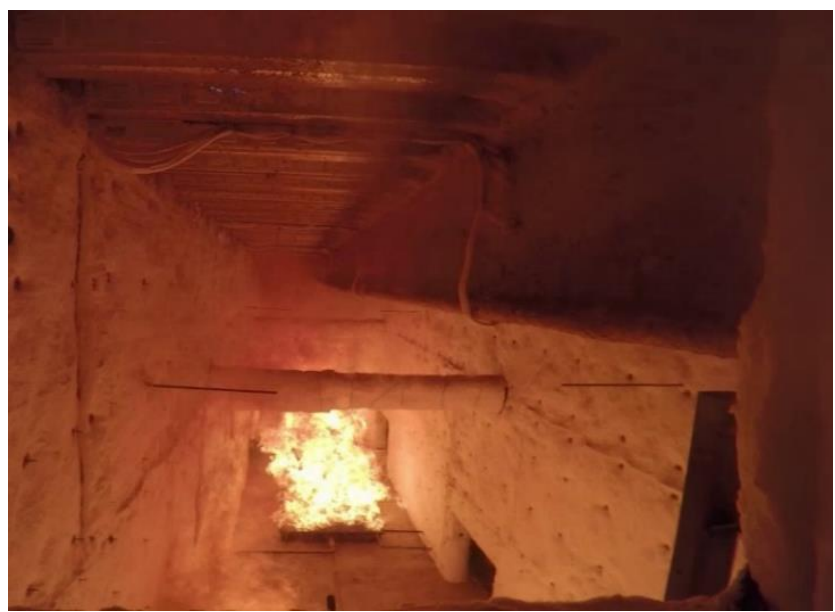

(a)

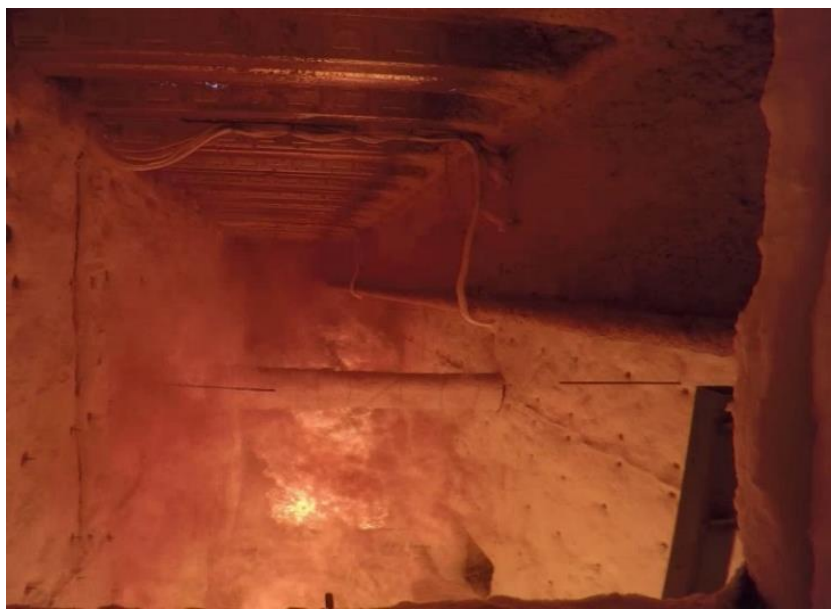

(b)

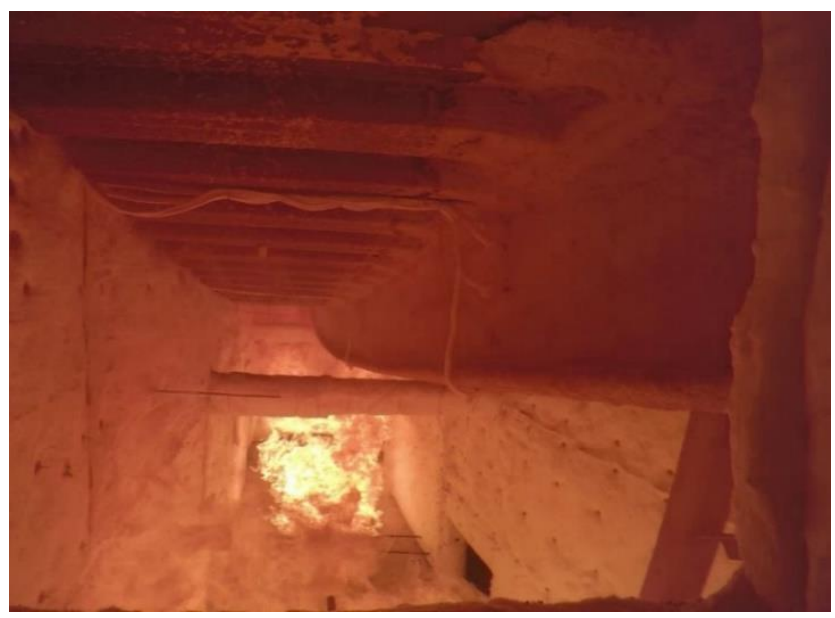

(c)

Figure 19 Snapshots of the video with the view from the east wall at (a) $12 \mathrm{~min}$, (b) $30 \mathrm{~min}$, and (c) $65 \mathrm{~min}$ from ignition. Specimen name: CB-DA-SC. 


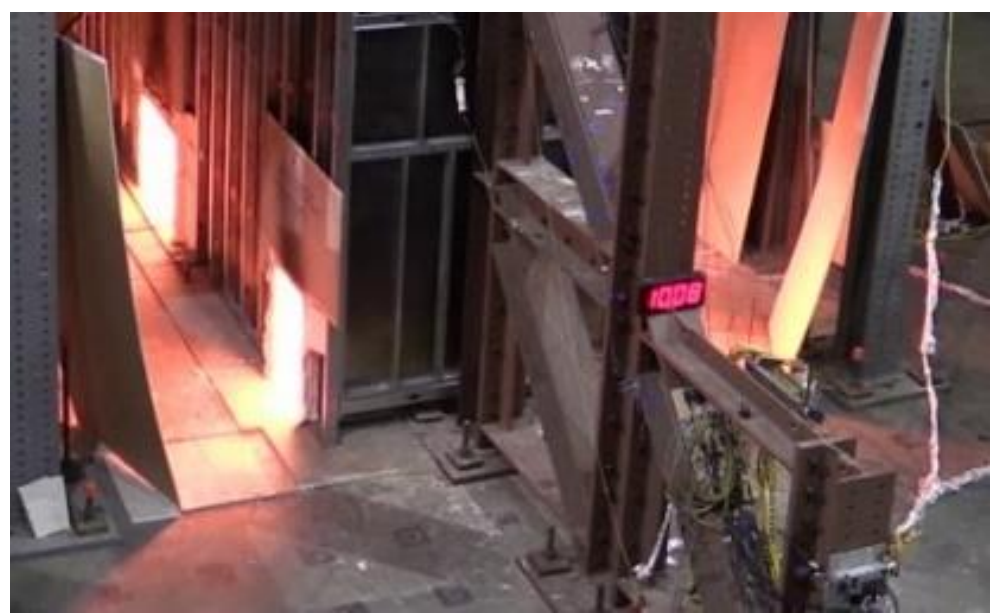

(a)

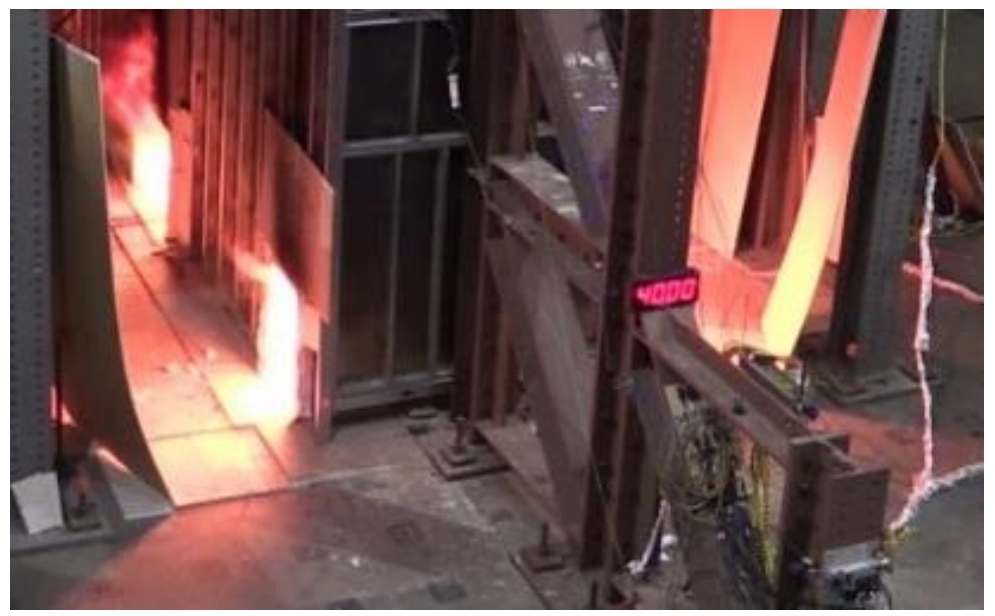

(b)

Figure 20 Snapshots of the video taken outside of the compartment at (a) $10 \mathrm{~min}$, and (b) $40 \mathrm{~min}$ from ignition. Specimen name: CB-DA-SC 


\subsubsection{Gas Temperature and Heat Flux}

The compartment fires produced using the natural gas burners created hot upper layer temperatures trapped below the composite beam assemblies. To measure the average upper layer gas temperature inside the test compartment, eight Inconel-sheathed thermocouple probes (TCC1 through TCC8) were mounted $81 \mathrm{~cm}$ below the exposed steel decking (Refer to Figure 9). Figure 21 shows the average gas temperatures as a function of the time recorded after ignition. The average gas temperature reached $900^{\circ} \mathrm{C}$ around $15 \mathrm{~min}$ after ignition and continuously increased while the HRRburner was set to $4000 \mathrm{~kW}$. The maximum temperature was $1020{ }^{\circ} \mathrm{C}$ at $40 \mathrm{~min}$ (CB-DA) and $1070{ }^{\circ} \mathrm{C}$ at $73 \mathrm{~min}$ (CB-SP-SC). The temperature variation along the length of the compartment was less than $50{ }^{\circ} \mathrm{C}$, indicating that the gas temperature distribution across the exposed surfaces of the specimens was practically uniform.

Figure 22 shows the temperature distribution within the upper layer of the test compartment, measured at three locations, $2.5 \mathrm{~cm}, 23 \mathrm{~cm}$, and $81 \mathrm{~cm}$ from the exposed surfaces of the specimens. Table 7 shows the list of thermocouples used in Figure 22 and summarizes the time-averaged values of temperatures over a period of which HRRburner was set to $4000 \mathrm{~kW}$ (Refer to Table 6). The values after \pm symbols indicate the standard deviation. Thermocouple layout is shown in Figure 9. For CB-DA, the thermocouples installed $2.5 \mathrm{~cm}$ from the exposed surface failed about 10 min from ignition and the data are not plotted. While the fire loading was constant, i.e., HRRburner $=4000 \mathrm{~kW}$, a thermal gradient developed within the upper portion of the compartment. The degree of thermal gradient was largest around $20 \mathrm{~min}$ after the burner ignition, showing that the temperature ranged from $500{ }^{\circ} \mathrm{C}$ to $900{ }^{\circ} \mathrm{C}$ within in the upper portion. However, this temperature gap reduced to around $50{ }^{\circ} \mathrm{C}$ at $60 \mathrm{~min}$.

For the specimens with shear-tab connections (CB-SP and CB-SP-SC), three plate thermometers were mounted on the east wall (PT1), the middle web (PT2), and the bottom flange (PT3) of the steel beam at midspan. Refer to Figure 10 for locations of the plate thermometers. Figure 23 shows the gas temperature measured using plate thermometers. While the heat release rate was maintained around $4000 \mathrm{~kW}$, the time-averaged temperatures measured using three plate thermometers were around $1000{ }^{\circ} \mathrm{C}$, comparable with the average gas temperatures shown in Figure 21. The standard deviation of gas temperatures measured using the plate thermometers was $3 \%$ for CB-SP and $7 \%$ for CB-SP-SC; therefore, the SFRM-protected steel beam appeared to be uniform. Figure 24 shows the heat flux estimated using PT data with the method described in Hoehler et al. (2019). From $20 \mathrm{~min}$ to $65 \mathrm{~min}$ of heating, the time-averaged value of heat fluxes ranged from $130 \mathrm{~kW} / \mathrm{m}^{2}$ to $200 \mathrm{~kW} / \mathrm{m}^{2}$ at the location of PT3. 


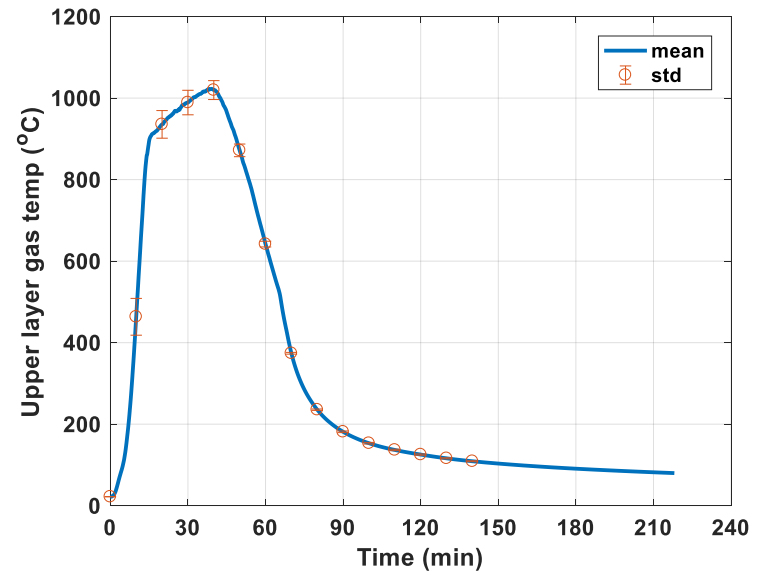

(a)

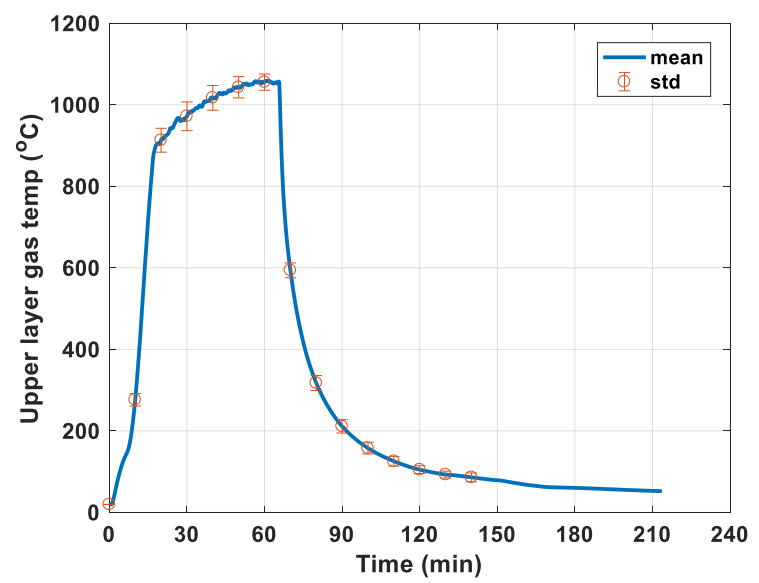

(c)

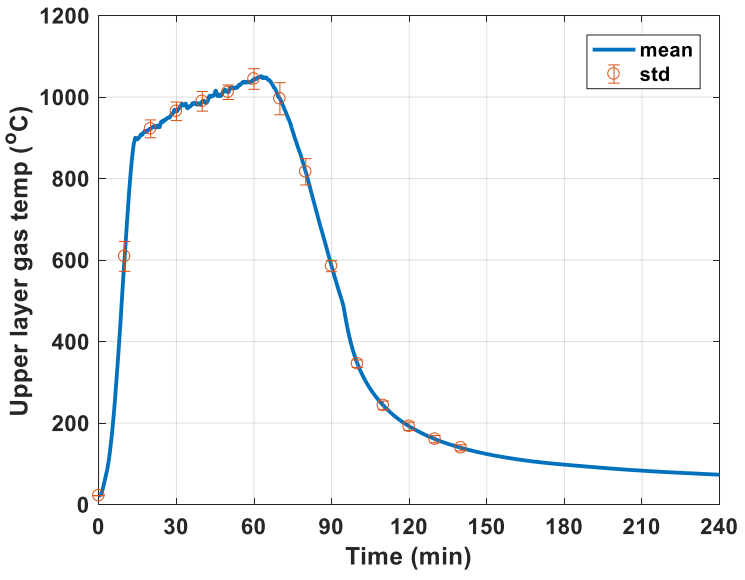

(b)

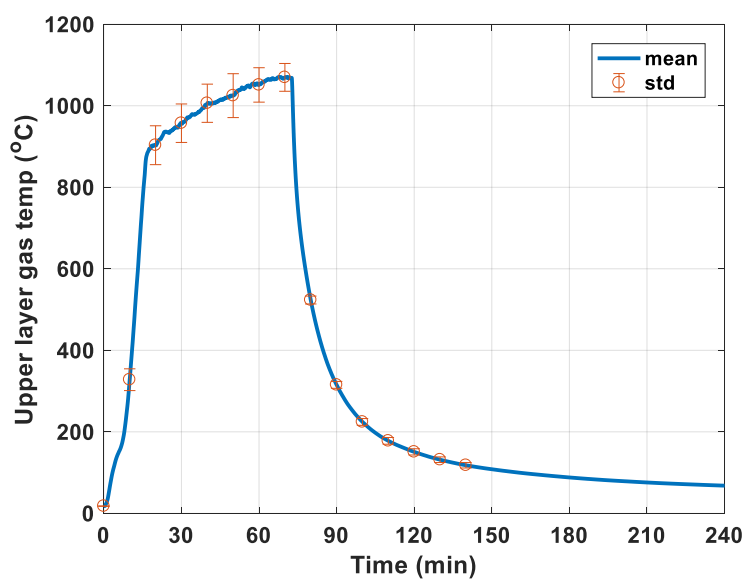

(d)

Figure 21 Upper layer gas temperature measured $81 \mathrm{~cm}$ below the exposed deck for (a) CB-DA, (b) CB-DASC, (c) CB-SP, and (d) CB-SP-SC. Error bars indicate the standard deviation of readings from the eight thermocouples (TCC1 through TCC8) shown in Figure 9. 


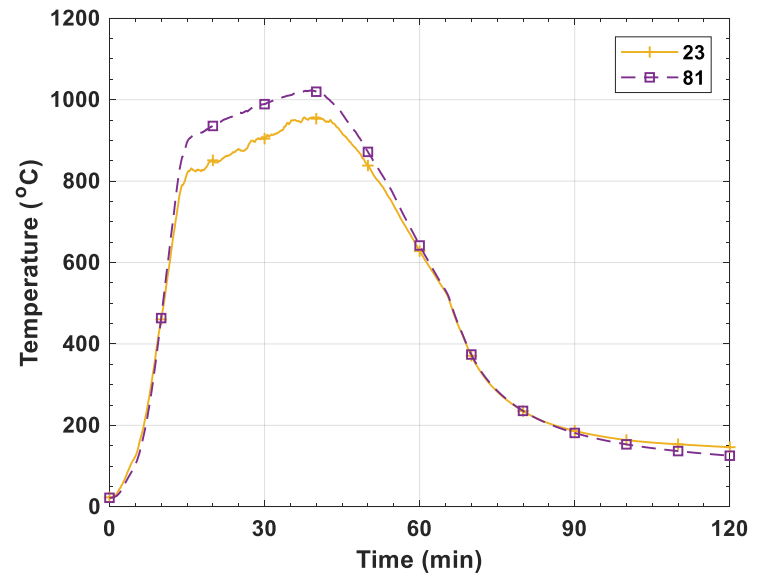

(a)

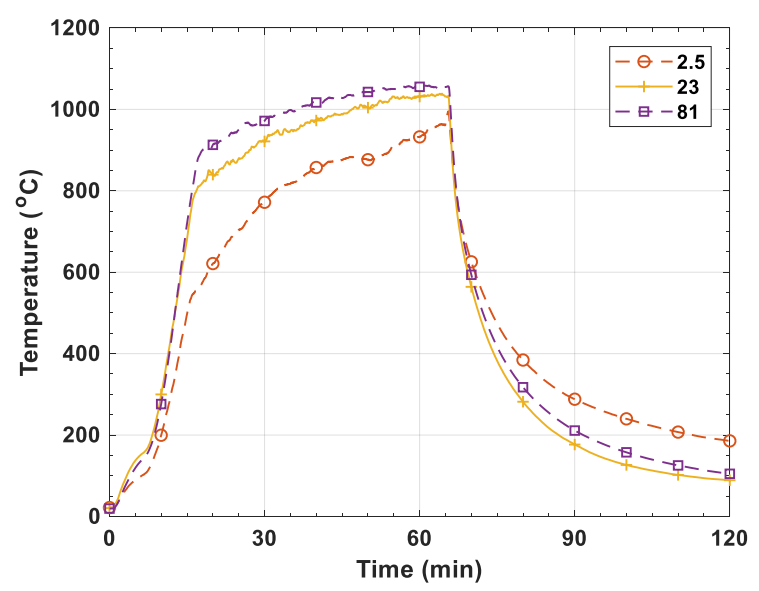

(c)

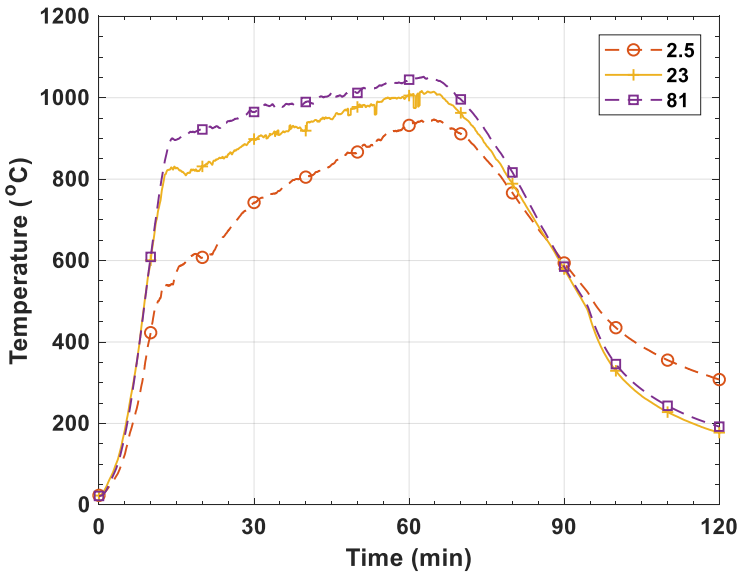

(b)

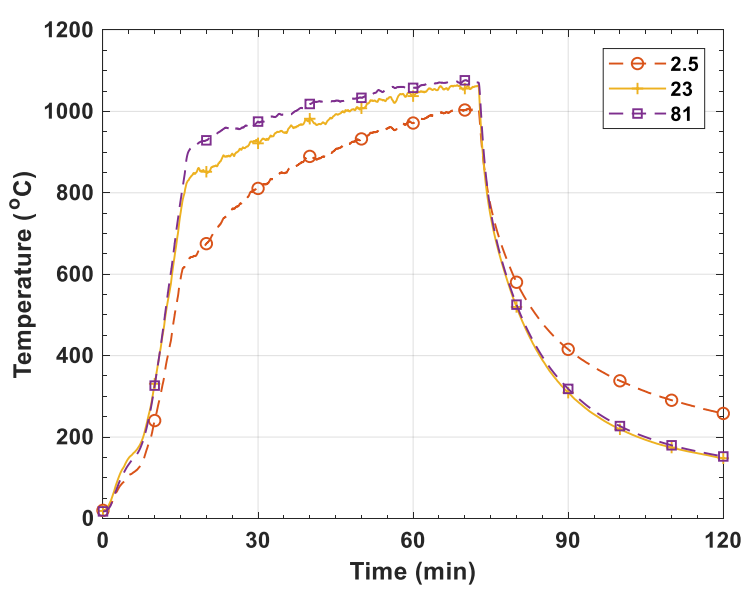

(d)

Figure 22 Gas temperature measured using thermocouple probes placed $2.5 \mathrm{~cm}, 23 \mathrm{~cm}$, and $81 \mathrm{~cm}$ below the exposed deck for (a) CB-DA, (b) CB-DA-SC, (c) CB-SP, and (d) CB-SP-SC.

Table 7 Thermocouple locations for Figure 22 and the average temperature while the burner heat release rate was set to $4000 \mathrm{~kW}$; the values after \pm symbols indicate the standard deviation.

\begin{tabular}{llllll} 
& \multicolumn{4}{c}{ Specimen ID } \\
\hline Legend & Thermocouple ID & CB-DA & CB-DA-SC & CB-SP & CB-SP-SC \\
\hline $2.5 \mathrm{~cm}$ & TCC9, TCC11, TCC13, TCC15 & - & $780 \pm 120$ & $820 \pm 110$ & $880 \pm 100$ \\
$23 \mathrm{~cm}$ & TCC10, TCC12, TCC14 & $900 \pm 20$ & $920 \pm 60$ & $950 \pm 70$ & $970 \pm 60$ \\
$81 \mathrm{~cm}$ & TCC1 through TCC8 & $960 \pm 50$ & $980 \pm 50$ & $1000 \pm 50$ & $1000 \pm 50$ \\
\hline
\end{tabular}




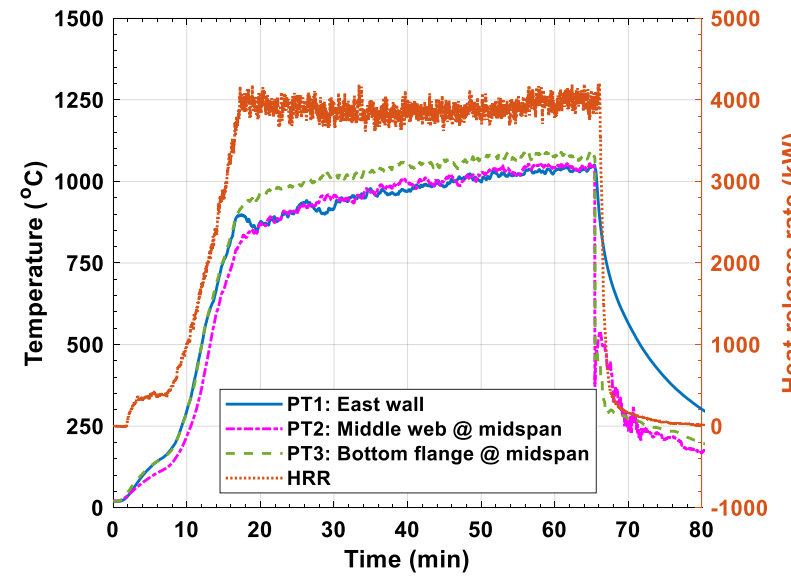

(a)

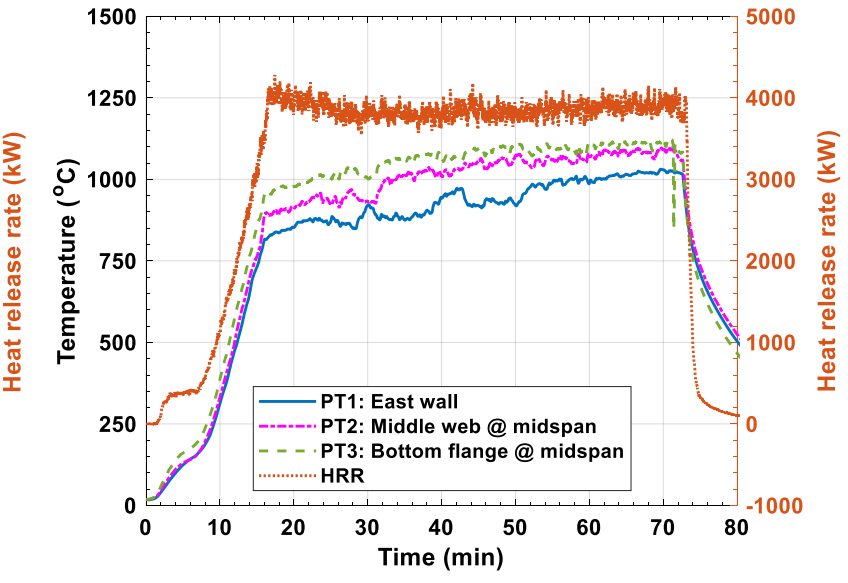

(b)

Figure 23 Gas temperature measured using plate thermometers for (a) CB-SP, and (b) CB-SP-SC comparing with the heat release rates measured using oxygen calorimetry.

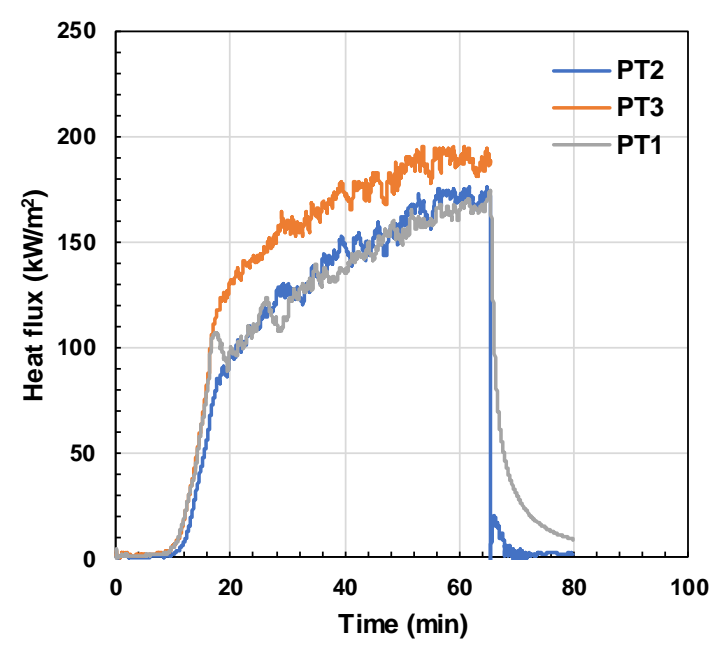

(a)

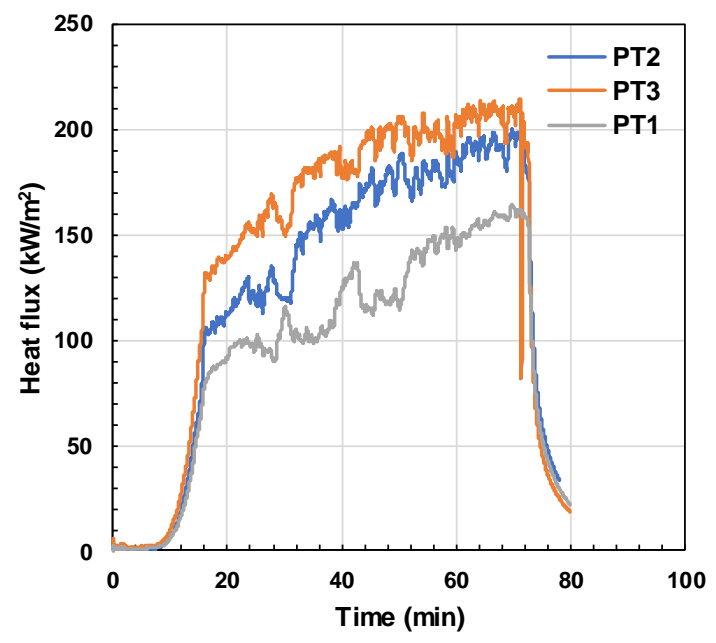

(b)

Figure 24 Calculated heat fluxes at locations of PT1 through PT3 shown in Figure 10: (a) CB-SP, and (b) CB-SP-SC. 


\subsection{Thermal Response of Specimens}

\subsubsection{Temperature-Time Responses}

Figure 25 shows the evolution of temperatures measured at various locations of the specimens, including exposed steel deck, the bottom flange of W18 $\times 35$ steel beams, the beam end connections (angles or shear tabs), and the top and bottom surfaces of concrete slabs along the longitudinal centerline of the specimen. The temperatures shown are the average temperature measured using thermocouples listed in Table 8 and the same gas temperatures as shown in Figure 21. General trends regarding the temperature evolution of the specimens is described as below.

1. Steel deck: Temperatures of the steel deck reached $600{ }^{\circ} \mathrm{C}$ before $15 \mathrm{~min}$ and increased to $1000{ }^{\circ} \mathrm{C}$ or higher before cooling (Figure 25). The deck thermocouples screwed to CB-DA fell off about $10 \mathrm{~min}$ after ignition. For the remaining tests, a $2 \mathrm{~mm}$ thick patch of high-temperature cement was placed over the thermocouples to secure them to the deck. The variation in temperatures of the steel deck along the beam length was as large as $20 \%$ during the first 15 min but decreased with time, falling below $2 \%$ before the cooling phase begun.

2. Bottom flange: The bottom flange temperatures of the $\mathrm{W} 18 \times 35$ steel beams near midspan were measured using Inconel-shielded thermocouples shown in Figure 7 for the CB-DA-SC, CB-SP, and CB-SP-SC specimens, and flange temperatures for CB-DA specimen were not measured. The temperature of the SFRM-protected bottom flange increased at a rate of $10^{\circ} \mathrm{C} / \mathrm{min}$ on average from $30 \mathrm{~min}$ to $65 \mathrm{~min}$. The average bottom flange temperature reached $600{ }^{\circ} \mathrm{C}$ at $45 \mathrm{~min}$ after ignition and reached nearly $800^{\circ} \mathrm{C}$ at $70 \mathrm{~min}$ (CB-DA-SC and CB-SP-SC).

3. Connection: The temperatures of the beam-to-column connections increased more slowly than those of the bottom flange but continued to increase during cooling (until 40 min after the fire was extinguished) but never exceeded $300{ }^{\circ} \mathrm{C}$. The variation in temperatures measured at discrete locations in the connections was below $30{ }^{\circ} \mathrm{C}$. This was thought that the connection temperature was affected by a thicker SFRM which slowed the heat transfer in this region. The connection was also cooled by thermal conduction to the support column outside of the heating zone. Refer to Table 2 for SFRM thickness applied on the specimens.

4. Concrete: The temperature rise in the concrete slab directly in contact with the top flange of the steel beam was slow. The maximum temperature at the bottom surface of the concrete slab (in contact with the top flange of the steel beam) was between $200{ }^{\circ} \mathrm{C}$ and $300{ }^{\circ} \mathrm{C}$; achieved during cool-down. The temperature of the unexposed (top) surface of the concrete never exceeded $100{ }^{\circ} \mathrm{C}$ during heating but increased to nearly $140{ }^{\circ} \mathrm{C}$ during cooling. 
Table 8 List of thermocouples used to estimate the average temperatures plotted in Figure 25.

\begin{tabular}{lll}
\hline Legend & Specimen ID & Thermocouple ID \\
\hline Steel Deck & All & TC3-25, TC4-26, TC5-25, TC6-26 \\
Bottom Flange & All & STC2, STC3 \\
Connection & CB-DA & TCE-4, TCE-5, TCE-6 \\
& CB-DA-SC & TCW-4, TCE-4, TCE-5, TCE-6 \\
& CB-SP & TCW-4, TCW-5, TCW-7, TCE-4, TCE-5, TCE-7 \\
& CB-SP-SC & TCW-4, TCW-5, TCW-6, TCW-7, TCE-4, TCE-5, TCE-6, TCE-7 \\
Bottom Concrete & All & TC3-10, TC4-10, TC5-10, TC6-10 \\
Top Concrete & All & TC3-6, TC4-6, TC5-6, TC6-6 \\
\hline
\end{tabular}

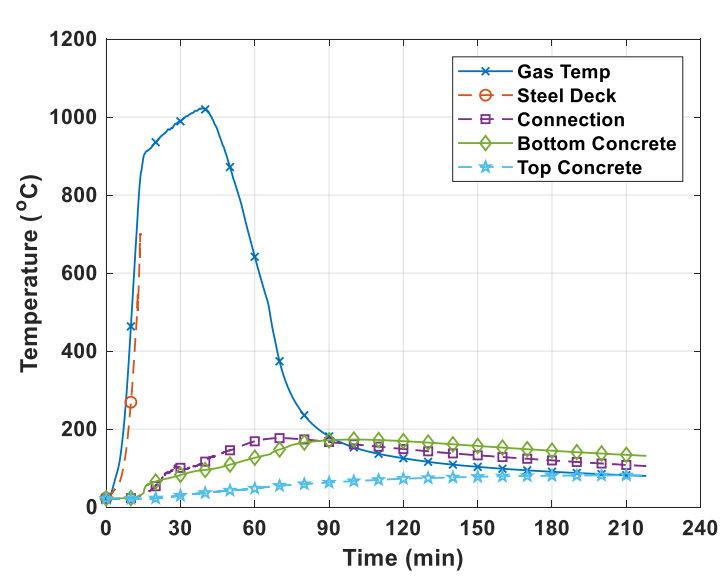

(a)

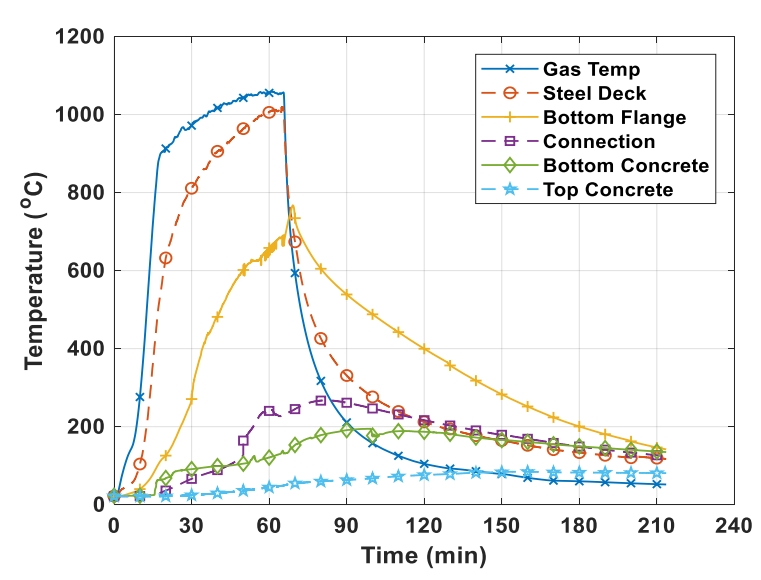

(c)

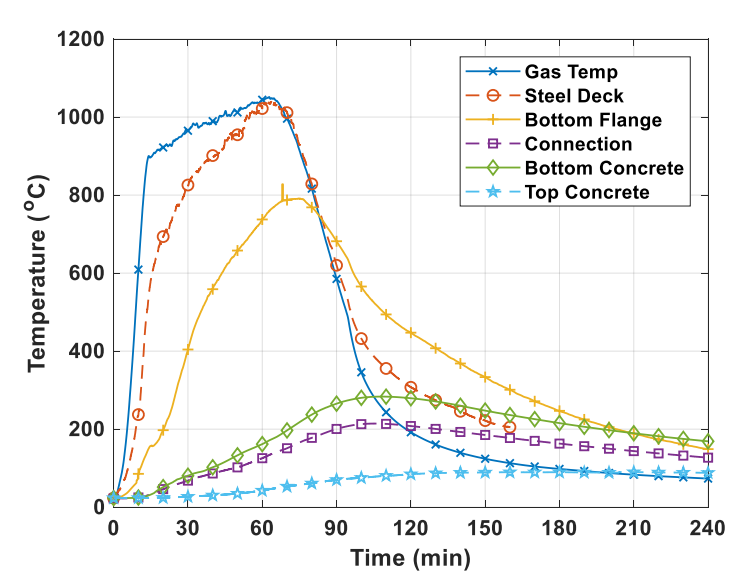

(b)

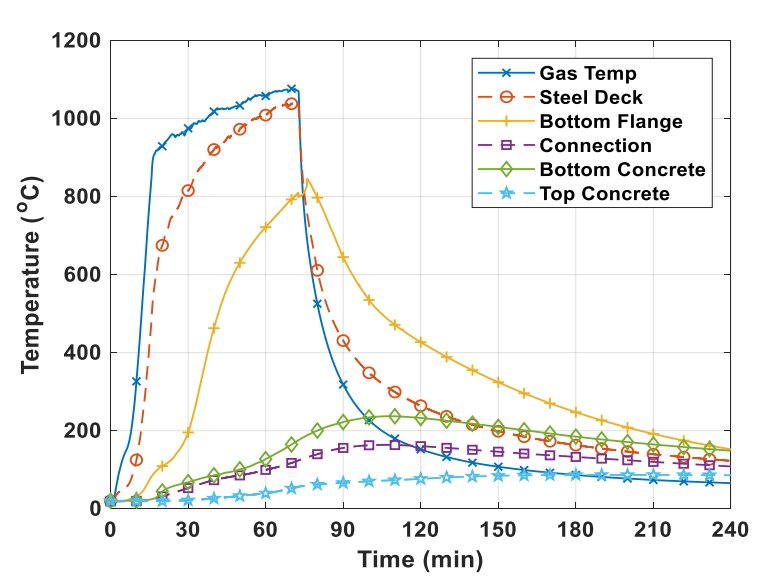

(d)

Figure 25 Temperature at various locations of the specimens for (a) CB-DA, (b) CB-DA-SC, (c) CB-SP, and (d) CB-SP-SC. 


\subsubsection{Temperature Distribution of CB-SP-SC}

Figure 26 shows measured temperatures at various locations through the section depth of CB-SP-SC. The plotted values are the average temperatures measured at each location in TC3 through TC6 sections shown in Figure 7. Table 9 shows the list of thermocouple channels used to calculate the average temperatures and the standard deviation of temperature readings at the same elevation within the cross sections. As shown in Figure 26, the lower portion of the protected W18 $\times 35$ beam (i.e., T13 through T15) rapidly reached the temperature ranging from $650{ }^{\circ} \mathrm{C}$ to $700{ }^{\circ} \mathrm{C}$ at $60 \mathrm{~min}$. A peak temperature at each thermocouple location of the $\mathrm{W} 18 \times 35$ section ranged from $500{ }^{\circ} \mathrm{C}$ to $740{ }^{\circ} \mathrm{C}$ when the fire was extinguished at $73 \mathrm{~min}$. On the other hand, temperatures of the concrete slab directly above the steel beam (T6 through T10) increased more slowly and remained below $200^{\circ} \mathrm{C}$. The concrete temperature continued to increase during cooling; however, the unexposed surface temperature along the longitudinal centerline of the specimen never exceeded $100{ }^{\circ} \mathrm{C}$ until the data acquisition was terminated (up to 4 hours of cooling).

Figure 27 shows the thermal gradient of the CB-SP-SC specimen, changing with the time recorded after the burner ignition. The steel beam appeared to be heated uniformly both in the longitudinal and transverse directions. The temperature variation in the longitudinal direction was less than $10 \%$ although the beam ends were much cooler because of a thicker SFRM on the connections. Temperatures of the concrete slab were less uniform in the longitudinal direction. The concrete temperature variation was in the range of $10 \%$ to $80 \%$ throughout the tests. The concrete temperature appeared to be significantly influenced by concrete cracks and the moisture content.

Table 9 List of thermocouples used in Figure 25 and the mean and standard deviation of the measured temperatures at $60 \mathrm{~min}, 73 \mathrm{~min}$, and $258 \mathrm{~min}$ from the burner ignition.

\begin{tabular}{llllllll} 
& & \multicolumn{2}{c}{$\mathbf{6 0}$ min } & \multicolumn{2}{c}{$\mathbf{7 3}$ min } & \multicolumn{2}{c}{ 258 min (cooling) } \\
\hline Legend & Thermocouple ID & Mean & Std & Mean & Std & Mean & Std \\
\hline T6 & TC3-6, TC4-6, TC5-6, TC6-6 & 40 & 13 & 60 & 17 & 85 & 5 \\
T7 & TC3-7, TC4-7, TC5-7, TC6-7 & 60 & 28 & 70 & 26 & 100 & 4 \\
T8 & TC3-8, TC4-8, TC5-8, TC6-8 & 70 & 25 & 90 & 18 & 120 & 6 \\
T9 & TC3-9, TC4-9, TC5-9, TC6-9 & 90 & 14 & 100 & 11 & 130 & 6 \\
T10 & TC3-10, TC4-10, TC5-10, TC6-10 & 130 & 21 & 180 & 31 & 140 & 6 \\
T11 & TC3-11, TC4-11, TC5-11, TC6-11 & 330 & 57 & 490 & 79 & 145 & 5 \\
T12 & TC3-12, TC4-12, TC5-12, TC6-12 & 520 & 28 & 670 & 45 & 140 & 10 \\
T13 & TC3-13, TC4-13, TC5-13, TC6-13 & 650 & 31 & 720 & 29 & 145 & 5 \\
T14 & TC3-14, TC4-14, TC5-14, TC6-14 & 690 & 44 & 740 & 21 & 150 & 5 \\
T15 & TC3-15, TC4-15, TC5-15, TC6-15 & 660 & 74 & 704 & 31 & 150 & 10 \\
\hline
\end{tabular}




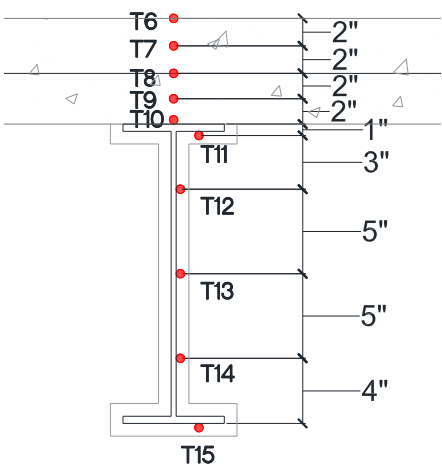

(a)

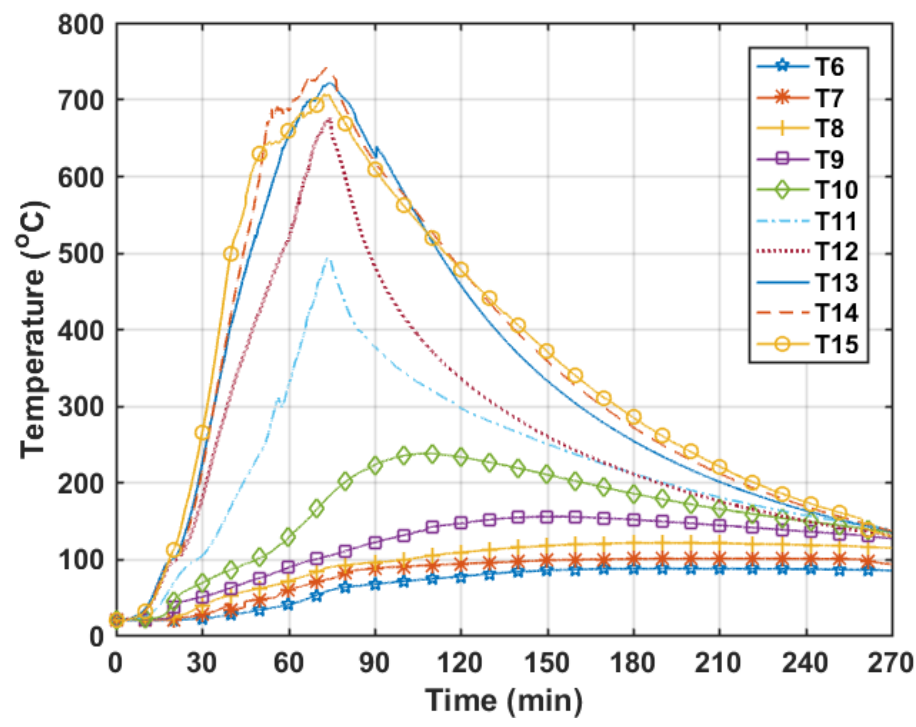

(b)

Figure 26 (a) Location of temperature measurements (units in inches. 1 inch $=25.4 \mathrm{~mm}$ ), and (b) average temperatures at various locations through the depth of CB-SP-SC.

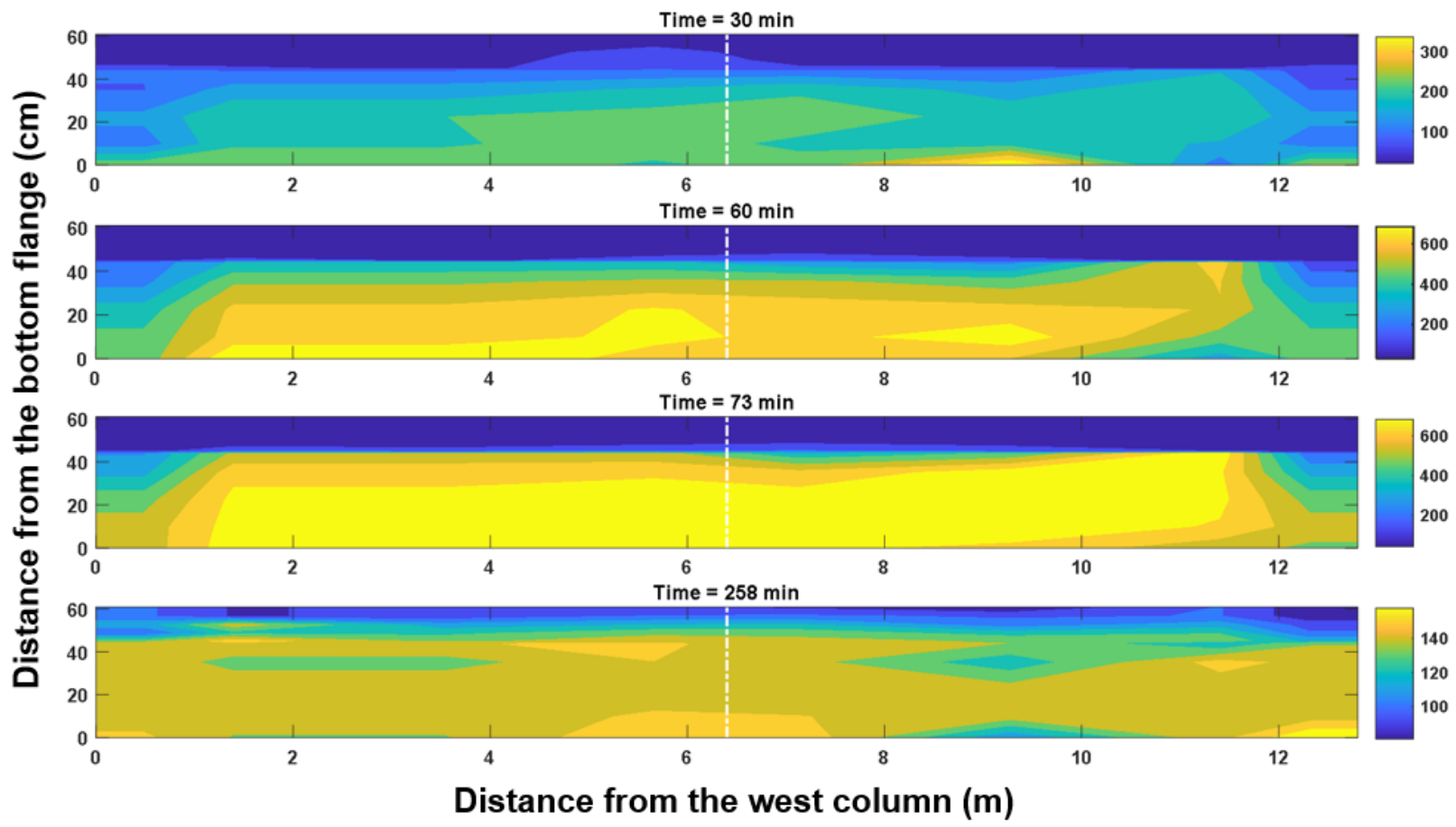

Figure 27 Temperature distribution of CB-SP-SC along the longitudinal centerline at various times after the burner ignition. The burner was extinguished 73 min after ignition. 


\subsubsection{Challenges in Temperature Measurement of Steel Beams}

Bare-bead thermocouples were mounted to the $\mathrm{W} 18 \times 35$ steel beams using a peening method (Choe et al. 2018) prior to the installation of the SFRM. However, the experiments showed that inadequate insulation of thermocouple lead wires affected the temperature data. For the first specimen (CB-DA), the exposed glass fiber shielding of thermocouples mounted to the steel beam (Figure 7b and Figure 7c) burned off around 10 min after ignition. As the specimen deformed in the fire, thermocouple lead wires made secondary junctions elsewhere inside the compartment in addition to the bead installed at the steel beams. For the remaining specimens, various insulation schemes were applied to salvage mounted thermocouples as described below.

For CB-DA-SC, both ceramic-impregnated fabric sleeves and stainless-steel piping were used to protect the glass-shielded thermocouple wires (Figure 28a). Figure 29a shows the bottom flange temperature measured using glass-sheathed thermocouples (TC3-15, TC4-15, TC5-15, TC6-15) and Inconel-shielded thermocouples (STC2, STC3). The temperature readings from both the glass shielded and Inconel sheathed thermocouples were similar until the fire exposure time reached around $11 \mathrm{~min}$. Despite the use of ceramic-impregnated fabric sleeves as a supplementary cover, the glass braid insulation of thermocouple wires burned off when the upper layer gas temperature exceeded $500{ }^{\circ} \mathrm{C}$. This insulation failure caused an apparent sudden increase in the bottom flange temperatures. Temperature readings from these thermocouples may indicate the average values of the bottom flange temperature and hot gas temperatures inside the compartment.

For CB-SP, each conductor of existing glass-shielded type-K thermocouples (alumel and chromel) were separated by high-temperature fabric sleeves and ceramic beads (Figure 28b). Figure 29b shows the bottom flange temperatures measured using glass-sheathed thermocouples with modified insulation (TC2-15, TC4-15) and Inconel-sheathed thermocouples (STC2, STC3). Both insulated thermocouples indicated the temperature data comparable until $32 \mathrm{~min}$ (Figure 29b) and became unreliable afterwards. For CB-SP-SC, glass-shielded thermocouple wires were placed under the SFRM coating of the steel beam and running through the concrete slab and thin grooved regions were then filled with fresh SFRM (Figure 28c). No thermocouple wires were directly exposed to upper layer gas temperatures. The temperature data from these thermocouples were more reliable as presented in Subsection 3.3.2.

For the CB-DA-SC, CB-SP, and CB-SP-SC specimens, additional Inconel-sheathed type-K thermocouples were mounted to the steel beams. Refer to Figure $7 \mathrm{~d}$ for the location of thermocouples. As shown in Figure 28d, each thermocouple probe was placed on the surface of the steel beam underneath of the SFRM layer. The Inconel-sheathed wires were routed through 
$1 \mathrm{~cm}$ diameter holes drilled in the concrete slab to minimize high temperature exposure in the compartment.

Figure 30 shows a comparison of the average temperature of the top flange, middle web, and bottom flange of the steel beam for CB-SP-SC using glass-sheathed thermocouples (protected under the SFRM layer) with that measured using Inconel-sheathed thermocouples. Glass-shielded thermocouples are indicated with TC; Inconel-sheathed thermocouples are labeled with STC. Table 10 shows a list of thermocouples used to calculate the average values and standard deviations plotted in Figure 30. Error bars indicate a maximum standard deviation. As shown in Figure 30a, for CB-SP-SC, both TC and STC thermocouples measured comparable bottom flange temperatures up to $50 \mathrm{~min}$; however, the peak temperature differed by $20 \%$ around $73 \mathrm{~min}$. The SFRM coating on the lower flange cracked in tension as the steel beam deformed in fire, possibly introducing hot gas around the probes of STC thermocouples. For the middle web and the top flange (Figure 30b and Figure 30c), the temperature data from the two different methods deviated after less than $30 \mathrm{~min}$ of fire exposure. During the heating phase, the Inconel-sheathed thermocouples indicated the higher temperatures at the middle web but the lower temperatures at the top flange than the glass-sheathed thermocouples. The maximum discrepancy was $41 \%$ at the middle web and $53 \%$ at the top flange, suggesting that the STC probes were separated from the steel substrate. As the specimen bent during heating, the STC probe beads contacting the middle web might have been partially exposed to hot gases, resulting the higher temperatures than the TC probes. Conversely, the STC probe measuring the top flange was surrounded by SFRM filled between the bottom rib of the trapezoidal steel decking and the steel beam; hence, the displaced STC probe measured lower temperatures than the TC probes. 


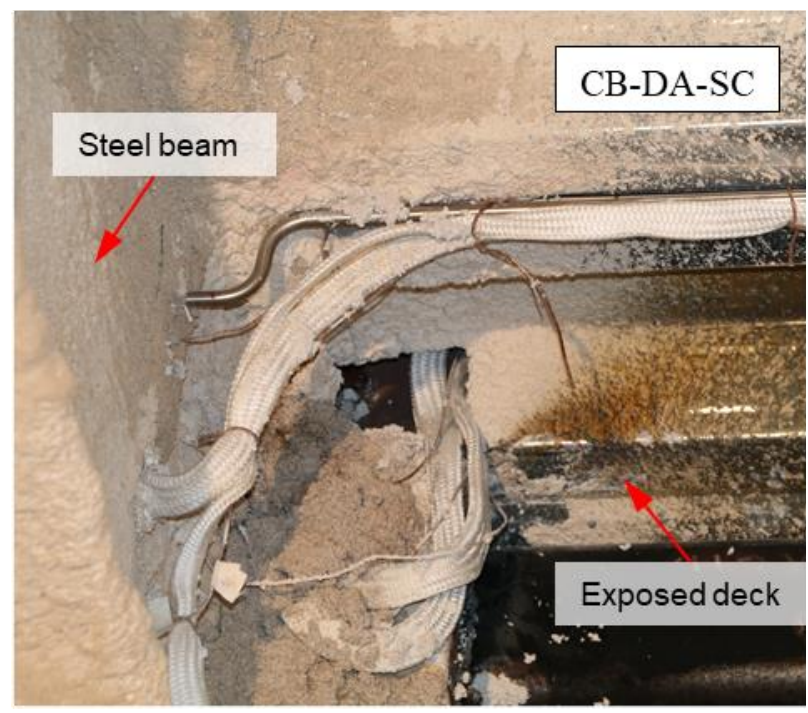

(a)

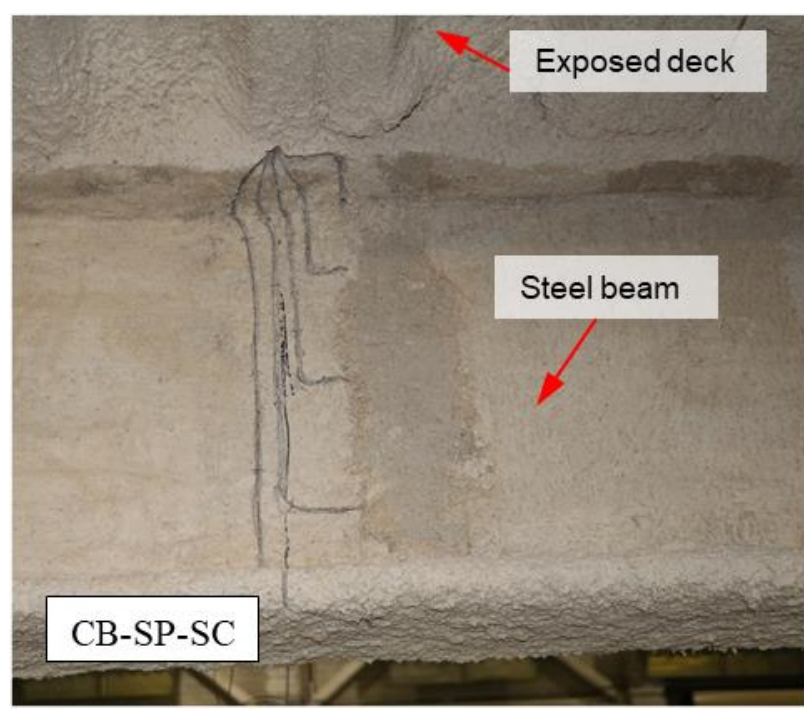

(c)

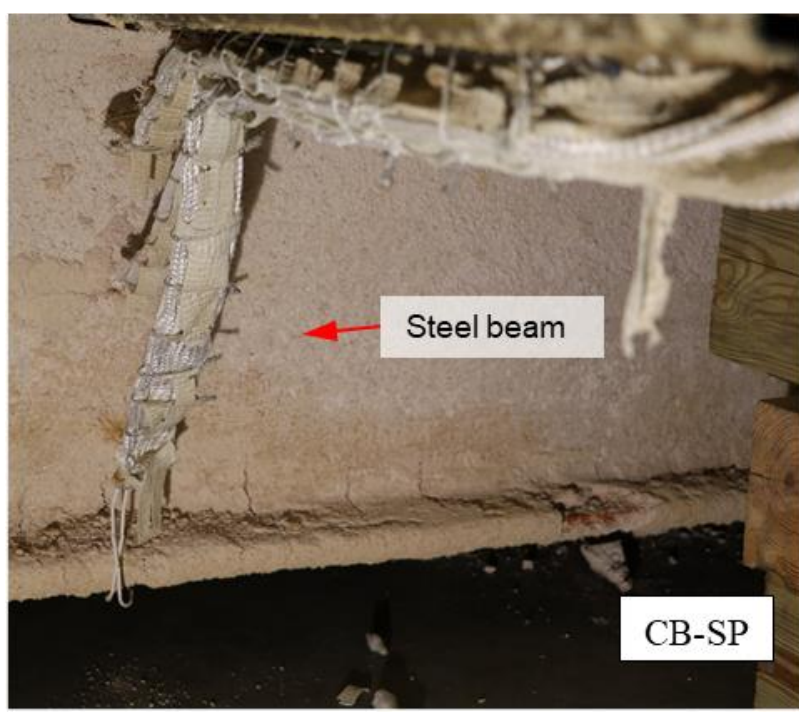

(b)

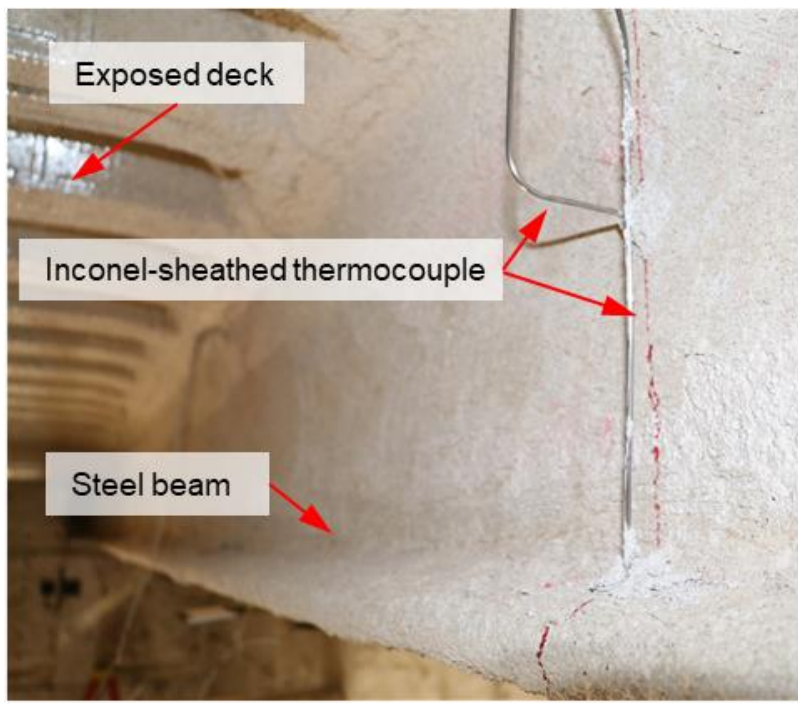

(d)

Figure 28 Photographs of thermocouples mounted to the steel beams with various insulation methods: (a) high-temperature ceramic fabric and stainless-steel tubing for CB-DA-SC, (b) ceramic beads and fabric used to separate chromel and alumel wires for CB-SP (photo taken after test), (c) grooved SFRM coating for CB-SP-SC, and (d) Inconel-sheathed thermocouples. 


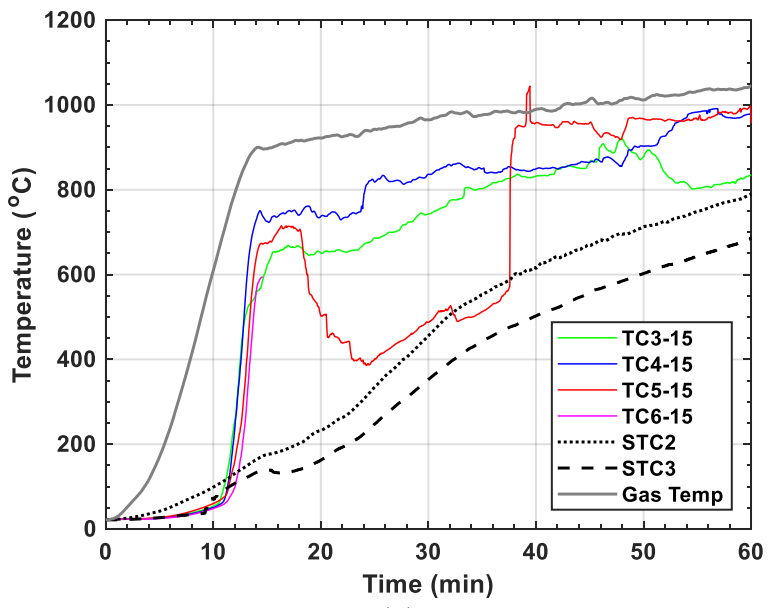

(a)

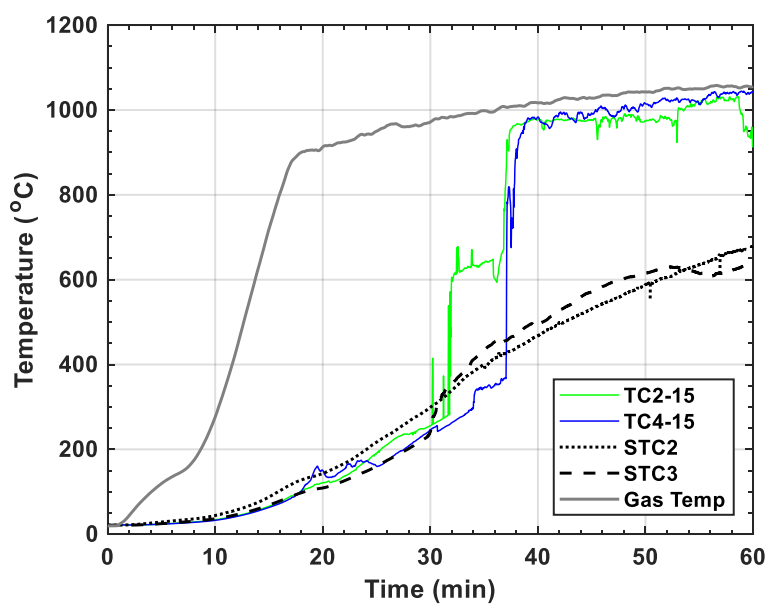

(b)

Figure 29 Comparison of the bottom flange temperatures measured using glass-sheathed (TC) and Inconelsheathed (STC) thermocouples for (a) CB-DA-SC, and (b) CB-SP.

Table 10 List of thermocouples used for temperature data plotted in Figure 30 for CB-SP-SC.

\begin{tabular}{lll}
\hline & \multicolumn{2}{l}{ Thermocouple ID } \\
\hline Legend & STC & TC \\
\hline Bottom flange & STC2, STC3 & TC3-15, TC4-15, TC5-15, TC6-15 \\
Middle web & STC5, STC7 & TC3-13, TC4-13, TC5-13, TC6-13 \\
Top flange & STC6, STC8 & TC3-11, TC4-11, TC5-11, TC6-11
\end{tabular}




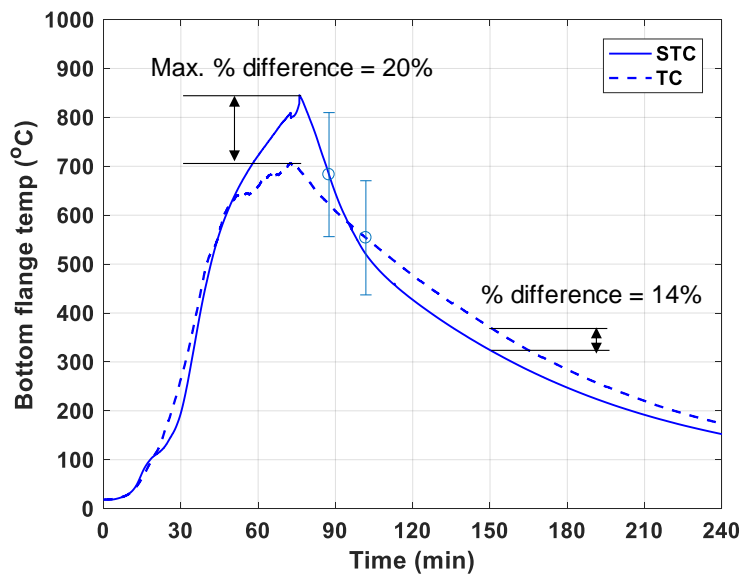

(a)

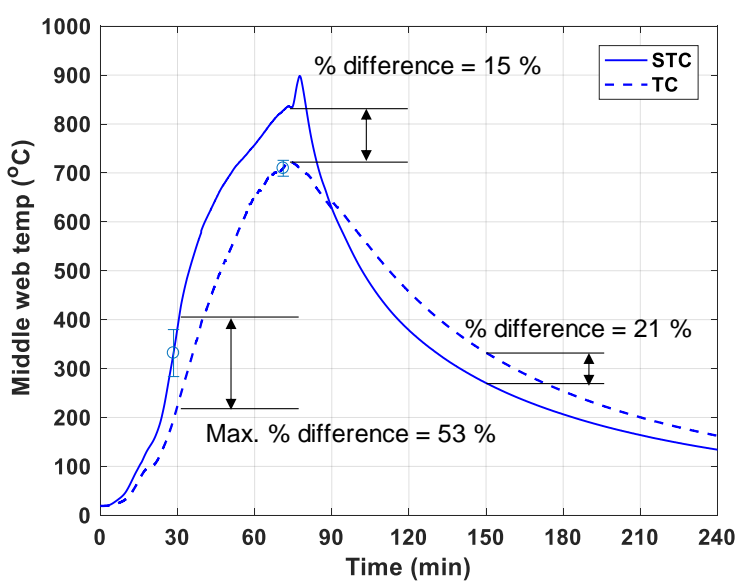

(b)

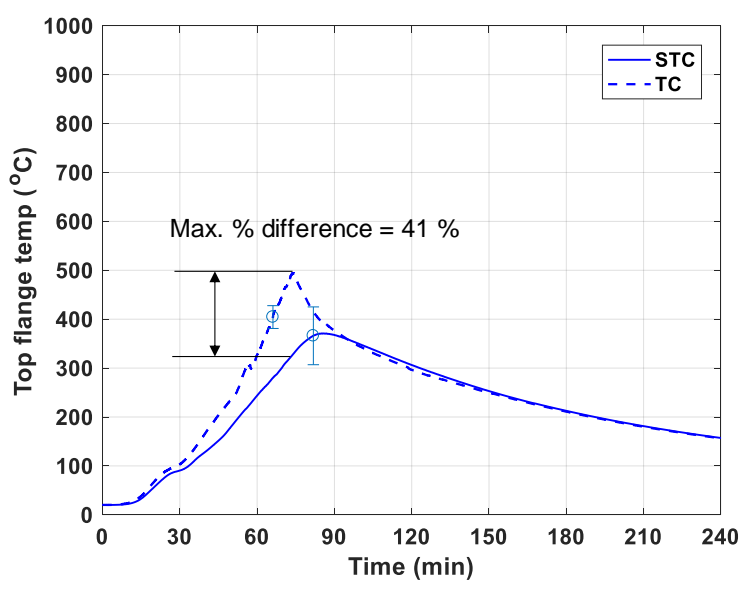

(c)

Figure 30 Comparison of temperatures of (a) bottom flange, (b) middle web, and (c) top flange measured using glass-sheathed (TC) and Inconel-sheathed (STC) thermocouples for CB-SP-SC. Error bars indicate the maximum standard deviation of temperatures measured at multiple locations along the beam length. 


\subsubsection{Slab Temperature}

Temperatures in the concrete slab were measured at various locations using bare-bead thermocouples. Figure 31 shows the history of measured slab temperatures near midspan directly above the top flange of the $\mathrm{W} 18 \times 35$ beam; refer to Figure 7 for sensor locations. Measurements from section TC4 are shown for CB-DA-SC only, because the measurements at TC4 were judged to be potentially faulty in the other specimens; all of the data is plotted in the Appendices.

Above the $\mathrm{W} 18 \times 35$ beam, the maximum temperature in the concrete was achieved some time after the fire was extinguished due to the thermal mass of the concrete and steel beam (Figure 31). The time at which the peak temperatures occurred varied depending on the thermocouple height in the slab. For CB-SP and CB-SP-SC, which were exposed to similar fire loading, the maximum temperatures at the bottom of the concrete slab directly above the $\mathrm{W} 18 \times 35$ beam (TC5-10) were between $200{ }^{\circ} \mathrm{C}$ and $270{ }^{\circ} \mathrm{C}$ around 1.5 hours after burner ignition. The temperatures near the top surface of the slab (TC5-7) increased more slowly. The influence of evaporation of the free water in the concrete during heating (moisture content $\approx 7 \%$ ) is evidenced in Figure 31 by the plateau in temperature at $100{ }^{\circ} \mathrm{C}$ as the liquid water converted to steam. This plateau is longer at higher positions in the slab. Similar results were observed for CB-DA and CB-DA-SC, although a 30-min decay of the fire exposure was used.

Figure 32 shows the slab temperatures measured on the north and south side of the specimen using thermocouples to the east and west of the centerline of the $\mathrm{W} 18 \times 35$ beam. Temperatures T2, T4, and T5 in Figure 32 were the average temperature measured $4 \mathrm{~cm}$ below the top surface, $4 \mathrm{~cm}$ above the bottom surface, and at the bottom surface of the concrete slab, respectively. The error bars indicate the maximum standard deviations throughout the measurement period.

As shown in Figure 32, for the CB-DA-SC, CB-SP, CB-SP-SC specimens, the bottom surface temperature of the concrete slab (T5) increased to its peak value of $850{ }^{\circ} \mathrm{C}$ on average before the fire was extinguished. These concrete temperatures are significantly higher than those directly above the W18 $\times 35$ beam in Figure 31. During cooling, temperatures near the top surface (T2) increased to around $150{ }^{\circ} \mathrm{C}$ for both CB-SP and CB-SP-SC and to nearly $200{ }^{\circ} \mathrm{C}$ for CB-DA-SC subjected to fire loading for a longer duration. For all four specimens, the average temperature measured on the north side of the slab was similar to that on the south side, demonstrating uniform temperature distribution in the north-south direction. However, some large temperature variation in the east-west direction (i.e., around the longitudinal axis) during heating occurred. This could be the result of combined effects, such as concrete cracks, localized evaporation of moistures in the concrete, variations in locations of thermocouple probes, and unexpected thermal junctions in the thermocouple wires. 


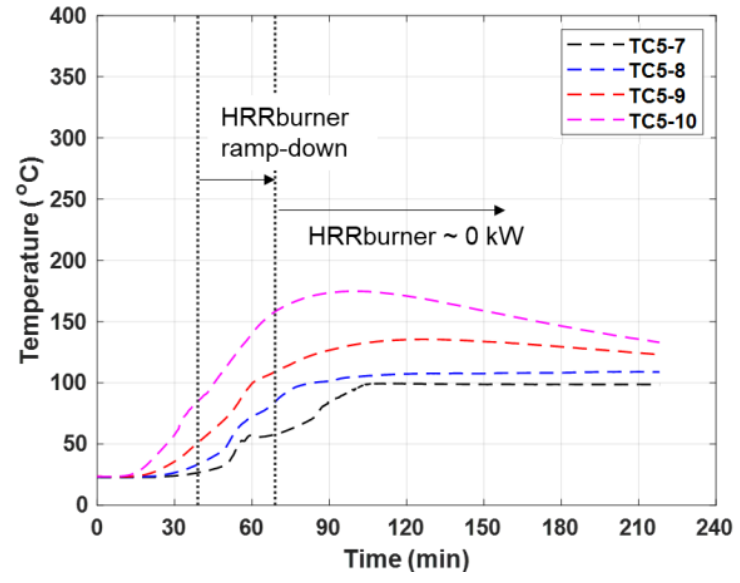

(a)

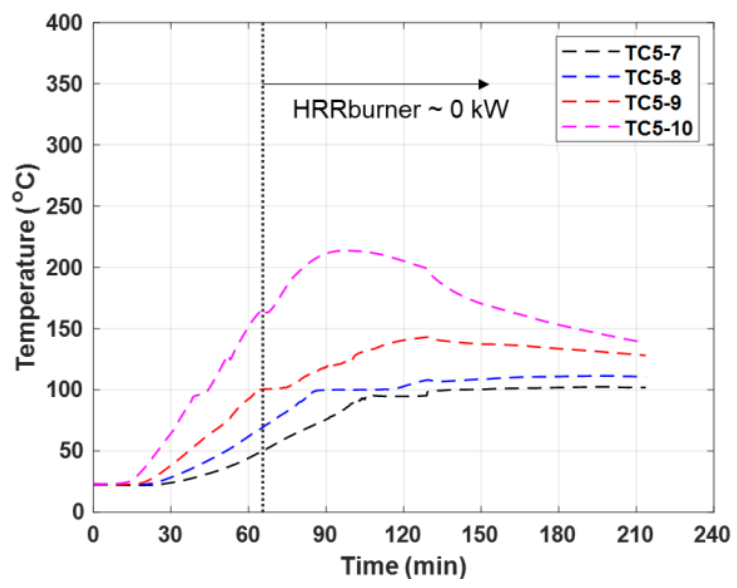

(c)

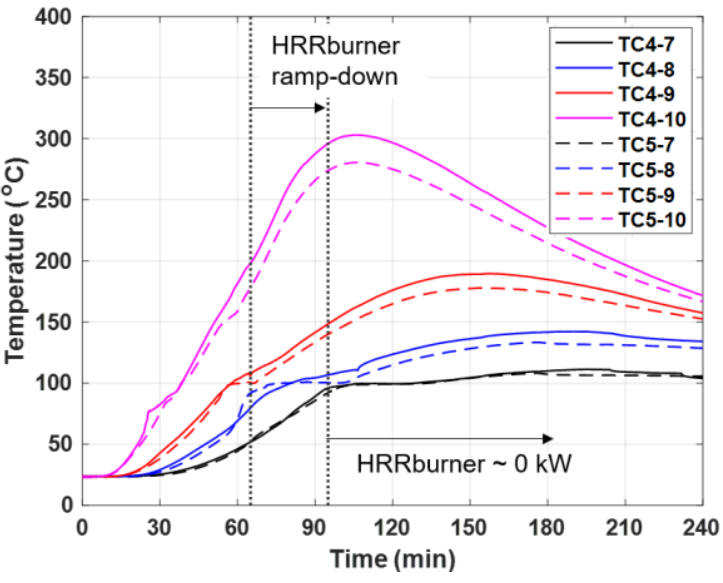

(b)

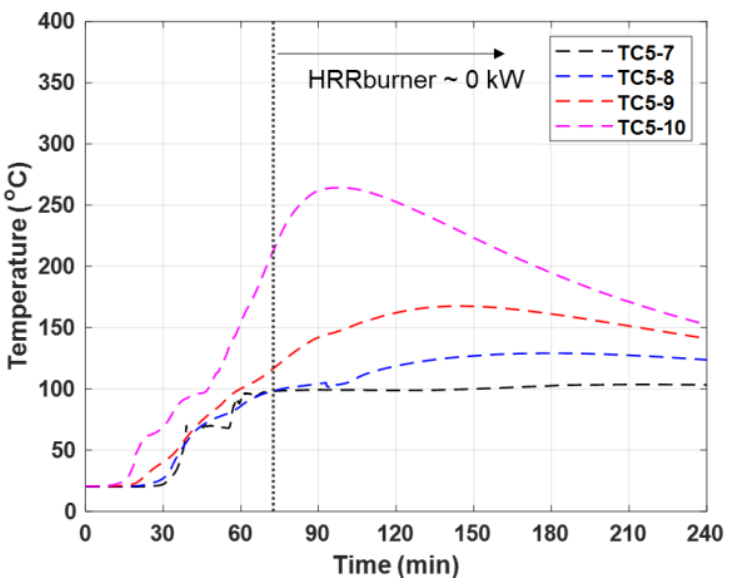

(d)

Figure 31 Measured concrete temperatures in sections TC4 and TC5 shown in Figure 7 (directly above the W18 $\times 35$ beam) for (a) CB-DA, (b) CB-DA-SC, (c) CB-SP, (d) CB-SP-SC. 


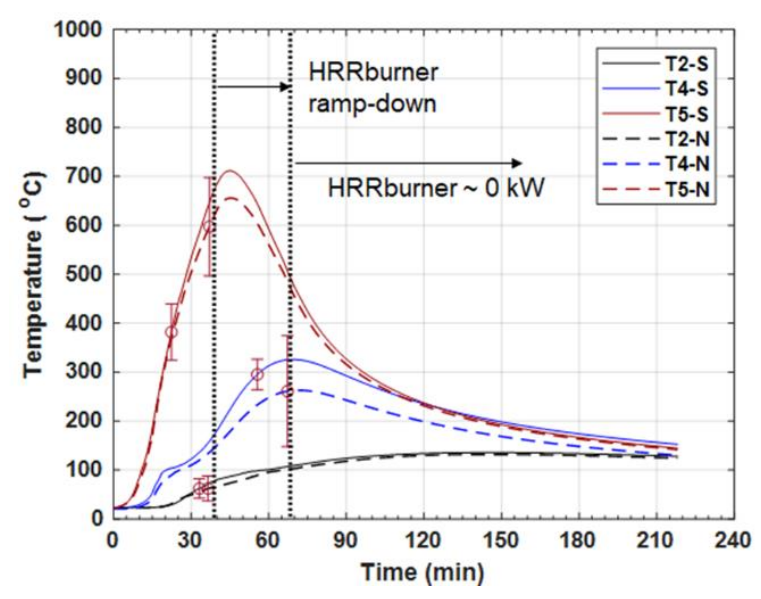

(a)

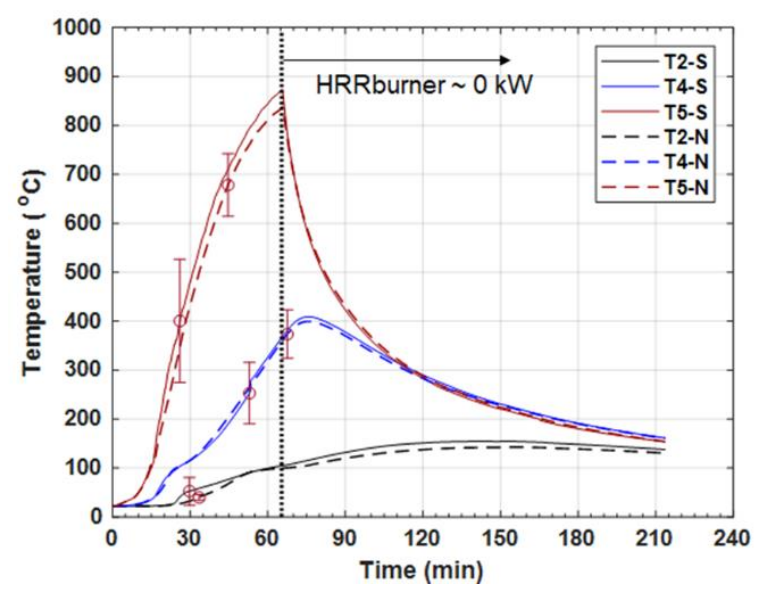

(c)

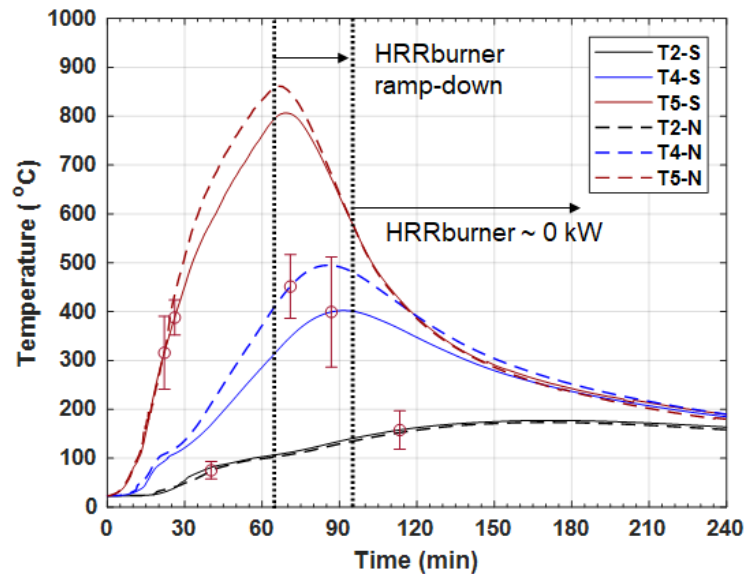

(b)

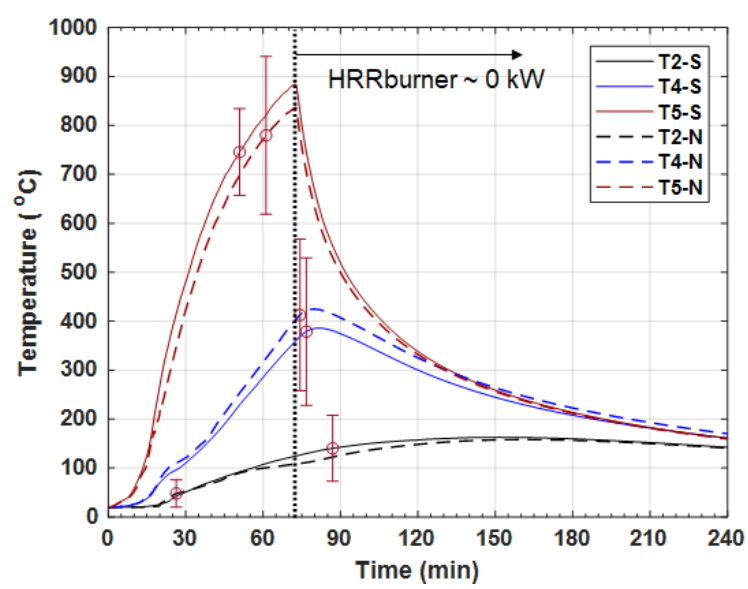

(d)

Figure 32 Average temperatures on the north and south side of the concrete slab measured $45 \mathrm{~cm}$ to the east and west of the W18 $\times 35$ beam for (a) CB-DA, (b) CB-DA-SC, (c) CB-SP, and (d) CB-SP-SC. Error bars indicate the maximum standard deviations of temperatures measured in eight sections (Figure 7) along the beam length. 


\subsubsection{Connection Temperature}

Figure 33 shows temperatures of the beam-to-column connections (double-angles or a shear-tab) with the test time recorded after the burner ignition. Refer to Figure 8 for the locations of thermocouples. Table 11 shows the list of thermocouples used in Figure 33 and the maximum average temperatures estimated using the temperature readings from the thermocouples that did not fail during the test, with the standard deviation denoted as the values after \pm symbols. Note that temperature readings from failed thermocouples (indicating the temperature change greater than $100^{\circ} \mathrm{C} / \mathrm{min}$ ) are not plotted in Figure 33 to avoid misinterpretation. For the CB-SP specimen, only one thermocouple (TCW-5) did not fail during cooling because this specimen collapsed after 65 min of heating.

As shown in Figure 33, the connection temperature reached its peak value during the cooling phase since the connection elements were protected with a thick layer of SFRM (refer to Table 2). For the CB-DA-SC, CB-SP and CB-SP-SC specimens which had a similar heating duration, the maximum temperature value was estimated to be in the range of $160{ }^{\circ} \mathrm{C}$ to $270{ }^{\circ} \mathrm{C}$. This value was much lower than temperature of the steel beam at midspan, which was in the range of $700{ }^{\circ} \mathrm{C}$ to $800{ }^{\circ} \mathrm{C}$.

Table 11 Thermocouples used in Figure 33 and the maximum average temperature of the beam-to-column connections with the test time.

\begin{tabular}{lll}
\hline Specimen ID & Thermocouple ID & Maximum average temperature \\
\hline CB-DA & TCE-5, TCE-6, TCE-7 & $180 \pm 20{ }^{\circ} \mathrm{C}$ at $73 \min (5 \min$ of cooling) \\
CB-DA-SC & TCW-4, TCE-4, TCE-5, TCE-6 & $210 \pm 26{ }^{\circ} \mathrm{C}$ at 105 min (11 min of cooling) \\
CB-SP & TCW-5 & $270{ }^{\circ} \mathrm{C}$ at 82 min (17 min of cooling) \\
CB-SP-SC & TCW-4, TCW-5, TCW-6, TCW-7, & $160 \pm 30{ }^{\circ} \mathrm{C}$ at 106 min (33 min of cooling) \\
& TCE-4, TCE-5, TCE-6, TCE-7 & \\
\hline
\end{tabular}




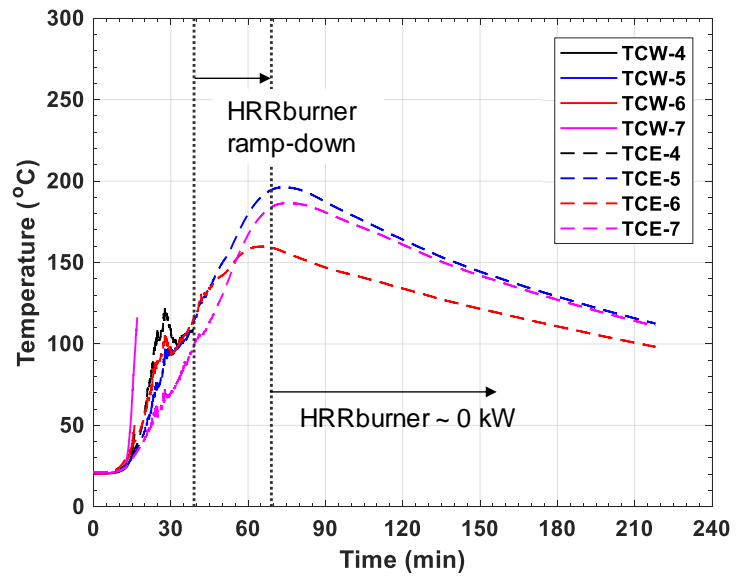

(a)

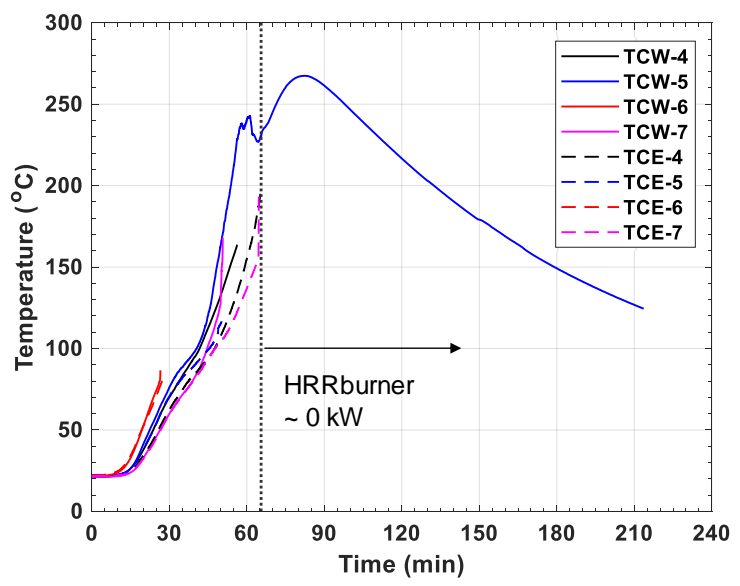

(c)

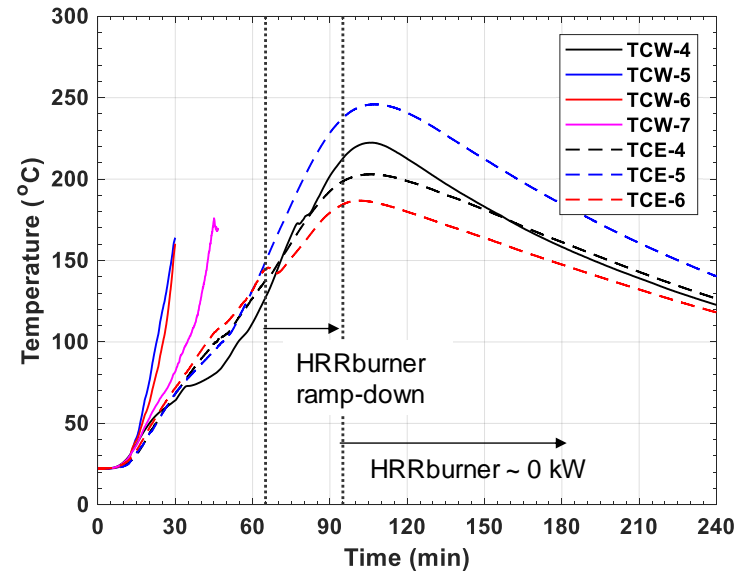

(b)

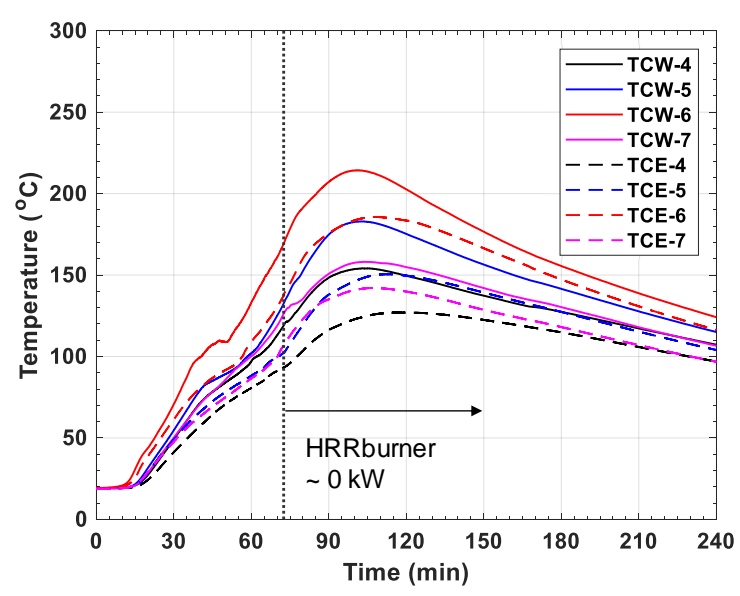

(d)

Figure 33 Connection temperatures of (a) CB-DA, (b) CB-DA-SC, (c) CB-SP, and (d) CB-SP-SC measured using the thermocouples shown in Figure 8. 


\subsection{Structural Response}

\subsubsection{Axial Load at Beam End}

Under fire conditions, the axial displacement of the specimen (e.g., due to thermal elongation or contraction) was restrained by the stiffness of support columns via the beam-to-column connections (double-angles or shear-tab connections). Thermally-induced axial loads at the ends of the specimen were estimated using measured axial strains in the diagonal braces of columns (Figure 11a) and the load-to-strain ratio of $3.90 \mathrm{kN} / \mu \varepsilon$. This ratio was measured at ambient temperature prior to fire experiments as presented in Ramesh et al (2019).

Figure 34 shows the average axial strains of the diagonal braces of the east and west columns as a function of the test time recorded after the burner ignition, where 'HRRburner ramp-down' indicates the initiation of a 30-min fire decay; 'HRRburner $\sim 0 \mathrm{~kW}$ ' is the extinguishment of a fire. The negative values of strains are the compressive strains. Table 12 indicates the list of strain gauges and the average values of the maximum compressive loads measured at the east and west ends. The values after \pm symbol indicate the standard deviations of the axial loads estimated using the strains of the top and the bottom diagonal braces at the east and west ends. Under the compartment fire loading, all four specimens exhibited a similar trend for the development of axial loads as follows:

- Within 10 min following the burner ignition, axial strains of the column braces rapidly increased in compression. The increase in compressive strains continued until the end of the steel beam locally buckled. As shown in Figure 34, for CB-DA and CB-DA-SC, it took about 30 min to reach a peak compressive strain, ranging from $-180 \mu \varepsilon$ to $-190 \mu \varepsilon$. For CB-SP and CB-SP-SC, a peak compressive strain (in the range of $-240 \mu \varepsilon$ to $-260 \mu \varepsilon$ ) was achieved around 40 min following the burner ignition.

- After local buckling occurred at the beam ends, the strain reversal occurred (Figure 34). The values of compressive strains continuously decreased until the fire was extinguished. For this period, the difference in measured strains between the east and west columns was less than $5 \%$. After the fire was extinguished, the diagonal braces of columns were in tension because the specimens contracted during cooling. For the specimens which did not collapse in fire (CB-DA, CB-DA-SC, and CB-SP-SC), tensile strains of the column braces continued to increase for a significant time during cooling.

Figure 35 shows estimated axial loads at the beam ends as a function of the bottom flange temperatures presented in Figure 25. The plotted values of axial loads were equal to the average 
axial strains of the column braces multiplied by the ratio of $3.90 \mathrm{kN} / \mu \varepsilon$. For CB-DA and CB-DA-SC, the maximum compressive loads (local buckling capacity) were $720 \mathrm{kN}$ and $730 \mathrm{kN}$, respectively, when the temperature of the bottom flange was around $400{ }^{\circ} \mathrm{C}$ (at $30 \mathrm{~min}$ ). For CB-SP and CB-SP-SC, the maximum compressive loads were $950 \mathrm{kN}$ and $1020 \mathrm{kN}$, respectively, when the bottom flange temperature was approximately $500{ }^{\circ} \mathrm{C}$ (at $40 \mathrm{~min}$ ).

For the CB-SP and CB-SP-SC specimens, the maximum tensile loads at the beam ends occurred when the specimen collapsed by connection failure. The maximum tensile load was $85 \mathrm{kN}$ for $\mathrm{CB}-\mathrm{SP}$ at the bottom flange temperature of $670{ }^{\circ} \mathrm{C}$ (during heating) and was $105 \mathrm{kN}$ for CB-SP$\mathrm{SC}$ at the bottom flange temperature of $130^{\circ} \mathrm{C}$ (during cooling). The CB-DA specimen did not collapse, and the maximum recorded tensile load was $180 \mathrm{kN}$ around 2.4 hours after the fire extinguishment. The CB-DA-SC specimen collapsed during cooling around 5 hours after the fire extinguishment; however, the tensile load was not recorded at that time.

Table 12 Strain gauges mounted on the column braces for estimation of axial loads plotted in Figure 34 and the maximum compressive loads at the beam ends.

\begin{tabular}{llll}
\hline \multicolumn{3}{c}{ Strain ID } \\
\hline Specimen ID & East column braces & West column braces & Peak axial load \\
\hline CB-DA & ColE2 through ColE8 & ColW2 through ColW8 & $716 \pm 85 \mathrm{kN}$ at $30 \mathrm{~min}$ \\
CB-DA-SC & ColE2 through ColE5, ColE7, ColE8 & ColW2 through ColW8 & $727 \pm 41 \mathrm{kN}$ at $30 \mathrm{~min}$ \\
CB-SP & ColE2 through ColE8 & ColW2 through ColW8 & $954 \pm 90 \mathrm{kN}$ at $40 \mathrm{~min}$ \\
CB-SP-SC & ColE1 through ColE8 & ColW1 through ColW8 & $1020 \pm 35 \mathrm{kN}$ at $41 \mathrm{~min}$ \\
\hline
\end{tabular}




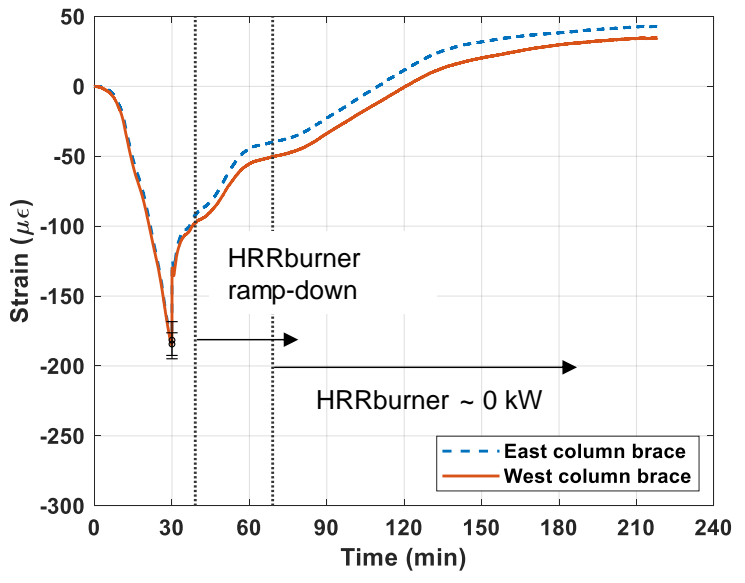

(a)

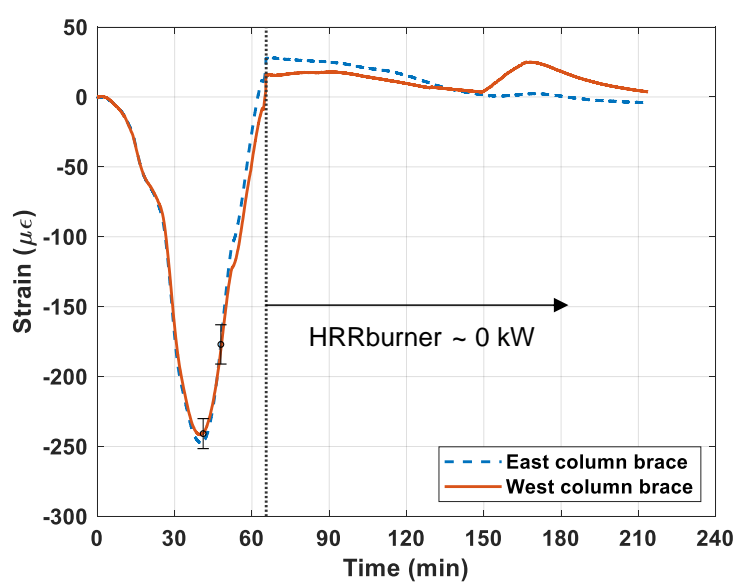

(c)

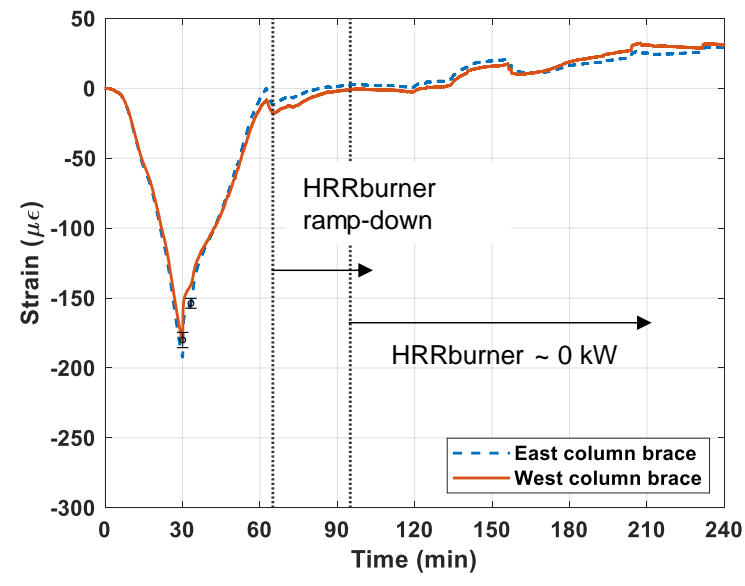

(b)

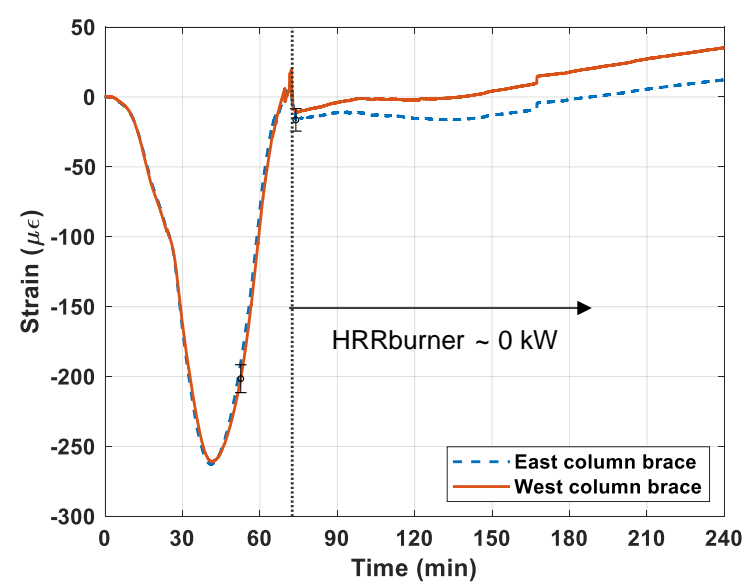

(d)

Figure 34 Measured axial strains developed in the braces of east and west columns for (a) CB-DA, (b) CB-DA-SC, (c) CB-SP, and (d) CB-SP-SC. Error bars indicate the maximum standard deviations of strains measured in the top and bottom diagonal braces shown in Figure 11a. 


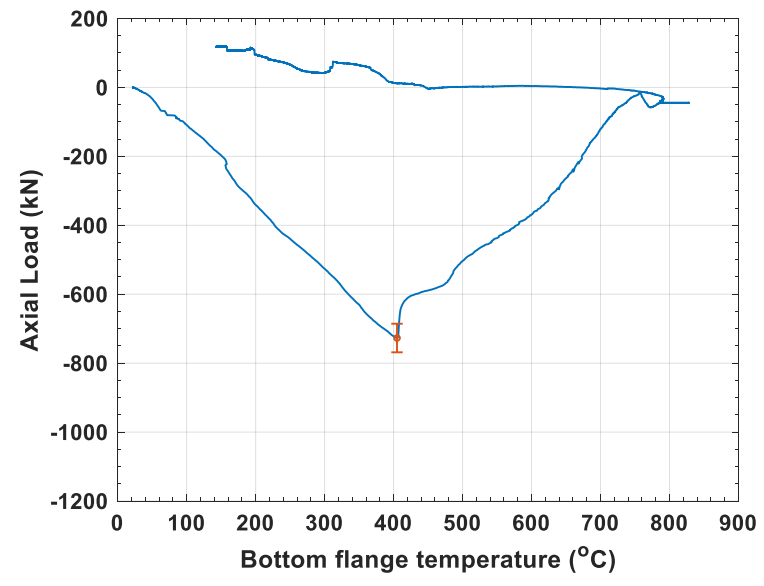

(a)

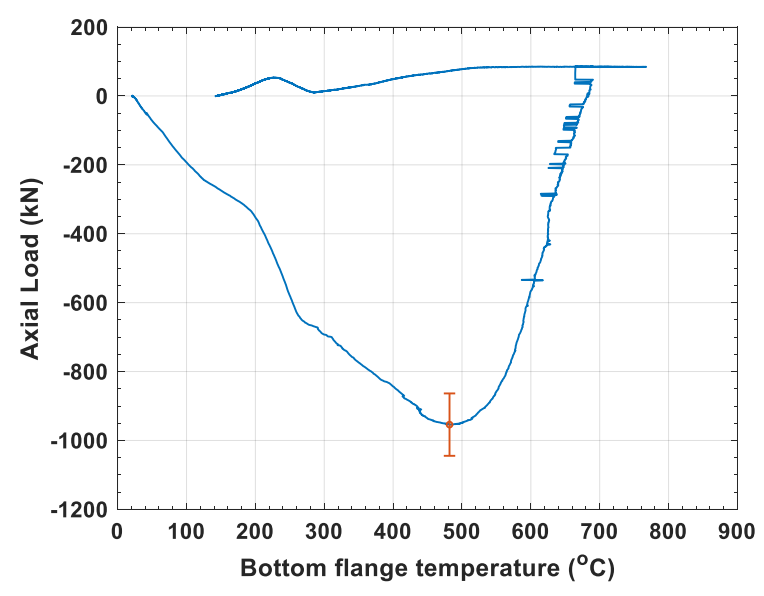

(b)

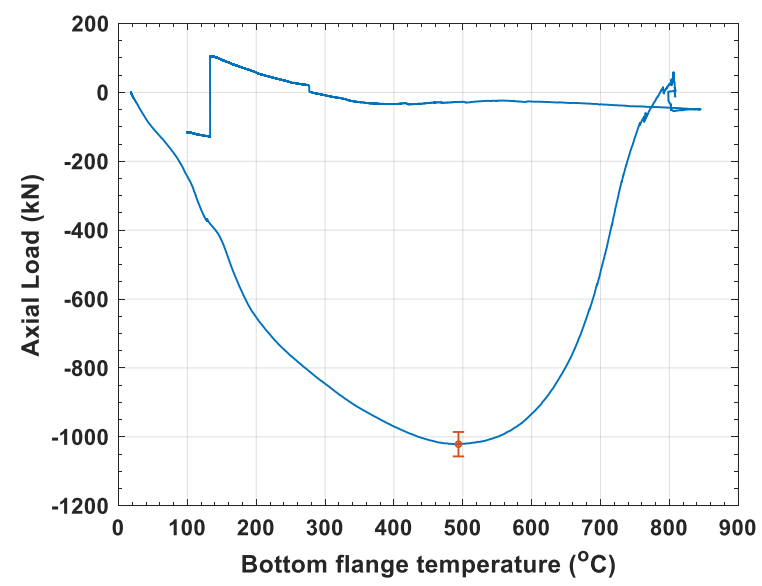

(c)

Figure 35 Estimated thermally-induced axial loads at the ends of (a) CB-DA-SC, (b) CB-SP, and (c) CB-SP-SC as a function of the bottom flange temperature. Error bars indicate the standard deviations of local buckling capacity. 


\subsubsection{Vertical Displacement}

The vertical displacement of the specimens was measured using displacement transducers, VD2 through VD5, as shown in Figure 6 . In addition, the vertical displacement near the east and west ends of the specimens was estimated using the displacement transducers in the hydraulic actuators. Table 13 summarizes the list of displacement channels and measurement locations with respect to the centerline of the west column.

Table 13 List of displacement transducer channels used for vertical displacement measurements.

\begin{tabular}{lll}
\hline Channel ID & $\begin{array}{l}\text { Distance from the } \\
\text { west column } \mathbf{( c m})\end{array}$ & Remarks \\
\hline MTSDispW & 213 & Average value of DispNW and DispSW measured using actuators \\
VD2 & 336 & Linear displacement transducer \\
VD3 & 548 & Linear displacement transducer \\
VD4 & 732 & Linear displacement transducer \\
VD5 & 944 & Linear displacement transducer \\
MTSDispE & 1067 & Average value of DispNE and DispSE measured using actuators \\
\hline
\end{tabular}

Figure 36 shows the displacement results of VD2 through VD5 as a function of the time recorded after ignition of the burners. The negative values in the y-axis indicate the downward vertical displacement. The initial values (at $0 \mathrm{~min}$ ) correspond to the vertical displacement of the specimen as a result of mechanical loading applied at ambient temperature. The vertical displacements of the tested specimens are summarized as follows.

- CB-DA: The downward vertical displacement increased throughout the heating phase. The mechanical loading was removed at $30 \mathrm{~min}$ due to the pre-set load limit triggered by local buckling at the beam ends (Figure 36a). The unloaded specimen continuously bent downward during the 30-min decay phase of a fire. After the fire was extinguished at $68 \mathrm{~min}$, the specimen gradually moved upward. No collapse occurred. The recorded peak vertical displacement was $330 \mathrm{~mm}$ (similar to the ratio $L / 39$ ).

- CB-DA-SC: The average vertical displacement measured around midspan (VD3 and VD4) was $100 \mathrm{~mm}$ when the beam end buckling occurred at $30 \mathrm{~min}$. The average vertical displacement increased to $640 \mathrm{~mm}$ at $65 \mathrm{~min}$ when the mechanical loading was automatically removed by the pre-set displacement limit (Figure 36b). During the 30-min decay of a fire, the unloaded specimen continued to bend downward because of its selfweight. The maximum displacement was recorded at $703 \mathrm{~mm}$ and $680 \mathrm{~mm}$, respectively. This displacement value corresponds to the ratio $L / 18.5$ on average. The specimen 
collapsed due to connection failure about 5 hours after the fire was extinguished. However, the displacement at failure was not measured.

- $\quad$ CB-SP: The average vertical displacement measured around midspan (VD3 and VD4) was approximately $110 \mathrm{~mm}$ (the ratio $L / 116$ ) when local buckling occurred near the beam ends at $40 \mathrm{~min}$. When this displacement increased to $550 \mathrm{~mm}(L / 22)$ around $65 \mathrm{~min}$, the specimen collapsed as a result of weld failure of the east connection (Figure 36c). The falling of the specimen was stopped by water-cooled catch beams inside the test compartment. A noticeable increase in the vertical displacement around $130 \mathrm{~min}$ was caused by damage in the east connection region (concrete, connection elements, or both) during cooling.

- CB-SP-SC: Similar to CB-SP, the displacement was approximately $110 \mathrm{~mm}$ when local buckling occurred around $41 \mathrm{~min}$. When the vertical displacement around midspan (VD3 and VD4) reached $580 \mathrm{~mm}$ on average around $73 \mathrm{~min}$, there was a sound indicating facture of one of three bolts connecting the east shear tab. The fire was extinguished immediately after this event, but the specimen did not collapse. The vertical displacement of this specimen continued to increase up to $10 \mathrm{~min}$ in cooling, reaching a peak displacement value of $590 \mathrm{~mm}$. About 3 hours into cooling, when the vertical displacement recovered back to $370 \mathrm{~mm}$, the specimen collapsed due to fracture of the reaming bolts in the east shear-tab connection.

Figure 37 shows the estimated deflected shape of the specimens at major events during heating and cooling. Since the vertical displacement at midspan was not measured due to the arrangement of loading frames (refer to Figure 6), this value was estimated using the second-order polynomial fit of the displacements measured using the sensors listed in Table 13. The estimated peak displacement at midspan for the specimens CB-DA, CB-DA-SC, CB-SP, and CB-SP-SC was $350 \mathrm{~mm}(L / 36.6)$ at $68 \mathrm{~min}, 710 \mathrm{~mm}(L / 18)$ at $95 \mathrm{~min}, 590 \mathrm{~mm}(L / 21.7)$ at $65 \mathrm{~min}$, and $610 \mathrm{~mm}$ $(L / 21)$ at $73 \mathrm{~min}$, respectively. 


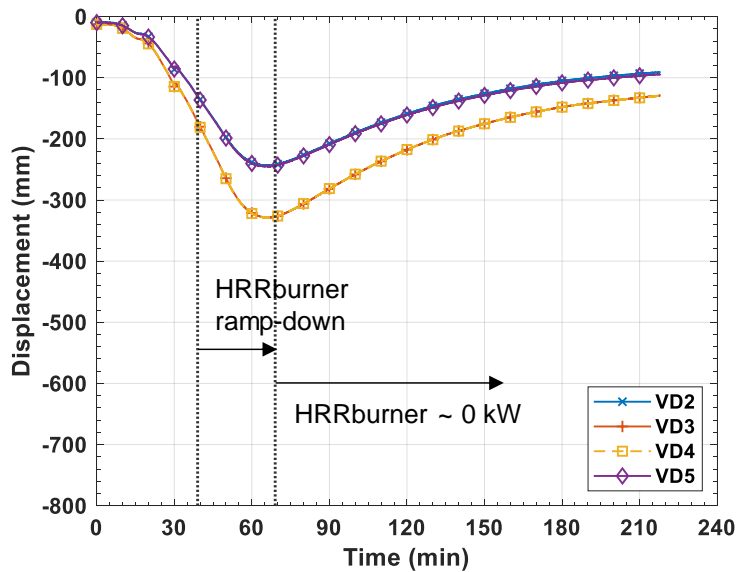

(a)

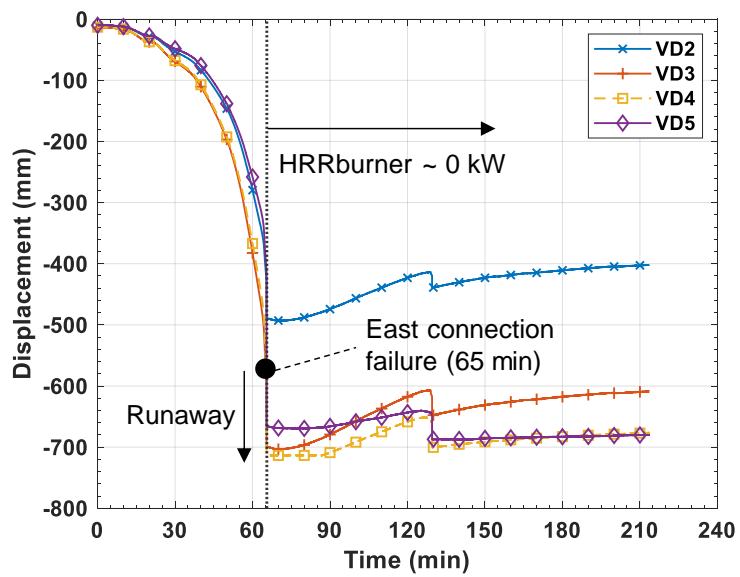

(c)

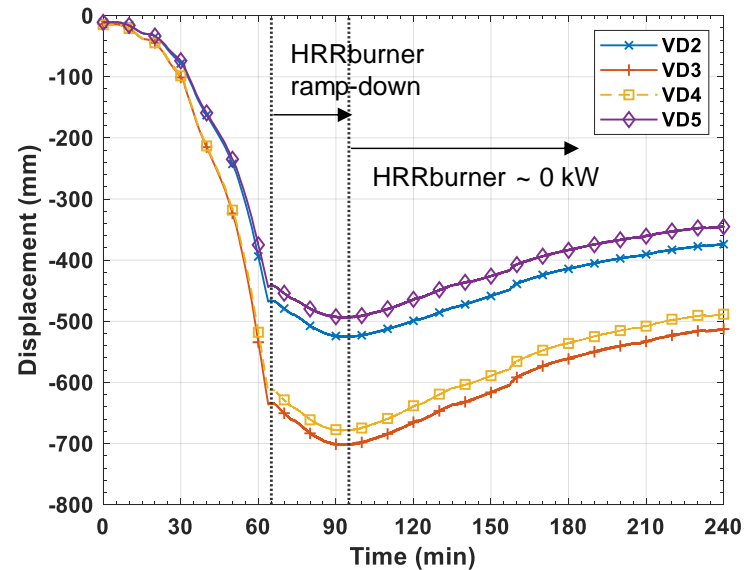

(b)

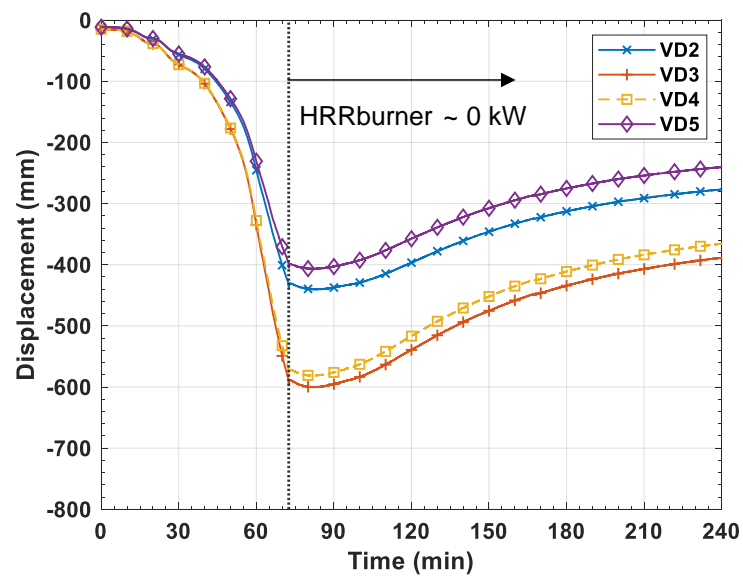

(d)

Figure 36 Vertical displacement versus time relationship for specimens (a) CB-DA, (b) CB-DA-SC, (c) CB-SP, and (d) CB-SP-SC. 


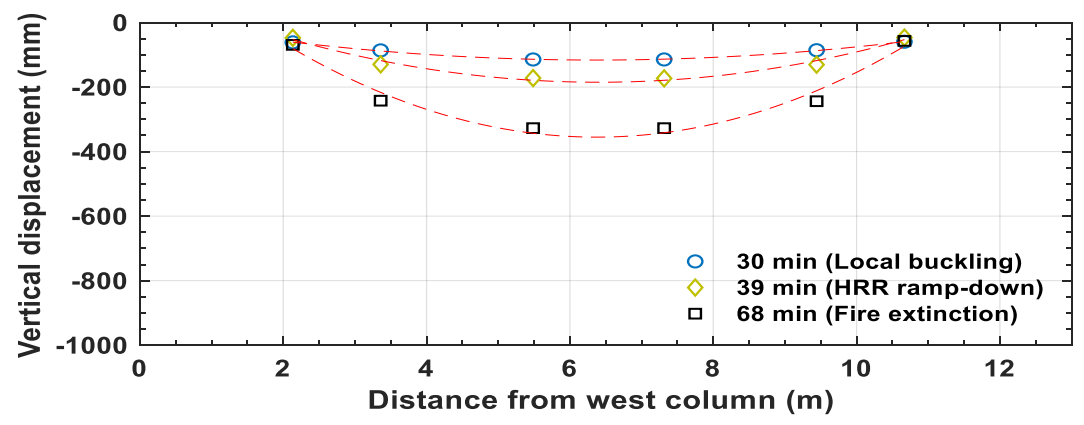

(a)

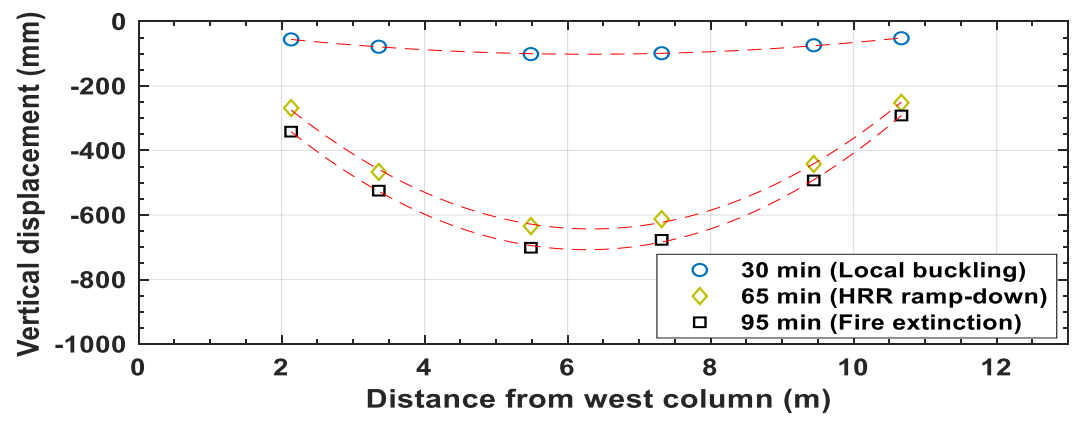

(b)

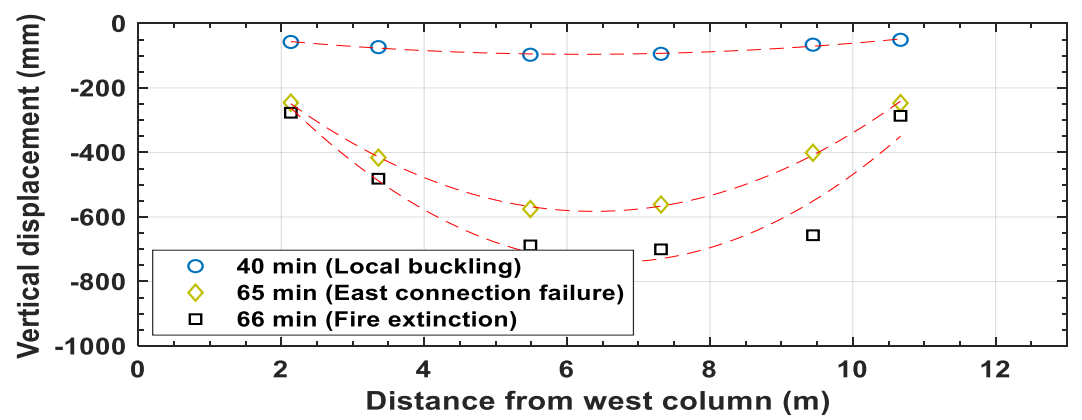

(c)

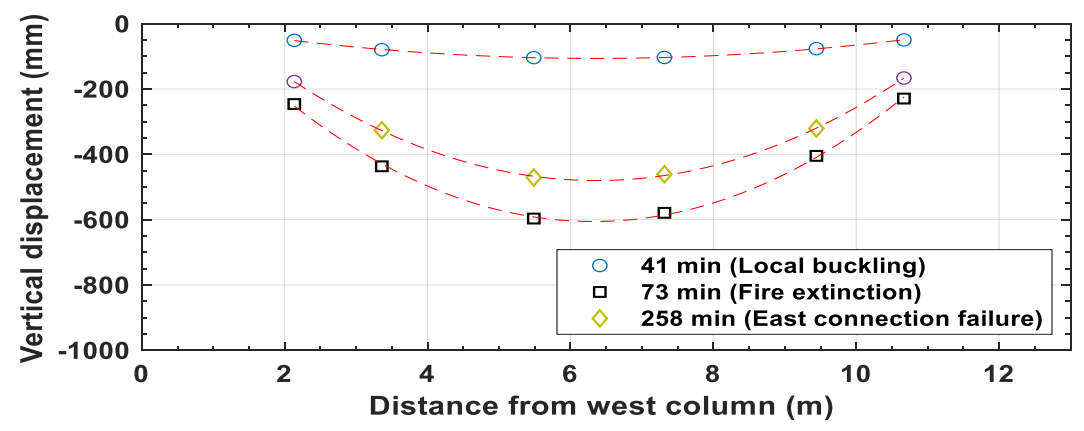

(d)

Figure 37 Deflected shapes of the speicmens: (a) CB-DA, (b) CB-DA-SC, (c) CB-SP, and (d) CB-SP-SC. 


\subsubsection{Slab End Rotation}

Dual-axes inclinometers were mounted on the top of the concrete slab at $54.6 \mathrm{~cm}$ from the centerline of the east and west columns (refer to Figure 6). Figure 38 shows the end rotations of the concrete slab as a function of the time recorded after the burner ignition. The positive values of RotSlabEy and the negative values of RotSlabWy indicate the east and west end rotations associated with sagging of the specimens. The rotation of the specimen about the longitudinal axis is indicated as RotSlabEx at the east end and RotSlabWx at the west end. The positive values of the RotSlabEx and RotSlabWx indicate the tilting of the concrete slab towards north at the east and west ends, respectively.

As shown in Figure 38a and Figure 38b, the specimens with the double angle connection (CB-DA and CB-DA-SC) exhibited similar end rotations until $48 \mathrm{~min}$. The end rotations due to sagging of the specimen (i.e., RotSlabEy and RotSlabWy) barely increased until 10 min possibly due to the initial rotational restraint from the angle connections. A small increase in the RotSlabEx values was observed at $30 \mathrm{~min}$ when local web occurred near the connections. For CB-DA, both RotSlabEy and RotSlabWy values continuously increased afterwards until the fire was extinguished (HRRburner $\approx 0 \mathrm{~kW}$ ). For CB-DA-SC with the slab continuity, the RotSlabWy values decreased around $48 \mathrm{~min}$, as a result of the concrete fracture around the inclinometer. Around $53 \mathrm{~min}$, the RotSlabEy values sharply increased. The rotation readings became unreliable after $56 \mathrm{~min}$ due to the exceedance of the sensor operating temperature of $85^{\circ} \mathrm{C}$.

For the specimens with the shear-tab connection (CB-SP and CB-SP-SC), Figure 38c and Figure $38 \mathrm{~d}$ show that the rotations of the east and west ends barely increased until $10 \mathrm{~min}$. For CB-SP, the values of RotSlabEy and RotSlabWy increased slowly and reached 'runaway' (unchecked) at the east end around 65 min due to weld failure of the east shear tab. As shown in Figure 38d, the end rotation of CB-SP-SC was resisted by the slab reinforcement anchored at the girders. The maximum strong axis rotation at the east and west ends was about 0.02 radian and 0.04 radian, respectively, until the fire was extinguished around $73 \mathrm{~min}$. Both the values of RotSlabEy and RotSlabWy decreased with increasing vertical displacements around 54 min and 57 min, respectively, indicating failure of the inclinometers. Post-test inspection showed that data cables of these inclinometers burned out.

It was observed that the shear tab connection had a less rotational flexibility than the double-angle connection. For CB-DA, deflection of angles allowed large end rotations and the end rotations linearly increased at an average rate of $2 \times 10^{-3} \mathrm{rad} / \mathrm{min}$ until $50 \mathrm{~min}$, reaching a peak value of 0.09 radian at $63 \mathrm{~min}$. However, for CB-SP, the bottom flange of the elongated steel beam was in contact with the columns and resisted large end rotations. The end rotations increased more slowly 
from $20 \mathrm{~min}$ to $50 \mathrm{~min}$ at a rate of $9 \times 10^{-4} \mathrm{rad} / \mathrm{min}$ and substantially increased at a rate of $5 \times 10^{-3}$ $\mathrm{rad} / \mathrm{min}$ until $63 \mathrm{~min}$. A runaway rotation was achieved at $65 \mathrm{~min}$ followed by failure of the east shear-tab connection.

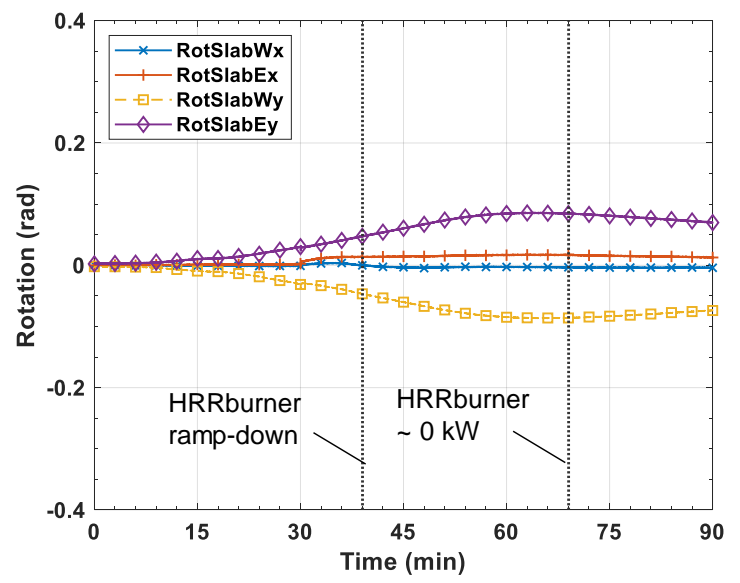

(a)

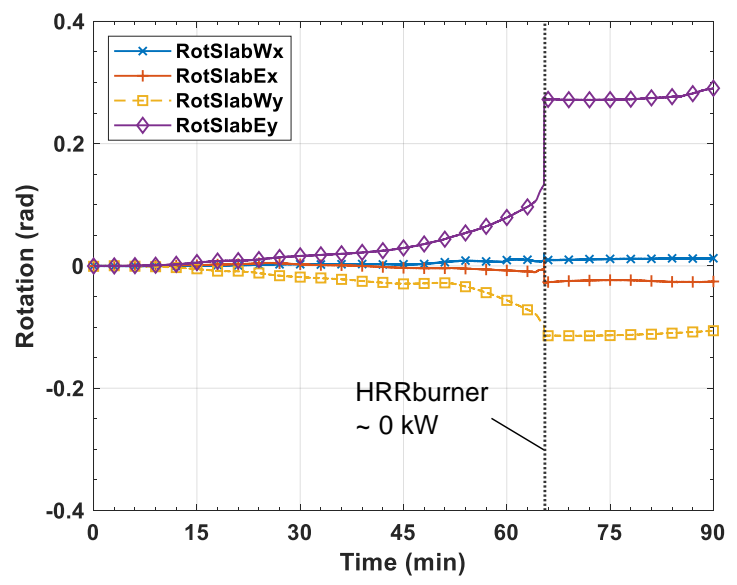

(c)

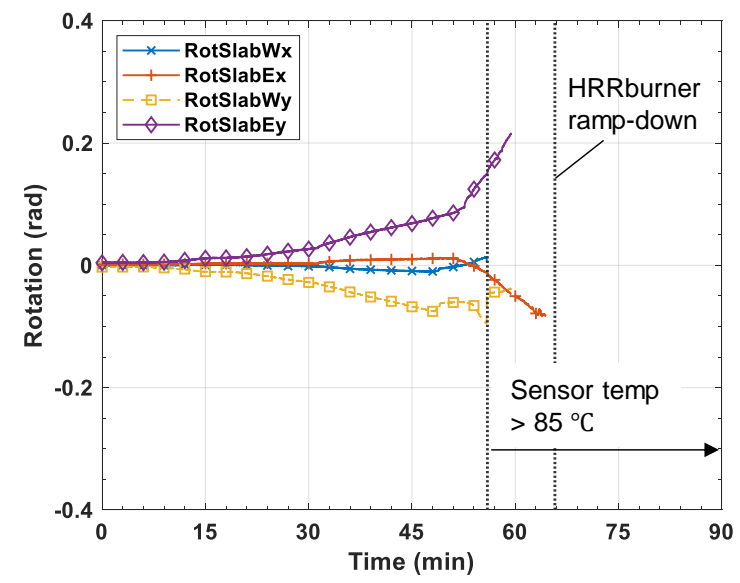

(b)

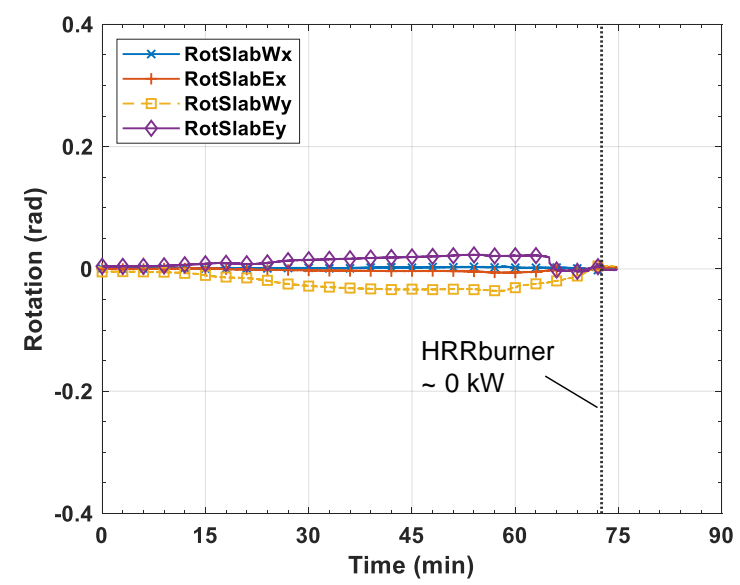

(d)

Figure 38 End rotations at the east and west ends as a function of the fire expsoure time for (a) CB-DA, (b) CB-DA-SC, (c) CB-SP, and (d) CB-SP-SC. 


\subsubsection{Tensile Loads in Reinforcing Bars}

For the CB-DA-SC and CB-SP-SC specimens, the east and west ends of the concrete slab were rotationally fixed by anchoring embedded No. 4 reinforcing bars and welded wire fabric at the location of support girders (refer to Figure 3). Tensile loads on the reinforcing bars increased due to negative (so-called 'hogging') moments induced by combined effects of gravity and thermal loading. Washer type load cells were installed around the No.4 reinforcing bars to measure tensile loads developed during the test. Refer to Figure 11c for locations of the load cells at the east and west ends of the concrete slab.

Figure 39 shows comparisons of the total tensile load on the embedded No.4 reinforcing bars at the east and west ends of the concrete slab. An initial variation in loads at ignition of a fire was due to posttensioning on the No. 4 bars for installation of load cells and gravity loading applied at ambient temperature. Some comparisons between the CB-DA-SC and CB-SP-SC specimens are as follows.

- Tensile loads decreased to nearly zero from $22 \mathrm{~min}$ to $26 \mathrm{~min}$ after the burner ignition, implying that the surrounding concrete was in compression due to the restraint against thermal elongation.

- For CB-DA-SC, tensile loads on the reinforcing bars sharply increased in response to local buckling of the steel beam at the ends. For CB-SP-SC, however, tensile loads on the reinforcing bars increased gradually; less sensitive to local buckling at the ends.

- The maximum load values were in the range of $100 \mathrm{kN}$ to $110 \mathrm{kN}$ from $45 \mathrm{~min}$ to $65 \mathrm{~min}$. The fluctuations in the loads were due to cracking of concrete and associated bond failure between the bars and surrounding concrete. For CB-DA-SC, tensile loads sharply dropped around $50 \mathrm{~min}$ (before the fire was extinguished), indicating the loss of the load transfer made by anchored reinforcing bars. However, for CB-SP-SC, the total tensile load dropped to the initial value (at $0 \mathrm{~min}$ ) at $73 \mathrm{~min}$ and further decreased during cooling. 


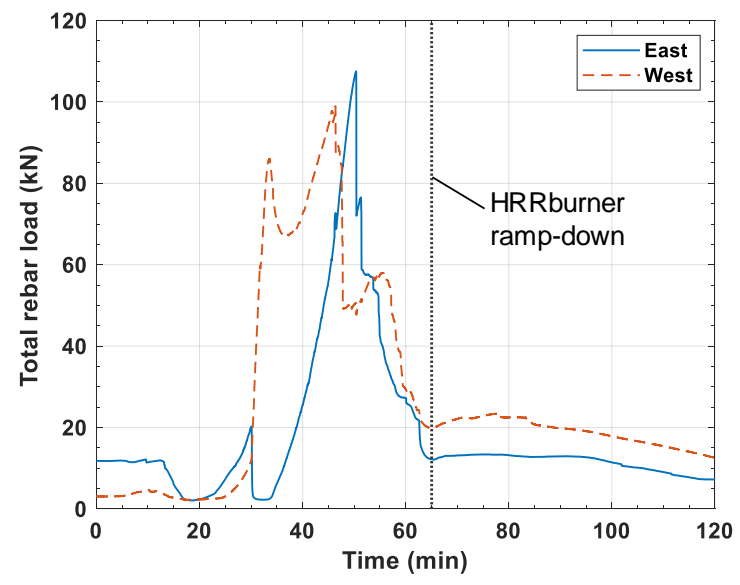

(a)

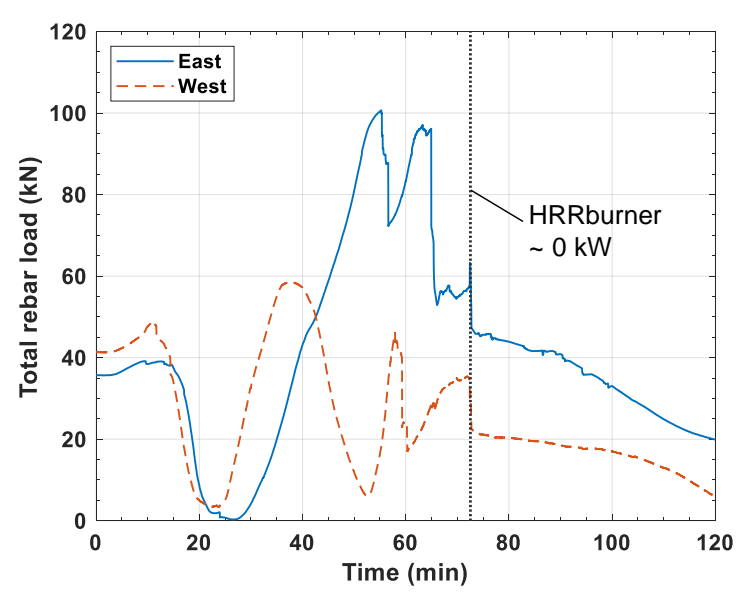

(b)

Figure 39 Total tensile loads in the east and west reinforcing bars for the specimens (a) CB-DA-SC, and (b) CB-SP-SC.

\subsubsection{Concrete Strain}

The concrete strains reported in this section are relative to the initial strain near the start of application of load by the hydraulic actuators. At this time, the concrete was in compression due to shrinkage during curing and downward bending of the specimen due to its self-weight. The amplitude of the compressive strain, however, was not measured and is unknown. Thus, positive $\Delta \mu \varepsilon$ does not necessarily indicate tension in the concrete. Nonetheless, the relative changes in strain amplitudes provide insight into the behavior of the concrete during heating of the specimens. 
Figure 40 shows the FBG strain on the left $y$-axis and the loading imposed on the right $y$-axis for specimen CB-DA. Initially, the strain is greater (more compression) near the top of the slab, as both sensors read the strain in the concrete above the neutral axis during application of the mechanical load. After ignition of the fire at 11:55, and then at $500 \mathrm{~kW} \mathrm{HRR}$ at 12:00, the bottom sensor sees a greater effect from the temperature change. Some damage (possibly cracking) occurs at 12:25, as evidenced by the rapid increase in strain, just before the mechanical load is removed from the specimen and cooling begins. It is noted that because the gauge length of the FBG sensors was $250 \mathrm{~mm}$, elongation of $0.1 \mathrm{~mm}$ (e.g., in conjunction with the formation of a small crack) within the gauge length would results in an increase in $\Delta \mu \varepsilon$ of $400 \mu \varepsilon$.

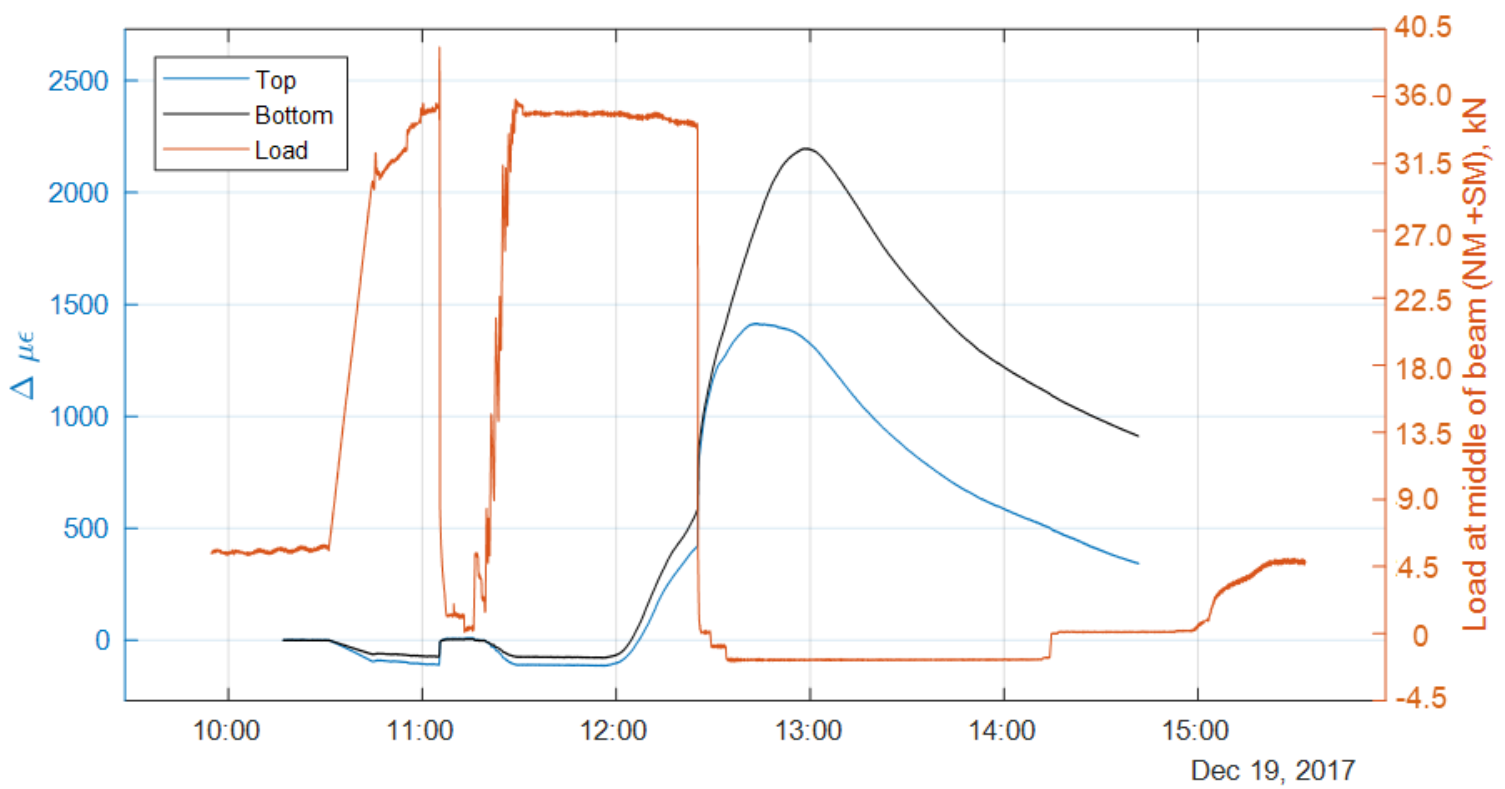

Figure 40 Fiber Bragg Grating strain and applied load (NM + SM actuators) on CB-DA.

While the jump in strain at 12:25 in Figure 40 appears instantaneous, it can be seen in Figure 41 that it occurs over $10 \mathrm{~s}$ from 12:25:10 to 12:25:20. It also occurs in three stages: large initial jump, followed by an increase of strain over $9 \mathrm{~s}$, and then a smaller jump at the end. The duration and stages of this event make it likely that it was due to multiple sources of damage. Similar behavior is observed in the top and bottom sensors. 


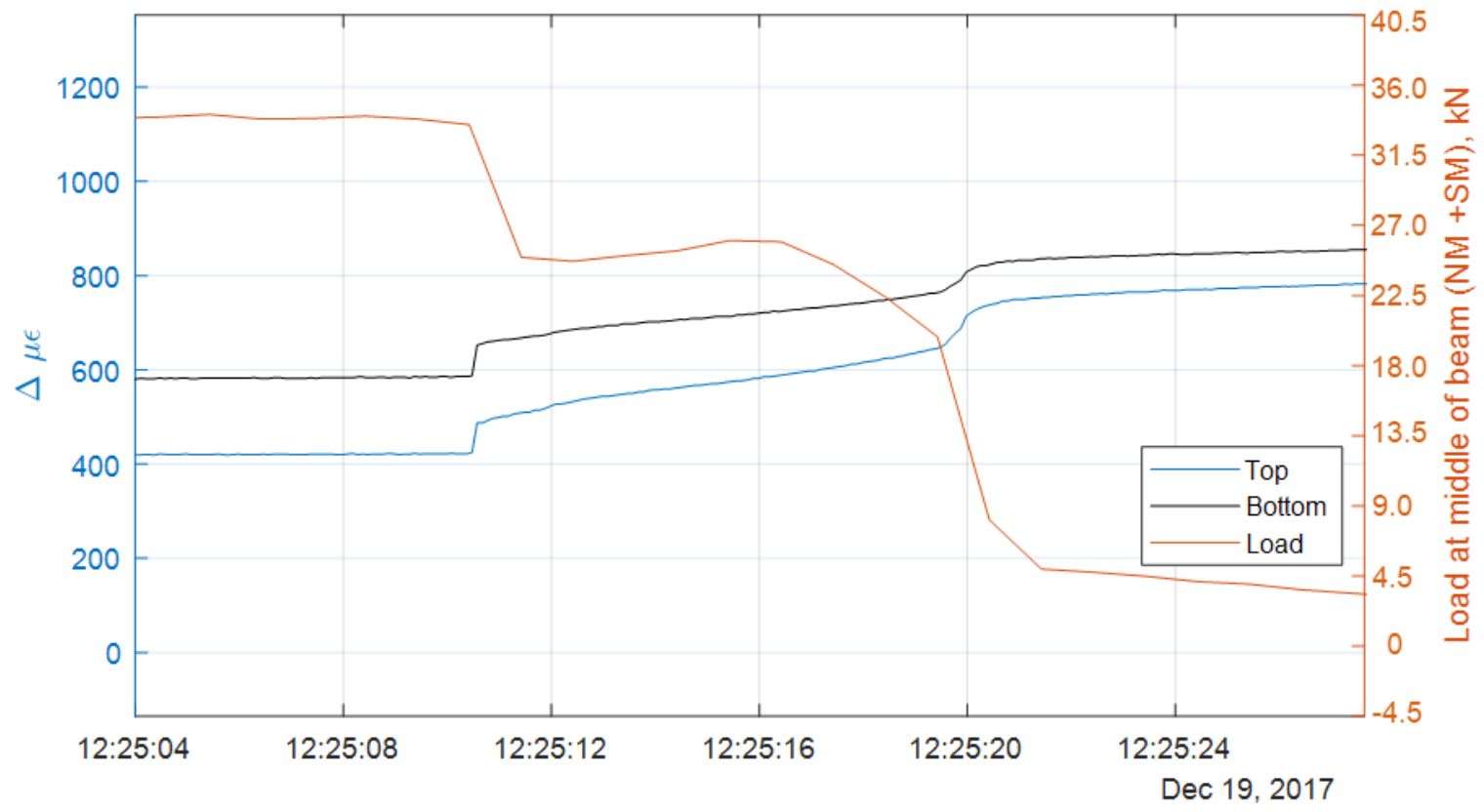

Figure 41 Fiber Bragg Grating strain and total applied zoom during concrete cracking for CB-DA test.

Figure 42 show the FBG strain measurements in specimen CB-DA-SC. During mechanical loading of the specimen (around 11:30), both top and bottom FBG sensors measure negative strain (increase in concrete compression) due to bending of the specimen. When the fire load is applied around 13:30, the strain begins to increase due to the increase in temperature in the steel beam. At 13:55 damage occurs and the two sensor readings diverge. During the testing of CB-DA-SC, the FBG sensors or fibers themselves experienced damage near 14:30 and cease to function. The cause of the damage is unknown. 


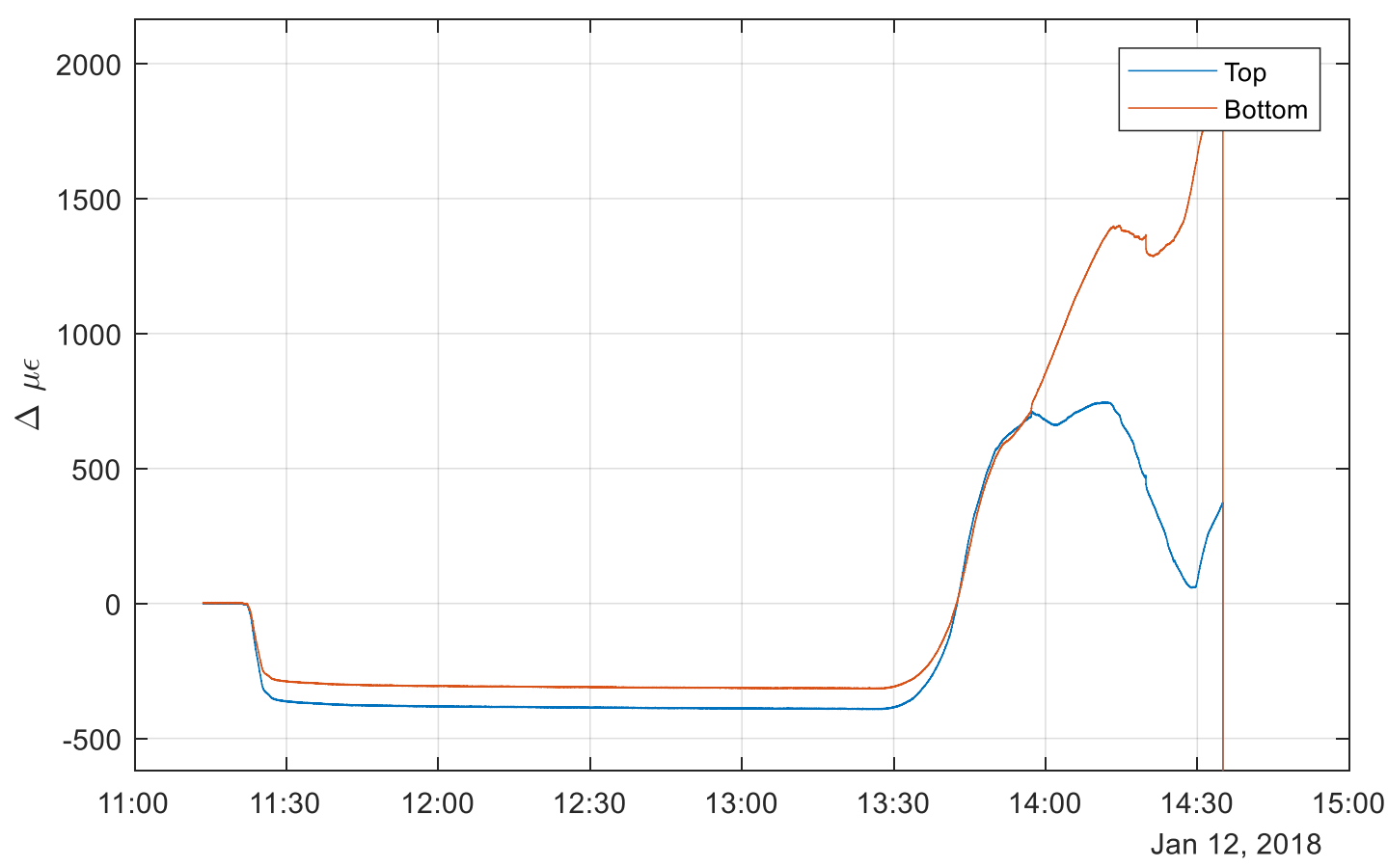

Figure 42 CB-DA-SC test Fiber Bragg Grating strain. 


\section{Chapter 4 \\ MODES OF FAILURE}

The long-span composite beam specimens with simple shear connections exhibited various limit states during the heating and cooling phases. This chapter discusses the observed sequence and modes of structural failure. Additional photographs of the specimens after cooling are presented in Appendices A through D.

\subsection{Local Buckling}

All four specimens exposed to fires exhibited local buckling of the W18×35 steel beams near the beam-to-column connections. The results are summarized as follows:

1. This failure occurred around $30 \mathrm{~min}$ to $40 \mathrm{~min}$ following the burner ignition. The bottom flange temperature at midspan was in the range of $400{ }^{\circ} \mathrm{C}$ to $500{ }^{\circ} \mathrm{C}$. Also, the vertical displacement around midspan was approximately equal to the ratio $L / 110$.

2. The geometry of the steel end section bearing against the columns, which varied by the connection type, influenced the local buckling capacity of the specimens. The specimens with double-angle connections (CB-DA and CB-DA-SC) had the coped bottom flange at the ends which reduced the cross-section bearing area by $25 \%$. The local buckling capacity of the CB-DA specimen was about $25 \%$ smaller than that of the CB-SP specimen.

3. In the testing of CB-DA, where a preset load limit was defined for unloading, local buckling at the beam ends caused temporary torsional instability of the steel beam, activating the automatic depressurization of the actuators. For CB-SP, local buckling appeared to be gradually developed over time, without causing any instability problem.

4. The presence of the end slab continuity led to a higher buckling capacity when the sheartab connection was used. The local buckling capacity of CB-SP-SC was approximately $7 \%$ higher than that of CB-SP. However, the difference between CB-DA and CB-DA-SC was around $1 \%$. Local buckling failure did not result in collapse of the specimens. 
Figure 43 and Figure 44 show the final buckling shape of the specimens after cooling. The CB-DA and CB-DA-SC specimens exhibited web local buckling approximately $20 \mathrm{~cm}$ from the beam end (Figure 43a and Figure 43b), resulting in fracture of the bottom web toe of fillet at the east coped bottom flange (Figure 43c). The CB-SP and CB-SP-SC specimens developed both flange and web local buckling in the steel beams, about $60 \mathrm{~cm}$ from the beam ends (Figure 44). For these specimens, the locally deformed regions did not exhibit fractures.

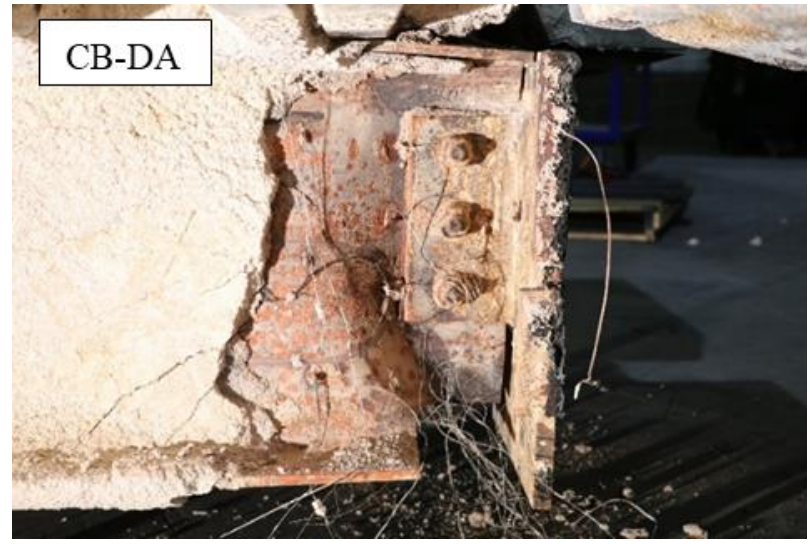

(a)

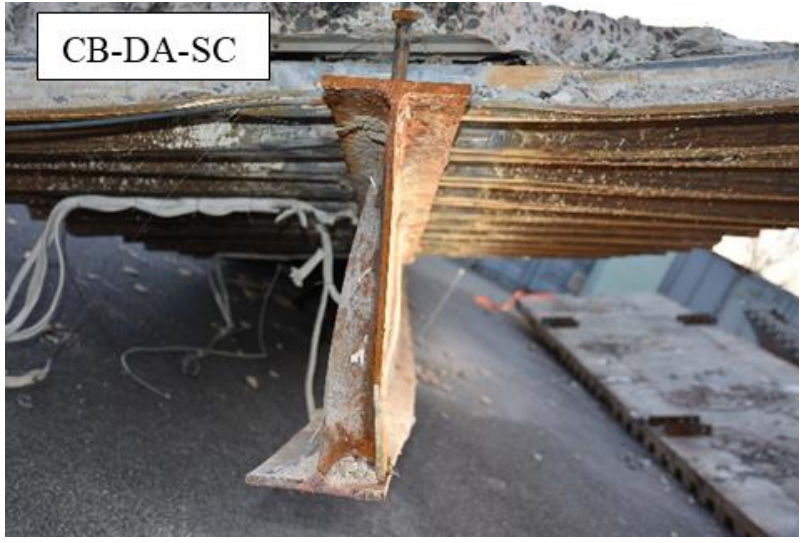

(b)

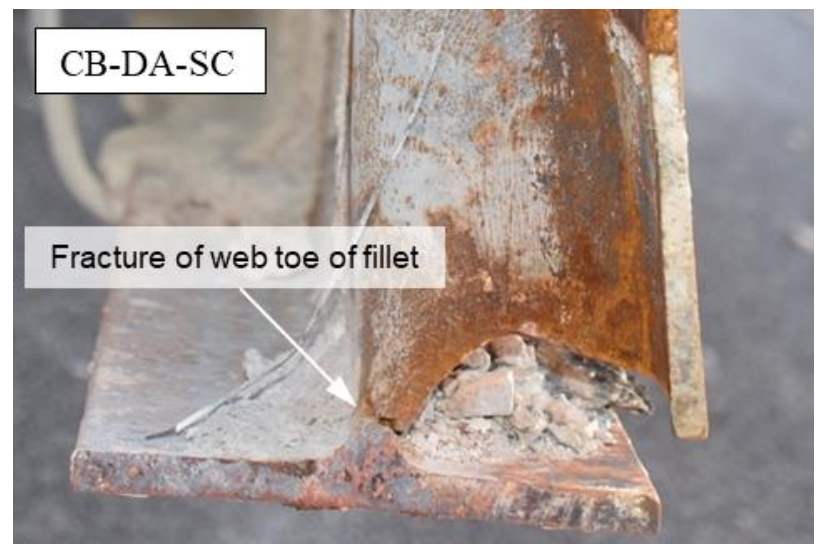

(c)

Figure 43 Photographs of locally buckled ends of the W18 $\times 35$ steel beam: (a) CB-DA, (b) CB-DA-SC, and (c) fracture of bottom web toe of fillet (CB-DA-SC). 


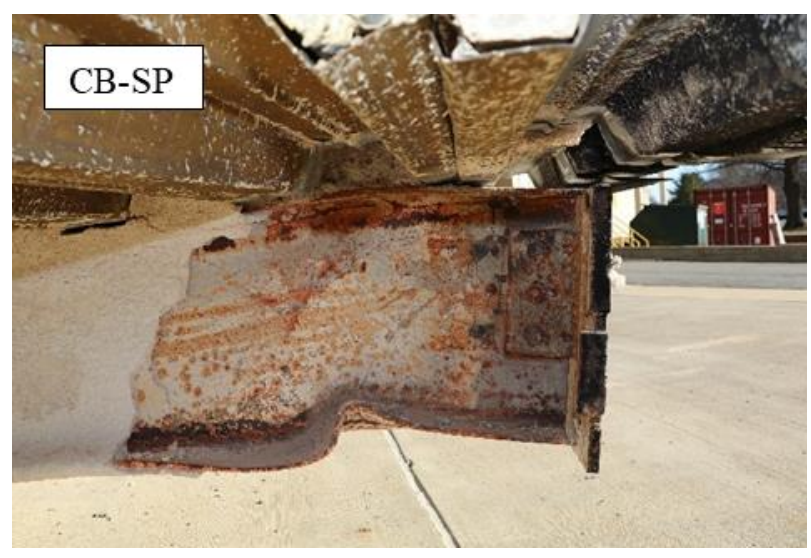

(a)

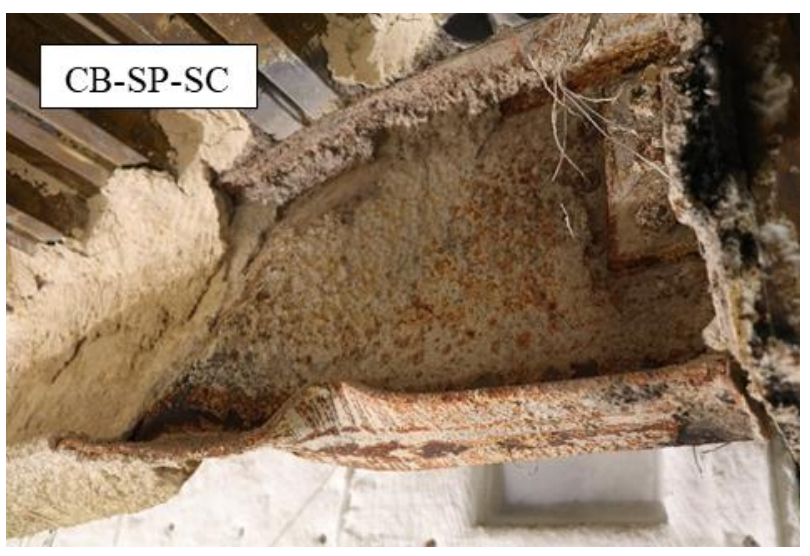

(b)

Figure 44 Photographs of locally buckled ends of the W18 $\times 35$ steel beam: (a) CB-SP, and (b) CB-SP-SC.

\subsection{Flexural Failure}

Following local buckling at the ends, the composite beam specimens continuously sagged as their flexural strengths and stiffnesses decreased with increasing temperatures. Fire exposure influenced the section behavior of the specimens which was designed for a partially-composite beam at ambient temperatures. In the ambient test, the specimen with the double angle connection (CBDA-AMB), subjected to increasing mechanical loads, failed at its ultimate moment capacity due to shear rupture in the shank of the first headed stud at the west end (Choe et al. 2018). Figure 45a shows a photograph of this specimen and ruptured shear stud at the west end after test. However, all four specimens, loaded to $45 \%$ of the ambient moment capacity and simultaneously exposed to fire loading, did not exhibit shear failure of end headed studs associated with flexural loads (Figure 45b).

Figure 46 shows a comparison of the deflected shape of the ambient specimen loaded to failure (CB-DA-AMB) and a specimen heated to failure (e.g., CB-DA-SC). For both CB-SP and CB-SP-SC, the heated steel beams did not display any permanent deformation associated with lateral torsional buckling at midspan. In addition, for all four specimens exposed to fire, the steel beams exhibited large vertical deflections; however, there were no significant damages to the SFRM coating on the deformed steel beams around midspan. 


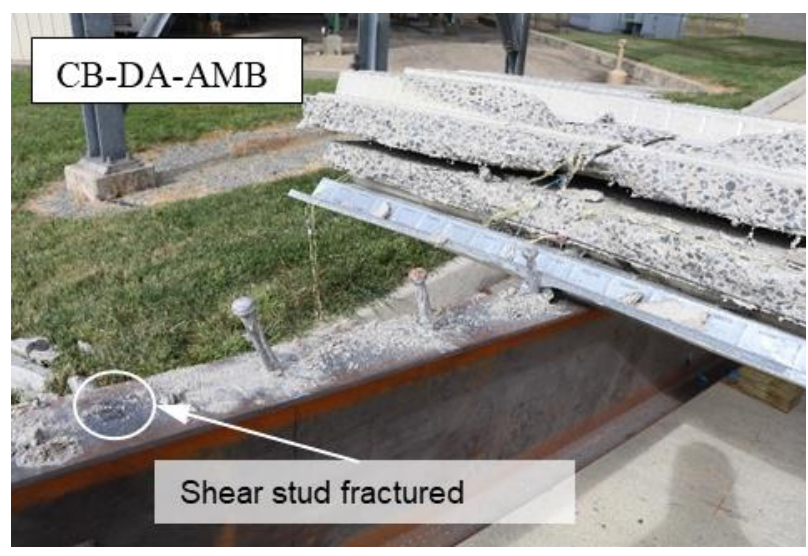

(a)

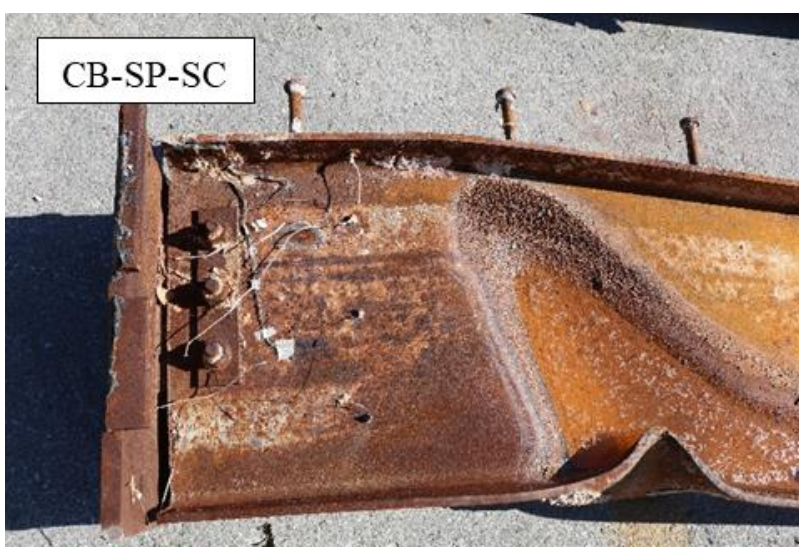

(b)

Figure 45 Photographs of west end of (a) CB-DA-AMB after removal of concrete slab, and (b) CB-SP-SC after removal of SFRM and concrete slab.

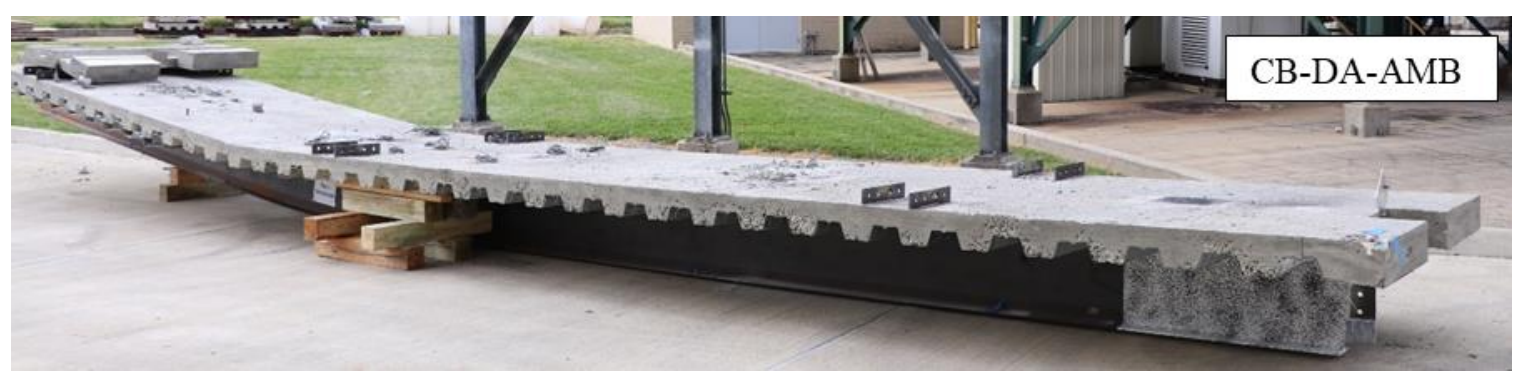

(a)

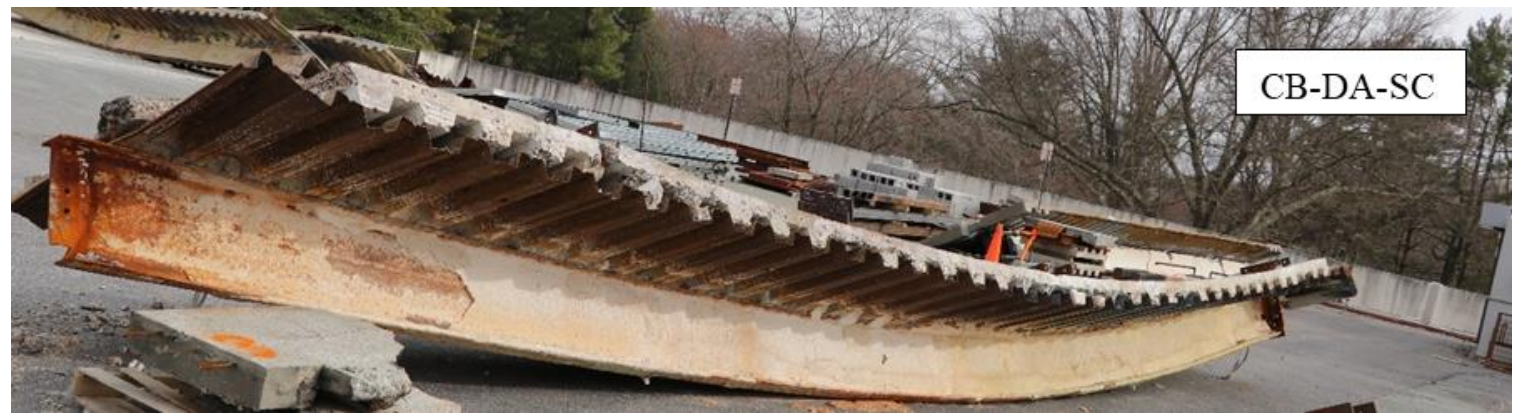

(b)

Figure 46 Photographs of deflected shape of (a) CB-DA-AMB and (b) CB-DA-SC. 
Figure 47 shows photographs of a typical deflected shape of the concrete slab after cool-down. All four specimens exposed to fire showed neither explosive spalling nor crushing of the concrete slab due to compressive forces from positive flexure. No flexural crack was detected on the top of the concrete slab along the longitudinal centerline of the specimens.

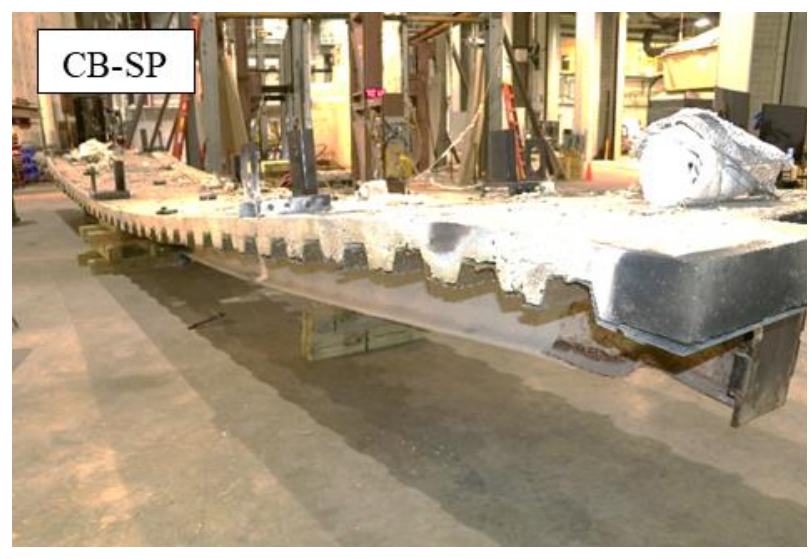

(a)

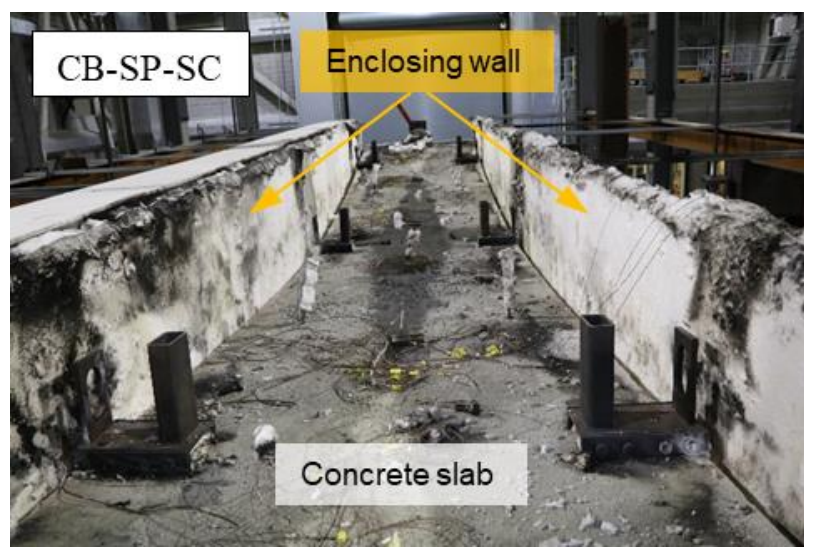

(b)

Figure 47 Photographs of deflected concrete slab of (a) CB-SP (side view), and (b) CB-SP-SC (top view).

The specimens with slab continuity, CB-DA-SC and CB-SP-SC, exhibited concrete cracks near the east and west ends due to negative flexure. For both specimens, smoke and flames leaked through these cracks, visible on the top of concrete between $50 \mathrm{~min}$ and $60 \mathrm{~min}$ from ignition. The measured vertical displacement corresponding to this event of flame leakage was approximately $320 \mathrm{~mm}(L / 40)$. The welded wire fabric ruptured at the crack planes, but the No. 4 reinforcing bars did not rupture.

Figure 48 shows photographs of concrete fractures near the west end, indicating different crack patterns between the two specimens. The CB-DA-SC specimen exhibited V-shaped cracks on the top of concrete (Figure 48a). The valley of this crack was located about $20 \mathrm{~cm}$ from the end of the steel beam, similar to the location of web local buckling of the steel beam. However, CB-SP-SC showed flat fractures along the width of slab approximately $66 \mathrm{~cm}$ from the end of the steel beam, similar to the location of flange local buckling of the steel beam (Figure 48b). 


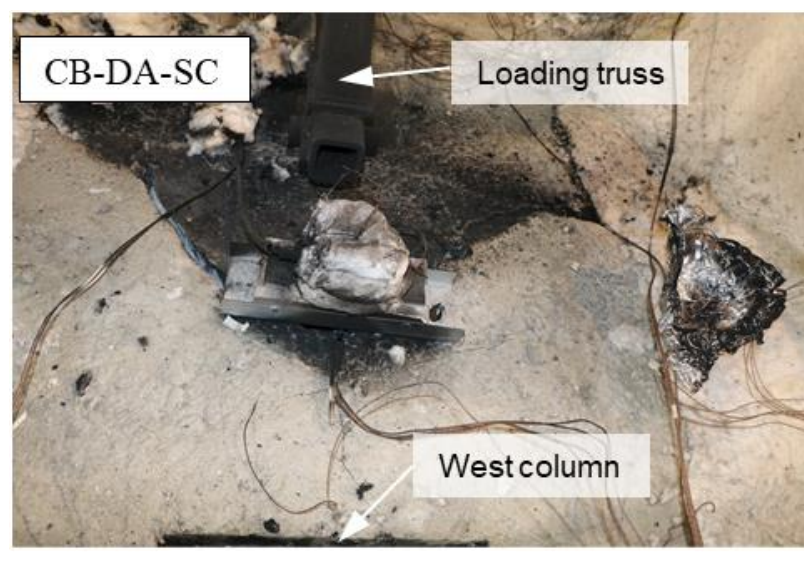

(a)

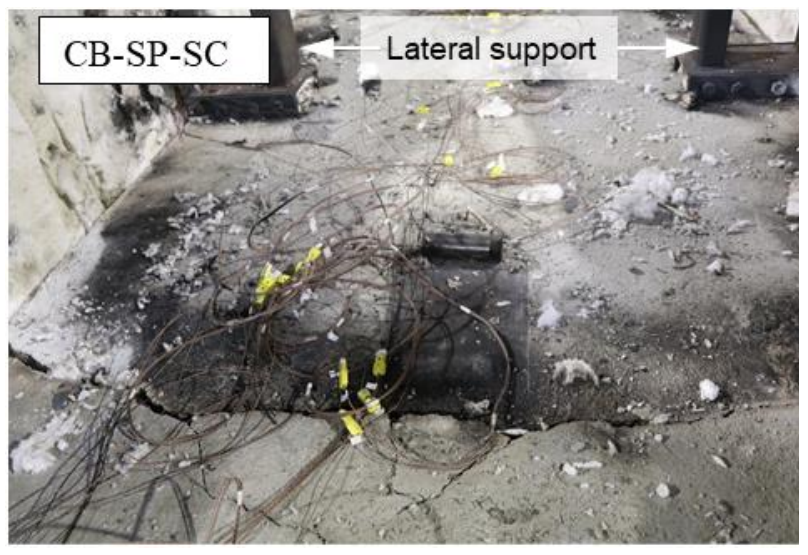

(b)

Figure 48 Photographs of concrete cracks of (a) CB-DA-SC, and (b) CB-SP-SC near the west end after cooldown.

The post-test inspection of CB-DA-SC and CB-SP-SC indicated that some shear studs welded at the beam ends failed by tensile fracture of the shank above the weld. The surrounding concrete appeared to fail by breakout, indicating that the concrete had fractured prior to or simultaneously with tensile failure of shear studs. Unlike the ambient specimen, the shear studs indicated negligible shear deformations. Although the exact cause of this failure needs to be further investigated, it is speculated that the end studs could be subjected to a large uplift force due to the negative moment caused by the rotational restraint of the slab continuity. There was no apparent failure of shear studs used in the specimens without slab continuity (CB-DA and CB-SP).

Flexural failure described above did not initiate collapse of the specimens; rather, they maintained their load-carrying capacity until the vertical displacement reached nearly $L / 20$ in fire. However, the minimum code-required shrinkage reinforcement (welded wire fabric) of the concrete slab (with the reinforcement area equivalent to $0.075 \%$ of gross concrete area) deemed not sufficient to resist thermally-induced negative flexure over the girders. 


\subsection{Connection Failure}

Figure 49 shows photographs of the tested specimens after cooling. Various failure modes were observed in the beam-to-column connections. The observed failure characteristics of the connections are as follows:

- The double-angle connections used in CB-DA and CB-DA-SC exhibited large ductility during heating but failed during cooling. All angle legs connected to the column face permanently deformed due to tensile loads associated with negative moments during heating as well as thermal contraction of the specimens during cooling (Figure 49a).

- For the CB-DA specimen, although no collapse failure was observed due to early termination of mechanical loading, a fillet weld joint on top of the east connection (i.e., weld return) was partially fractured.

- The CB-DA-SC specimen, exposed to heating for a longer period time (94 min), collapsed by weld fracture of the east connection about five hours after the fire was extinguished, as shown in Figure 49b. The slab continuity over girders did not appear to influence the governing failure mode (weld fracture).

- The shear-tab connection used in CB-SP and CB-SP-SC failed during heating but had dissimilar failure characteristics between two specimens.

- The CB-SP specimen collapsed by weld failure (unzipping) of the east connection approximately $65 \mathrm{~min}$ from the burner ignition. The bottom flange temperature and the vertical displacement were $680{ }^{\circ} \mathrm{C}$ and $L / 22$, respectively.

- For the CB-SP-SC specimen, the bottom bolt of the east connection fractured in shear around $73 \mathrm{~min}$. The bottom flange temperature was over $700{ }^{\circ} \mathrm{C}$, and the vertical displacement was $L / 22$ at this event. About 3 hours after extinguishment of the fire, the other two bolts (top and middle bolts) connecting the east shear tab to the steel beam fractured in shear due to the axial restraint against thermal contraction (Figure 49e). Fractured bolts are shown in Figure 49f. 


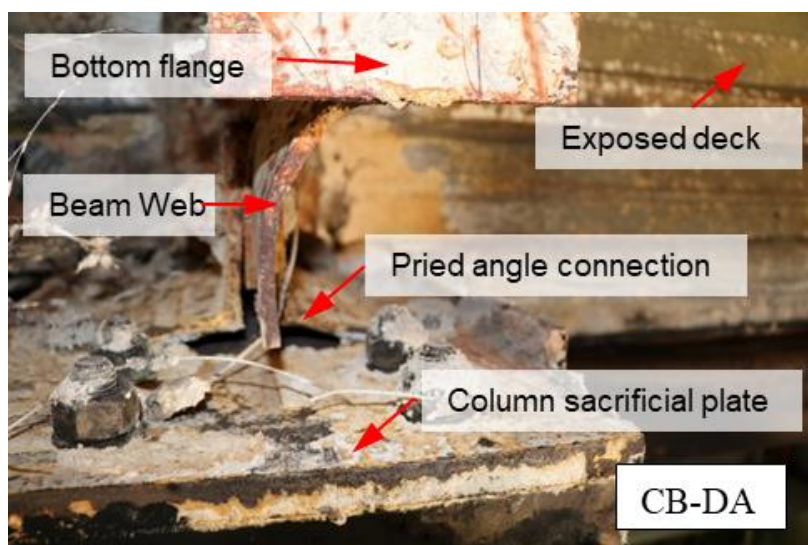

(a)

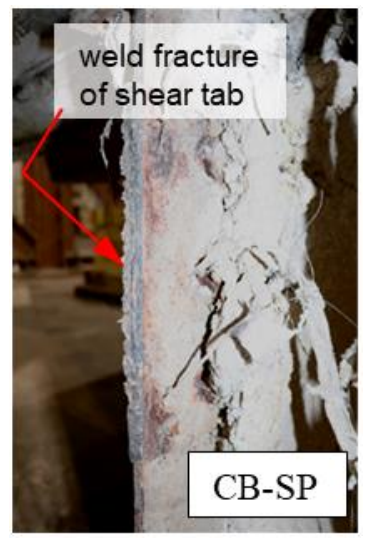

(c)

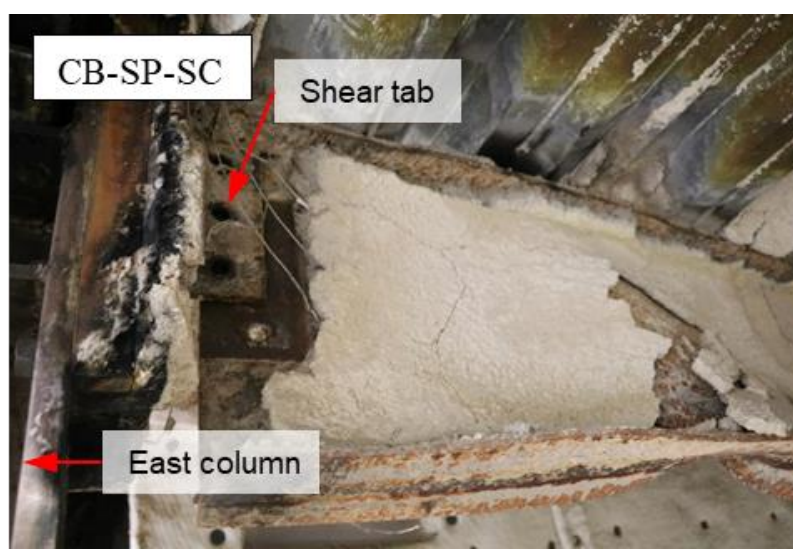

(e)

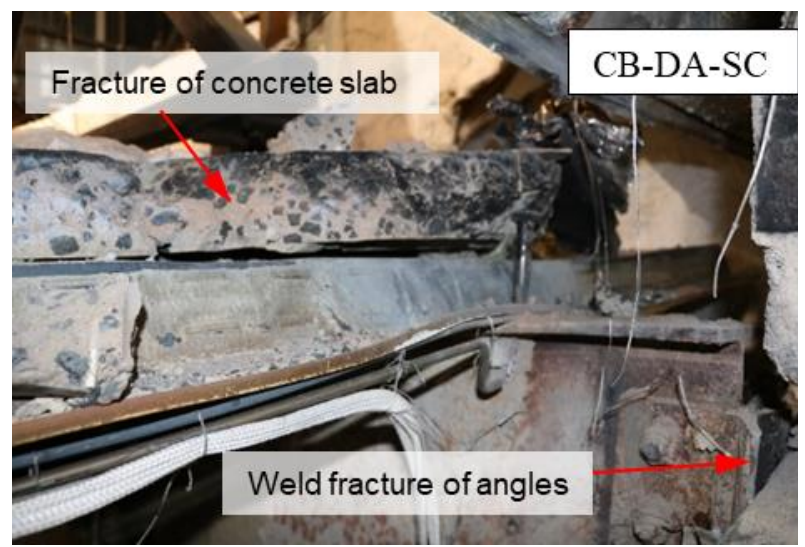

(b)

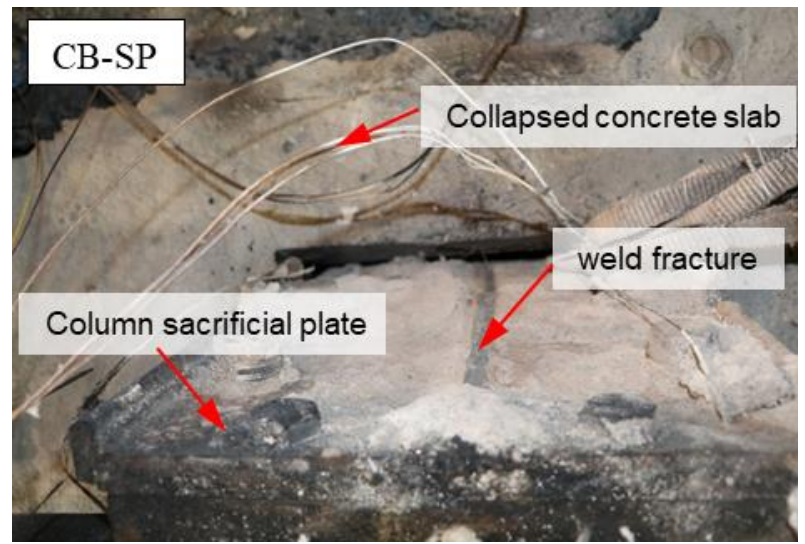

(d)

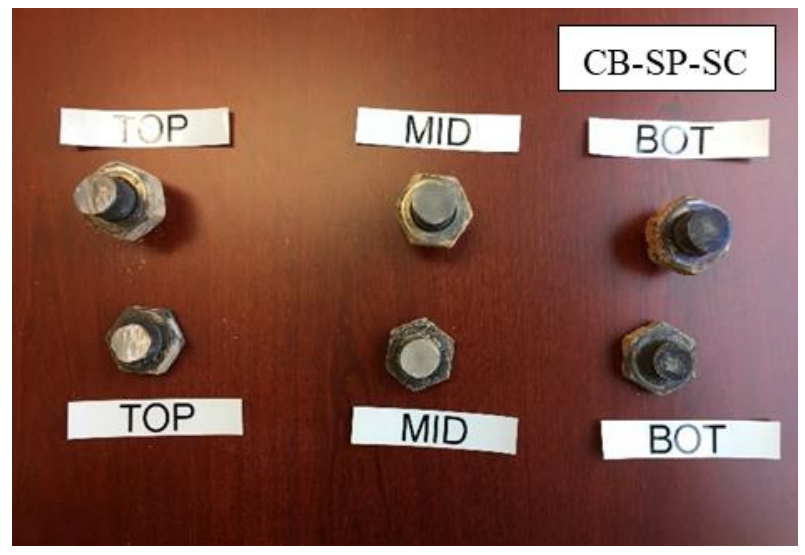

(f)

Figure 49 Photographs of beam-to-column connections after cool-down: (a) CB-DA (prying of angles at west end), (b) CB-DA-SC (weld fracture of east angle connection), (c) CB-SP (weld fracture of east shear tab),

(d) CB-SP (weld fracture on a sacrificial plate connected to east column), (e) CB-SP-SC (east shear tab), and (e) CB-SP-SC (fracture of bolts used in east shear tab). 


\section{Chapter 5 \\ SUMMARY AND CONCLUSIONS}

A series of compartment fire experiments was conducted on four $12.8 \mathrm{~m}$ long composite floor beam assemblies resisting gravity loads to study the performance and limit states under realistic fire conditions. The specific objectives for this study were (a) to create realistic, structurally significant fire conditions using natural gas fueled burners to study the failure mechanisms of fullscale beam assemblies and (b) to produce data that can be used to guide the development or validation of numerical models and design tools used for performance-based design of similar structures in the event of fire. The Part 1 report (Ramesh et al. 2019) describes details of the experimental design, including design and construction of the composite beam specimens and mechanical loading system, design of a test fire, measurement systems, and the ambient capacity and behavior of the composite beam specimen. This report (Part 2) presents the results of four compartment fire experiments conducted at the NIST National Fire Research Laboratory.

In this test program, five composite beam specimens were designed as a partially-composite floor beam assemblies protected with SFRM to meet the 2-hour fire-resistance rating in accordance with the national building codes and standards. One specimen (CB-DA-AMB) was tested at ambient temperature as a baseline to compare with the results from subsequent fire experiments. Four specimens (CB-DA, CB-DA-SC, CB-SP, and CB-SP-SC) were tested by subjecting them to combined gravity loads $(1.2 \times$ dead load $+0.5 \times$ live load $)$ and compartment fires with the heat release rate of $4000 \mathrm{~kW}$. The test variables considered in this study were the end support conditions of the specimens, including two types of simple shear connections (welded-bolted double-angle versus shear-tab connections) and the presence or absence of slab continuity over the girders. The testing criteria were developed to evaluate the fire performance of the specimens as follows. The specimens were automatically unloaded using two different limits, either a load limit of $15 \%$ reduction in the total mechanical loads for the CB-DA specimen or a displacement limit of the $L / 20$ ratio for the CB-DA-SC, CB-SP, and CB-SP-SC specimens. A 30-min decay phase of the fire was simulated for the specimens which did not collapse after removal of mechanical loading (CB-DA and CB-DA-SC).

The compartments fires with natural gas as a fuel created extreme heating conditions across the exposed surfaces of the specimens. The fire durations varied from $65 \mathrm{~min}$ to $94 \mathrm{~min}$ among four specimens. The equivalent fuel load was in the range of $400 \mathrm{MJ} / \mathrm{m}^{2}$ to $600 \mathrm{MJ} / \mathrm{m}^{2}$. The upper layer gas temperatures within the test compartment reached over $1000{ }^{\circ} \mathrm{C}$. When exposed to a 
compartment fire, the specimens developed the time-varying thermal gradient across the composite sections, influenced by the duration and intensity of a fire. Temperatures of the SFRMprotected bottom flanges exceeded $600{ }^{\circ} \mathrm{C}$ at $45 \mathrm{~min}$ after ignition while the top surface of the concrete slab remained below $100{ }^{\circ} \mathrm{C}$ during heating but increased to nearly $140{ }^{\circ} \mathrm{C}$ during cooling. The average temperature of the beam-to-column connections increased even after extinguishment of a fire but never exceed $300{ }^{\circ} \mathrm{C}$ because a thicker SFRM layer was applied.

Under combined mechanical loading and fire exposure, all tested specimens exhibited diverse structural responses which varied by the end support conditions and achieved various modes of failure throughout the heating and cooling phases. Based on the study reported herein, the conclusions were reached as follows:

1. The long-span composite beam specimen exhibited local buckling failure of the steel beam near the beam-to-column connections due to the restraint of thermal elongation. This failure mode was achieved prior to yielding of the composite section at midspan and did not cause incipient collapse of the specimens. The local buckling capacity of the specimens was affected by the geometry of the end sections, in particular, whether or not the bottom flange of the steel beams was coped.

2. Although the slab continuity over the girders helped to increase the local buckling capacity, the minimum code-required shrinkage reinforcement $(0.075 \%$ of gross concrete area) was not sufficient to resist thermally-induced negative moments. The concrete slab in the negative moment region fractured during fire when the vertical displacement at midspan was approximately equal to $L / 40$. Although this failure did not lead to incipient collapse of the specimens, it could allow the fire spread above the test compartment.

3. Unlike the ambient specimen, the shear strength of headed stud anchors did not appear to govern the flexural capacity of the partially-composite sections at elevated temperatures. Provided that the mechanical loading was unchanged during fire exposure, the temperature rise in the steel beam exacerbated the yield strength of the composite section.

4. The welded-bolted double-angle connections exhibited superior robustness during fire. The long-span composite beam specimens with this connection type maintained their loadcarrying capacity at large vertical displacements (over $L / 20$ ), through a catenary action. However, weld joints used in this connection type could fail in tension due to the restraint to thermal contraction of the long-span floor beams during cooling. 
5. The rotation capacity (ductility) of the shear-tab connections was less than that of the double-angle connections. The specimens exhibited connection failures before the vertical displacement increased to $L / 20$ during fire loading. The rotational restraint of concrete slabs over the girders slightly increased the time at which the connection failed. However, there could be vulnerabilities in shear-tab connections used in long-span floor construction during both the heating and cooling periods of severe fires, although further study is needed.

The findings from this study are limited to the range of parameters included in this study. The experimental data can be used to guide the development and validation of computational models that predict the fire performance of similar structures with a wider range of parameters such as the beam span, connections, applied load ratios, etc. Future research will involve the experimental study on the fire performance of full-scale composite floor systems as well as ductility and robustness of simple shear connections influenced by thermal restraints during fire exposure and cooling. 


\section{REFERENCES}

AISC (2016). "Specification for Structural Steel Buildings", ANSI/AISC 360-16, AISC, Chicago, IL.

ASCE (2018). "Structural fire engineering." ASCE MOP 138, Reston, VA.

ASCE (2016). "Minimum design loads for buildings and other structures.” ASCE 7-16, Reston, VA.

ASTM (2018). "Standard test methods for fire tests of building construction and materials." ASTM E119, West Conshohocken, PA.

ASTM (2016). "Standard test methods for tension testing of metallic materials." ASTM E8 / E8M-16a, West Conshohocken, PA.

Bryant, R., Bundy, M., and Zong, R. (2015). "Evaluating measurements of carbon dioxide emissions using a precision source-A natural gas burner." J. the Air \& Waste Manage. Assoc., 65(7), 863870.

Bryant, R., Ohlemiller, T. J., Johnson, E. L et al (2004). "The NIST 3-megawatt quantitative heat release rate facility." NIST SP 1007, Gaithersburg, MD.

Bundy, M., Hamins, A., Gross, J., Grosshandler, W., and Choe, L. (2016). "Structural fire experimental capabilities at the NIST National Fire Research Laboratory." Fire Tech., 52(4), 959-966.

Choe, L., Ramesh, S., Hoehler, M., Seif, M., Gross, J., Zhang, C., Bundy, M. (2018). "National Fire Research Laboratory Commissioning Project: Testing Steel Beams under Localized Fire Exposure", NIST TN 1983, Gaithersburg, MD.

Choe, L., Ramesh, S., Hoehler, M., Gross, J. (2018). "Experimental study on long-span composite floor beams subject to fire: baseline data at ambient temperature." Proc., Structures Congress 2018, Fort Worth, TX.

Hoehler, M., Andres, B., Bundy, M. (2019). "Influence of Fire on the Lateral Resistance of Cold-Formed Steel Shear Walls - Phase 2: Oriented Strand Board, Strap Braced, and Gypsum-Sheet Steel Composite" NIST 2038, Gaithersburg, MD.

ICC (International Code Council). (2018). International Building Code, Country Club Hills, IL.

NFPA (National Fire Protection Association). (2018). "Building Construction and Safety Code." NFPA 5000, Quincy, MA.

NIST (National Institute of Standards and Technology). (2008). "Final report on the collapse of World Trade Center Building 7.” NIST NCSTAR 1A, Gaithersburg, MD.

Pour-Ghaz, M., Castro, J., Kladivko, E., J., and Weiss, J. (2011). “Characterizing lightweight aggregate desorption at high relative humidities using a pressure plate apparatus." J Mater Civil Eng, 24(8), 10.1061/(ASCE)MT.1943-5533.0000422.

SCI (Steel Construction Institute). (2008). Best practice in steel construction, commercial buildings, guidance for architects, designers, and constructors, Ascot, U.K.

SDI (Steel Deck Institute). (2017). "C-2017 Standard for composite steel floor deck-slabs.” ANSI/SDI C17, < http://www.sdi.org/wp-content/uploads/2017/02/ANSI-SDI-C-2017-Standard.pdf> (Apr. 12. 2019). 
Ramesh et al. (2019). "Compartment fire experiments on long-span composite beams with simple shear connections, Part 1: experimental design and beam behavior at ambient temperature." NIST TN 2054, Gaithersburg, MD. 


\section{Appendix A \\ SPECIMEN CB-DA}

\section{A.1 Test Information}

Test Date:

Record Start Time:

Program Version:

Test Name:

Test Series information:

Peak HRR (kW)

Total HRR (MJ)

Oxygen Drift (ppmv)

Baseline Hood Flow

$(\mathrm{kg} / \mathrm{s})$
12/19/2017 (Concrete placement: 12/6/2016)

10:21:25 AM

MIDAS.exe Ver. 2.124.0.696

CB-DA

- The $12.8 \mathrm{~m}$ span composite beam specimen was supported by welded-bolted double-angle connections.

- No slab continuity reinforcement was present.

- Unloading of hydraulic actuators was triggered when a total mechanical load dropped below $85 \%$ of its initial value applied prior to the burner ignition.

4010

10540

$-5$

77.680

\section{A.2 Test Procedure and Observations}

Table 14 Test procedure and observations for CB-DA. Test time was recorded after the burner ignition and rounded to the nearest 1 min.

\begin{tabular}{|c|c|}
\hline Time (min) & Description \\
\hline 0 & $\begin{array}{l}\text { - Fire ignition was confirmed. } \\
\text { - The total heat release rate of the burners (HRRburner) started increasing. }\end{array}$ \\
\hline 13 & - HRRburner reached a set point of $4000 \mathrm{~kW}$. \\
\hline 30 & $\begin{array}{l}\text { - Local buckling of the steel beam occurred near the angle connections. } \\
\text { - A } 15 \% \text { reduction in mechanical loads activated automatic depressurization } \\
\text { of hydraulic actuators. } \\
\text { - While fire loading continued, the vertical displacement of the unloaded } \\
\text { specimen increased. }\end{array}$ \\
\hline 38 & $\begin{array}{l}\text { - HRRburner was linearly ramped down over a period of } 30 \mathrm{~min} \text {. } \\
\text { - The unloaded specimen continued to deflect downward. }\end{array}$ \\
\hline 68 & $\begin{array}{l}\text { - Fire was extinguished }(\mathrm{HRR} \text { burner } \approx 0 \mathrm{~kW}) \text {. } \\
\text { - The vertical displacement of the specimen started to decrease. }\end{array}$ \\
\hline
\end{tabular}


After cooling - The specimen did not collapse.

- Actuator data (Figure 50) confirmed that mechanical loads applied using coupled actuators were steady. The standard variation of loads from coupled actuators was less than $1 \%$ during fire. The concrete slab of the test specimen did not appear to have a rigid rotation about its longitudinal axis since stoke lengths of coupled actuators remained almost identical until unloading occurred.

- The upper layer gas temperature within the compartment (Figure 51a), measured using eight thermocouples mounted $81 \mathrm{~cm}$ below exposed steel decking, increased to a maximum value of $(1020 \pm 35){ }^{\circ} \mathrm{C}$ prior to decay of a fire. The value after \pm symbol is the standard deviation of temperatures measured using TCC1 through TCC8. The south side of the compartment $81 \mathrm{~cm}$ below exposed steel decking was about $70{ }^{\circ} \mathrm{C}$ lower than the north side.

- The temperature measured using thermocouples mounted outside of the test compartment above the vent openings was in the range of $800{ }^{\circ} \mathrm{C}$ to $870{ }^{\circ} \mathrm{C}$ while the HRRburner value was fixed at $4000 \mathrm{~kW}$ from $13 \mathrm{~min}$ to $38 \mathrm{~min}$ (Figure $51 \mathrm{~b}$ ).

- Figure 52 shows the concrete temperatures in the slab directly above the W18 $\times 35$ beam. The following sensors are believed to potentially be faulty; possibly due to undesired junctions in the thermocouple wire: Figure 52a (TC1-10), Figure 52c (TC6-all), and Figure 52d (TC4all). This judgement is based on observed temperature rise rates much faster than would be anticipated for a sensor embedded in concrete, higher temperature observed further from heat source then close to source and/or an inexplicably long temperature plateau at $100{ }^{\circ} \mathrm{C}$. These data should be further interrogated and view critically.

- Figure 53 and Figure 54 indicate that the north and south side of the slab $(45.7 \mathrm{~cm}$ from the longitudinal centerline) developed a similar thermal gradient through the depth of the concrete. The middle depth of the concrete slab reached its maximum value of $300{ }^{\circ} \mathrm{C}$ on average. The maximum temperature of the unexposed surface never exceeded $150{ }^{\circ} \mathrm{C}$.

- SFRM cracked at both east and west ends due to local buckling (Figure 55a-b).

- Except the beam ends, SFRM on the steel beam did not dislodge or delaminate (Figure 55c).

- Weld joint between the top of angle legs fractured (Figure 55d).

- No flexural cracks appeared on top of the concrete. 


\section{A.3 Additional Data}

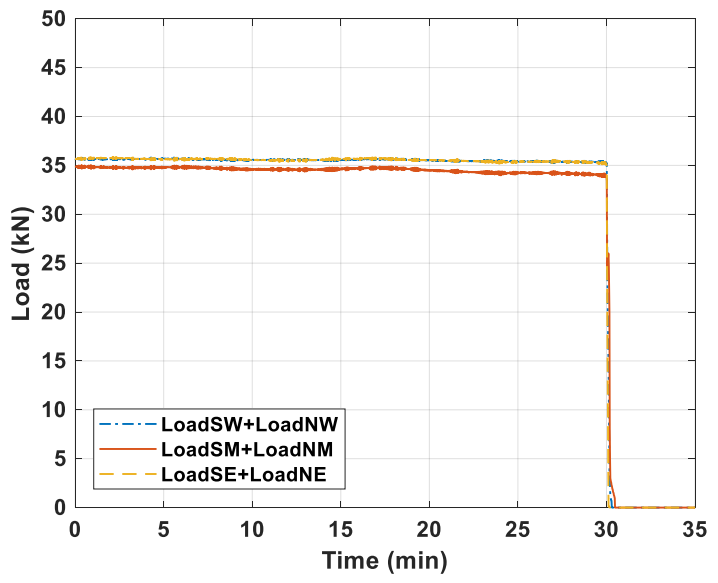

(a)

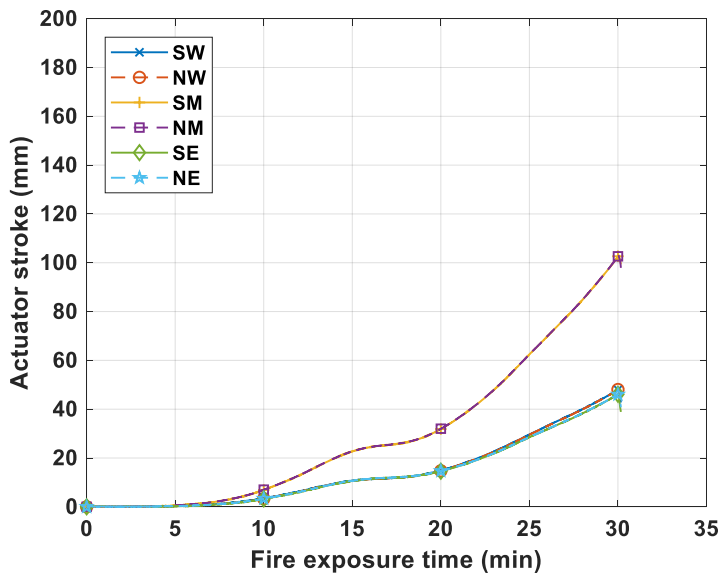

(b)

Figure 50 Actuator data of CB-DA: (a) loads, and (b) stroke lengths applied using six actuators (SW, NW, SM, NM, SE, and NE). Actuator stroke was not recorded after unloading.

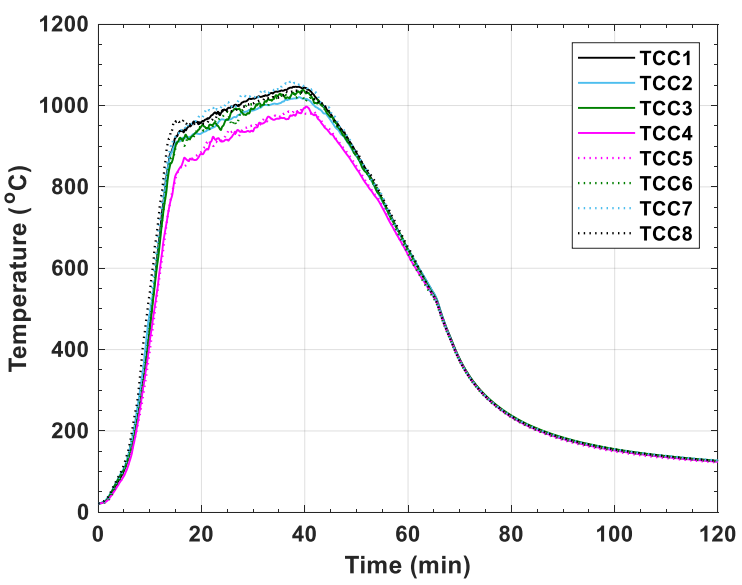

(a)

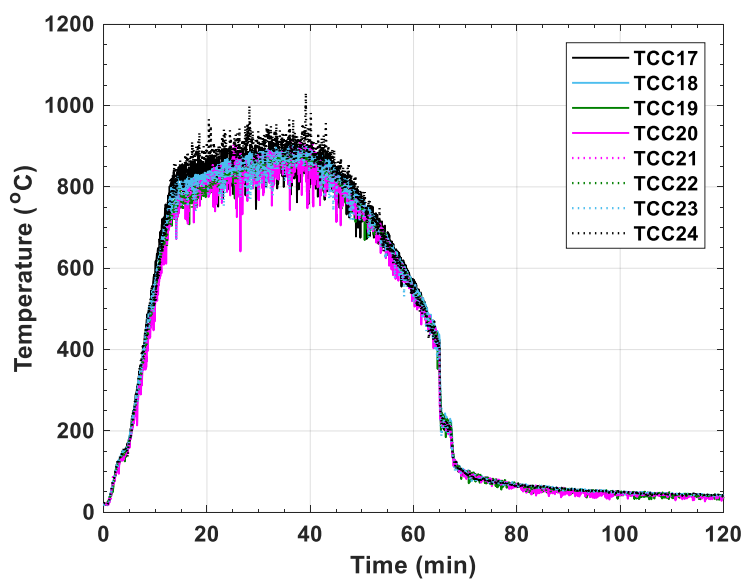

(b)

Figure 51 Gas temperature data of CB-DA: (a) $81 \mathrm{~cm}$ below exposed steel decking and (b) above vent openings outside of the test compartment. 


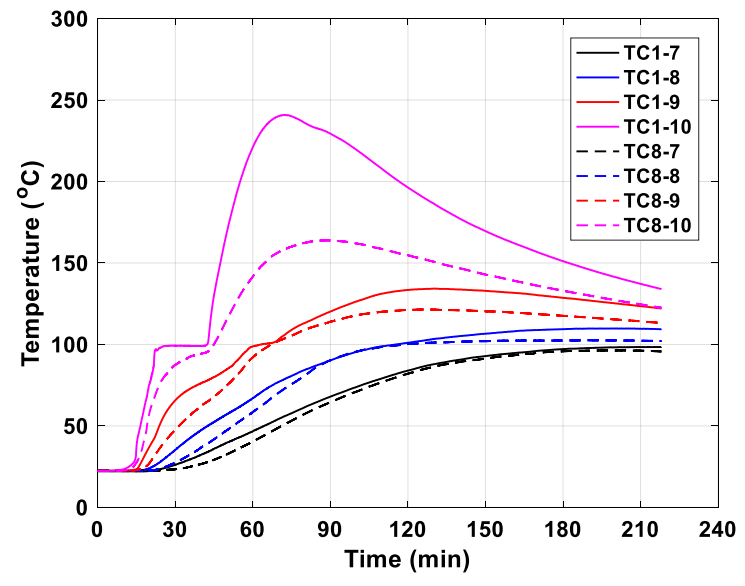

(a)

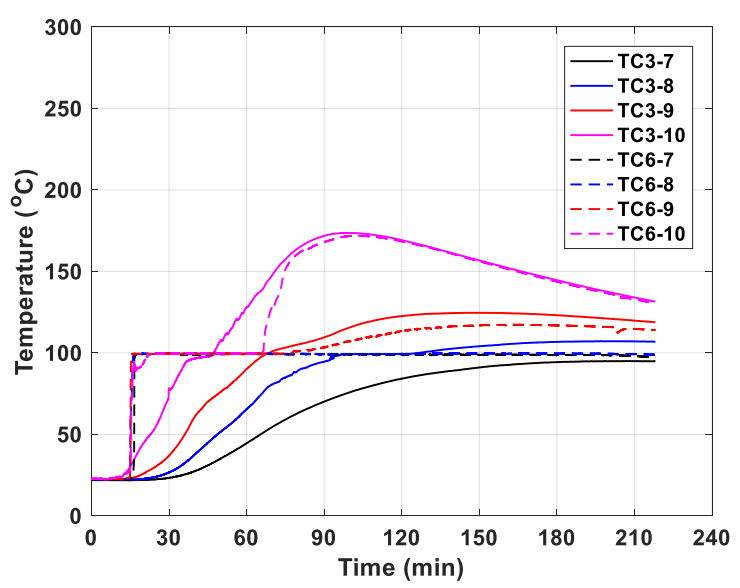

(c)

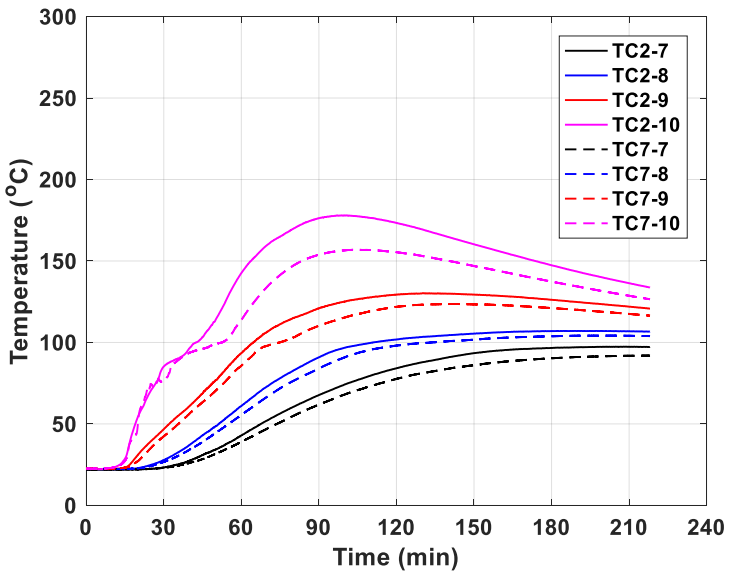

(b)

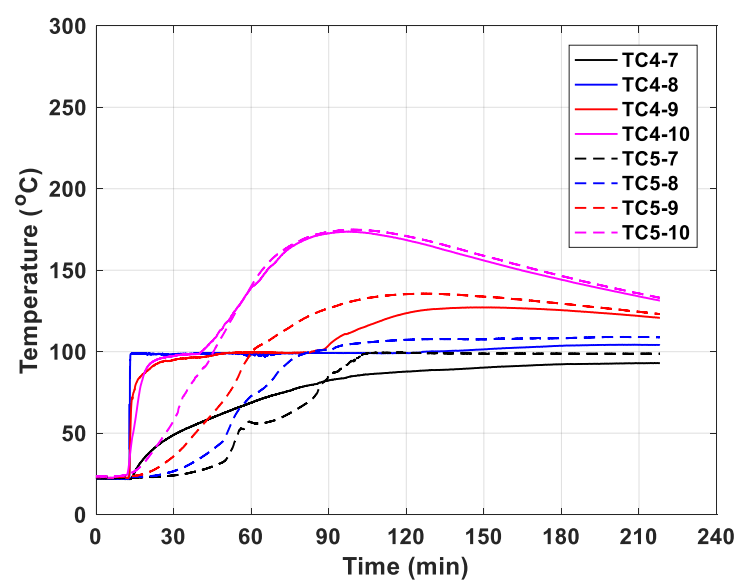

(d)

Figure 52 Concrete temperature along the longitudinal centerline of CB-DA: (a) sections TC1 and TC8, (b) sections TC2 and TC7, (c) sections TC3 and TC6, and (d) sections TC4 and TC5. 


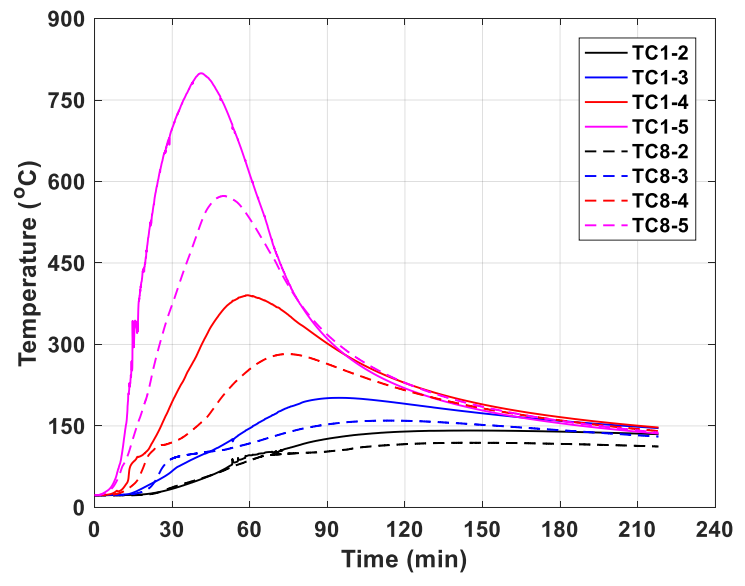

(a)

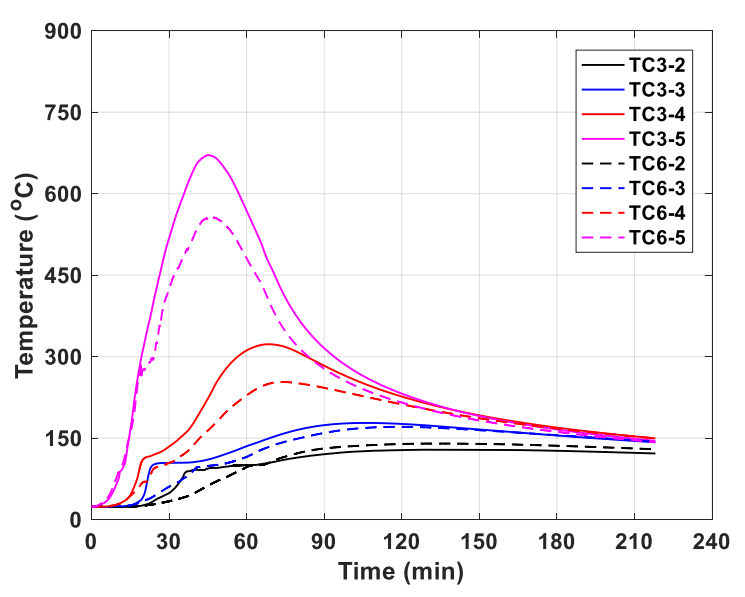

(c)

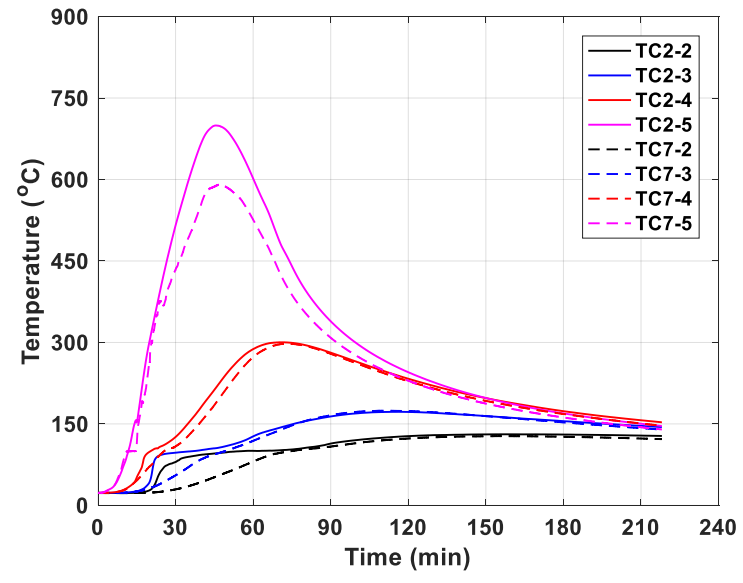

(b)

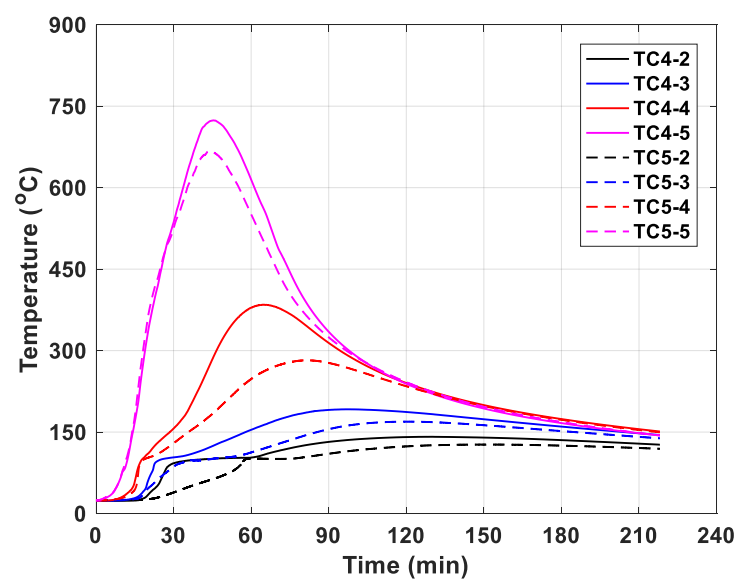

(d)

Figure 53 Concrete temperature measured $45.7 \mathrm{~cm}$ from the north edge of CB-DA: (a) sections TC1 and TC8, (b) sections TC2 and TC7, (c) sections TC3 and TC6, and (d) sections TC4 and TC5. 


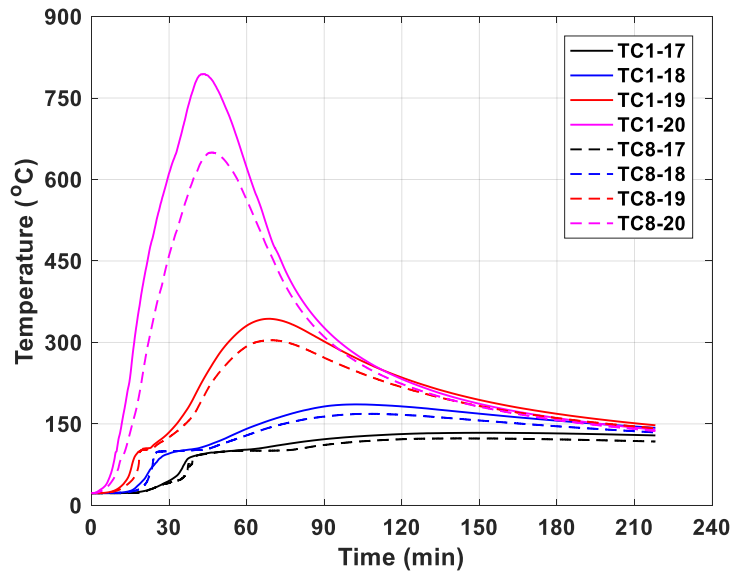

(a)

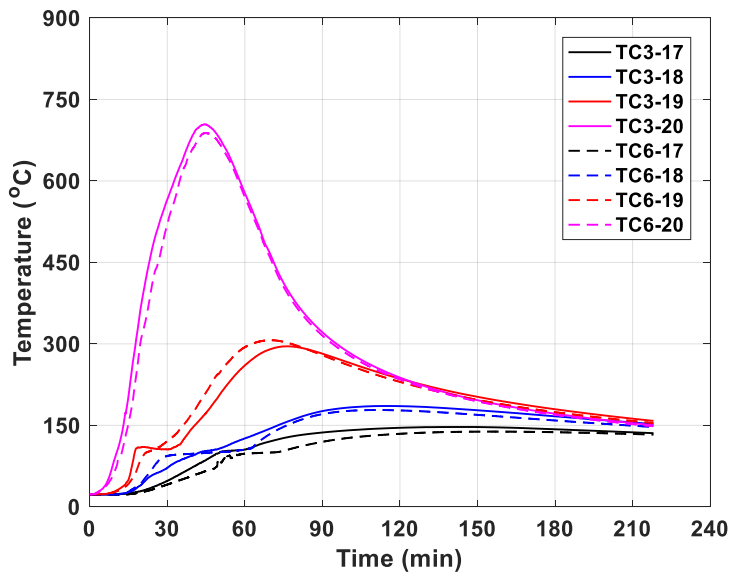

(c)

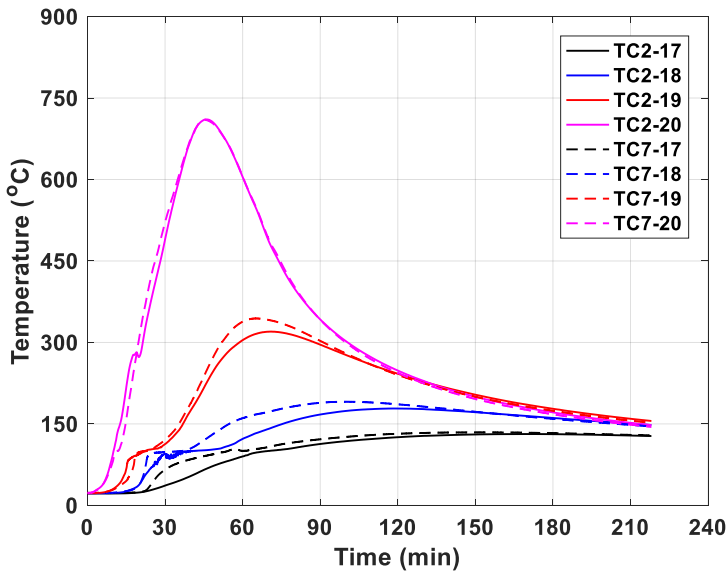

(b)

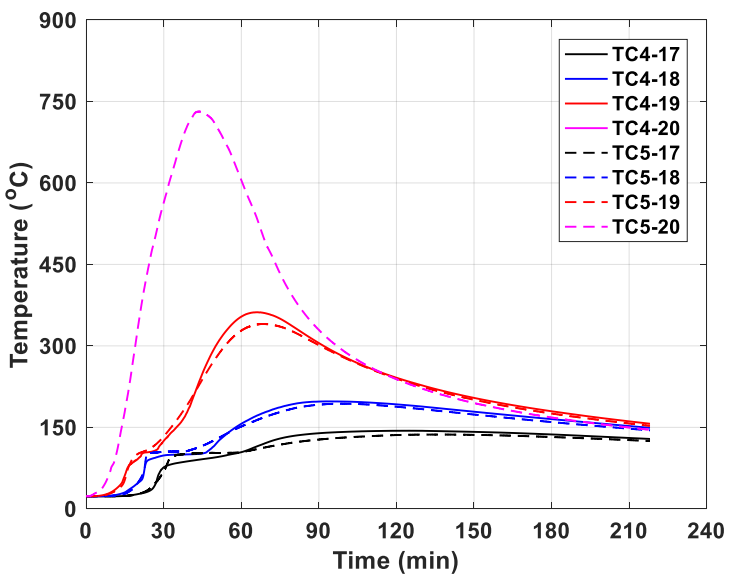

(d)

Figure 54 Concrete temperature measured $45.7 \mathrm{~cm}$ from the south edge of CB-DA: (a) sections TC1 and TC8, (b) sections TC2 and TC7, (c) sections TC3 and TC6, and (d) sections TC4 and TC5. 


\section{A.4 Post-Test Conditions}

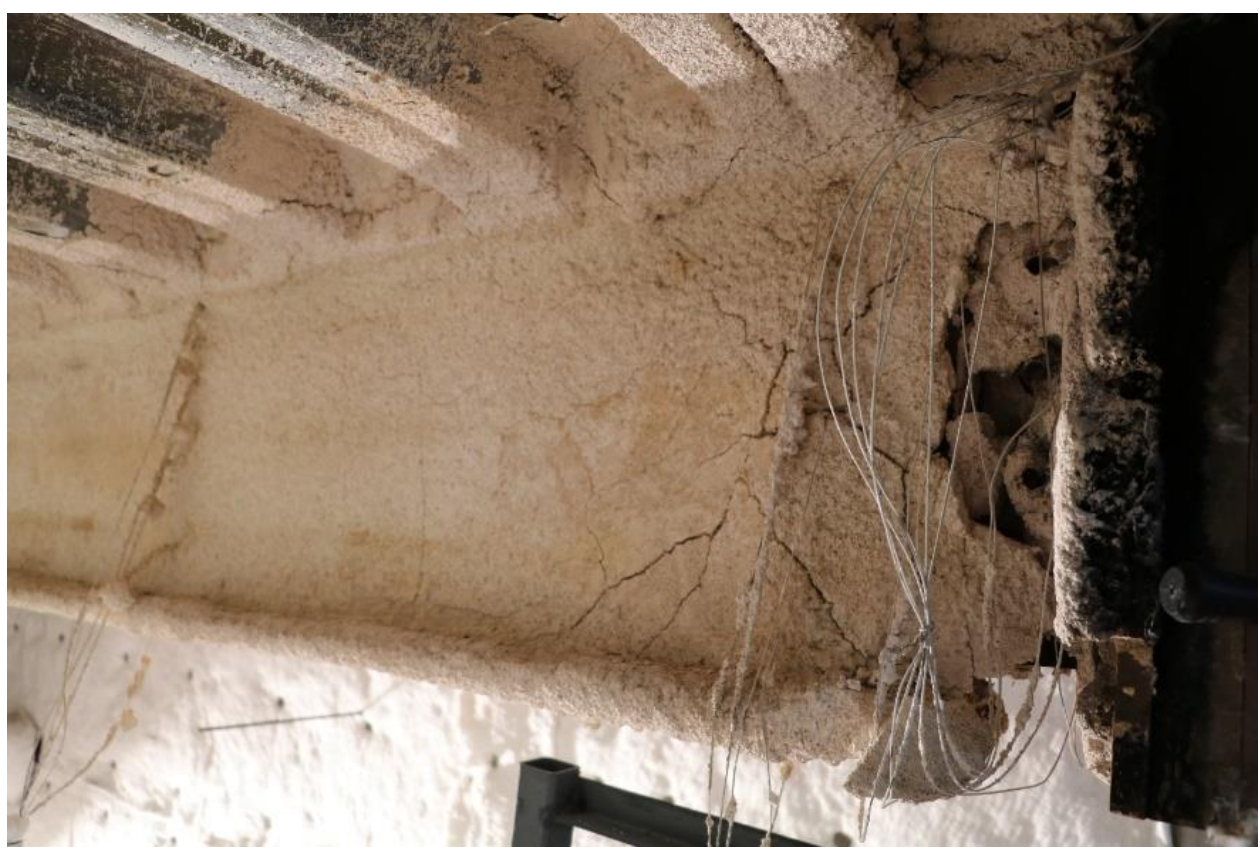

(a)

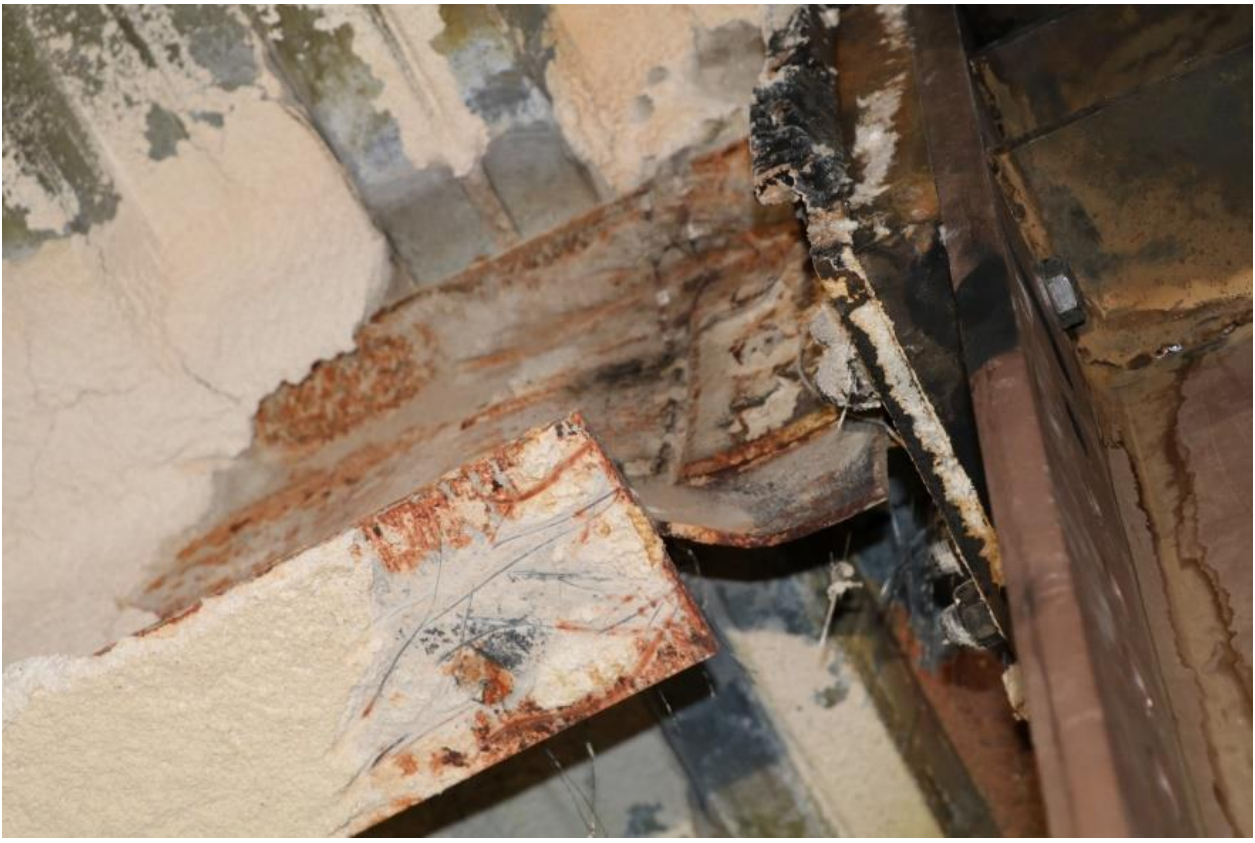

(b) 


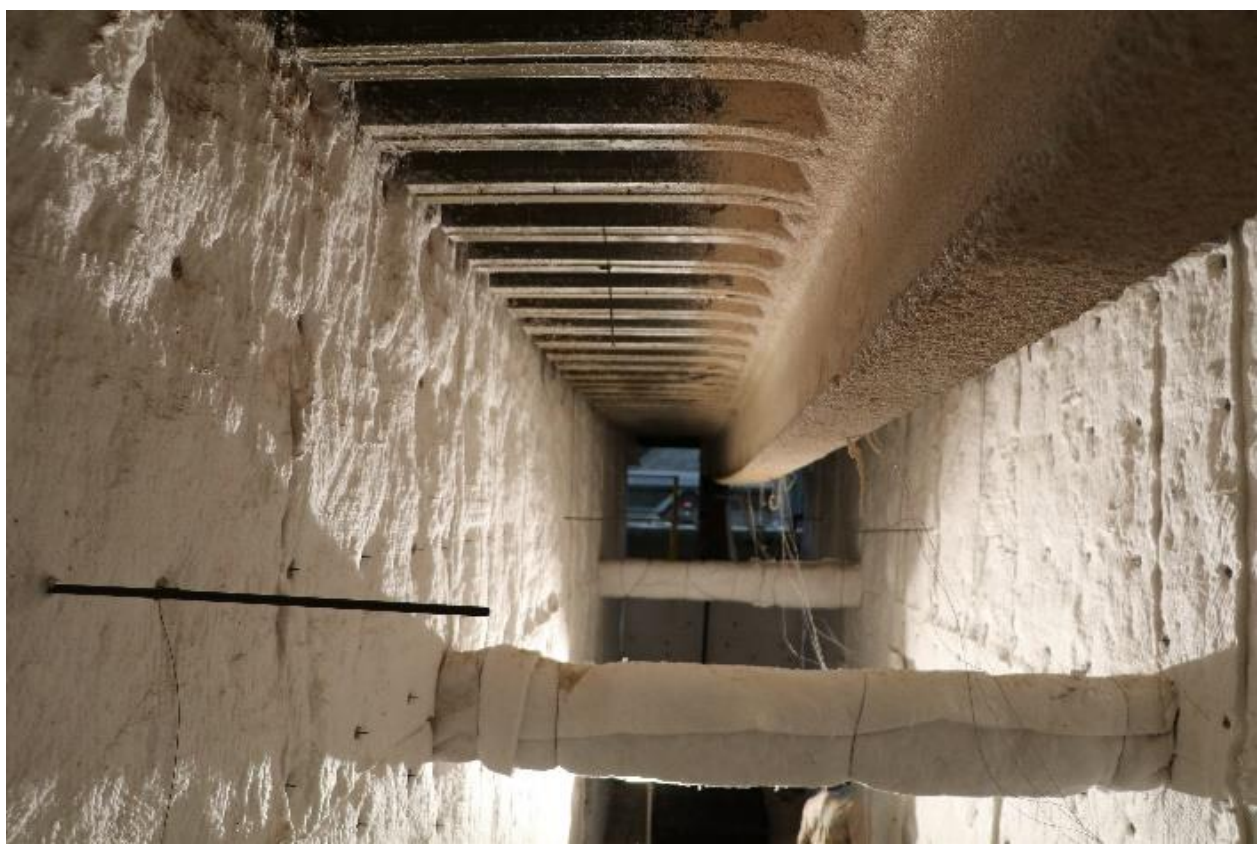

(c)

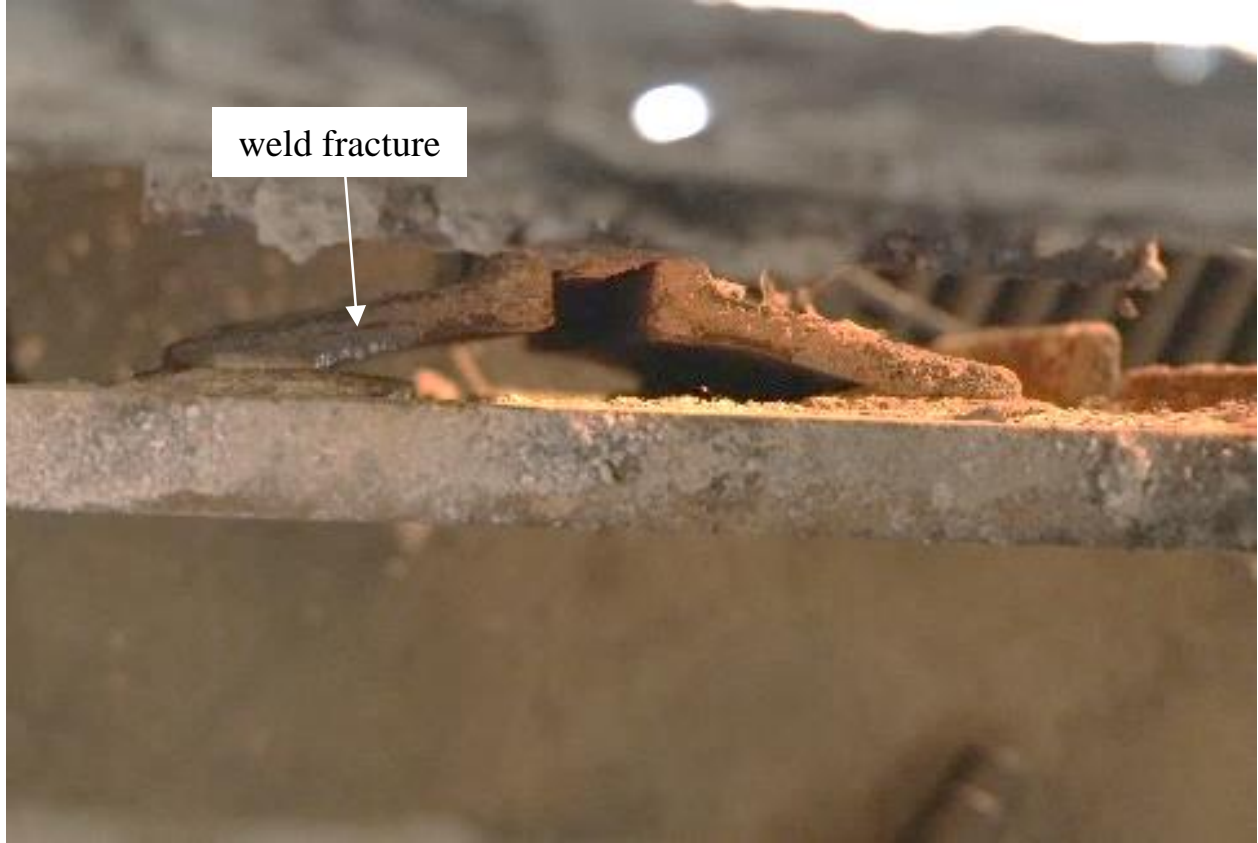

(d)

Figure 55 Post-test images of CB-DA: (a) cracked SFRM near east connection, (b) west angle connection after SFRM was removed, (c) steel beam covered with SFRM that remained intact after test, and (d) fracture of weld between top of angle legs and a sacrificial plate attached to the flange of east column. 


\section{Appendix B \\ SPECIMEN CB-DA-SC}

\section{B.1 Test Information}

Test Date:

1/12/2018 (Concrete placement: 12/6/2016)

Record Start Time:

1:02:50 PM

Program Version:

Test Name:

MIDAS.exe Ver. 2.124.0.698

CB-DA-SC

- A 12.8 m span composite beam specimen supported by weldedbolted double-angle connections.

- Slab continuity reinforcement was included. No. 4 reinforcing bars and welded wire fabric were anchored at location of

Test Series information: girders.

- Unloading of hydraulic actuators was triggered when the stroke length of actuators exceeded $63 \mathrm{~cm}$.

- The decay of a fire was simulated by linearly ramping down heat release rate of the burner to $0 \mathrm{~kW}$ over $30 \mathrm{~min}$.

Peak HRR (kW)

4026

$\begin{array}{ll}\text { Total HRR (MJ) } & 16377 \\ \text { Oxygen Drift (ppmv) } & -16\end{array}$

Baseline Hood Flow

$(\mathrm{kg} / \mathrm{s})$

77.380

\section{B.2 Test Procedure and Observations}

Table 15 Test procedure and observations for CB-DA-SC. Test time was recorded after the burner ignition and rounded to the nearest 1 minute.

\begin{tabular}{cll}
\hline Time (min) & \\
\hline 0 & - Fire ignition was confirmed. \\
13 & - The total heat release rate of the burners (HRRburner) started increasing. \\
30 & - HRRburner reached a target value of $4000 \mathrm{~kW}$. \\
43 & - The concrete slab above the west angle connection cracked. \\
48 & - Black smoke (soot) appeared on top of concrete near the west support. \\
50 & - The concrete slab near the east support cracked.
\end{tabular}


52 - Black smoke (soot) appeared on top of concrete near the east support.

- Flames and heavy smoke were visible on the top of concrete near the west support.

60

- Flames and heavy smoke were visible on the top of concrete near the east support.

- Mechanical loading was automatically removed by a preset displacement limit of actuators $(630 \mathrm{~mm})$

- A 30 min decay of the fire began.

- Fire was extinguished. (HRRburner $\approx 0 \mathrm{~kW}$ )

- The specimen collapsed by weld failure of the east angle connection.

- Mechanical loads applied using SE and NE actuators oscillated under fire loading (Figure 56a), possibly due to servo-valve problems. This resulted the standard deviation of $4 \%$ of the summed value (i.e., LoadSE +LoadNE) over time. Loads from other coupled actuators (LoadSW+LoadNW or LoadSM+LoadNM) remained relatively steady with the standard deviation less than $2 \%$.

- The coupled actuators maintained the same stroke length during fire loading (Figure 56b), indicating negligible rotation of the slab about its longitudinal axis.

- As shown in Figure 57, after 20 min from the burner ignition, the rotation of east and west loading trusses (RotLT1 and RotLT3, respectively) increased as the specimen deflected downward. The maximum standard deviation in six-point loads was over $10 \%$ before unloading. The time-averaged value of six-point loads was $17.3 \mathrm{kN}$, estimated for a period of $63 \mathrm{~min}$.

- The upper layer gas temperature within the compartment (Figure 58a), measured using eight thermocouples mounted $81 \mathrm{~cm}$ below exposed steel decking, increased to a maximum value of $(1050 \pm 25){ }^{\circ} \mathrm{C}$ prior to decay of a fire. The value after \pm symbol is the standard deviation of temperatures measured using TCC1 through TCC8.

- The temperature measured using thermocouples mounted outside of the test compartment above the vent openings was in the range of $800{ }^{\circ} \mathrm{C}$ to $900{ }^{\circ} \mathrm{C}$ on average while HRRburner value was fixed at $4000 \mathrm{~kW}$ from $13 \mathrm{~min}$ to $63 \mathrm{~min}$ (Figure 58b). TCC24 (above the SW vent opening) was about $150{ }^{\circ} \mathrm{C}$ higher than other vent openings. Larger flame leak was observed at the SW vent opening (Figure 59).

- Figure 60 shows the concrete temperatures in the slab directly above the W18 35 beam. The following sensors may have been faulty: TC1-7, TC1-10.

- Figure 61 and Figure 62 indicate that the north and south side of the slab $(45.7 \mathrm{~cm}$ from the longitudinal centerline) developed a similar thermal gradient through the depth of the concrete. Concrete cracks near the east and west ends did not appear to have an impact on temperature changes of the concrete away from the longitudinal centerline. The bottom of the concrete slab reached its maximum value of $800{ }^{\circ} \mathrm{C}$ on average. The maximum temperature of the unexposed surface never exceeded $150{ }^{\circ} \mathrm{C}$ during heating and $200{ }^{\circ} \mathrm{C}$ during cooling.

- Temperatures of exposed steel deck increased from $600{ }^{\circ} \mathrm{C}$ to over $1000{ }^{\circ} \mathrm{C}$ while the heat release rate was approximately $4000 \mathrm{~kW}$ from $13 \mathrm{~min}$ to $94 \mathrm{~min}$ (Figure 63a). 
- The bottom flange temperature measured using Inconel sheathed thermocouples (STC2 through STC4) increased to nearly $700{ }^{\circ} \mathrm{C}$ on average at $60 \mathrm{~min}$ and to $800{ }^{\circ} \mathrm{C}$ at $94 \mathrm{~min}$ (Figure 63b) The higher temperature of STC1 was caused by dislodging of this thermocouple.

- For the east connection region, the beam web next to angle legs increased to $400{ }^{\circ} \mathrm{C}$ and the temperature of angles never exceeded $250{ }^{\circ} \mathrm{C}$ due to thicker coating of SFRM (Figure 64a). Some thermocouples in the west connection region were dislodged after 30 min (Figure 64b).

- Figure 65 shows the tensile loads on the No. 4 reinforcing bars anchored at the location of girders as a function of fire exposure time. In the east support, the load transferred through middle reinforcing bars (LCE2 and LCE3) sharply diminished around 50 min possibly due to concrete facture. In the west support, the slab continuity achieved by middle reinforcing bars (LCW2 and LCW3) appeared to be lost around $57 \mathrm{~min}$.

- Figure 66 through Figure 69 show additional views of the test specimen during the test.

- Figure 70 through Figure 73 are additional views of the post-test conditions of the test specimen.

\section{B.3 Additional Data}

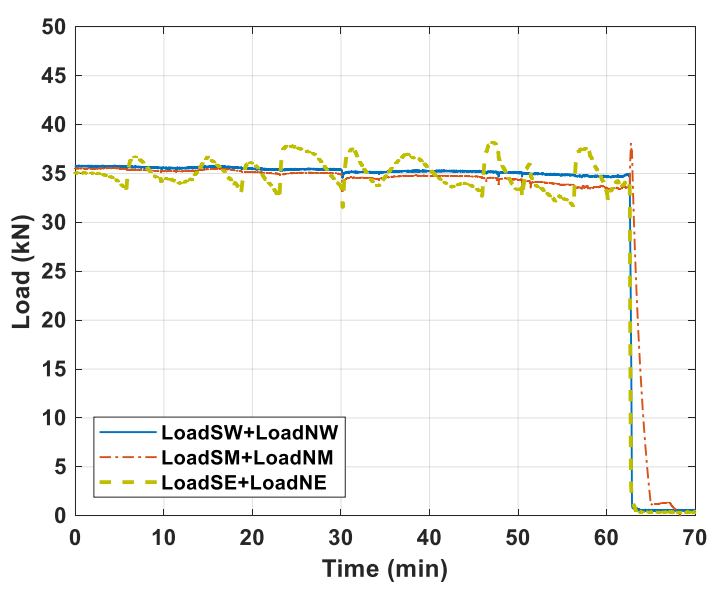

(a)

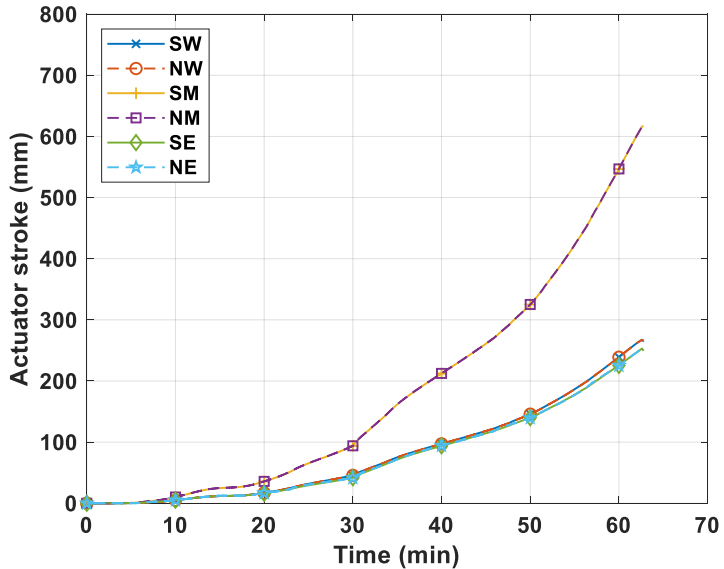

(b)

Figure 56 Actuator data of CB-DA-SC: (a) loads and (b) stroke lengths applied using six actuators (SW, NW, SM, NM, SE, and NE). Actuator stroke was not recorded after unloading. 


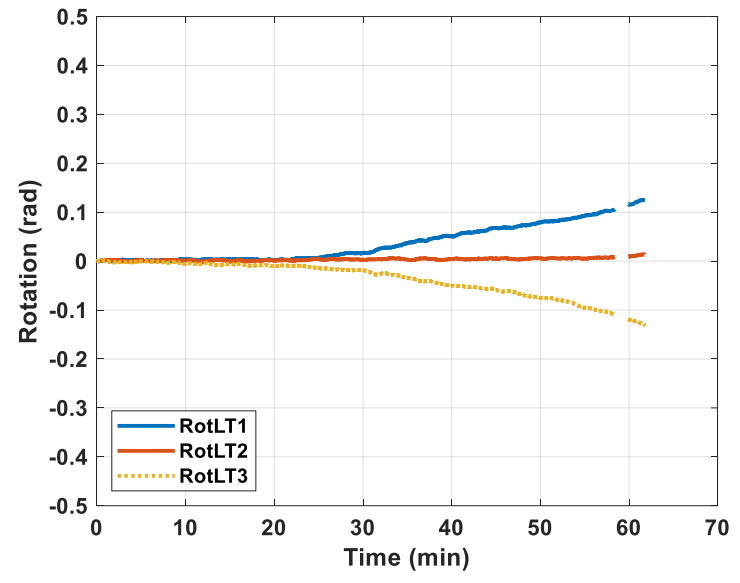

(a)

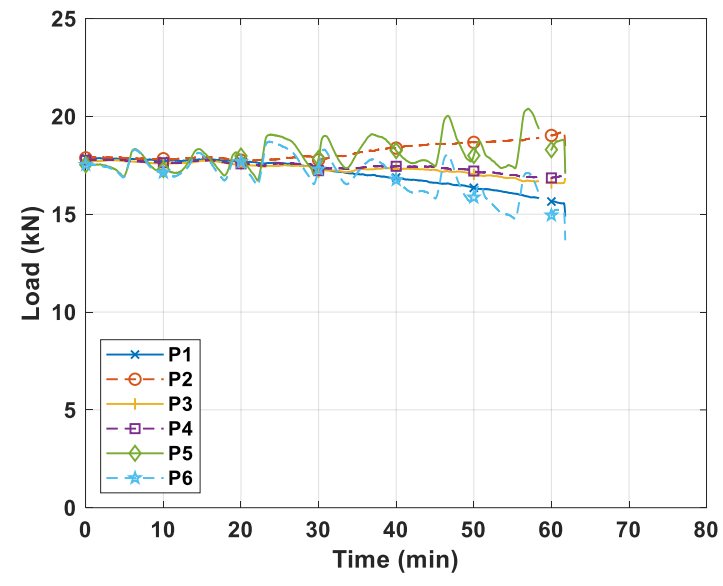

(b)

Figure 57 (a) Rotations of three loading trusses placed on top of the concrete and (b) six-point loads during fire loading, where P1 through P6 are the point loads from east to west ends (CB-DA-SC).

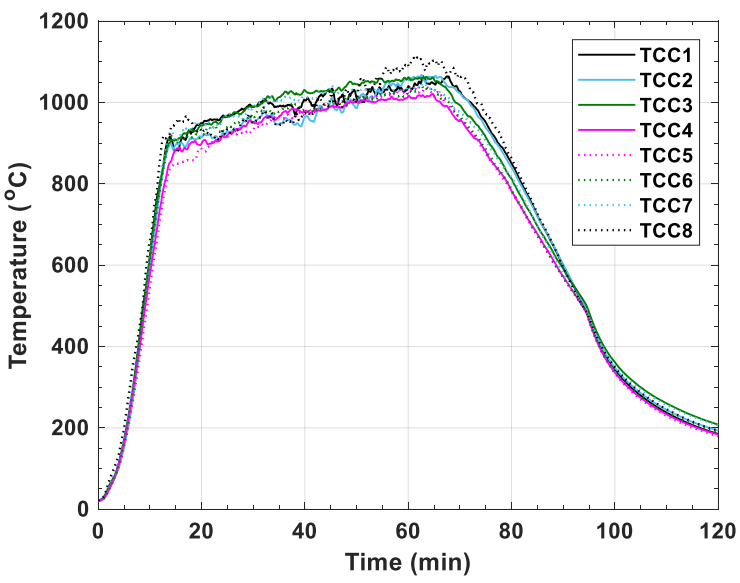

(a)

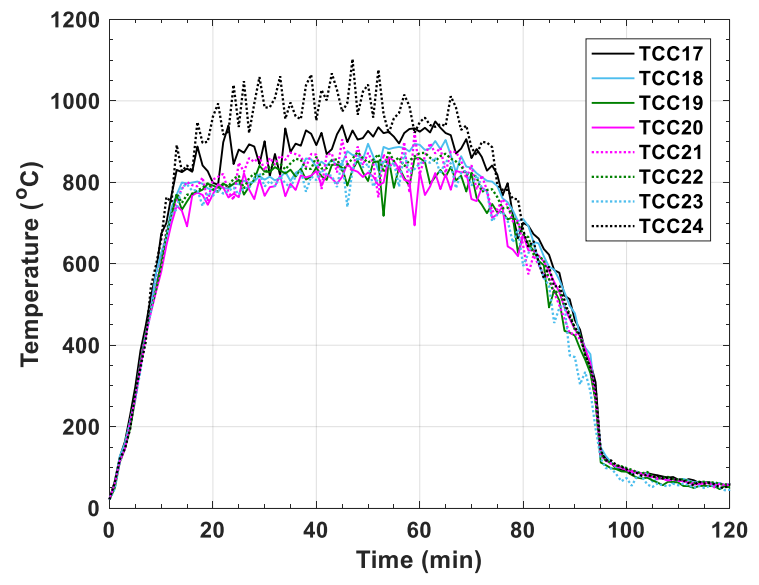

(b)

Figure 58 Gas temperature data of CB-DA-SC: (a) $81 \mathrm{~cm}$ below exposed steel decking and (b) above vent openings outside of the test compartment. 


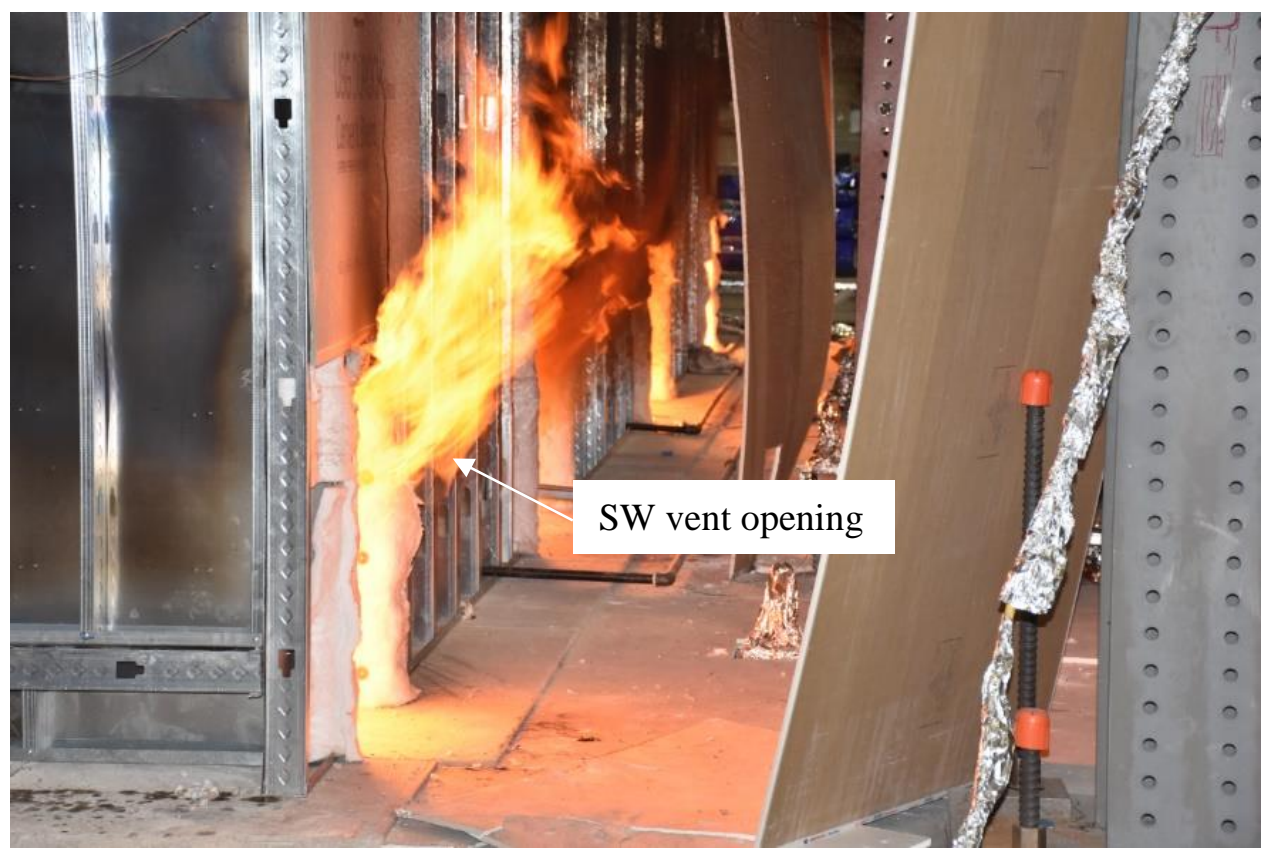

Figure 59 Photograph of flames coming out from vent openings of the south compartment wall during fire loading (CB-DA-SC). 


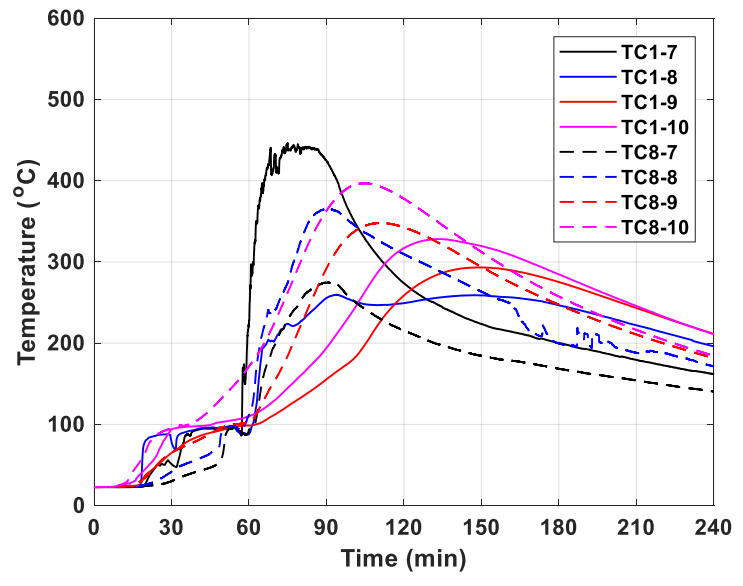

(a)

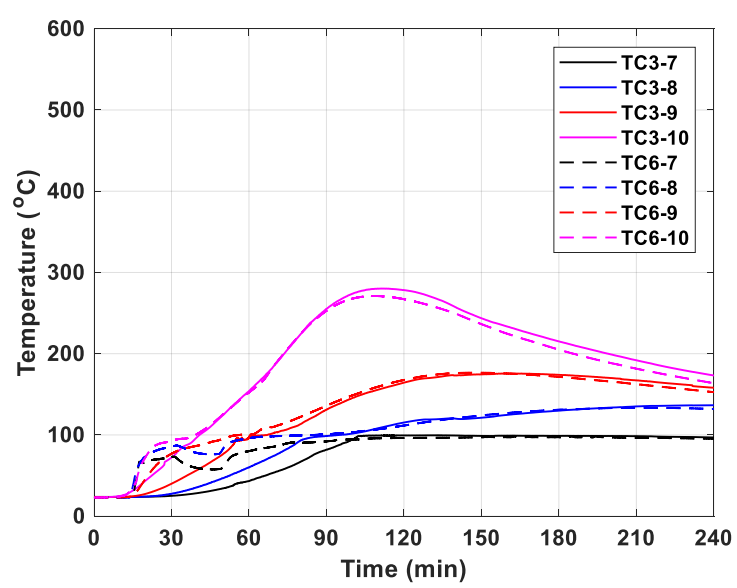

(c)

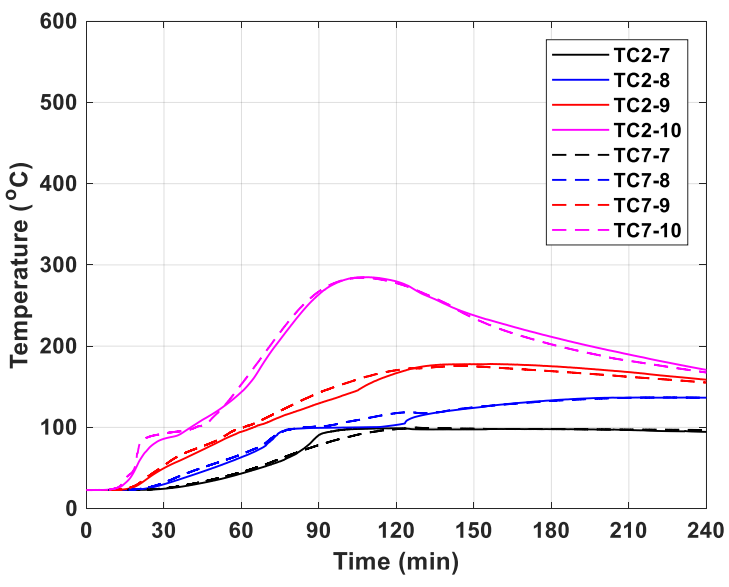

(b)

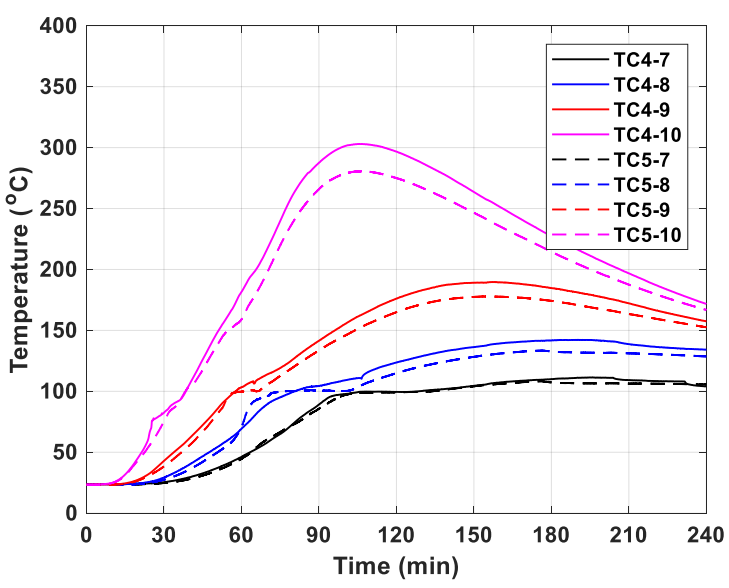

(d)

Figure 60 Concrete temperature along the longitudinal centerline of CB-DA-SC: (a) sections TC1 and TC8, (b) sections TC2 and TC7, (c) sections TC3 and TC6, and (d) sections TC4 and TC5. 


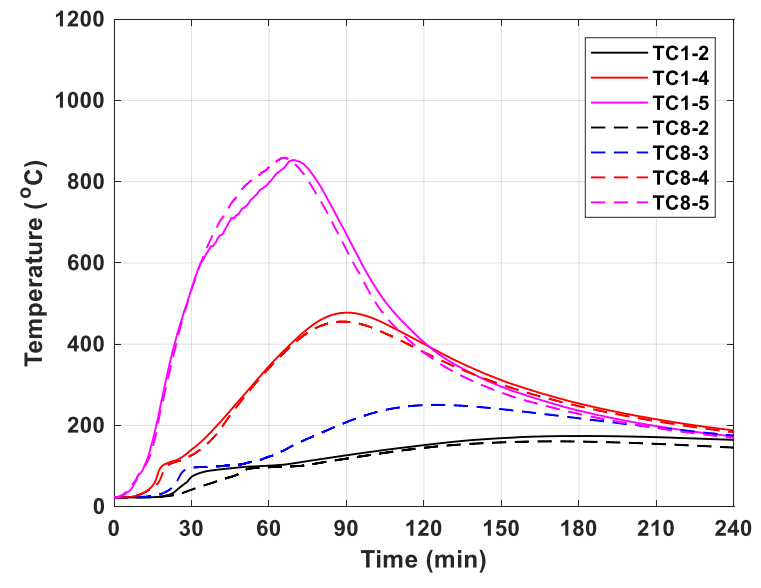

(a)

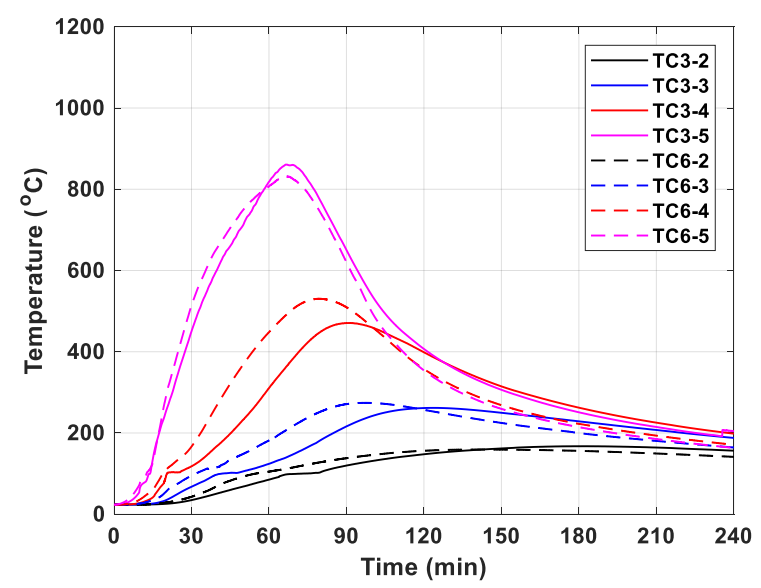

(c)

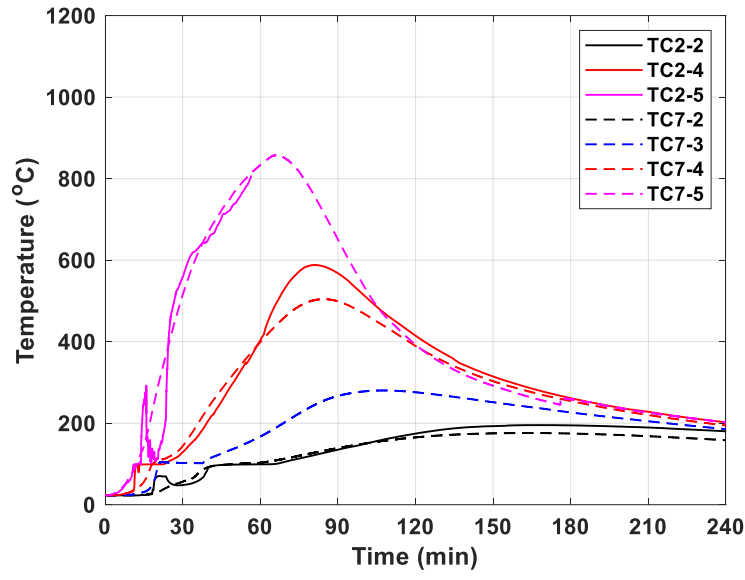

(b)

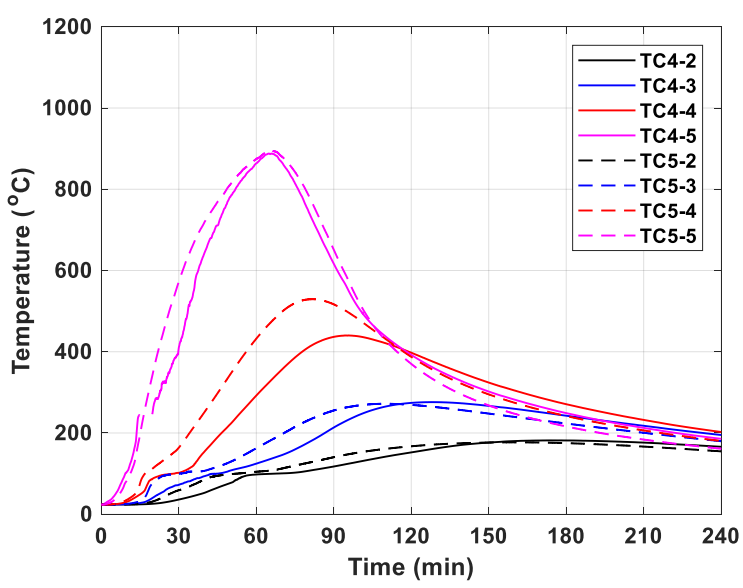

(d)

Figure 61 Concrete temperature measured $45.7 \mathrm{~cm}$ from the north edge of CB-DA-SC: (a) sections TC1 and TC8, (b) sections TC2 and TC7, (c) sections TC3 and TC6, and (d) sections TC4 and TC5. 


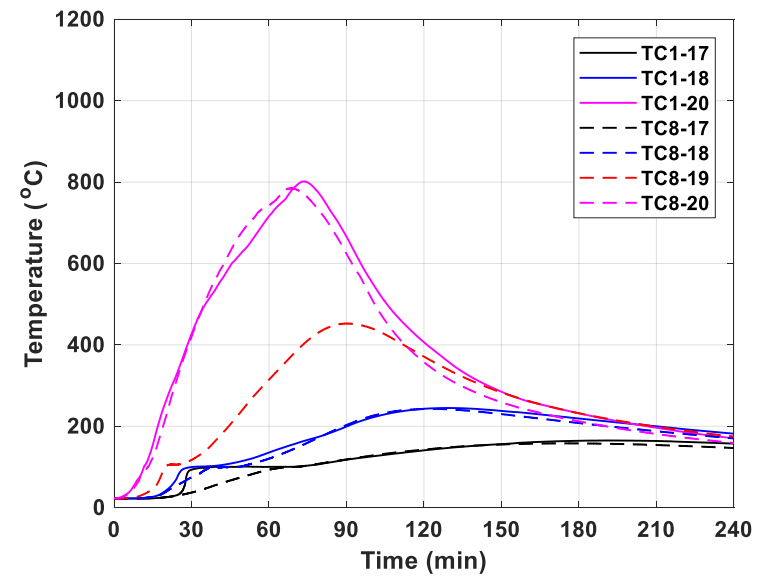

(a)

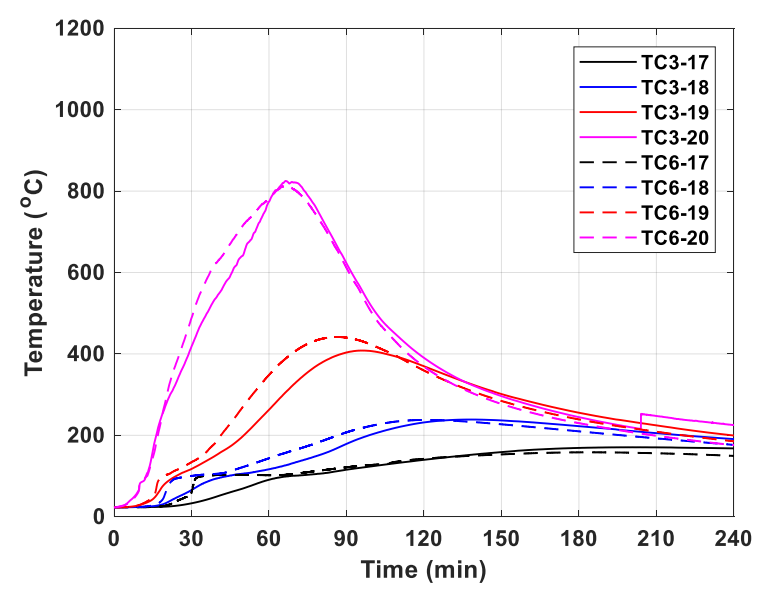

(c)

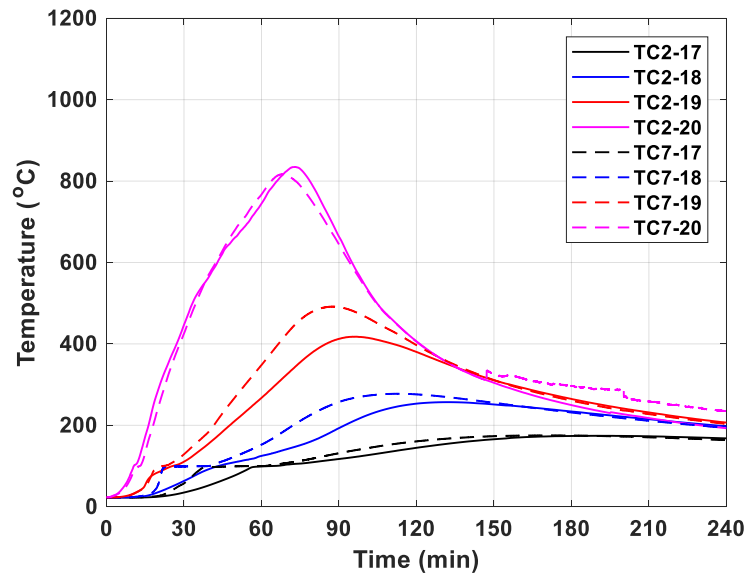

(b)

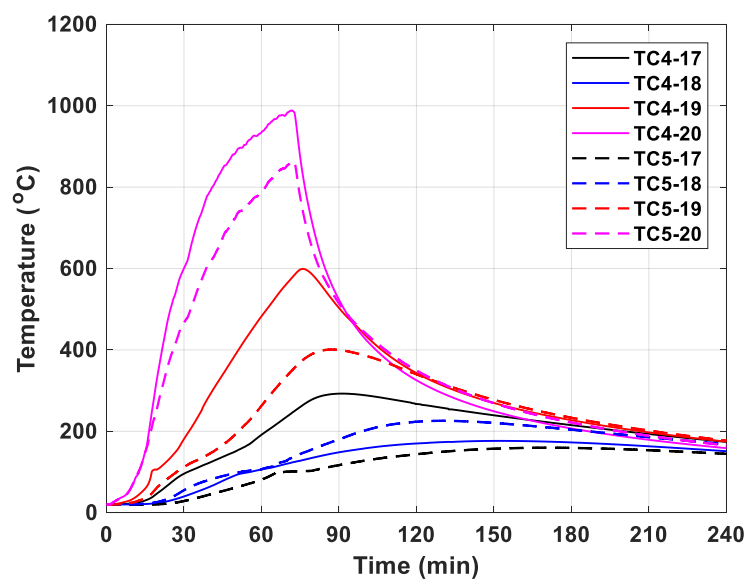

(d)

Figure 62 Concrete temperature measured $45.7 \mathrm{~cm}$ from the south edge of CB-DA-SC: (a) sections TC1 and TC8, (b) sections TC2 and TC7, (c) sections TC3 and TC6, and (d) sections TC4 and TC5. 


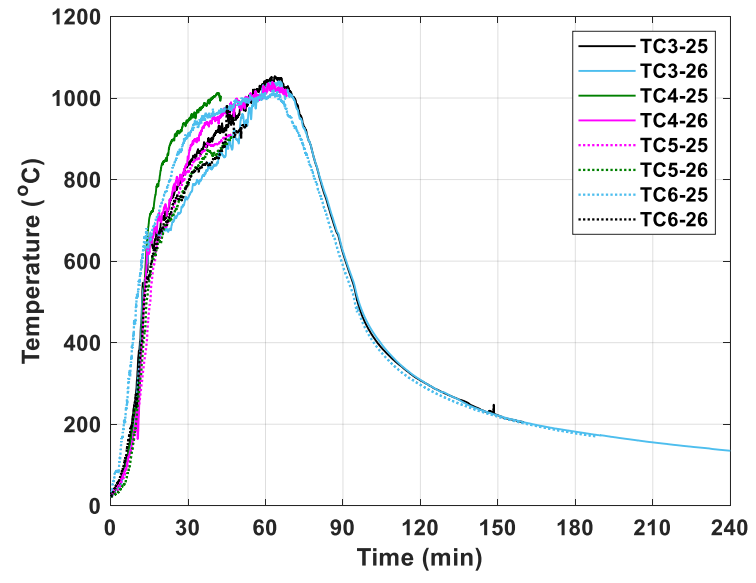

(a)

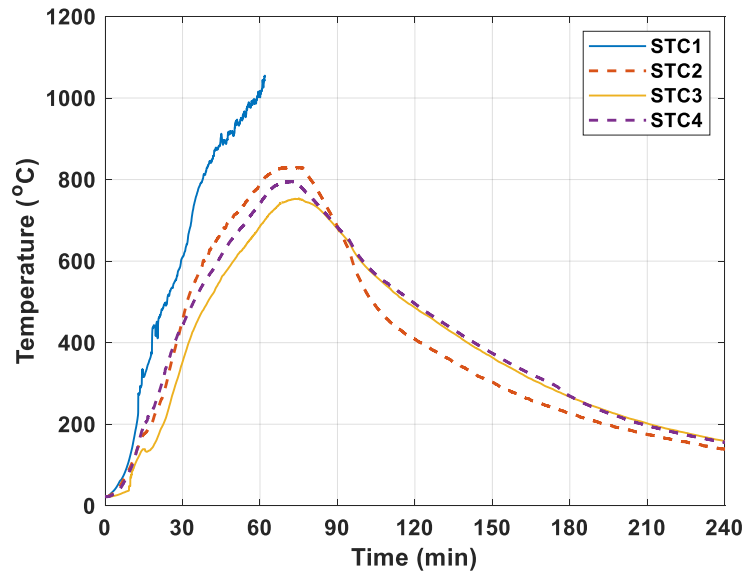

(b)

Figure 63 Temperatures of (a) exposed steel deck and (b) bottom flange temperature for CB-DA-SC. Discontinuity of data indicates dislodging of thermocouples.

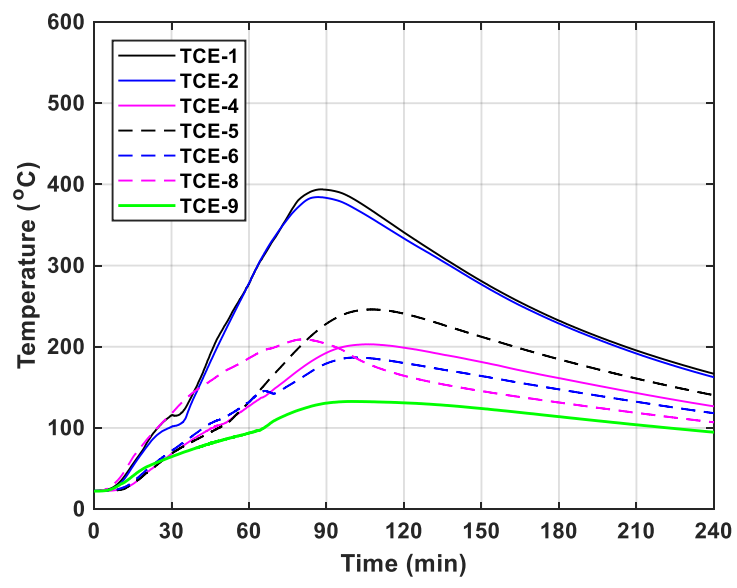

(a)

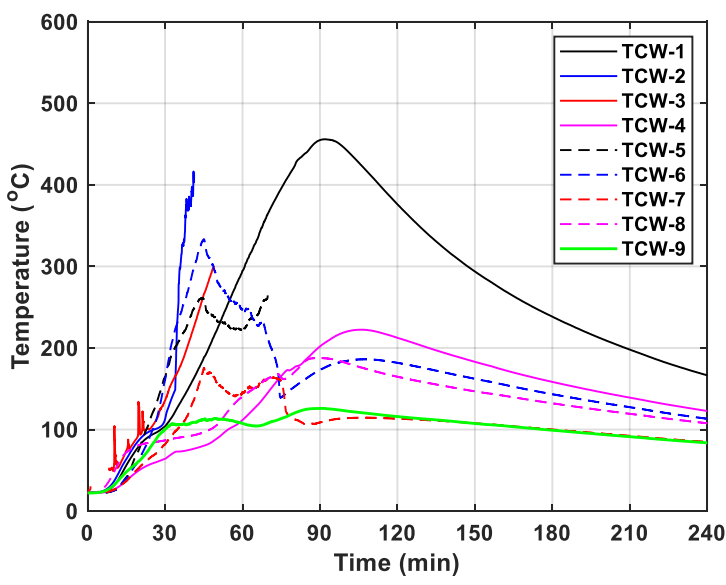

(b)

Figure 64 Temperatures of (a) east and (b) west connection region for CB-DA-SC. Discontinuity of data indicates dislodging of thermocouples. 


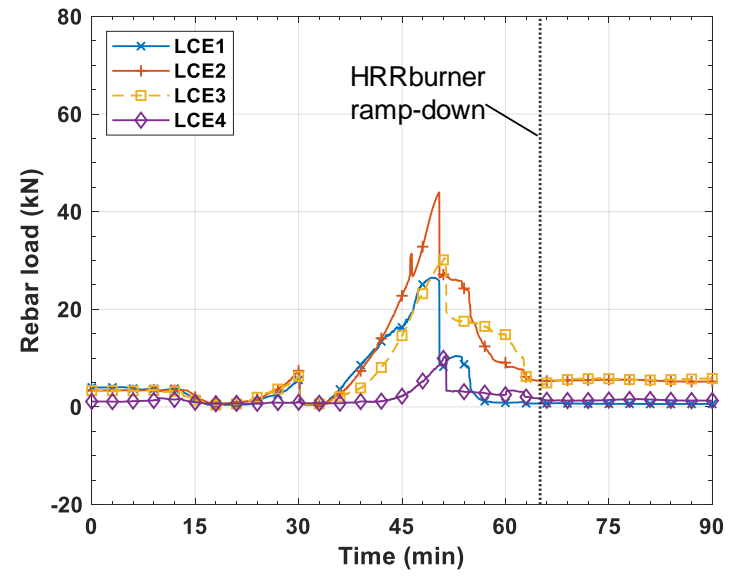

(a)

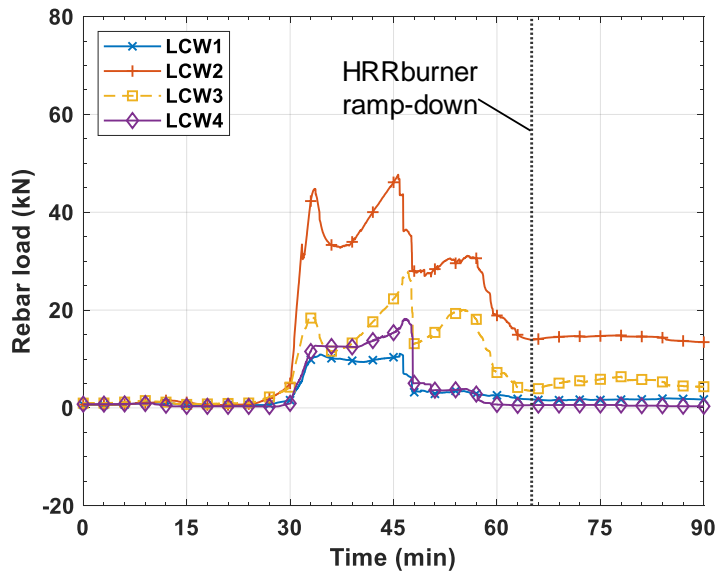

(b)

Figure 65 Tensile loads on No. 4 reinforcing bars anchored at (a) east and (b) west end (CB-DA-SC).

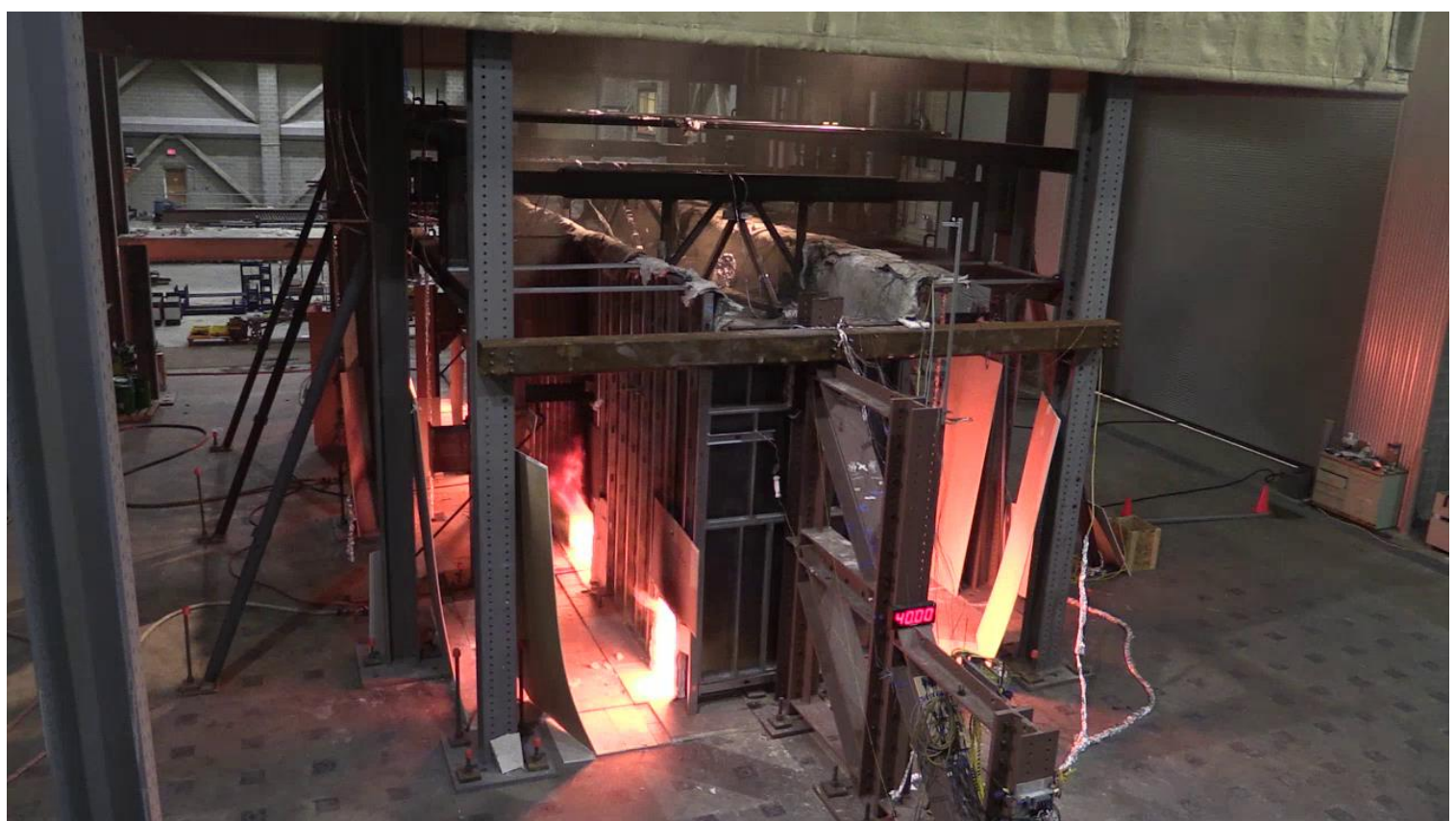

Figure 66 Still image of a video viewing the outside of the test compartment at $40 \mathrm{~min}$ after the burner ignition (CB-DA-SC). 


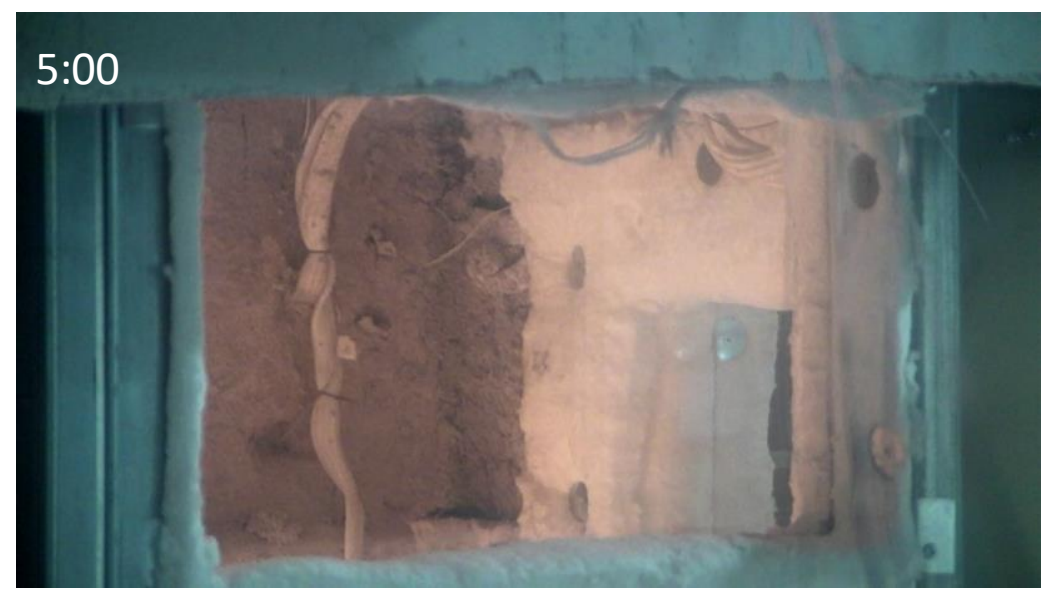

(a)

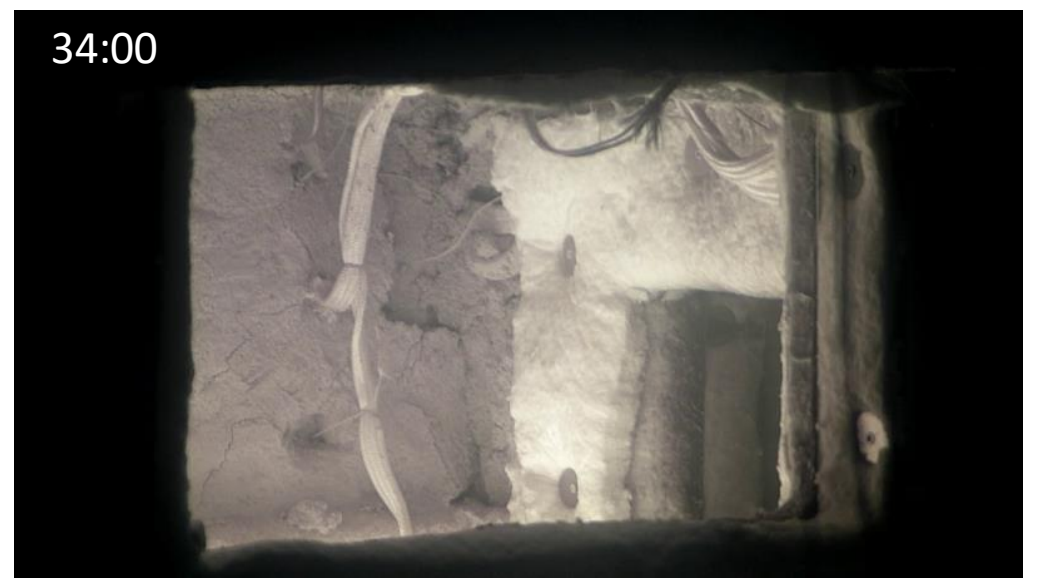

(b)

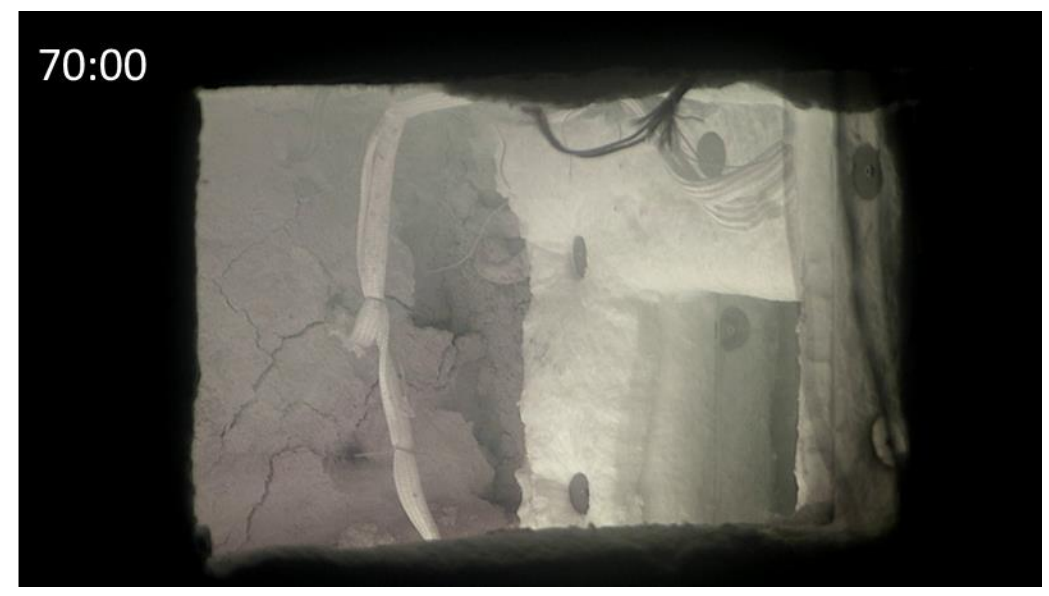

(c)

Figure 67 Still images of a video viewing the east connection region for CB-DA-SC. Time (min: sec) is recorded after the fire was ignited. 


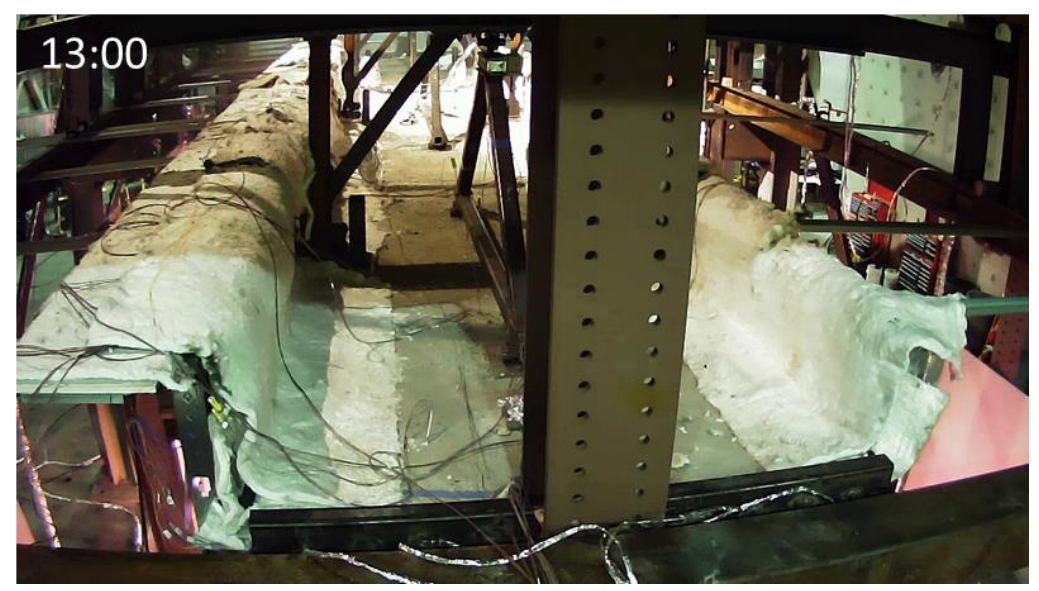

(a)

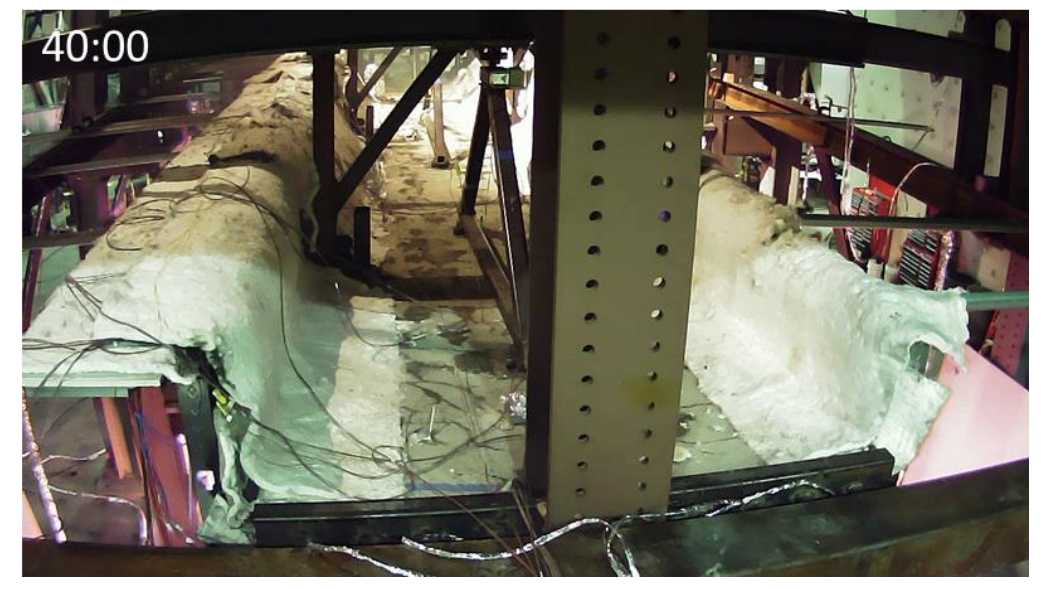

(b)

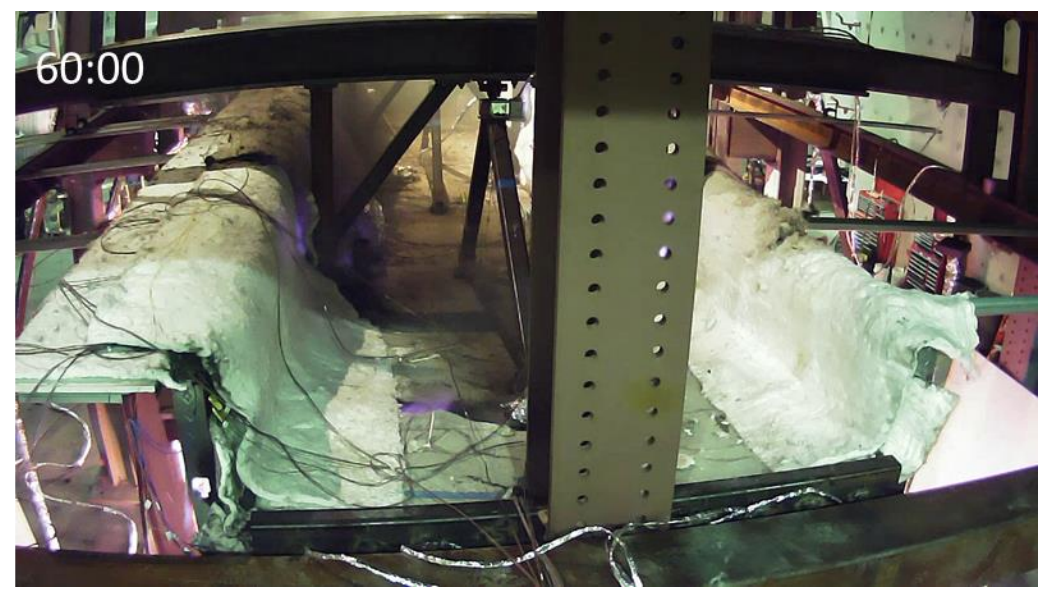

(c)

Figure 68 Still images of a video viewing top of the concrete near the east column for CB-DA-SC. Time (min: sec) is recorded after the fire was ignited. 


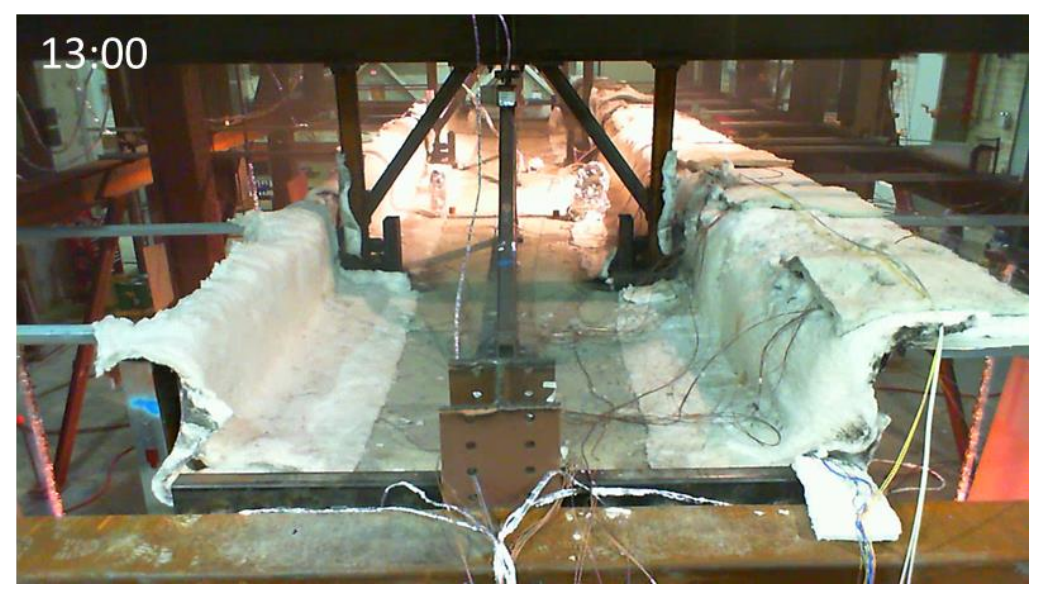

(a)

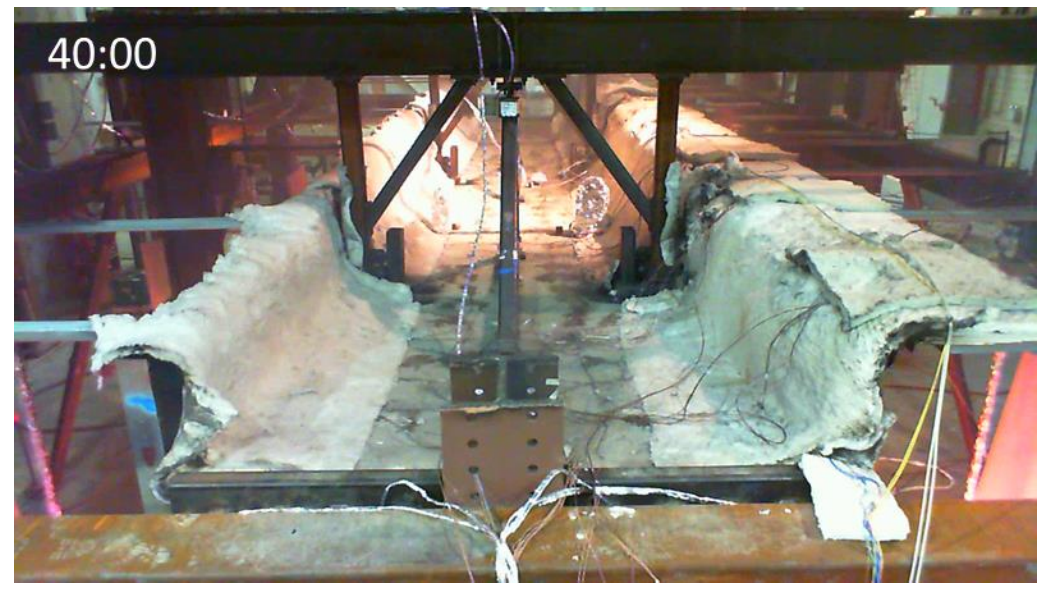

(b)

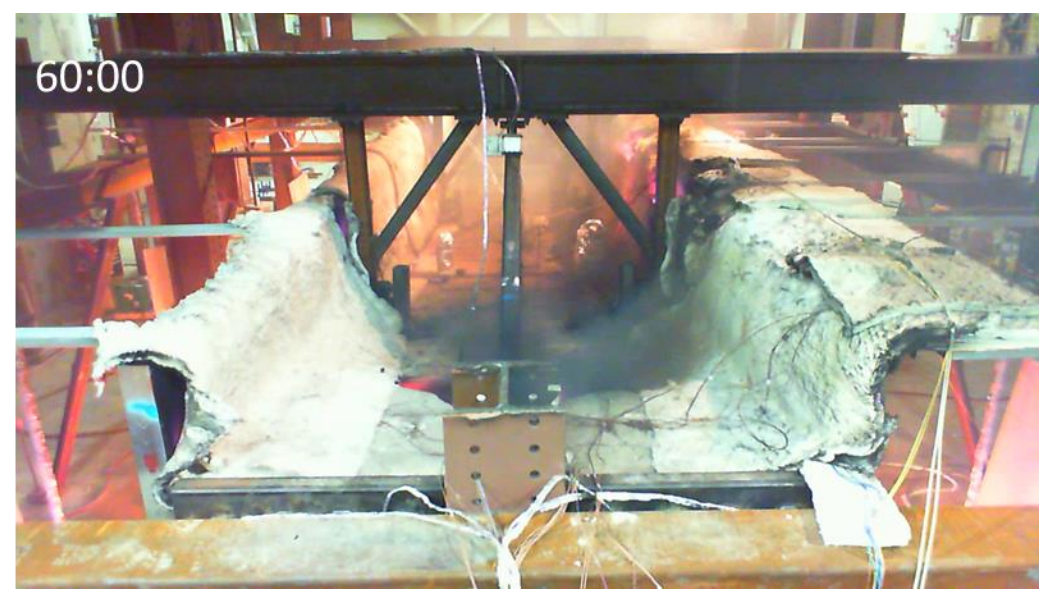

(c)

Figure 69 Still images of a video viewing top of the concrete near the west column for CB-DA-SC. Time (min: sec) is recorded after the fire was ignited. 


\section{B.4 Post-Test Conditions}

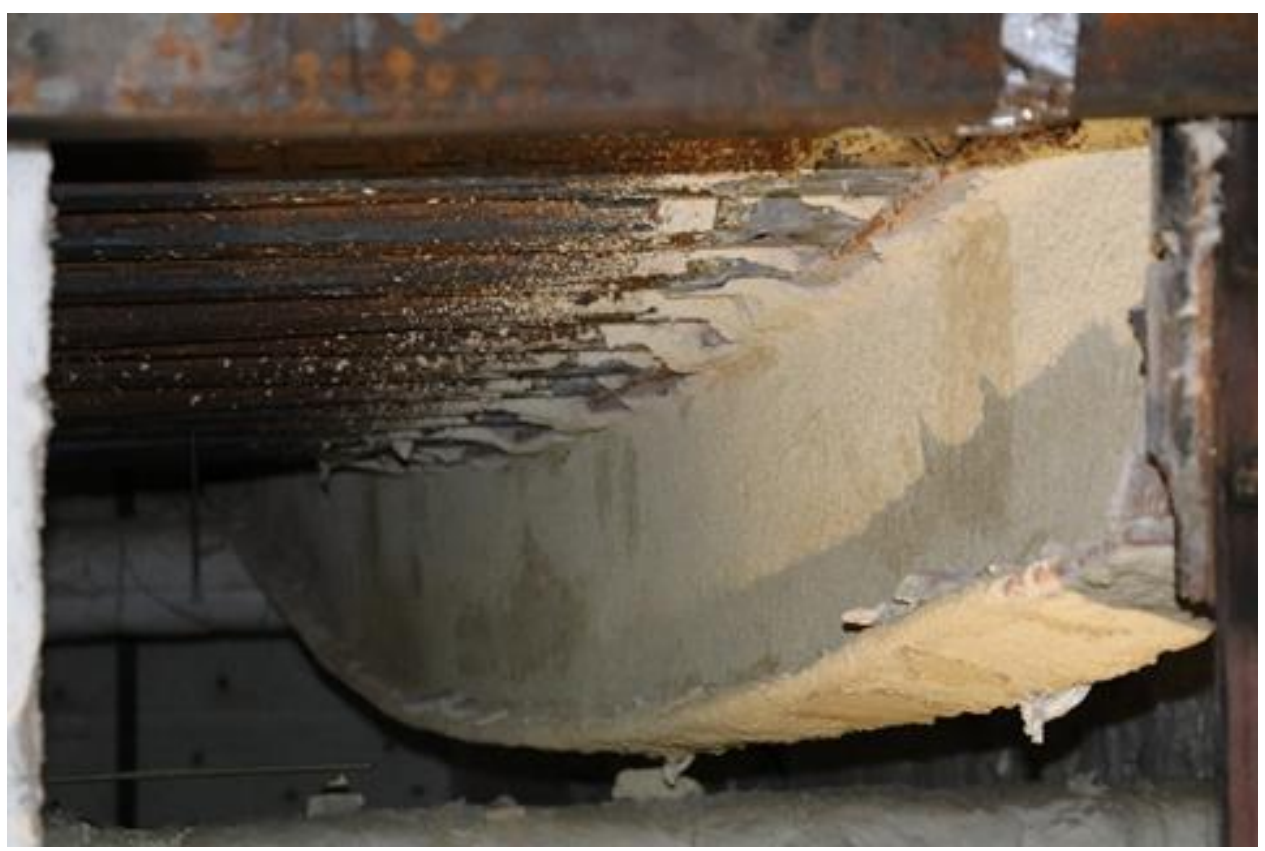

(a)

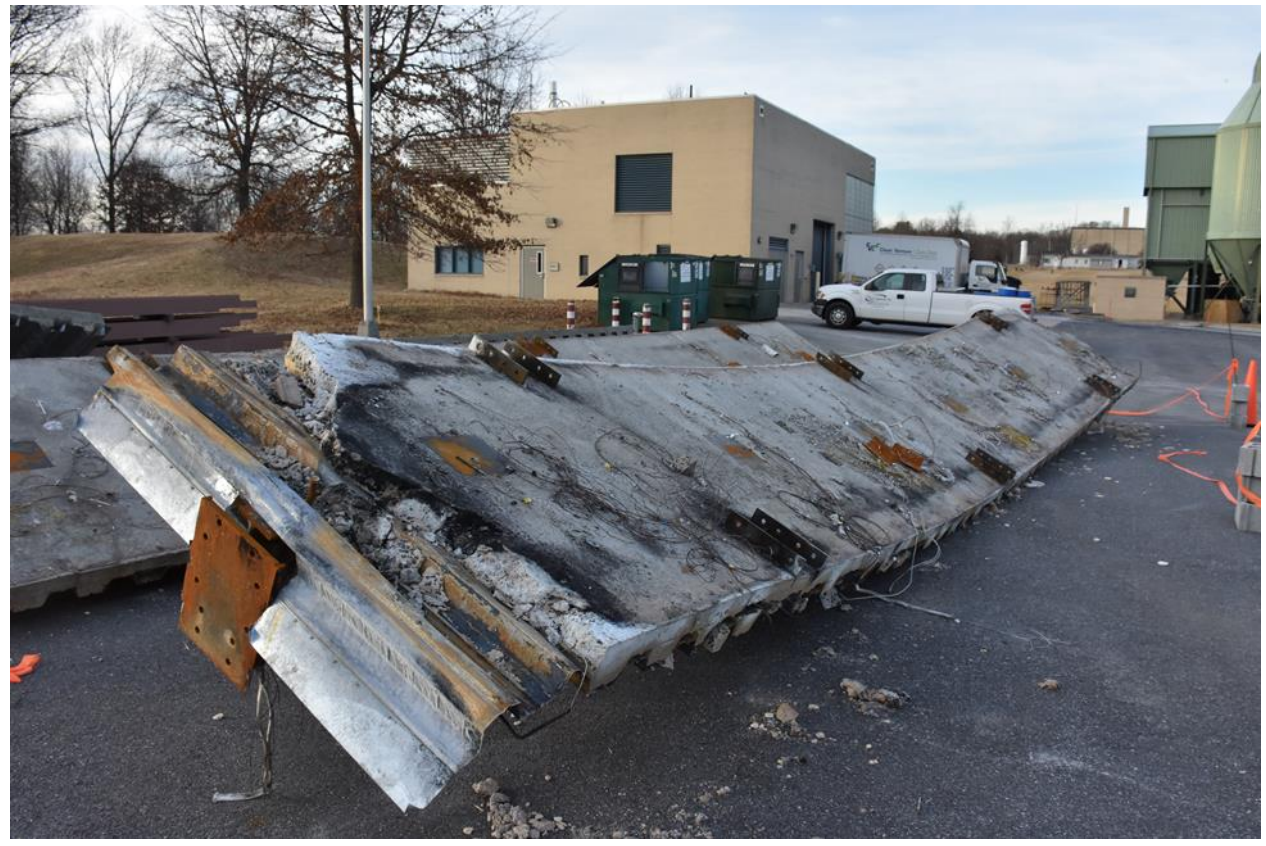

(b)

Figure 70 Photographs of (a) deflected shape of the steel beam covered with SFRM inside the test compartment, and (b) deformation of the concrete slab after cooling (CB-DA-SC) 


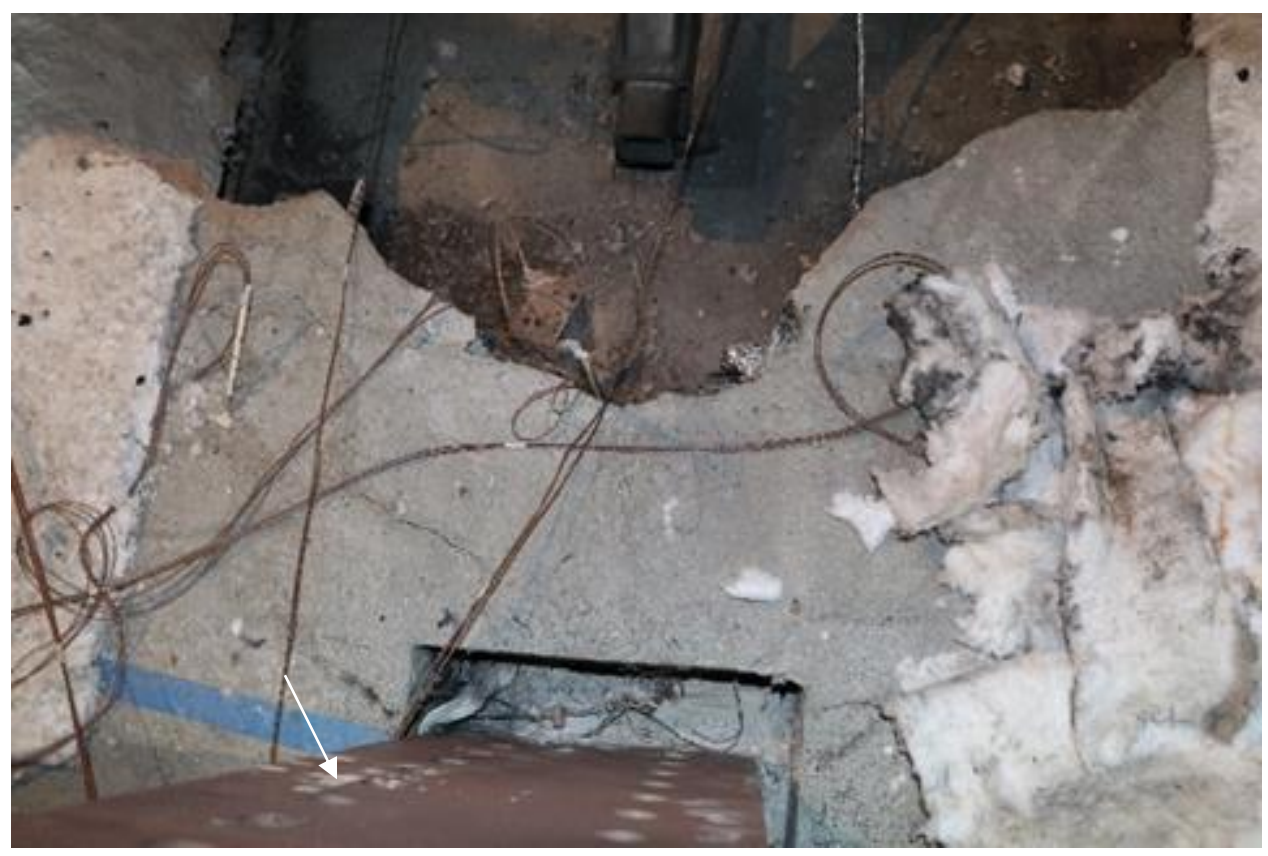

Figure 71 Photograph of concrete fracture and separation near the east column after the angle connection failed during cooling (CB-DA-SC).

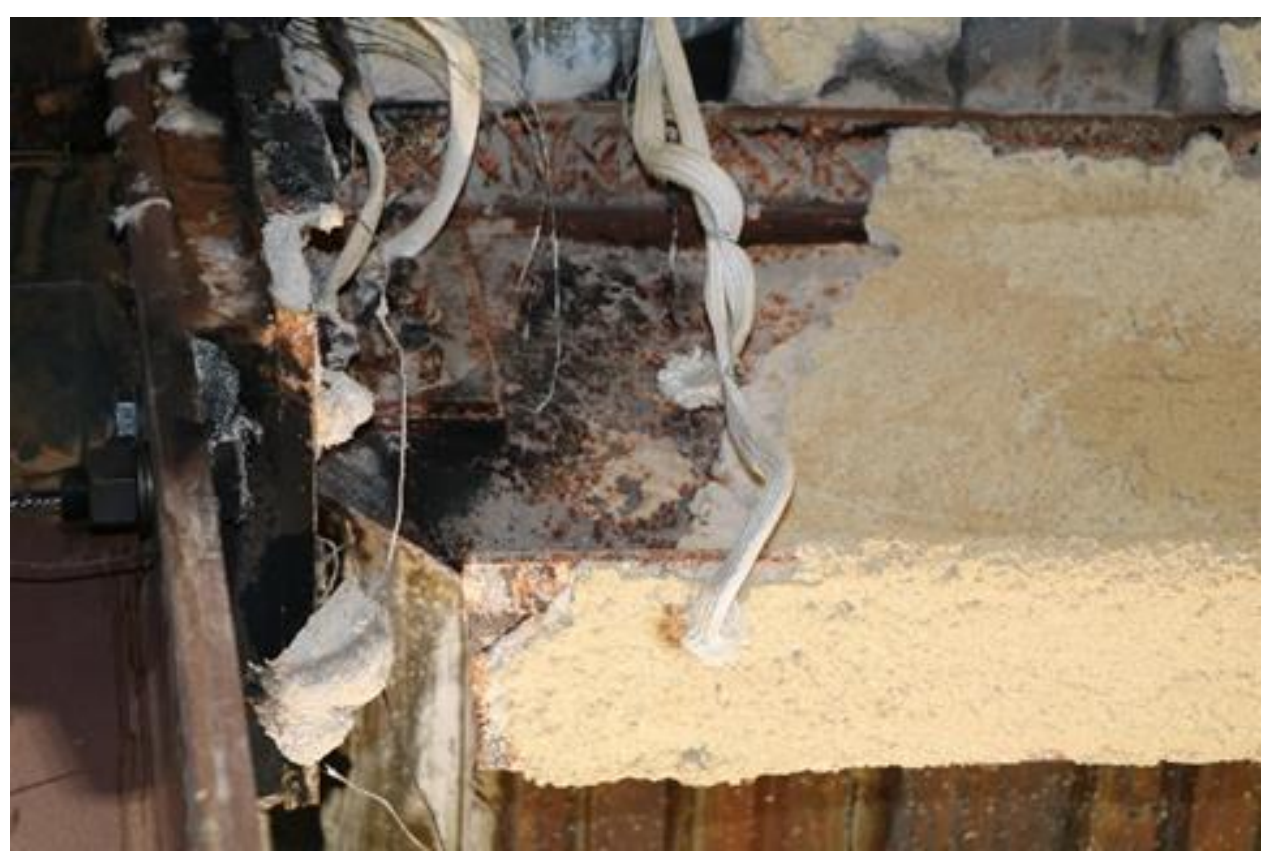

Figure 72 Photograph of local web buckling of the steel beam connected to the west column after cooling (CB-DA-SC). 


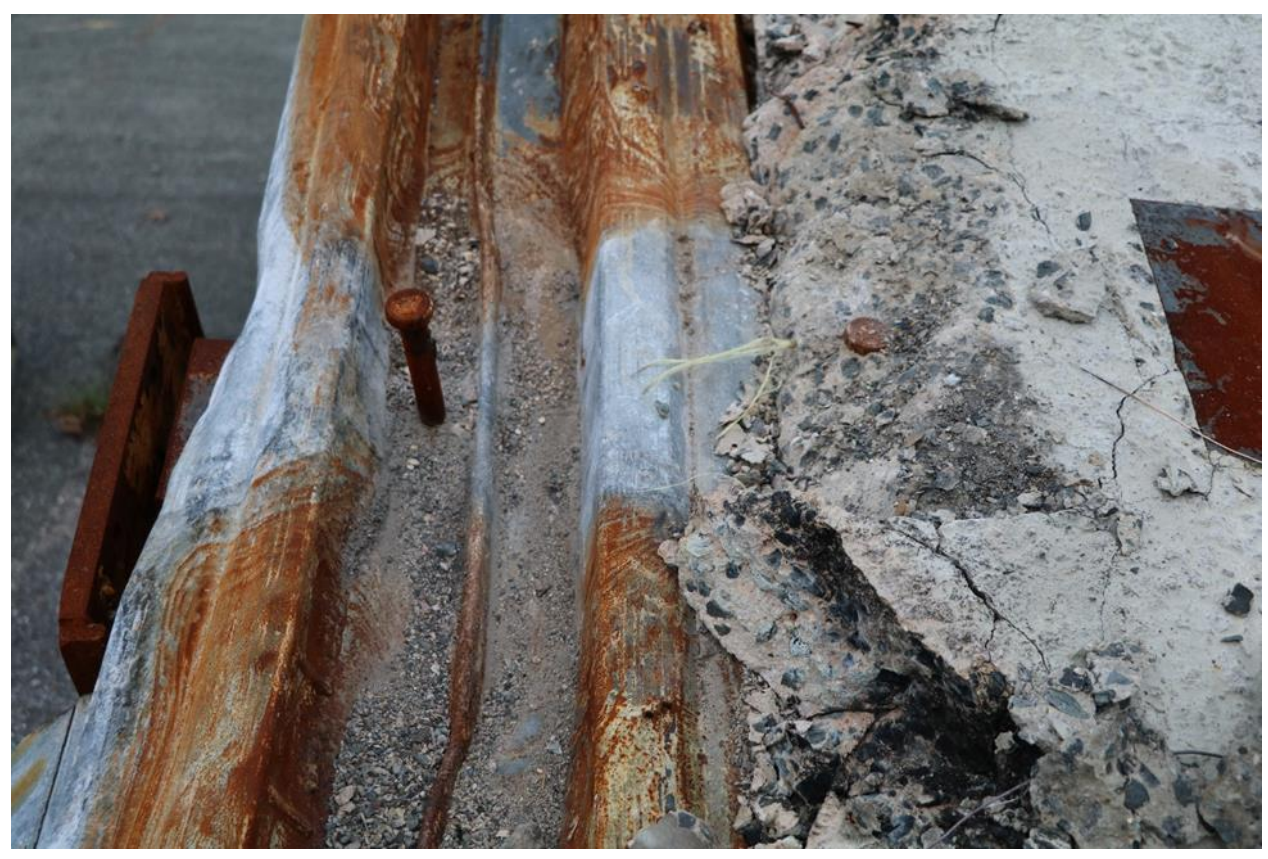

Figure 73 Photograph of shear studs at the west end after cooling (CB-DA-SC). 


\section{Appendix $C$ \\ SPECIMEN CB-SP}

\section{C.1 Test Information}

Test Date:

Record Start Time:

Program Version:

Test Name:

Test Series information:

Peak HRR (kW)

Total HRR (MJ)

Oxygen Drift (ppmv)

Baseline Hood Flow

$(\mathrm{kg} / \mathrm{s})$
2/13/2018 (Concrete placement: 12/6/2016)

1:07:10 PM

MIDAS.exe Ver. 2.124.0.707

CB-SP

- A $12.8 \mathrm{~m}$ span composite beam specimen supported by sheartab connections.

- No slab continuity reinforcement was present.

- Both unloading of hydraulic actuators and the burner extinguishment were achieved manually following failure of the east connection.

4139

12618

$-9$

75.360

\section{C.2 Test Procedure and Observations}

Table 16 Test procedure and observations for CB-SP. Test time was recorded after the burner ignition and rounded to the nearest 1 min.

\begin{tabular}{cll}
\hline Time (min) & \\
\hline & - & \multicolumn{1}{c}{ Description } \\
0 & - & $\begin{array}{l}\text { The total heat release rate of the natural gas fueled burners (HRRburner) } \\
\text { started increasing. }\end{array}$ \\
15 & - HRRburner reached a target value of $4000 \mathrm{~kW}$. \\
40 & - Local buckling of the steel beam occurred near the shear connections. \\
65 & - The test beam collapsed by weld failure in the east shear tab. \\
& - Both mechanical loading and fire were removed manually.
\end{tabular}

- As shown in Figure 74a, loads applied using SE and NE actuators fluctuated due to a servovalve problem similar to that observed in the testing of CB-DA. The standard deviation of the summed value (LoadNE+LoadSE) was almost $7 \%$ over time. Loads applied using other 
coupled actuators appeared to be relatively steady during fire and the standard deviation was approximately $2 \%$.

- All coupled actuators maintained the same stroke length during fire loading (Figure 74a), implying negligible twisting of the test specimen.

- As shown in Figure 75, the rotation of east and west loading trusses (RotLT1 and RotLT3, respectively) diverged after $15 \mathrm{~min}$, resulting in unequal loads at six points. The timeaveraged value of six-point loads was $17.5 \mathrm{kN}$ (estimated for a period of $72 \mathrm{~min}$ ). The maximum standard variation was $3.5 \mathrm{kN}$ before unloading.

- The upper layer gas temperature within the compartment (Figure 76a), measured $81 \mathrm{~cm}$ below exposed steel decking, reached a maximum value of $(1055 \pm 20){ }^{\circ} \mathrm{C}$ before the fire was extinguished at $65 \mathrm{~min}$. The value after \pm symbol is the standard deviation of temperatures measured using TCC1 through TCC8.

- The temperature measured using thermocouples mounted outside of the test compartment above the vent openings was in the range of $800{ }^{\circ} \mathrm{C}$ to $900{ }^{\circ} \mathrm{C}$ while the HRRburner value was steady at $4000 \mathrm{~kW}$ from 15 min to 65 min (Figure $76 \mathrm{~b}$ ). TCC 24 was about $100{ }^{\circ} \mathrm{C}$ lower.

- Figure 77 shows the concrete temperatures in the slab directly above the W18 335 beam. The following sensors may have been faulty: TC2-all, TC3-all, TC4-all.

- Figure 78 and Figure 79 show that the north and south side of the slab $(45.7 \mathrm{~cm}$ from the longitudinal centerline of the specimen) developed a consistent thermal gradient through the depth of the concrete. The bottom of the concrete slab (above exposed steel deck) reached a maximum value of $900{ }^{\circ} \mathrm{C}$ on average. The maximum temperature of the unexposed surface never exceeded $150{ }^{\circ} \mathrm{C}$ during heating and $200{ }^{\circ} \mathrm{C}$ during cooling.

- Temperatures of exposed steel deck increased from 600 to over $1000{ }^{\circ} \mathrm{C}$ while the heat release rate was fixed at $4000 \mathrm{~kW}$ from $13 \mathrm{~min}$ to $65 \mathrm{~min}$ (Figure 80a).

- Figure $80 \mathrm{~b}$ shows temperatures of the protected steel beam measure using Inconel sheathed thermocouples. Temperatures of the bottom flange (STC1 through STC4) and middle web (STC5 and STC7) reached nearly $750{ }^{\circ} \mathrm{C}$ on average at $65 \mathrm{~min}$. Temperature of the protected top flange was very low and deemed unreliable because of possible dislocation of thermocouple beads into the concrete slab.

- As shown in Figure 81, thermocouples mounted in the west connection region were dislodged before $60 \mathrm{~min}$. For the west connection region, temperatures of the web next to a shear tab increased to $500{ }^{\circ} \mathrm{C}$ and the temperature of the shear tab reached nearly $250{ }^{\circ} \mathrm{C}$ due to a thicker SFRM.

- Figure 82 and Figure 83 show additional views of the test specimen during the test.

- Figure 84 through Figure 86 are additional views of the post-test conditions of the test specimen. 


\section{C.3 Additional Data}

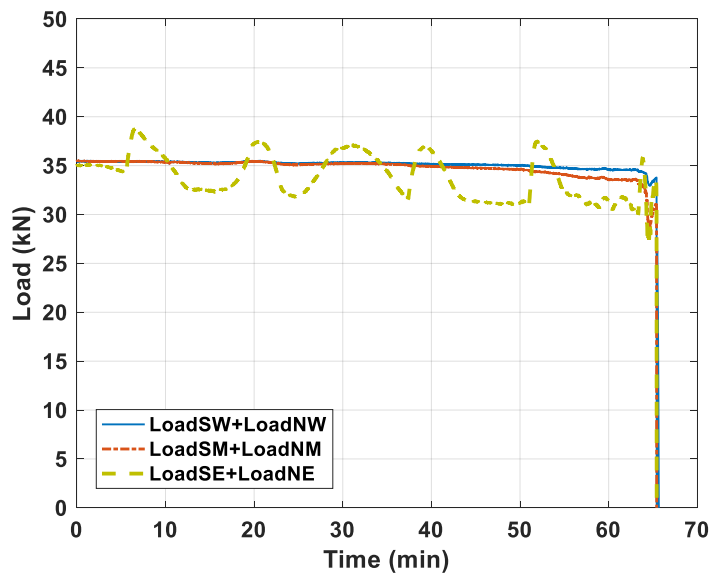

(a)

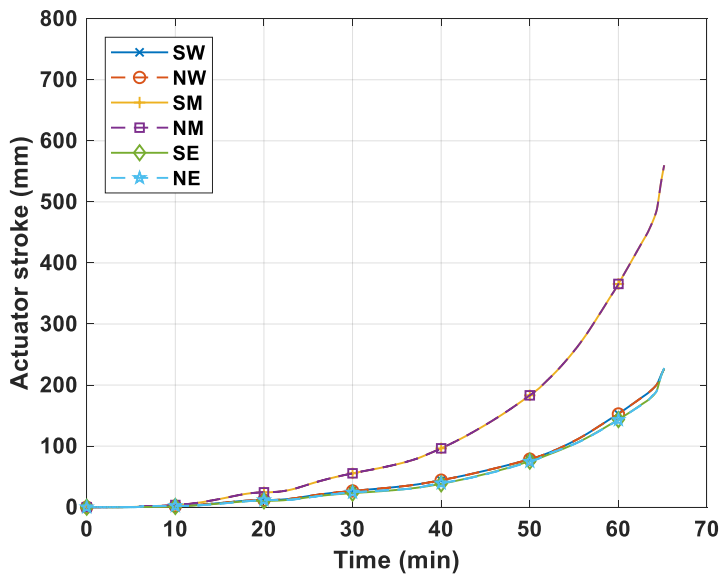

(b)

Figure 74 Actuator data of CB-SP: (a) loads and (b) stroke lengths applied using six actuators (SW, NW, SM, NM, SE, and NE). Actuator stroke was not recorded after unloading.

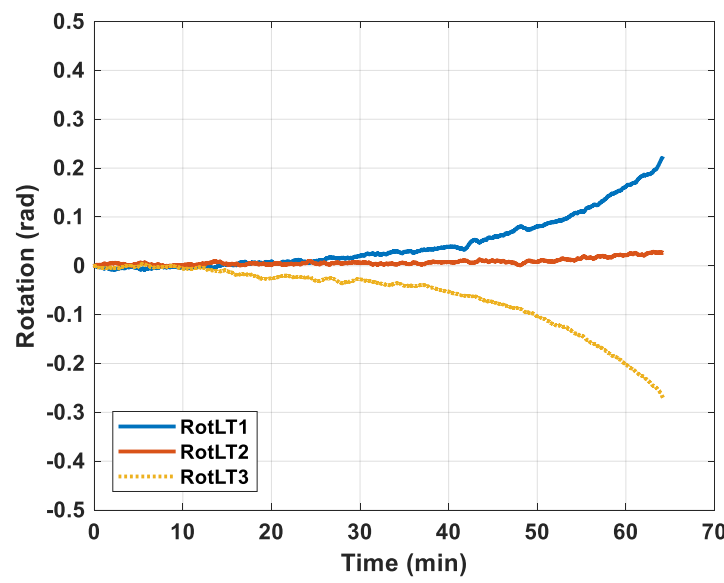

(a)

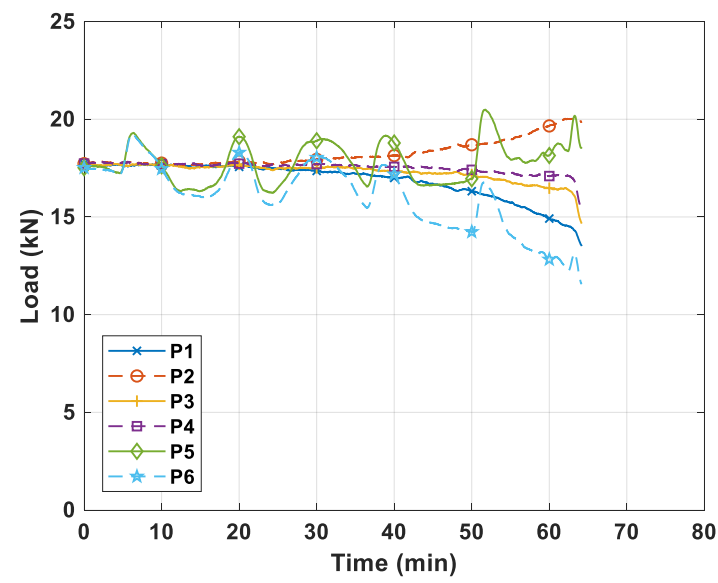

(b)

Figure 75 (a) Rotations of three loading trusses placed on top of the concrete and (b) six-point loads during fire loading, where P1 through P6 are the point loads from east to west ends (CB-SP). 


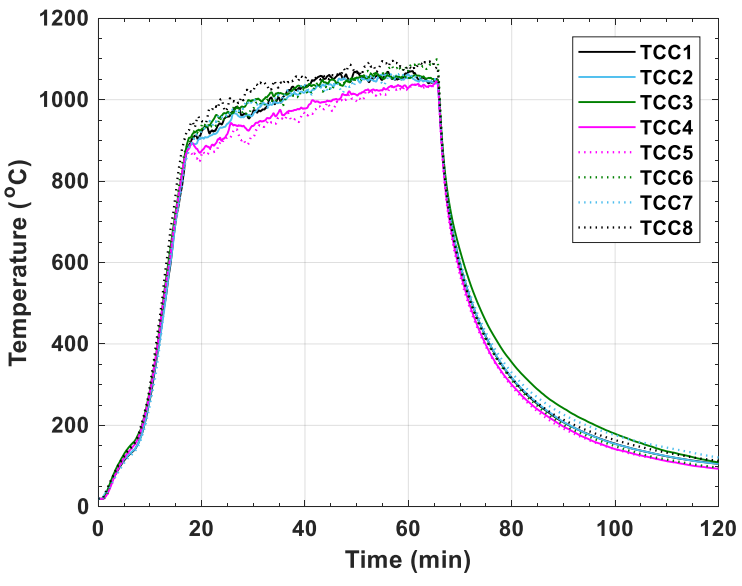

(a)

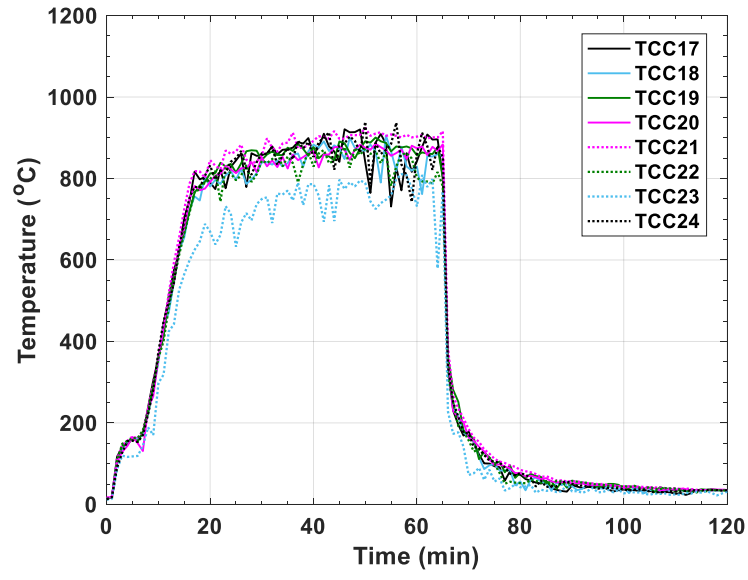

(b)

Figure 76 Gas temperature data of CB-SP: (a) $81 \mathrm{~cm}$ below exposed steel decking and (b) above vent openings outside of the test compartment. 


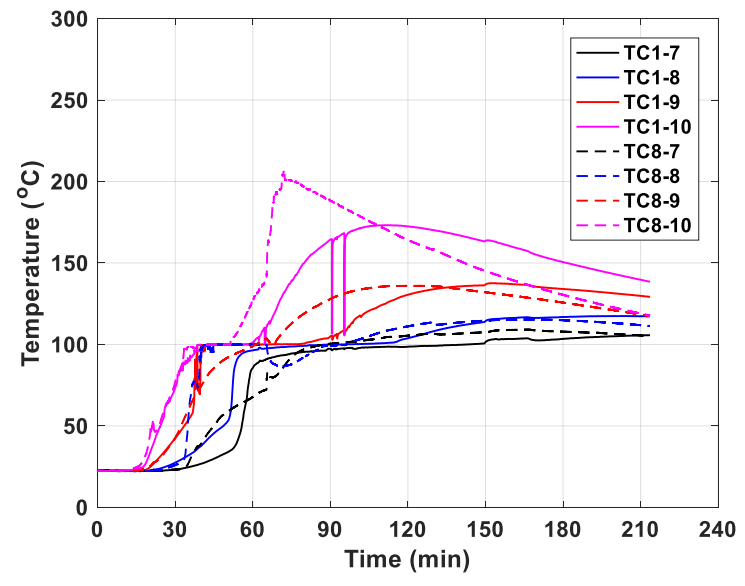

(a)

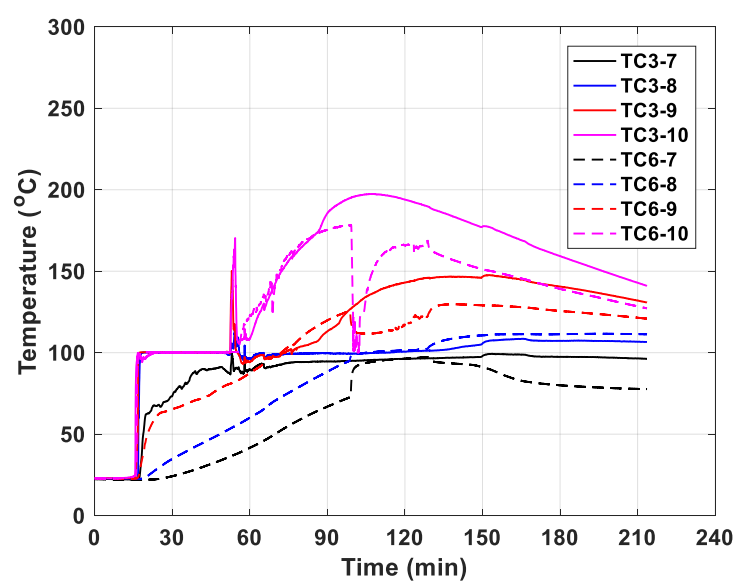

(c)

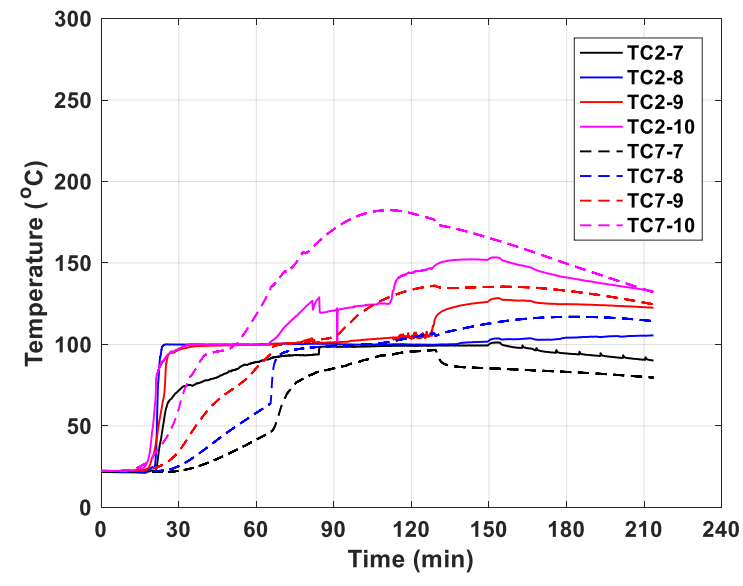

(b)

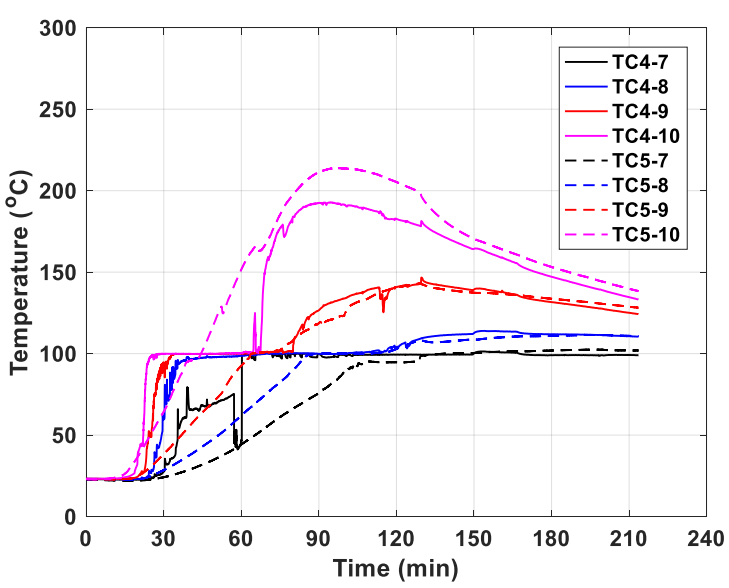

(d)

Figure 77 Concrete temperature along the longitudinal centerline of CB-SP: (a) sections TC1 and TC8, (b) sections TC2 and TC7, (c) sections TC3 and TC6, and (d) sections TC4 and TC5. 


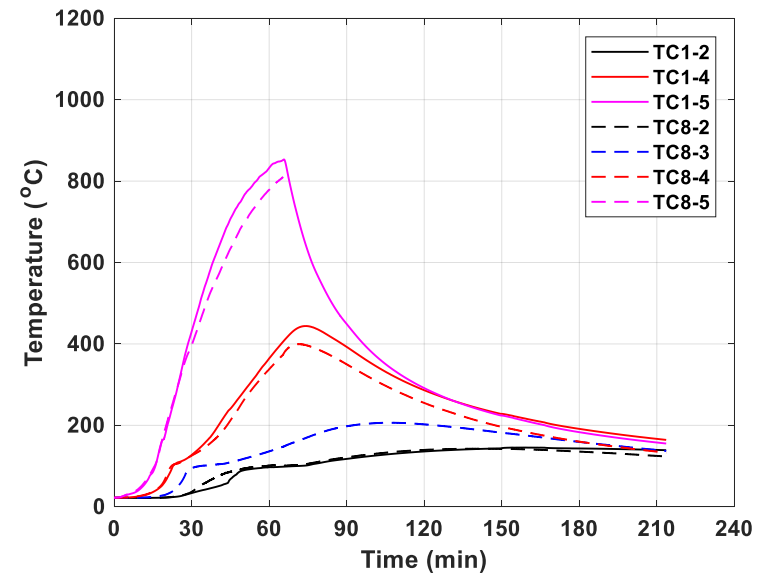

(a)

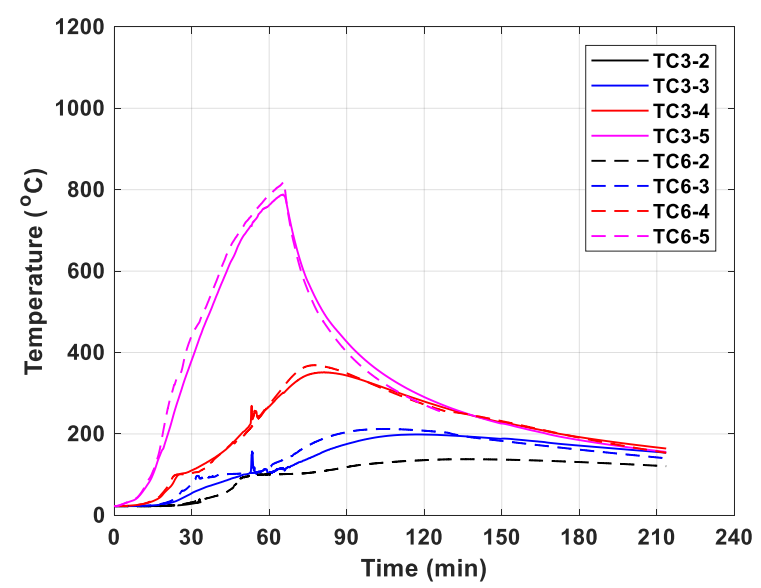

(c)

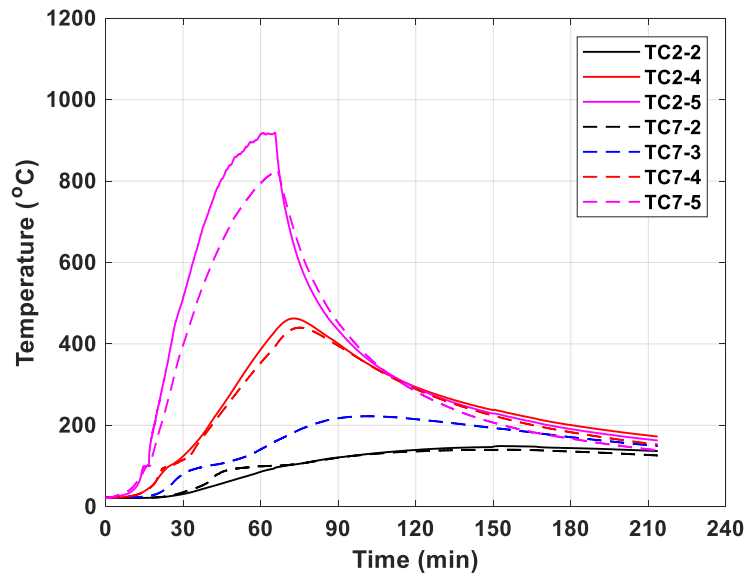

(b)

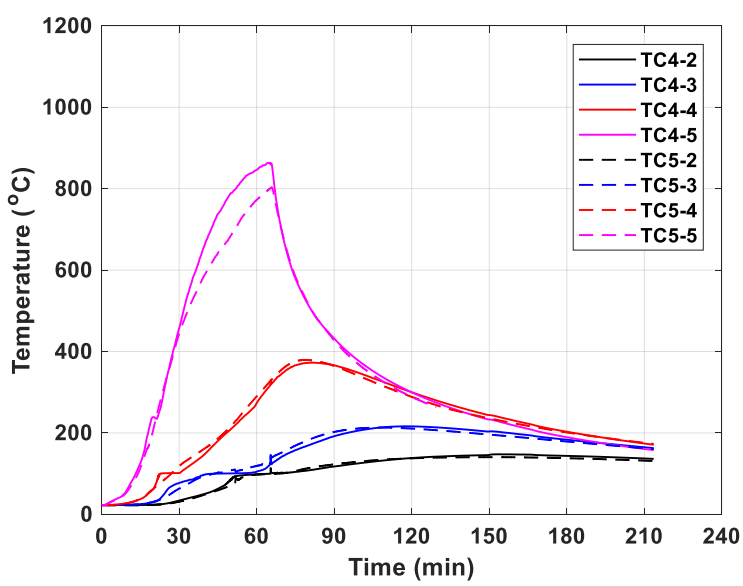

(d)

Figure 78 Concrete temperature measured $45.7 \mathrm{~cm}$ from the north edge of CB-SP: (a) sections TC1 and TC8, (b) sections TC2 and TC7, (c) sections TC3 and TC6, and (d) sections TC4 and TC5. 


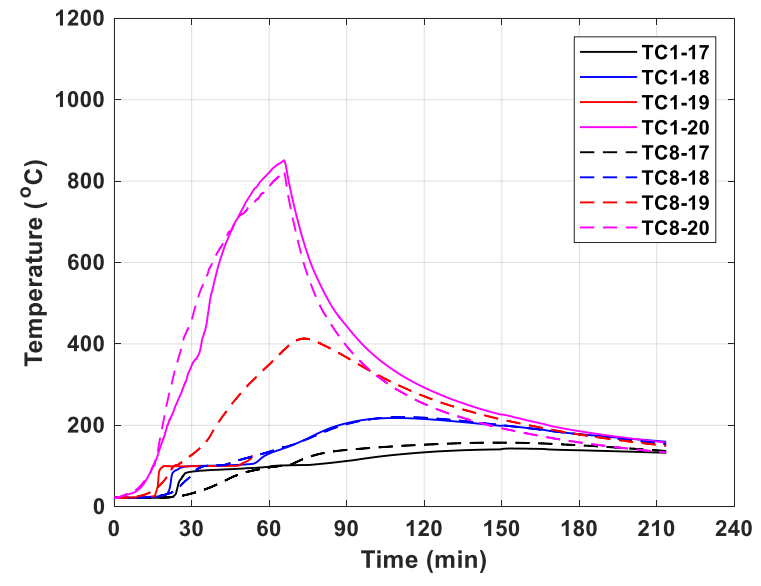

(a)

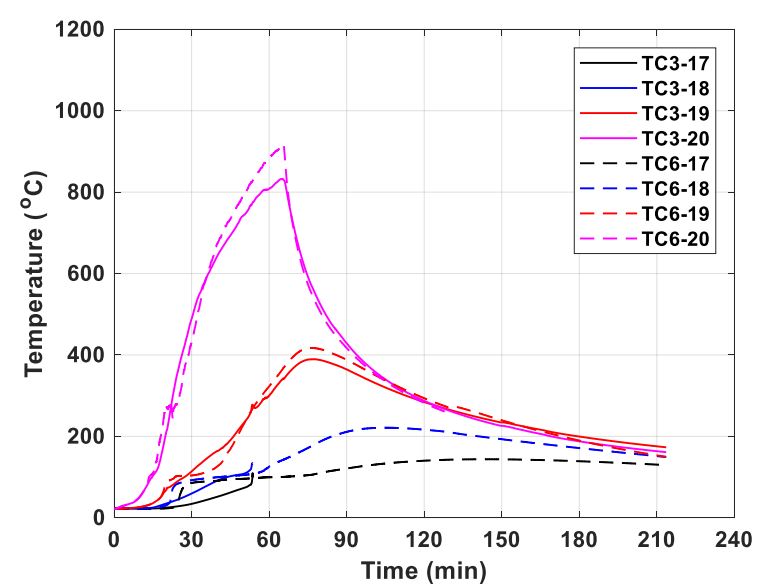

(c)

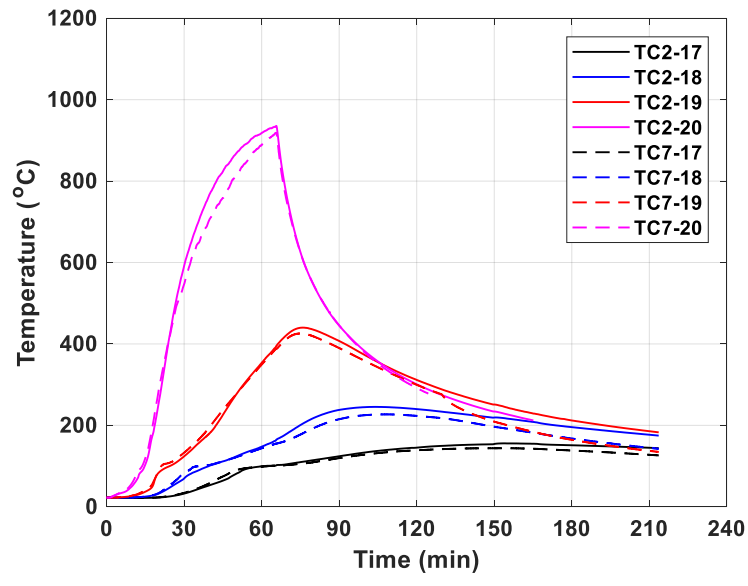

(b)

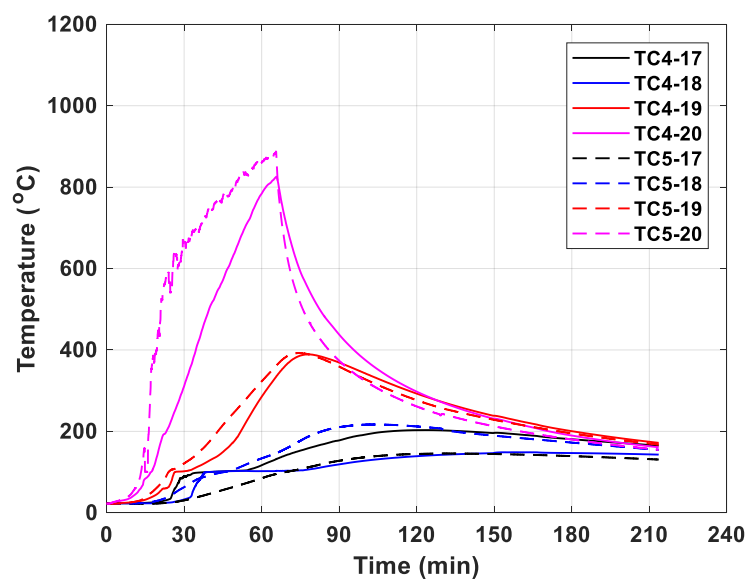

(d)

Figure 79 Concrete temperature measured $45.7 \mathrm{~cm}$ from the south edge of CB-SP: (a) sections TC1 and TC8, (b) sections TC2 and TC7, (c) sections TC3 and TC6, and (d) sections TC4 and TC5. 


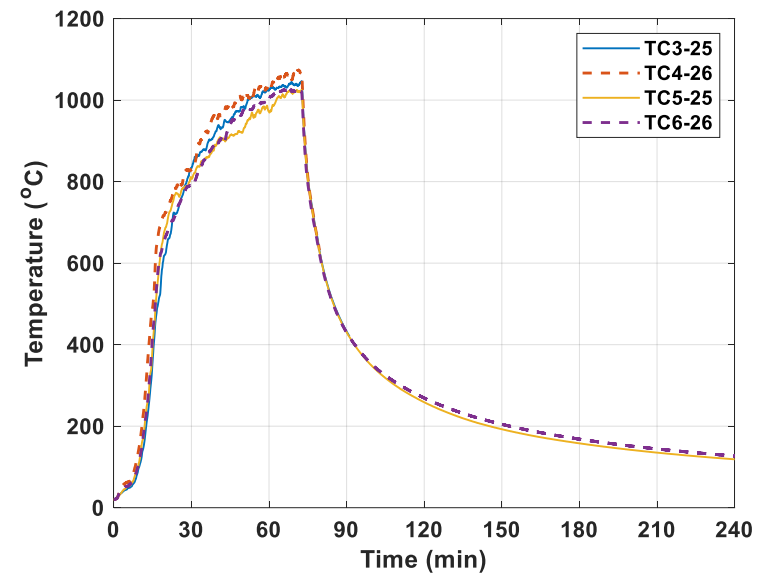

(a)

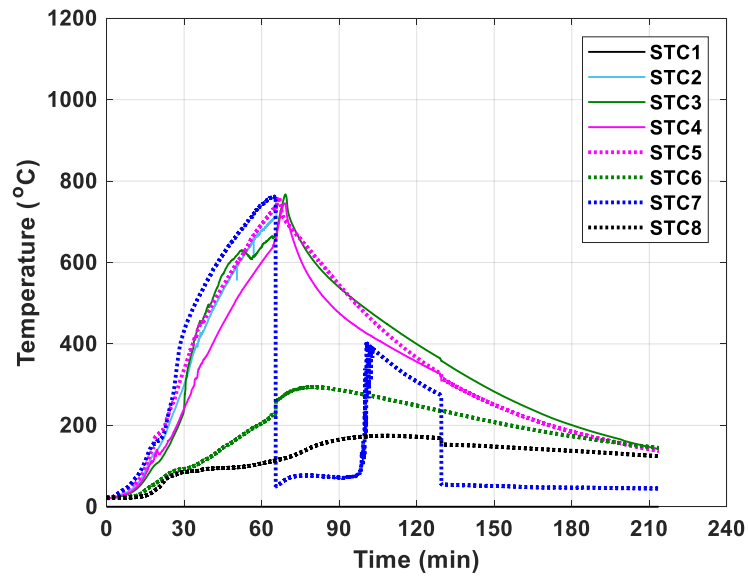

(b)

Figure 80 Temperatures of (a) exposed steel deck and (b) bottom flange temperature for CB-SP. Discontinuity of data indicates dislodging of thermocouples.

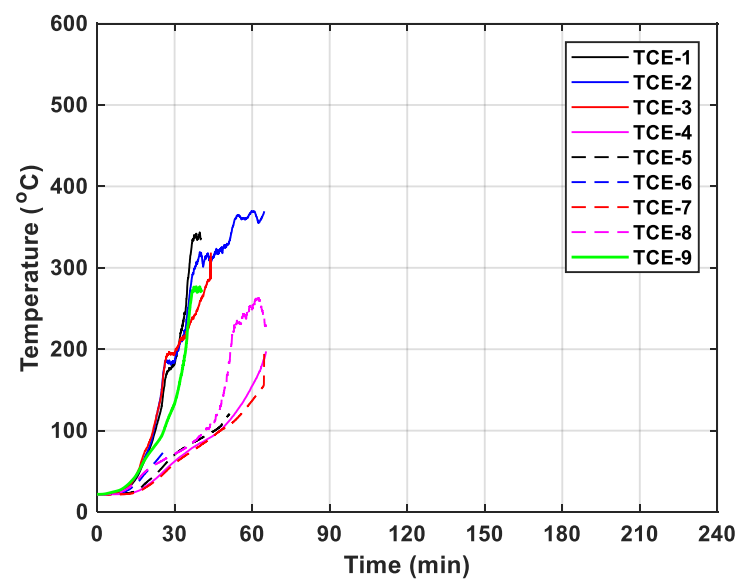

(a)

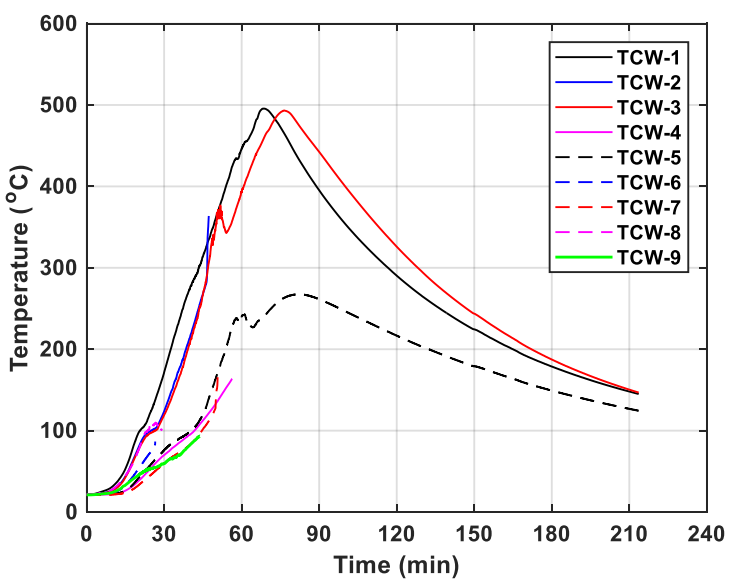

(b)

Figure 81 Temperatures of (a) east and (b) west connection region for CB-SP. Discontinuity of data indicates dislodging of thermocouples. 


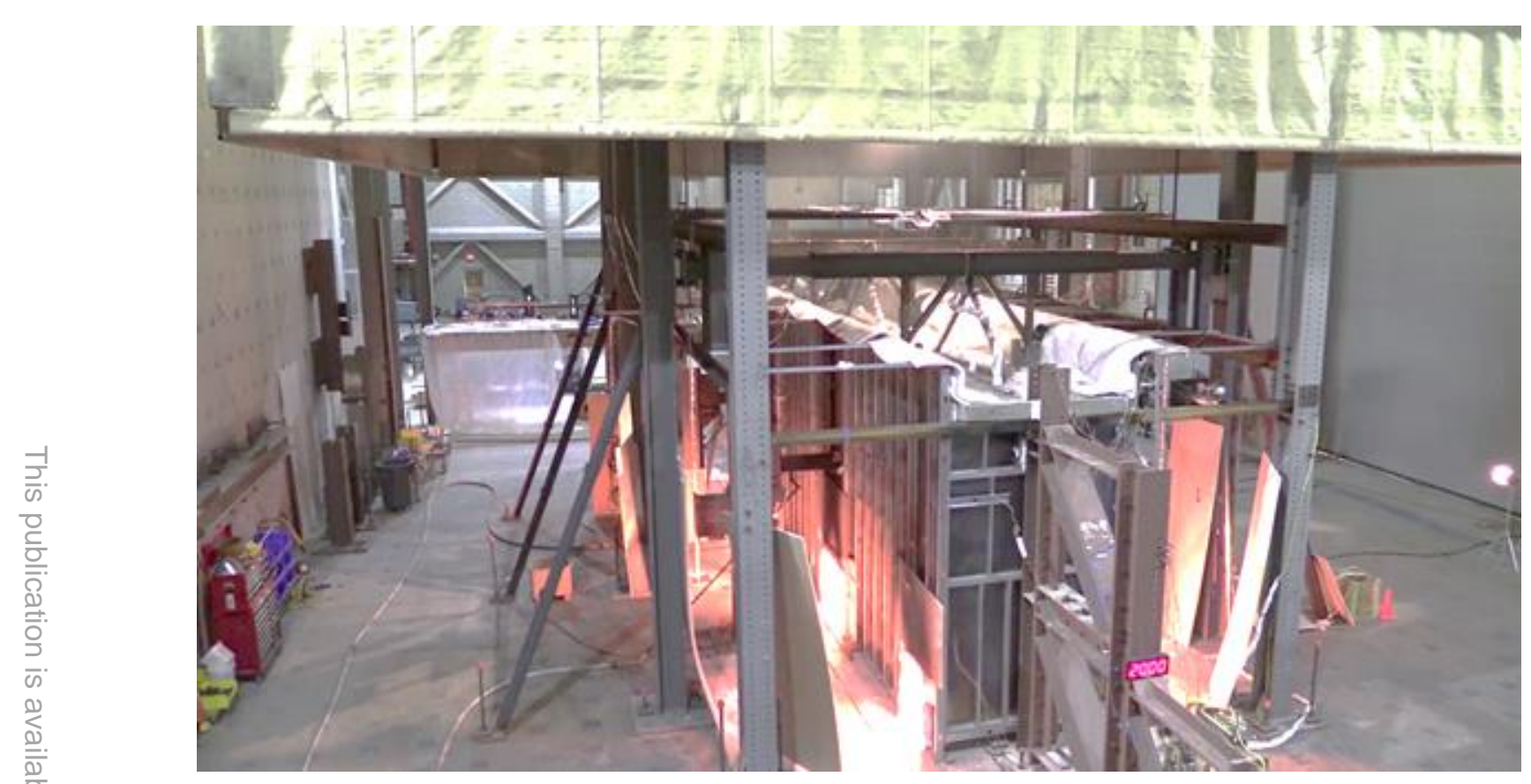

(a)

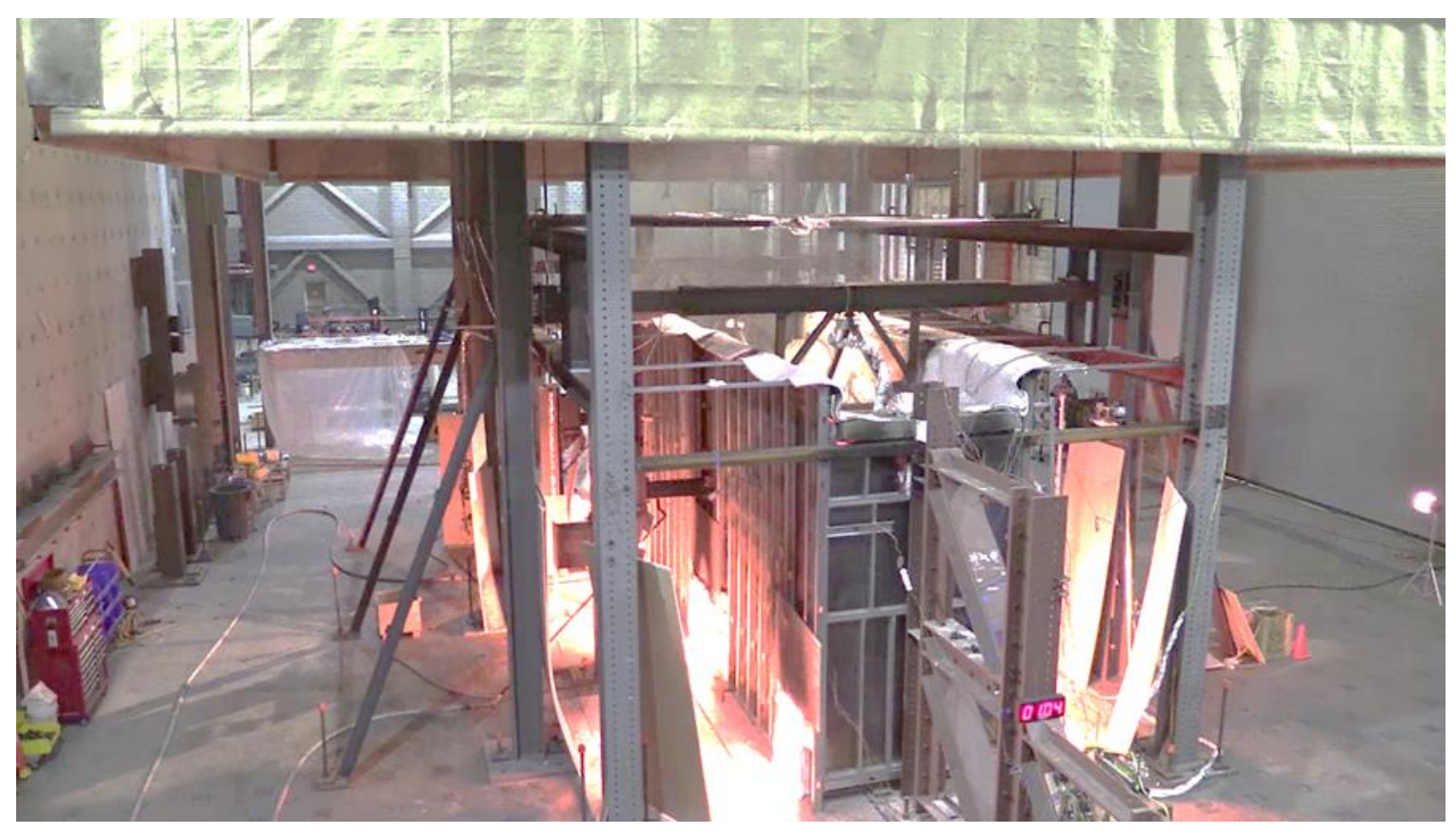

(b)

Figure 82 Still images of a video viewing outside of the test compartment at (a) 20 min and (b) 64 min after the burner ignition (CB-SP). 


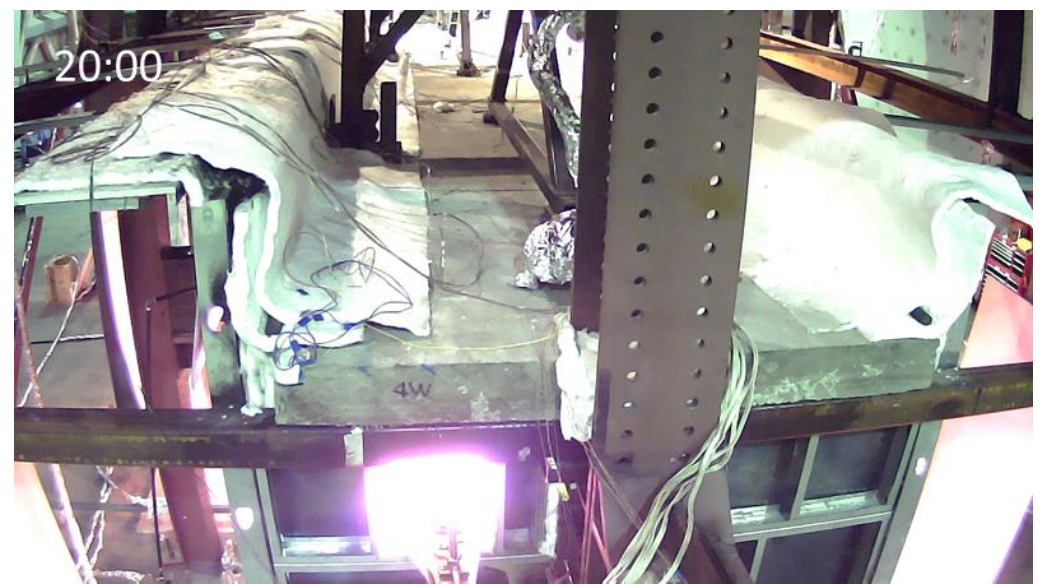

(a)

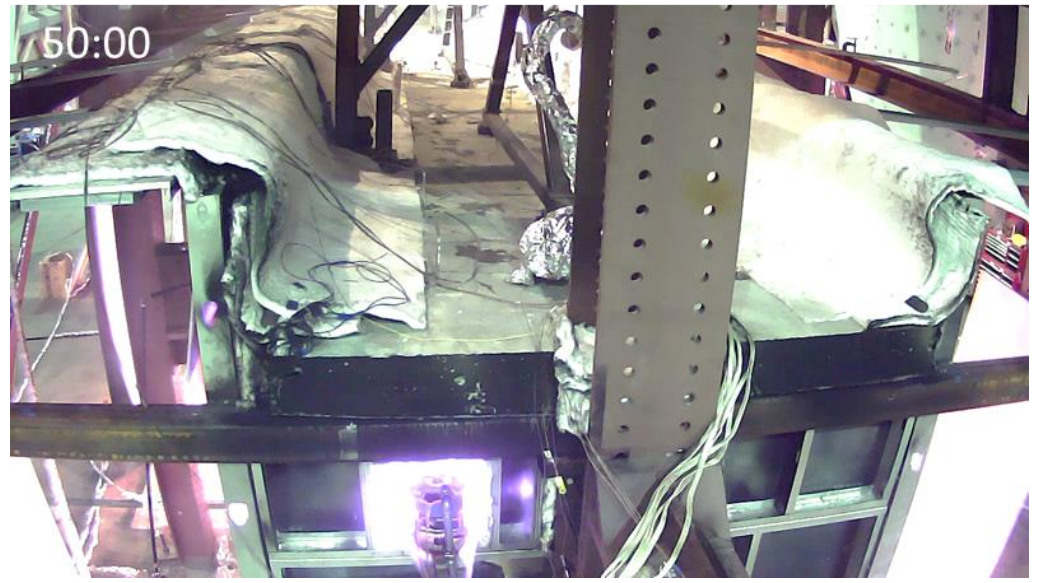

(b)

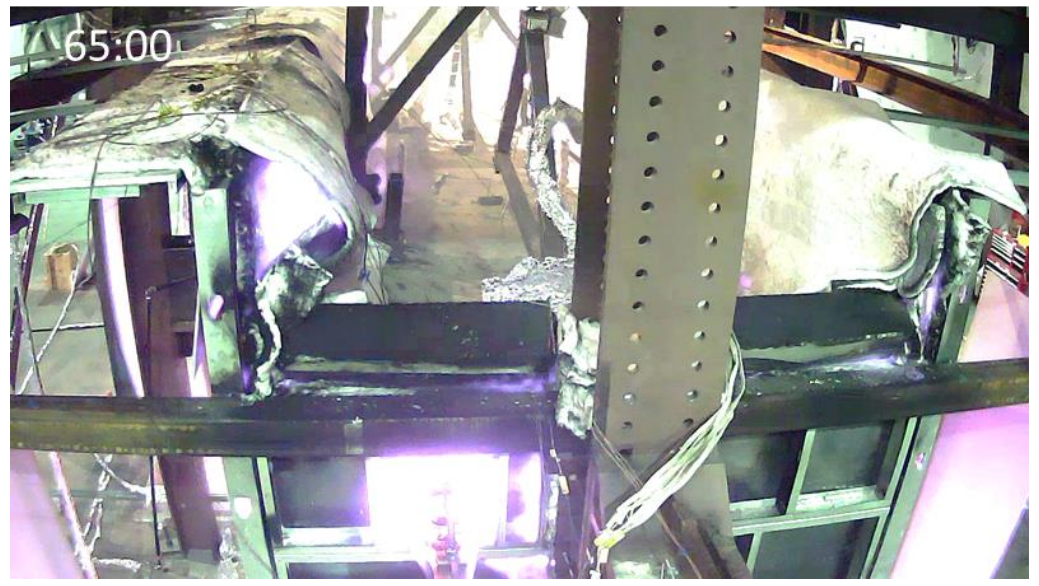

Figure 83 Still images of a video viewing top of the concrete near the east column for CB-SP. Time (min: sec) is recorded after the fire was ignited. 


\section{C.4 Post-Test Conditions}

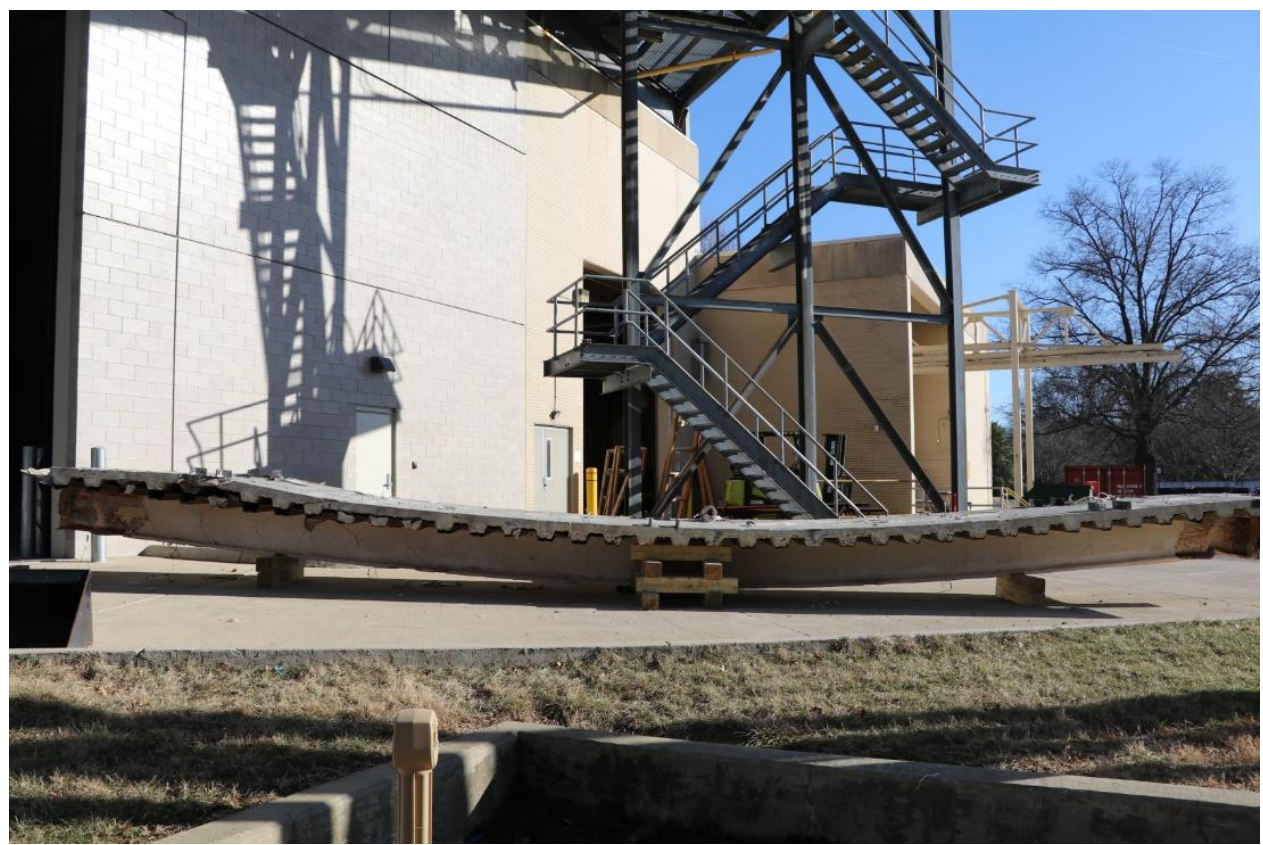

(a)

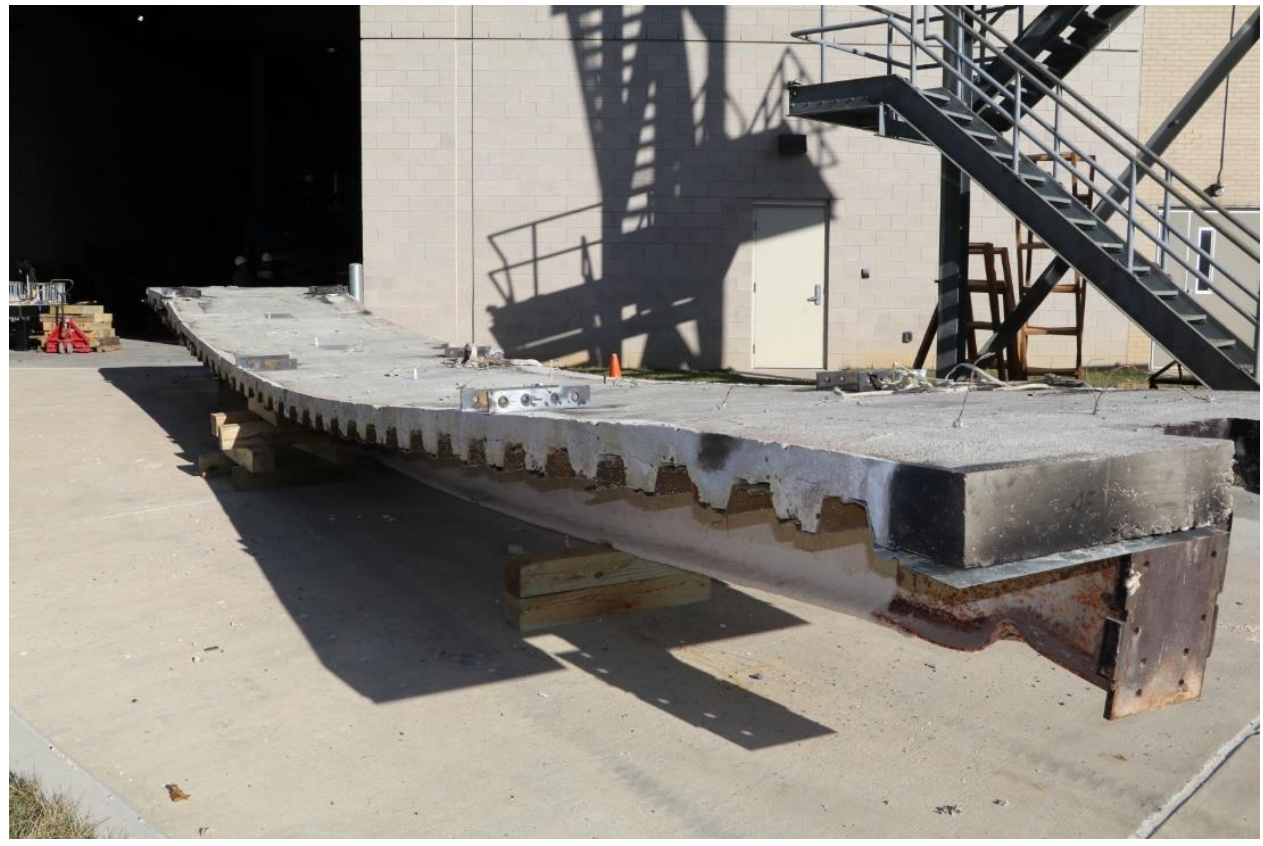

(b)

Figure 84 Photographs of the deflected shape of CB-SP: (a) front view and (b) perspective view. 


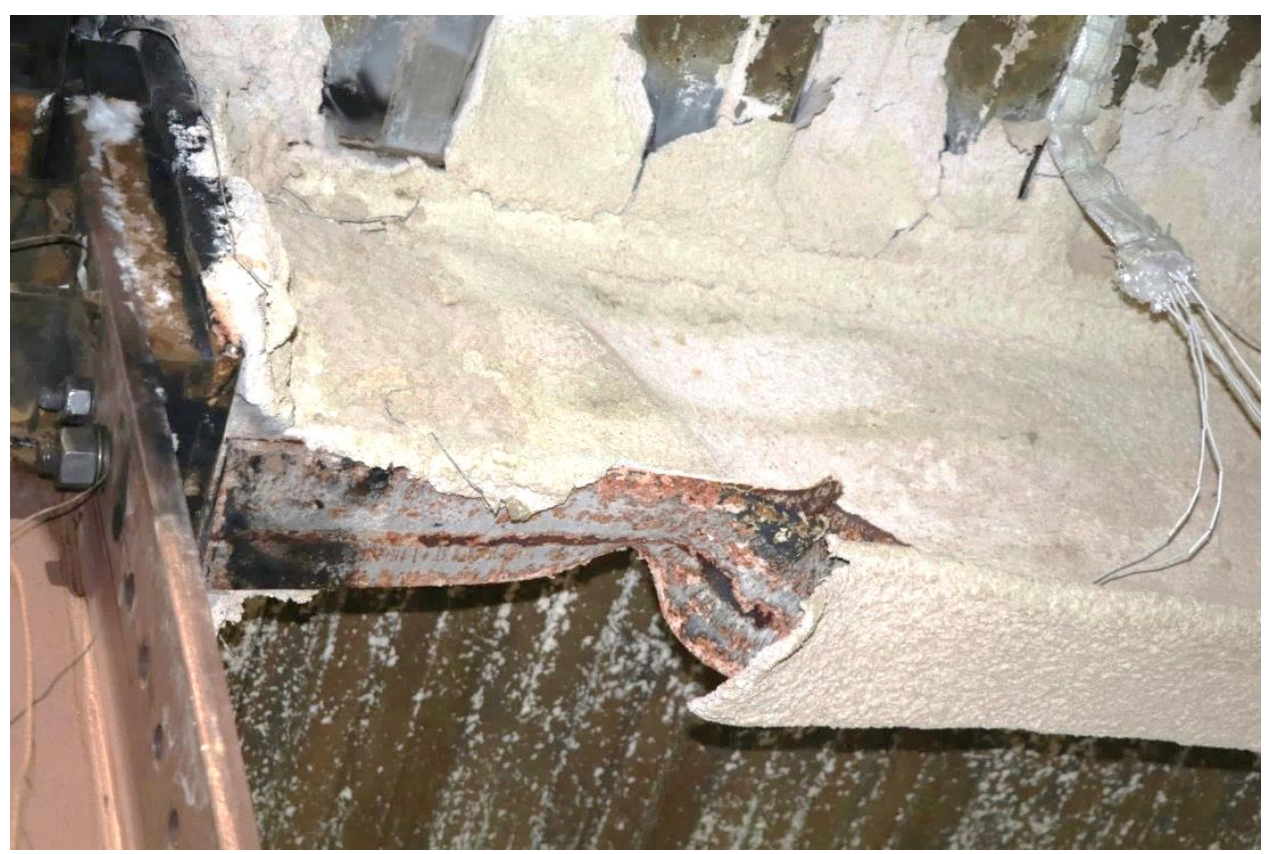

(a)

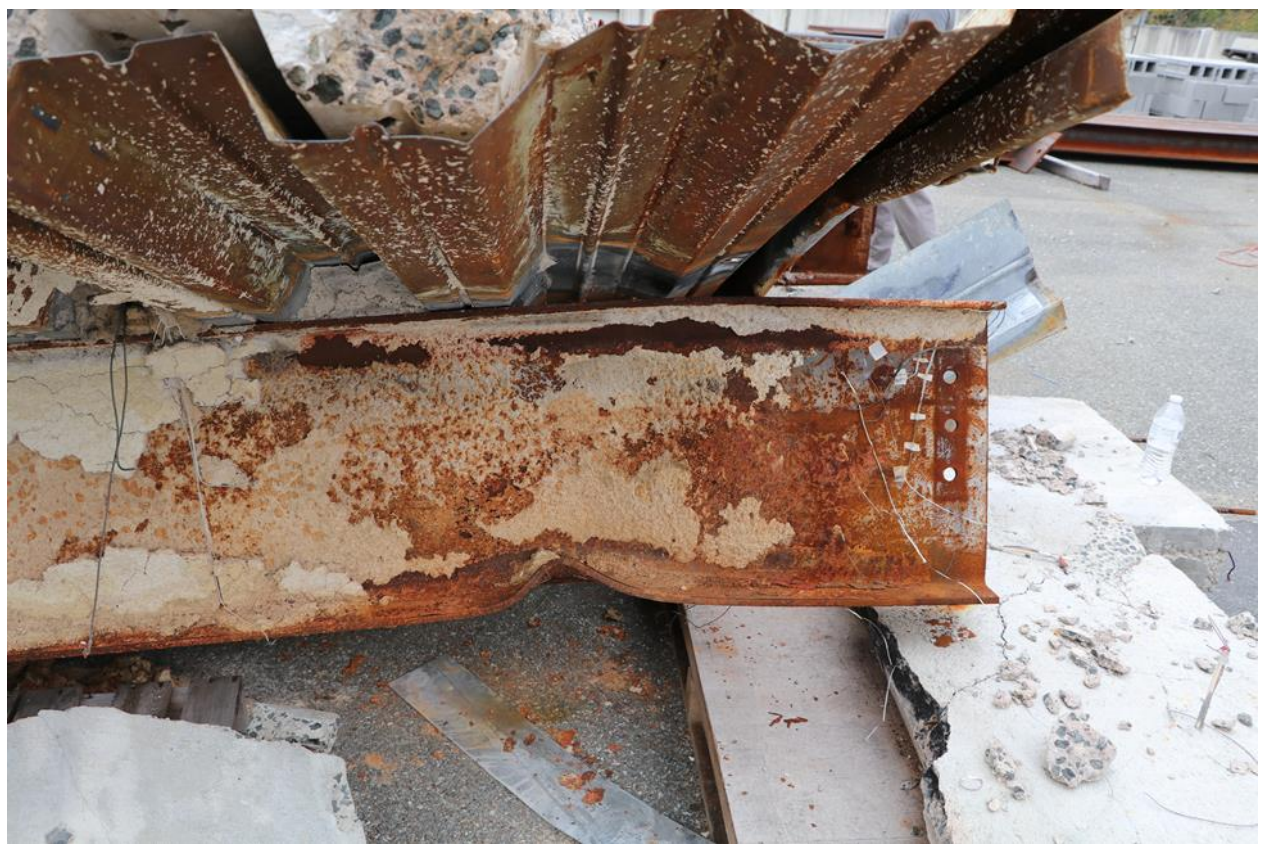

(b)

Figure 85 Photographs of CB-SP after cooling: (a) west connection region inside the test compartment and (b) east connection region after removal of the shear tab. 


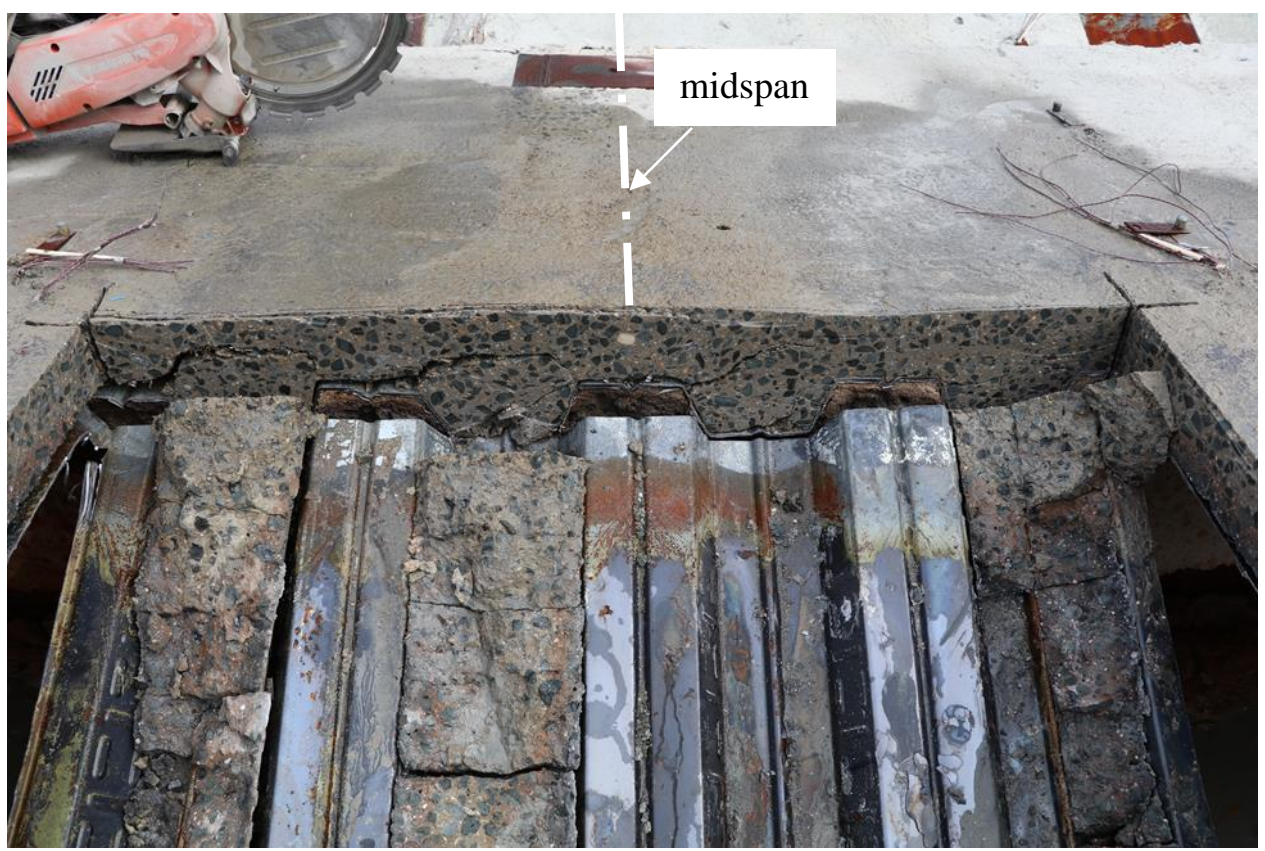

(a)

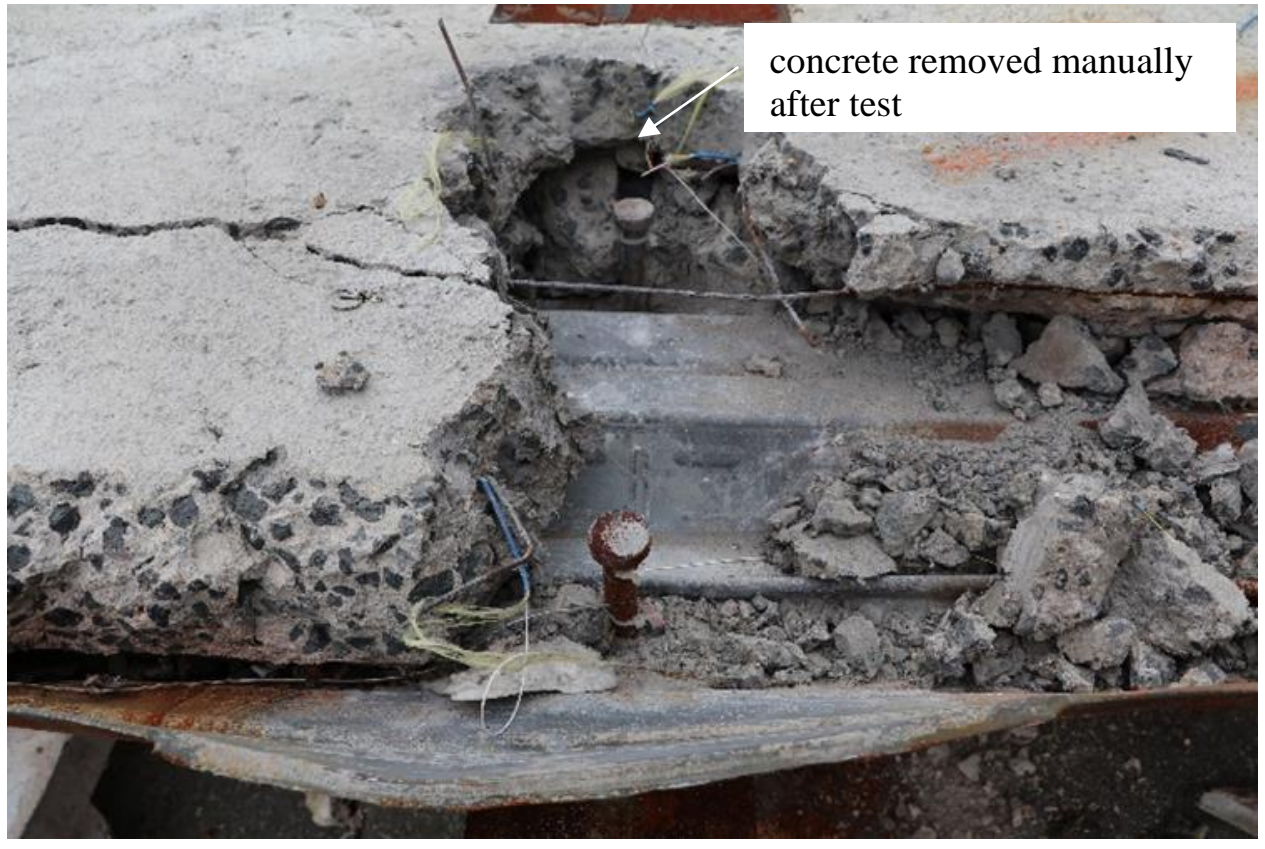

(b)

Figure 86 Photographs of CB-SP: (a) concrete slab at midspan after cut and (b) concrete slab and shear studs at west end. 


\section{Appendix D \\ SPECIMEN CB-SP-SC}

\section{D.1 Test Information}

Test Date:

Record Start Time:

Program Version:

Test Name:

Peak HRR $(\mathrm{kW})$

Total HRR (MJ)

Oxygen Drift (ppmv)

Baseline Hood Flow (kg/s)
3/6/2018 (Concrete placement: 12/6/2016)

1:10:37 PM

MIDAS.exe Ver. 2.124.0.695

CB-SP-SC

- A 12.8 m span composite beam specimen supported by sheartab connections.

- Slab continuity reinforcement was present.

- Both unloading of hydraulic actuators and the burner extinguishment were achieved manually following failure of the east connection.

- A crane accident caused damage to the west end of the slab. The concrete placement of a damaged zone was completed on 10/25/2018 (Ramesh et al., 2019).

4111

14200

$-144$

75.2

\section{D.2 Test Procedure and Observations}

Table 17 Test procedure and observations for CB-SP-SC. Test time was recorded after the burner ignition and rounded to the nearest 1 min.

Time (min) Description

- Fire ignition was confirmed.

0 - The total heat release rate of the natural gas fueled burners (HRRburner) started increasing.

16 - HRRburner approached a target value of $4000 \mathrm{~kW}$.

37 - The concrete slab near the west support cracked.

41 - Local buckling occurred in the steel beam near the angle connections.

55 - The concrete slab near the east support cracked. 
- Black smoke (soot) were visible on top of the concrete near the west and east supports.

- Flames and heavy smoke were visible on top of the concrete near the west and east supports.

- The bottom bolt in the east shear tab fractured; Both mechanical and fire loading was manually removed.

260

- The test beam collapsed by failure of the remaining bolts in the east shear tab.

- A servo-valve of the NE actuator was replaced prior to the test. As shown in Figure 87, mechanical loads applied using coupled actuators were steady. The standard variation of loads from coupled actuators was less than $2 \%$ during fire. The stoke lengths of coupled actuators remained almost identical prior to unloading, implying that no twisting of the concrete slab occurred.

- Similar to previous tests, the rotation of east and west loading trusses (RotLT1 and RotLT3, respectively) diverged after 15 min (Figure 88), resulting in unequal loads at six points. The time-averaged value of six-point loads was $17.5 \mathrm{kN}$ (estimated for a period of $72 \mathrm{~min}$ ). The maximum standard variation was $3.8 \mathrm{kN}$ before unloading.

- Gas temperatures measured $81 \mathrm{~cm}$ below exposed steel decking inside the test compartment reached a maximum value of $(1070 \pm 30){ }^{\circ} \mathrm{C}$ before the extinguishment of a test fire at 73 min (Figure 89a). The value after \pm symbol is the standard deviation of temperatures measured using TCC1 through TCC8. The temperature at the top of vent openings ranged from $800{ }^{\circ} \mathrm{C}$ to $900{ }^{\circ} \mathrm{C}$ at the HRRburner of $4000 \mathrm{~kW}$ from 16 min to $73 \mathrm{~min}$ (Figure $89 \mathrm{~b}$ ).

- Figure 90 through Figure 92 show measured temperatures of the concrete slab at various locations. shows the concrete temperatures in the slab directly above the W18 $\times 35$ beam.

- Temperatures of exposed steel deck increased from 600 to over $1000{ }^{\circ} \mathrm{C}$ while the heat release rate was fixed at $4000 \mathrm{~kW}$ from 16 min to 73 min (Figure 93a).

- Temperatures of the protected steel beam measured using Inconel sheathed thermocouples reached about $800{ }^{\circ} \mathrm{C}$ at the bottom flange and middle web (Figure 93b). Temperatures measured using glass-sheathed thermocouples protected under SFRM reached a peak value of $750{ }^{\circ} \mathrm{C}$ (Figure 94).

- Temperatures of the connection region increased to a peak value of $350{ }^{\circ} \mathrm{C}$ at the beam web and around $200{ }^{\circ} \mathrm{C}$ at the shear tab (Figure 95).

- Figure 96 shows the tensile loads on the No. 4 reinforcing bars anchored at the location of girders as a function of fire exposure time.

- Figure 97 presents additional views of the test specimen during the test.

- Figure 98 through Figure 100 are additional views of the post-test conditions of the test specimen. 


\section{D.3 Additional Data}

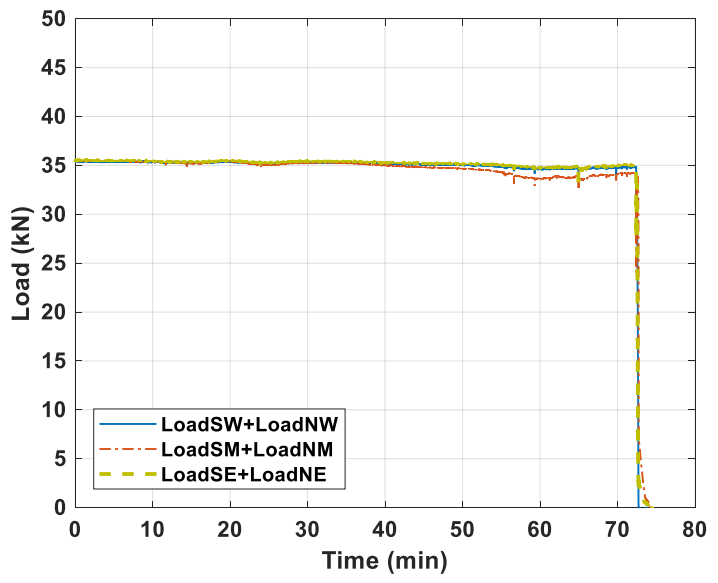

(a)

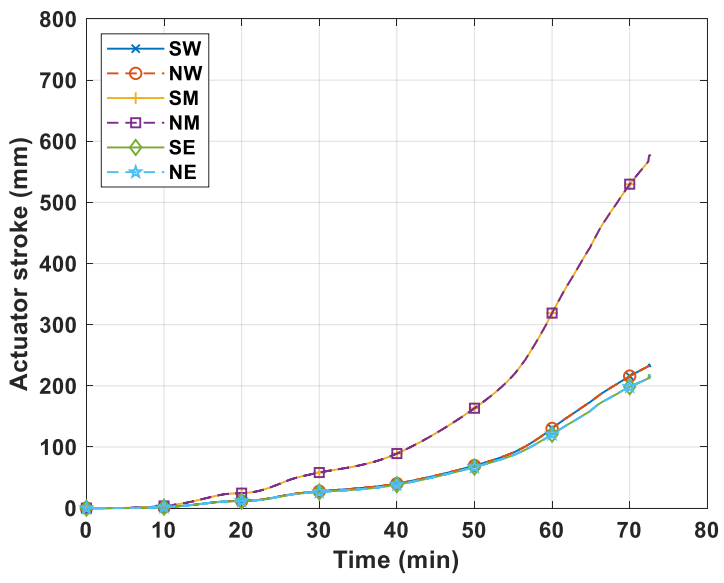

(b)

Figure 87 Actuator data of CB-SP-SC: (a) loads and (b) stroke lengths applied using six actuators (SW, NW, SM, NM, SE, and NE). Actuator stroke was not recorded after unloading.

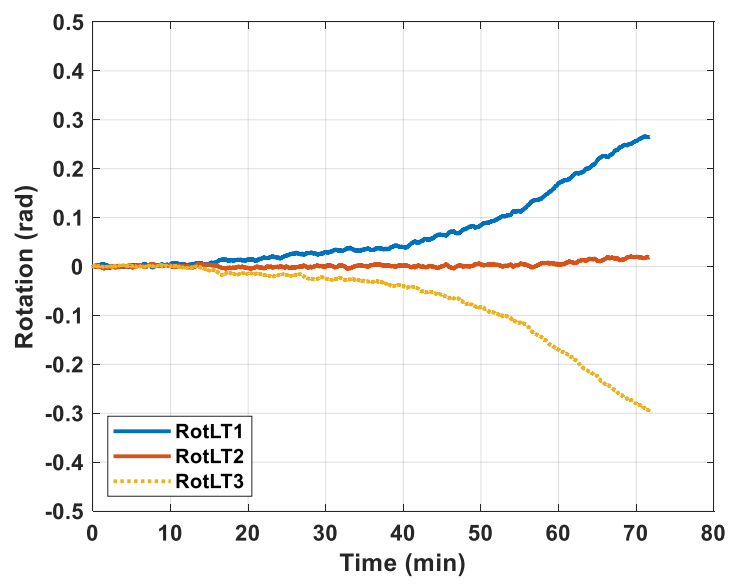

(a)

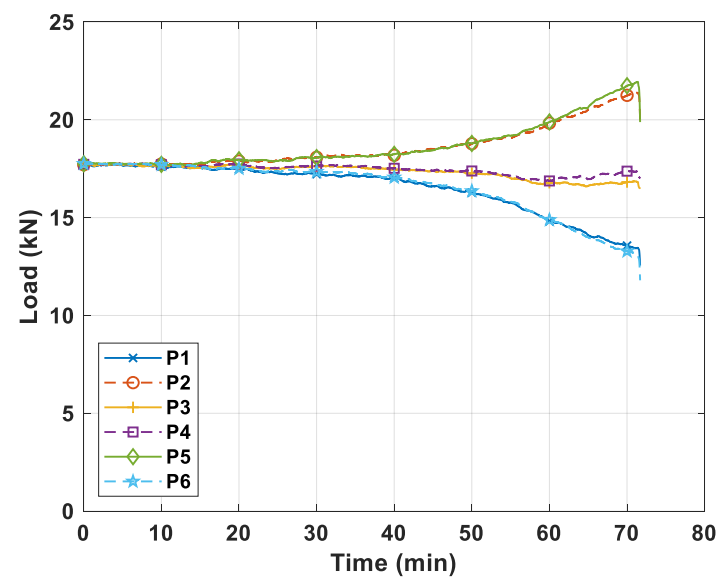

(b)

Figure 88 (a) Rotations of three loading trusses placed on top of the concrete and (b) six-point loads during fire loading, where P1 through P6 are the point loads from east to west ends (CB-SP-SC). 


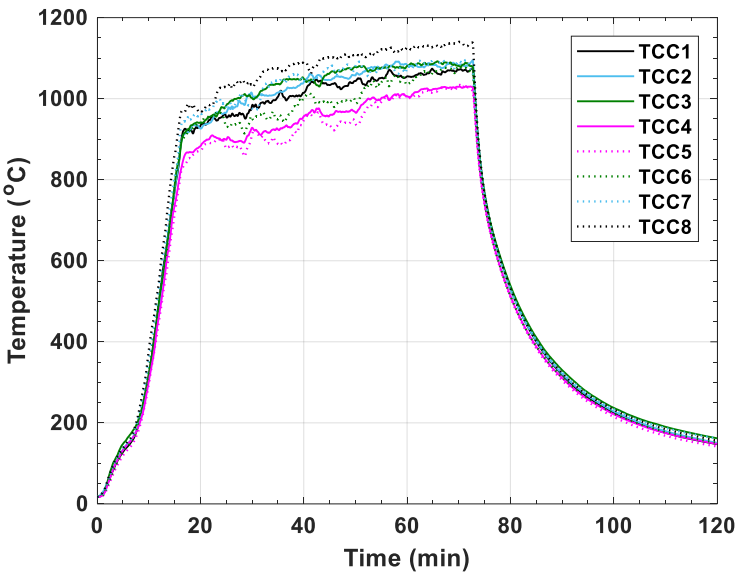

(a)

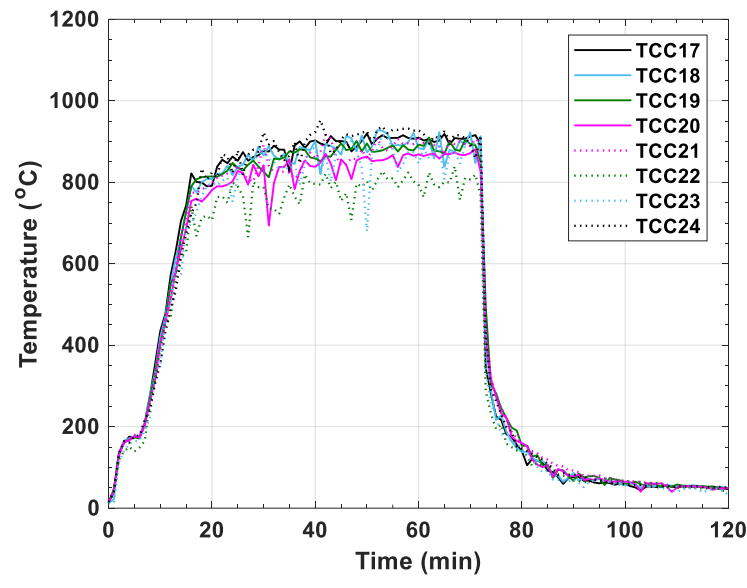

(b)

Figure 89 Gas temperature data of CB-SP-SC: (a) $81 \mathrm{~cm}$ below exposed steel decking and (b) above vent openings outside of the test compartment. 


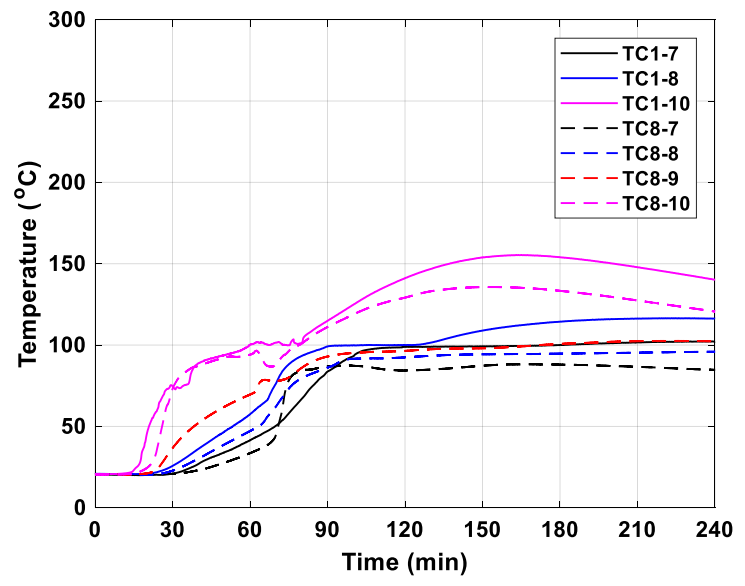

(a)

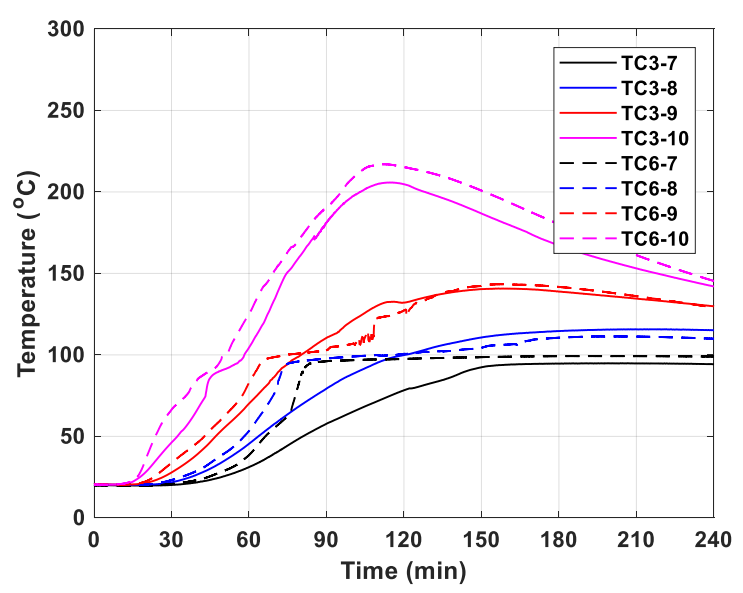

(c)

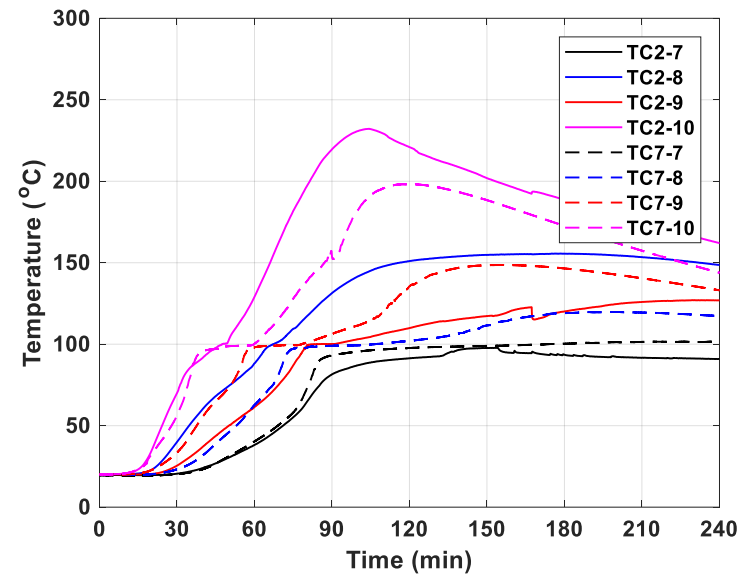

(b)

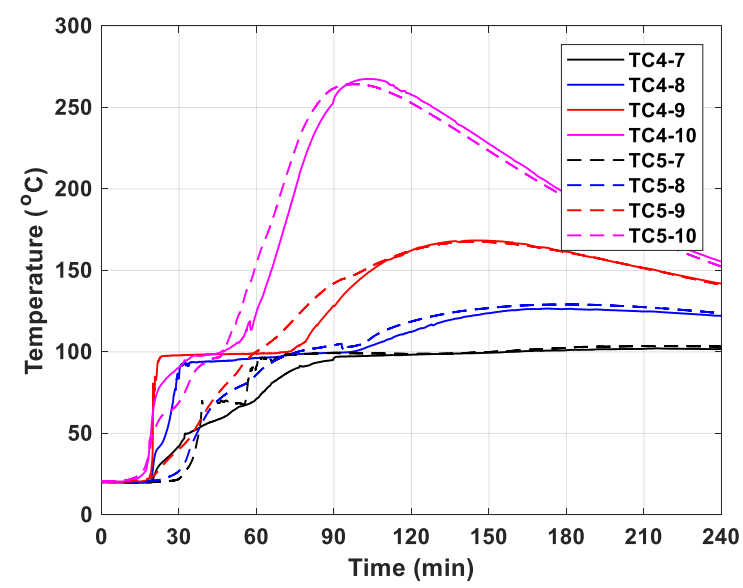

(d)

Figure 90 Concrete temperature along the longitudinal centerline of CB-SP-SC: (a) sections TC1 and TC8, (b) sections TC2 and TC7, (c) sections TC3 and TC6, and (d) sections TC4 and TC5. 


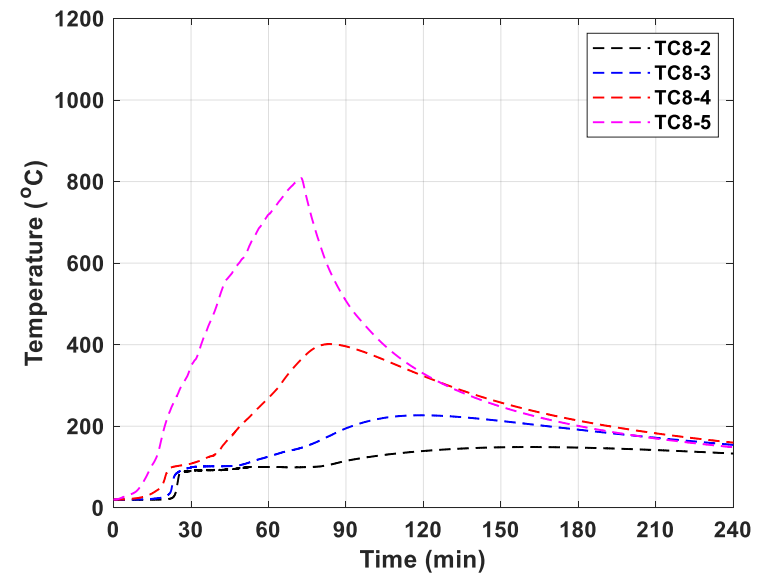

(a)

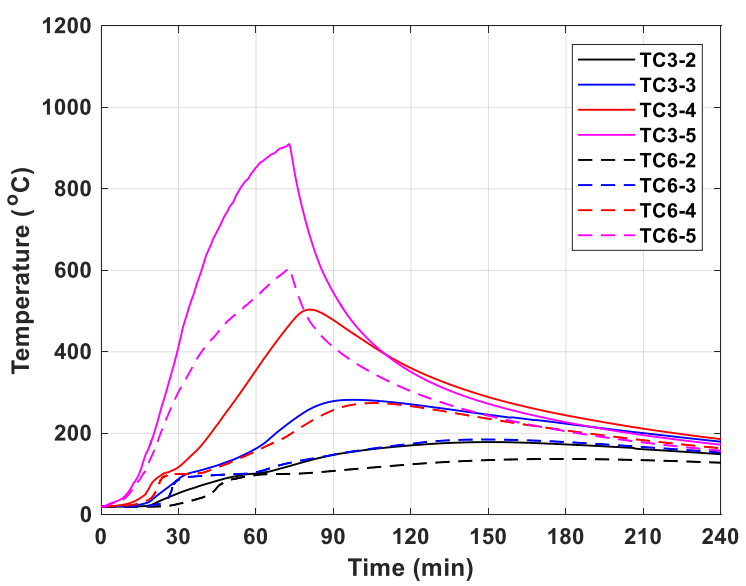

(c)

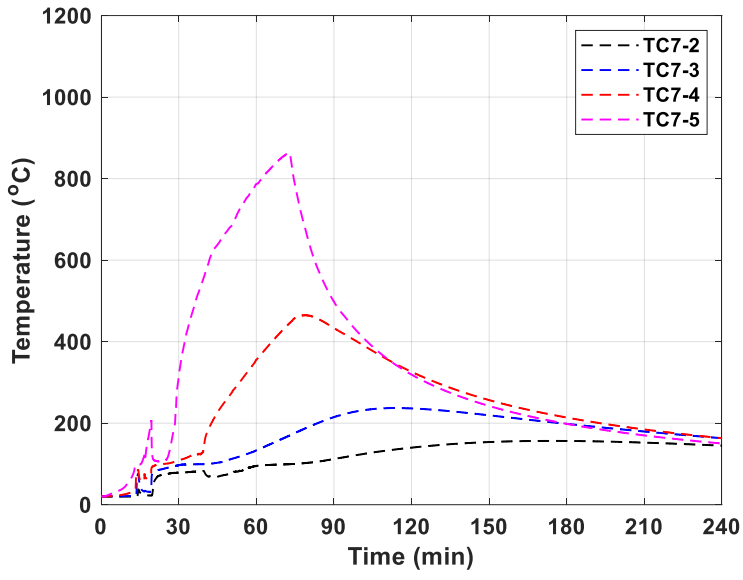

(b)

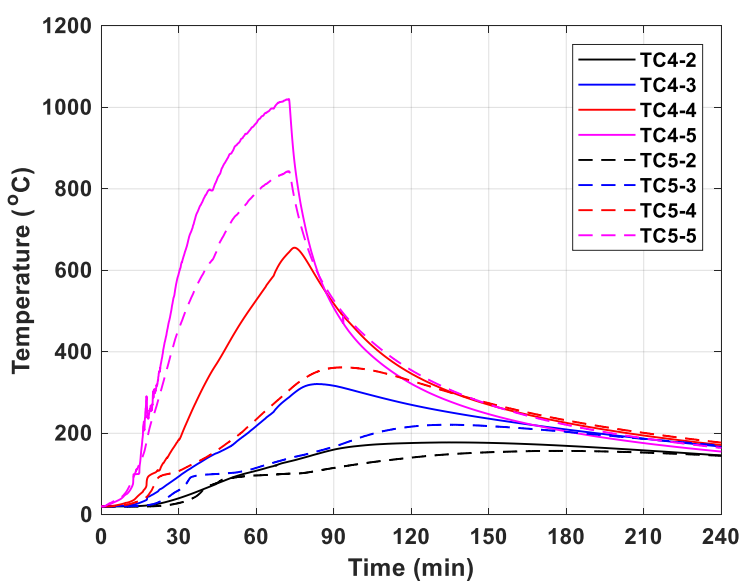

(d)

Figure 91 Concrete temperature measured $45.7 \mathrm{~cm}$ from the north edge of CB-SP-SC: (a) sections TC1 and TC8, (b) sections TC2 and TC7, (c) sections TC3 and TC6, and (d) sections TC4 and TC5. 


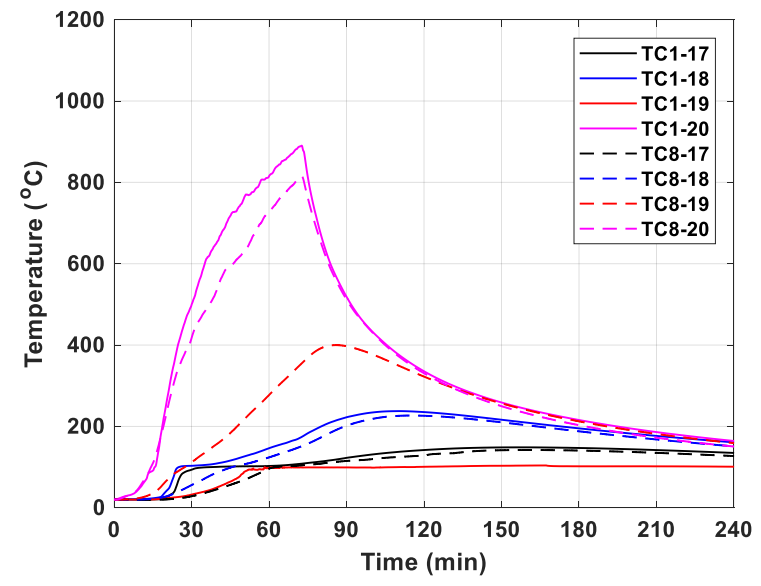

(a)

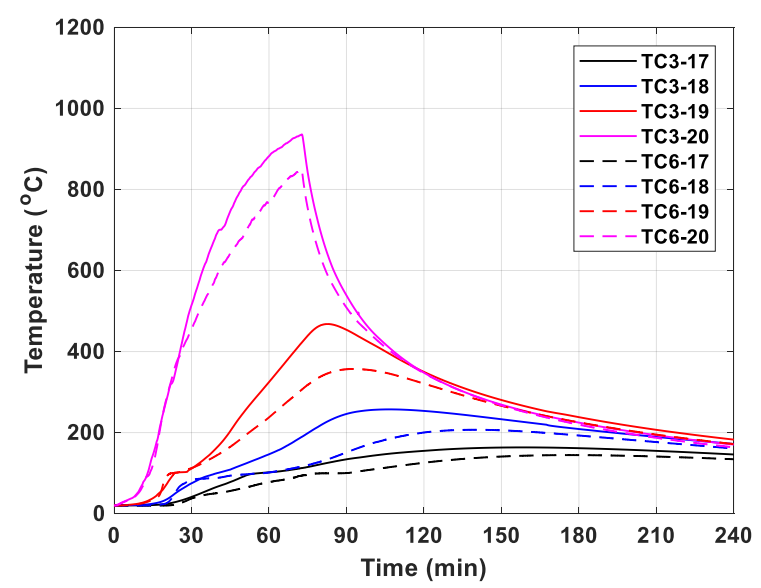

(c)

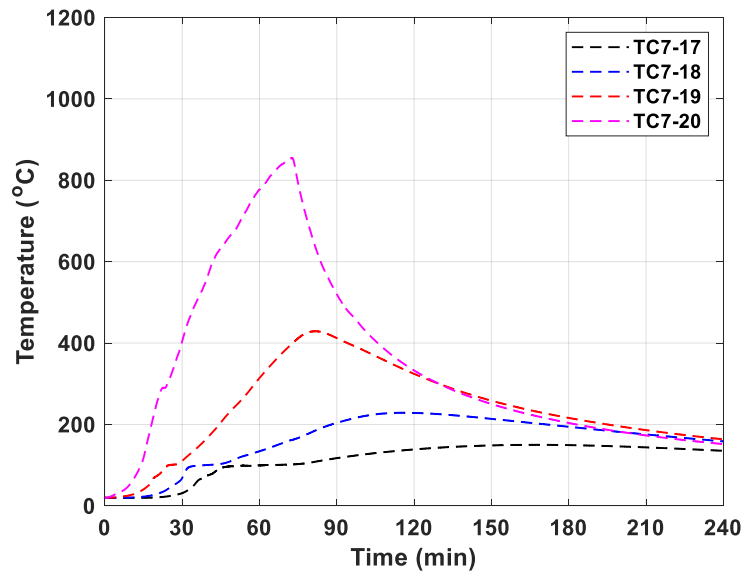

(b)

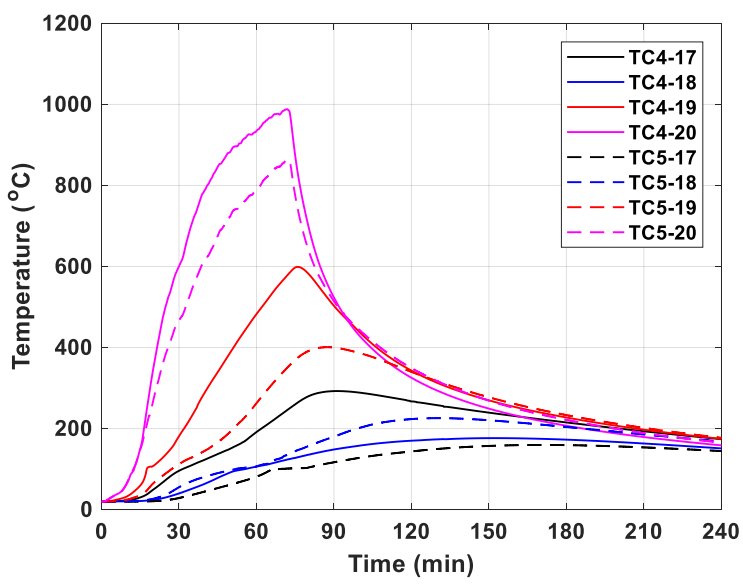

(d)

Figure 92 Concrete temperature measured $45.7 \mathrm{~cm}$ from the south edge of CB-SP-SC: (a) sections TC1 and TC8, (b) sections TC2 and TC7, (c) sections TC3 and TC6, and (d) sections TC4 and TC5. 


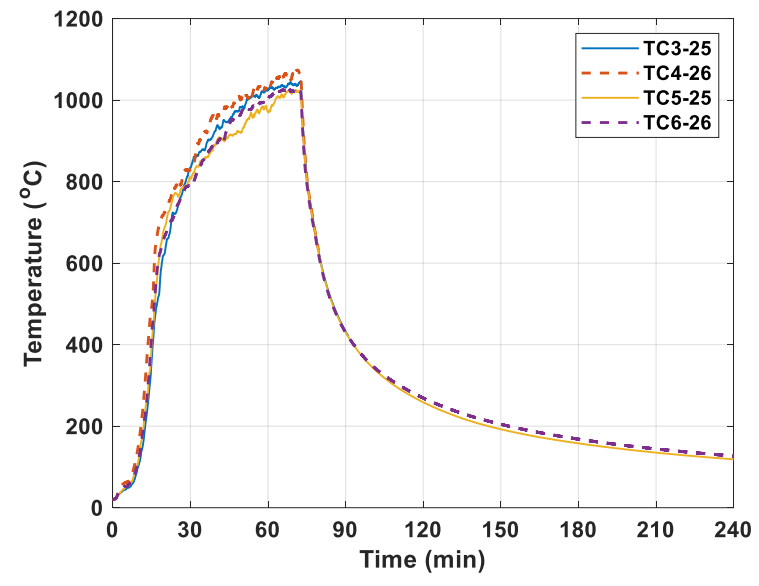

(a)

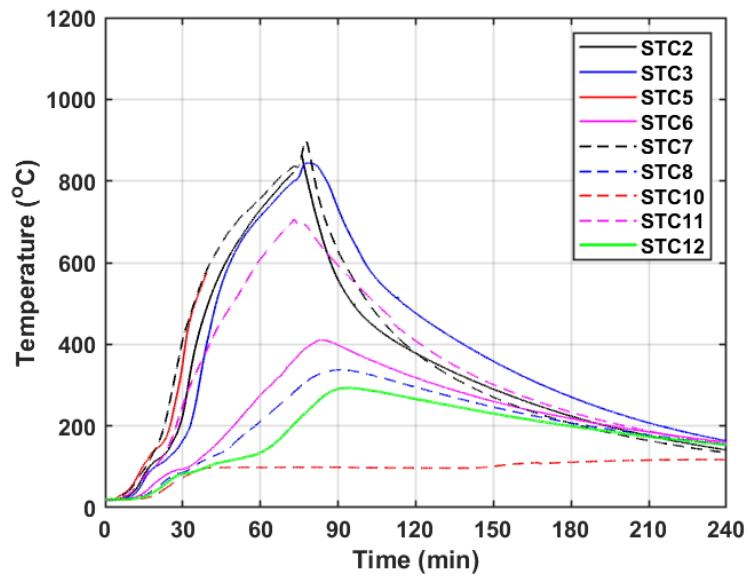

(b)

Figure 93 Temperatures of (a) exposed steel deck and (b) steel beam measured using Inconel sheathed thermocopules for CB-SP-SC. Discontinuity of data indicates dislodging of thermocouples. 


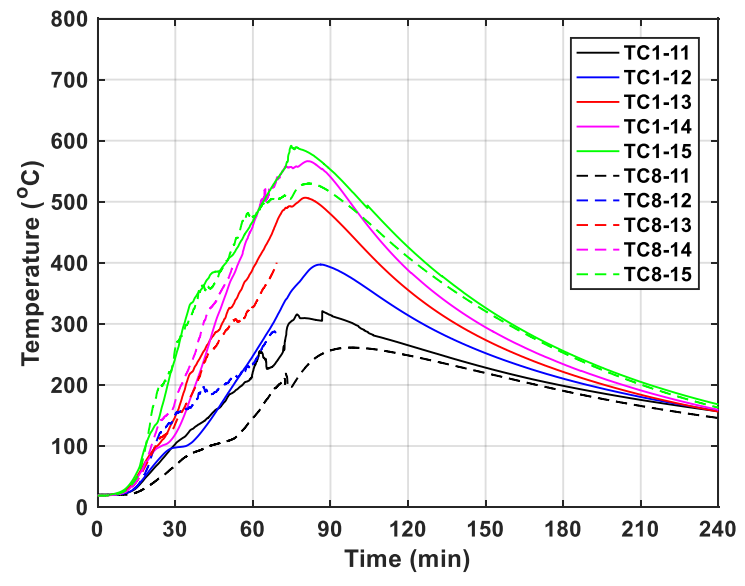

(a)

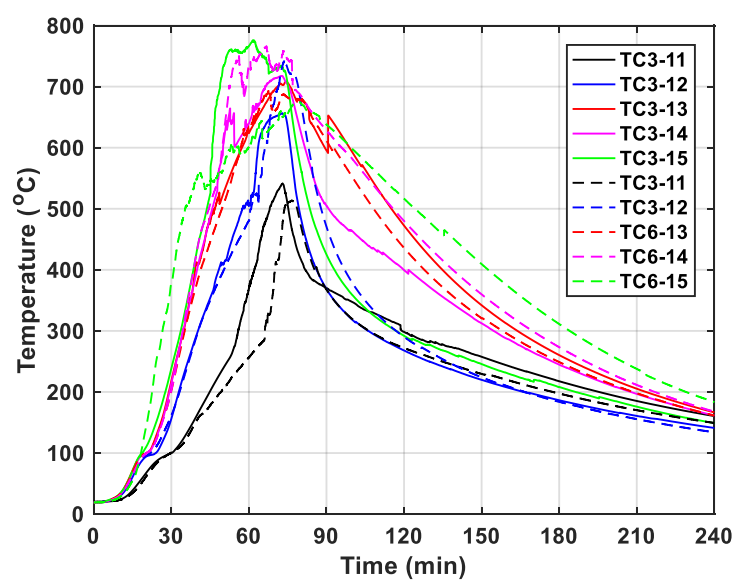

(c)

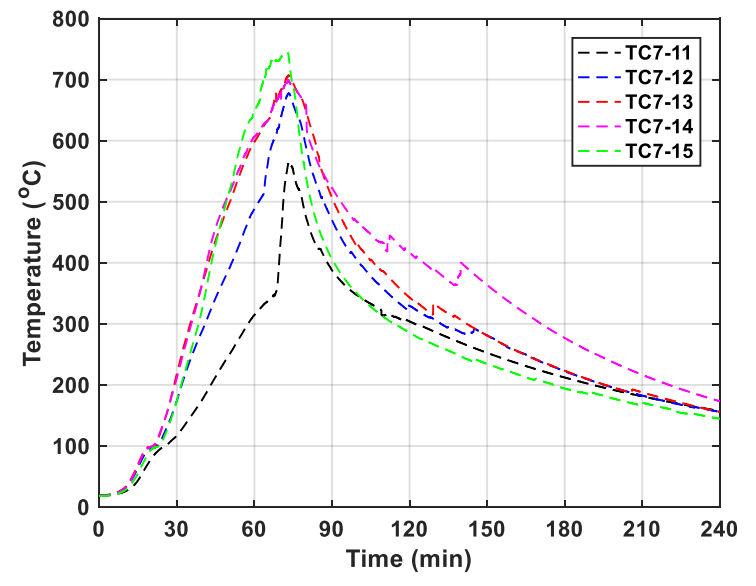

(b)

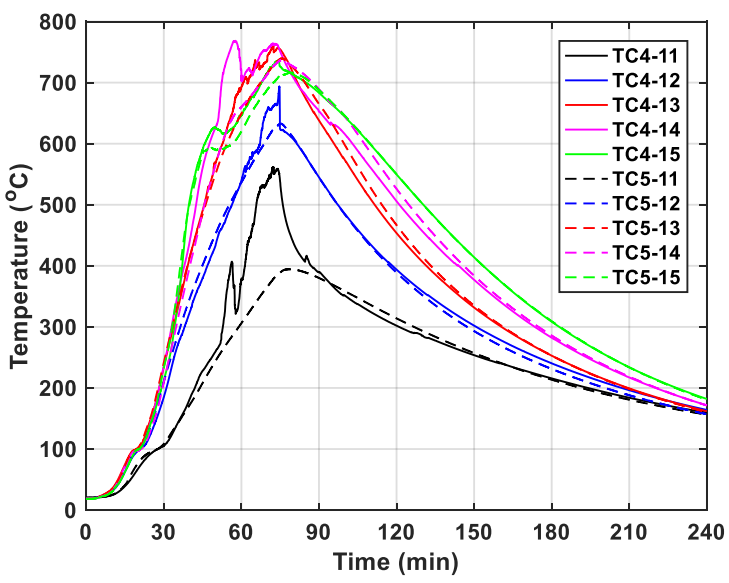

(d)

Figure 94 Temperatures of steel beam measured using glass-sheathed thermocouples for CB-SP-SC: (a) sections TC1 and TC8, (b) sections TC2 and TC7, (c) sections TC3 and TC6, and (d) sections TC4 and TC5. Discontinuity of data indicates dislodging of thermocouples. 


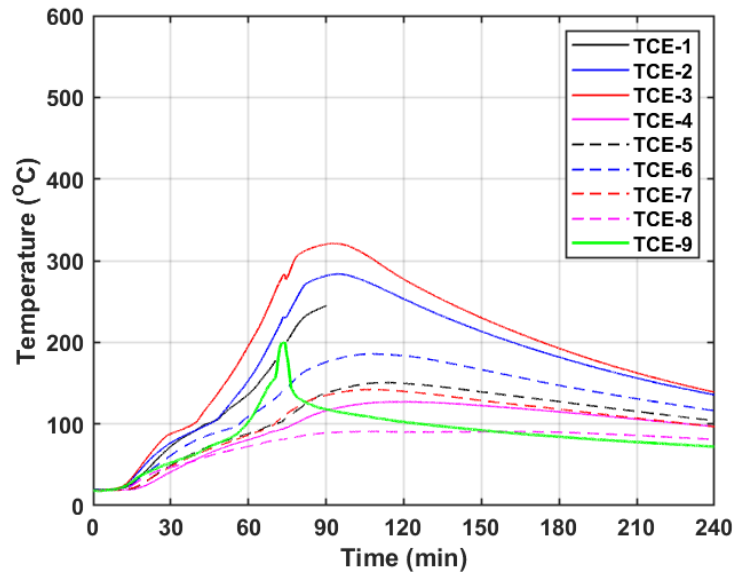

(a)

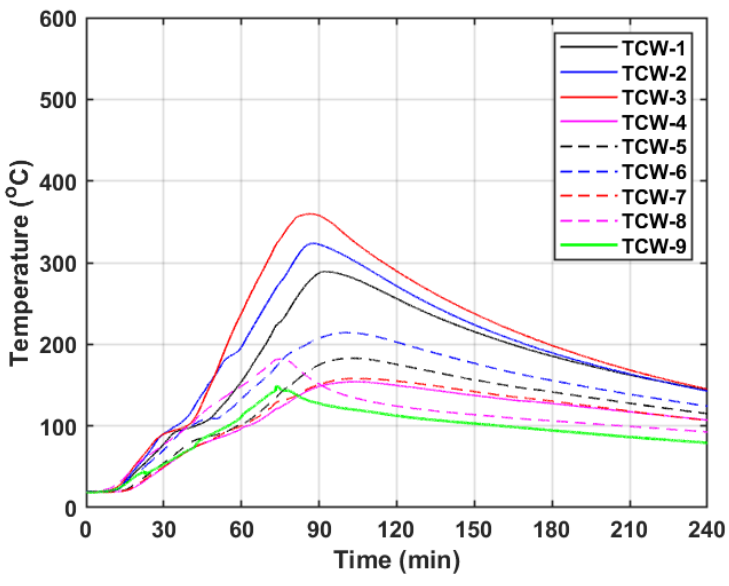

(b)

Figure 95 Temperatures of (a) east and (b) west connection region for CB-SP-SC. Discontinuity of data indicates dislodging of thermocouples.

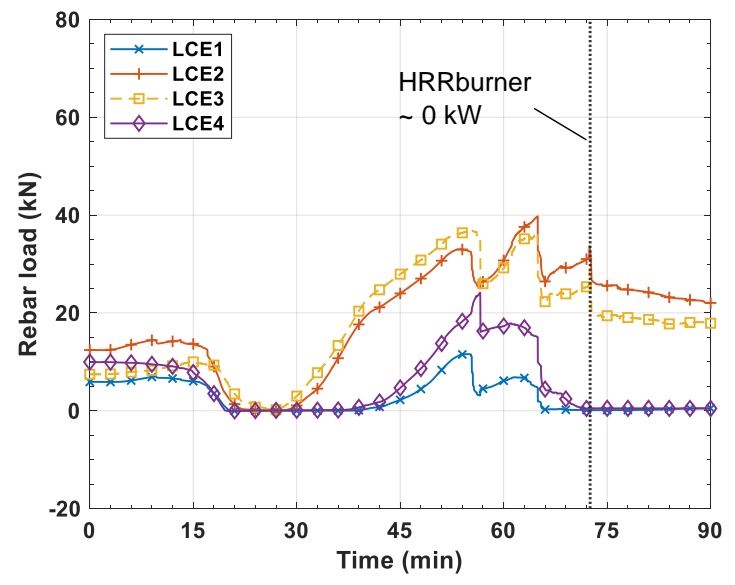

(a)

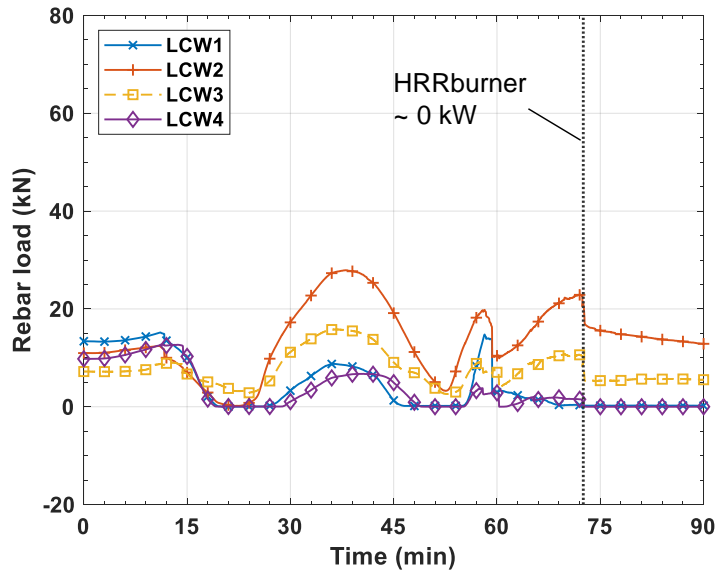

(b)

Figure 96 Tensile loads on No. 4 reinforcing bars anchored at (a) east and (b) west end (CB-SP-SC). 


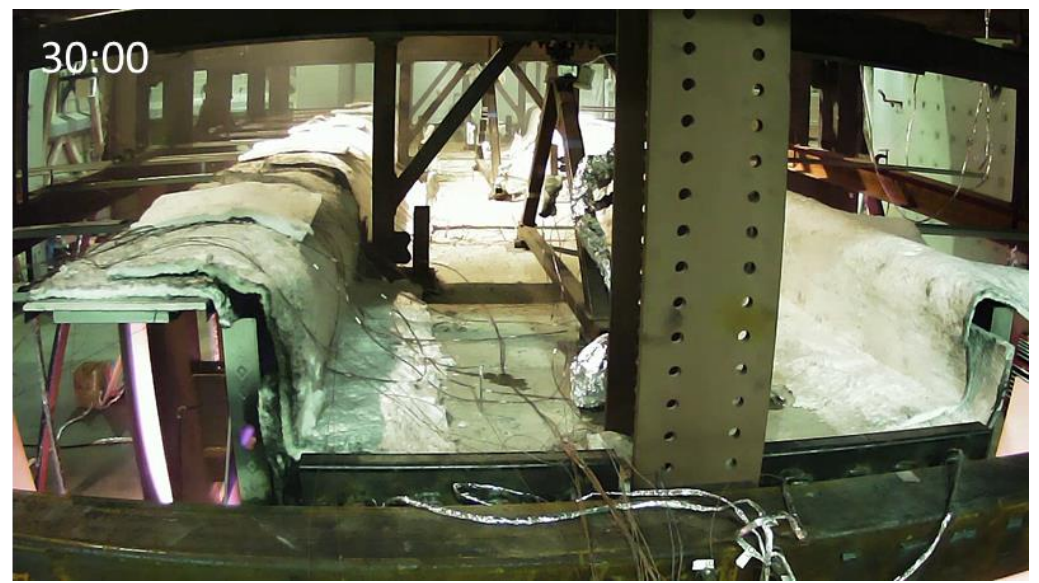

(a)

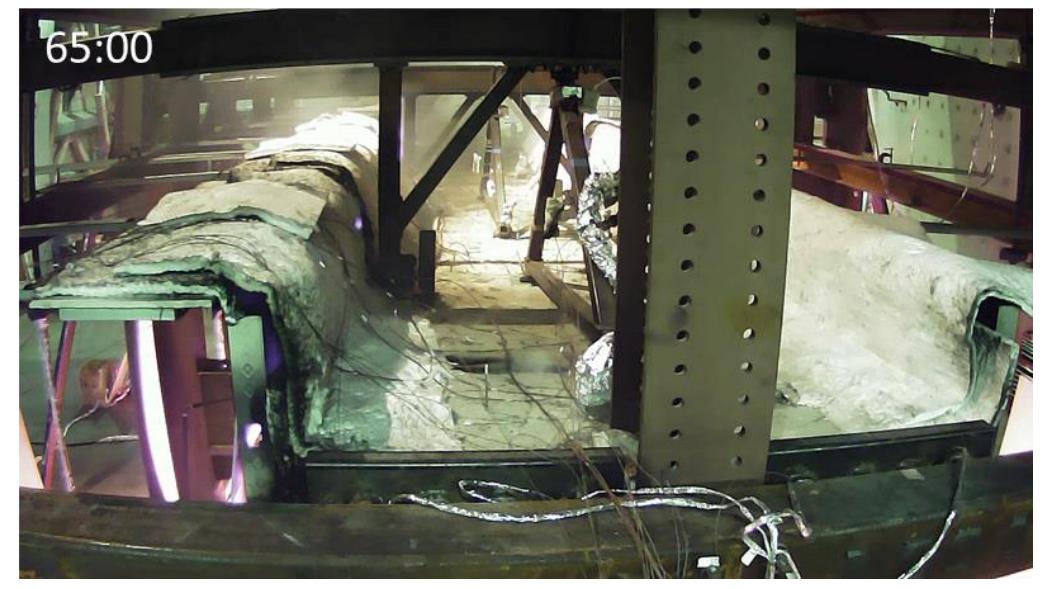

(b)

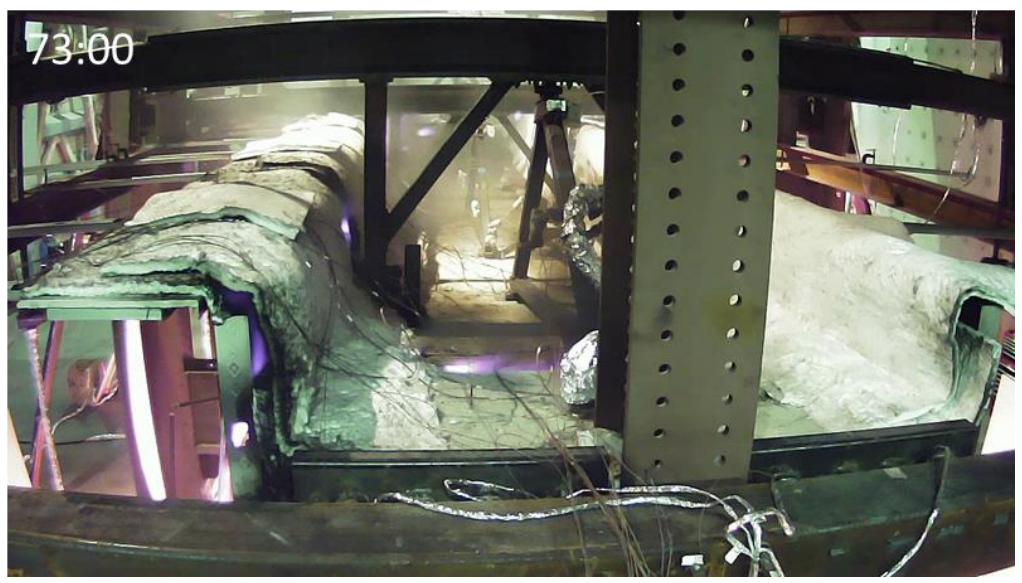

(c)

Figure 97 Still images of a video viewing top of the concrete near the east column for CB-SP-SC. Time (min: sec) is recorded after the fire was ignited. 


\section{D.4 Post-Test Conditions}

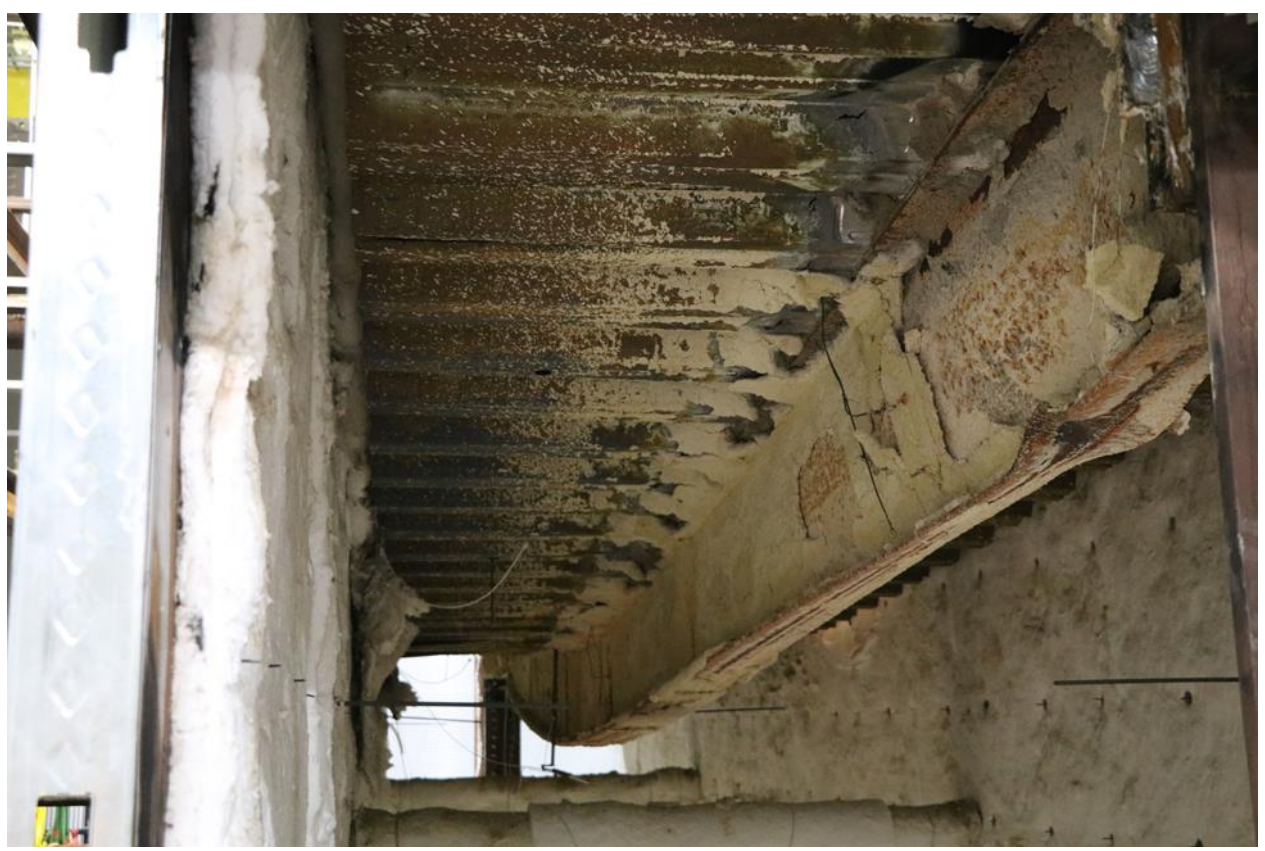

(a)

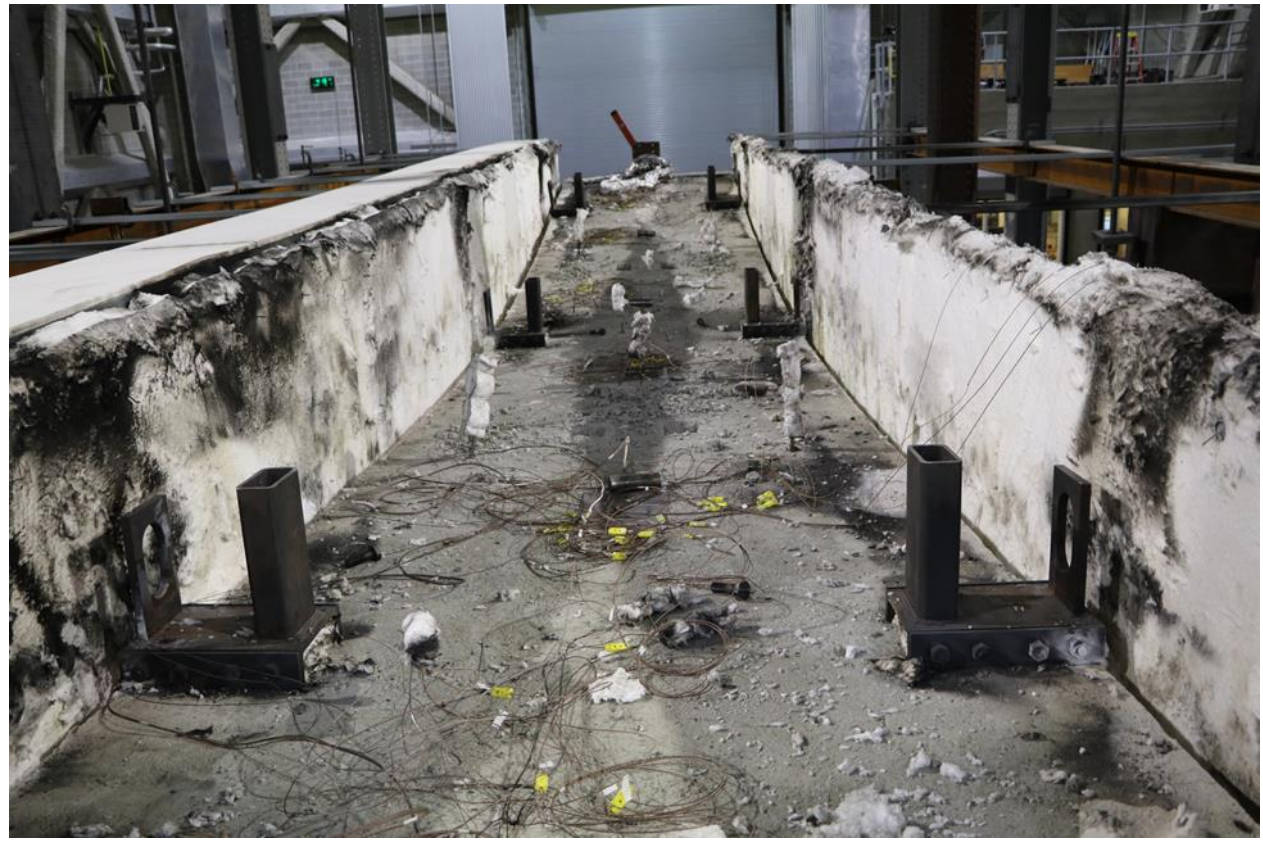

(b)

Figure 98 Photographs of CB-SP-SC after cooling: (a) deflected shape of the steel beam and (b) concrete slab after removal of loading frames. 


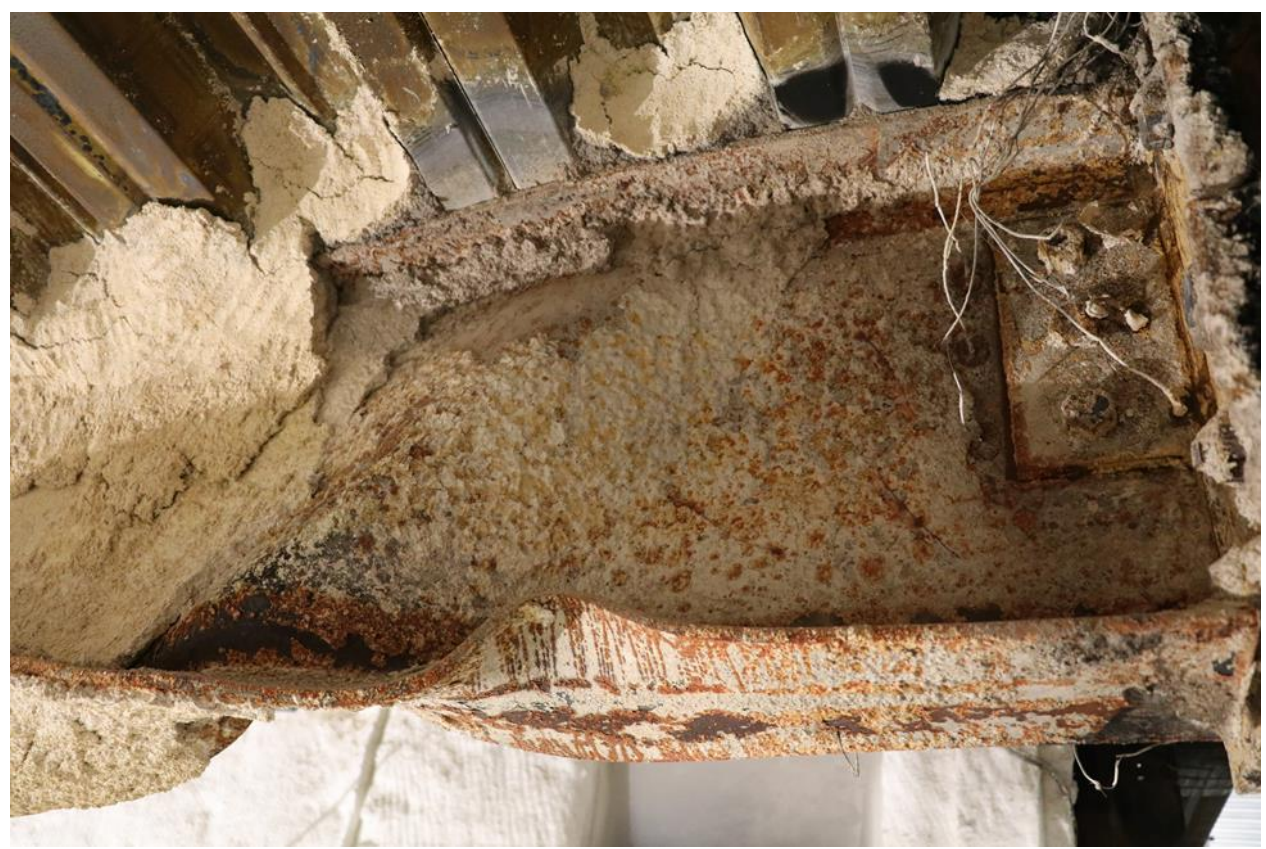

(a)

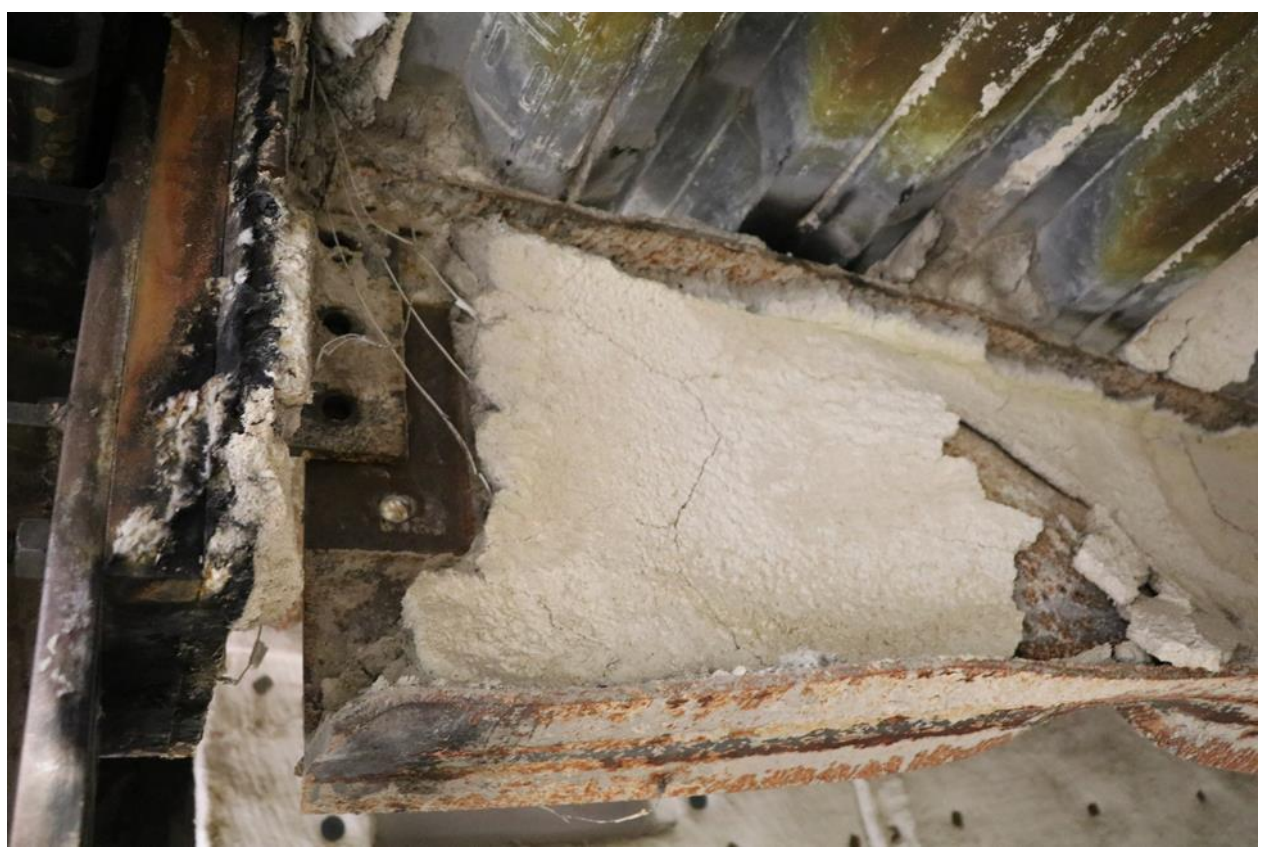

(b)

Figure 99 Photographs of CB-SP-SC after cooling: (a) the west shear tab connected to the column and (b) east connection region where three bolts connecting the shear tab fractured. 


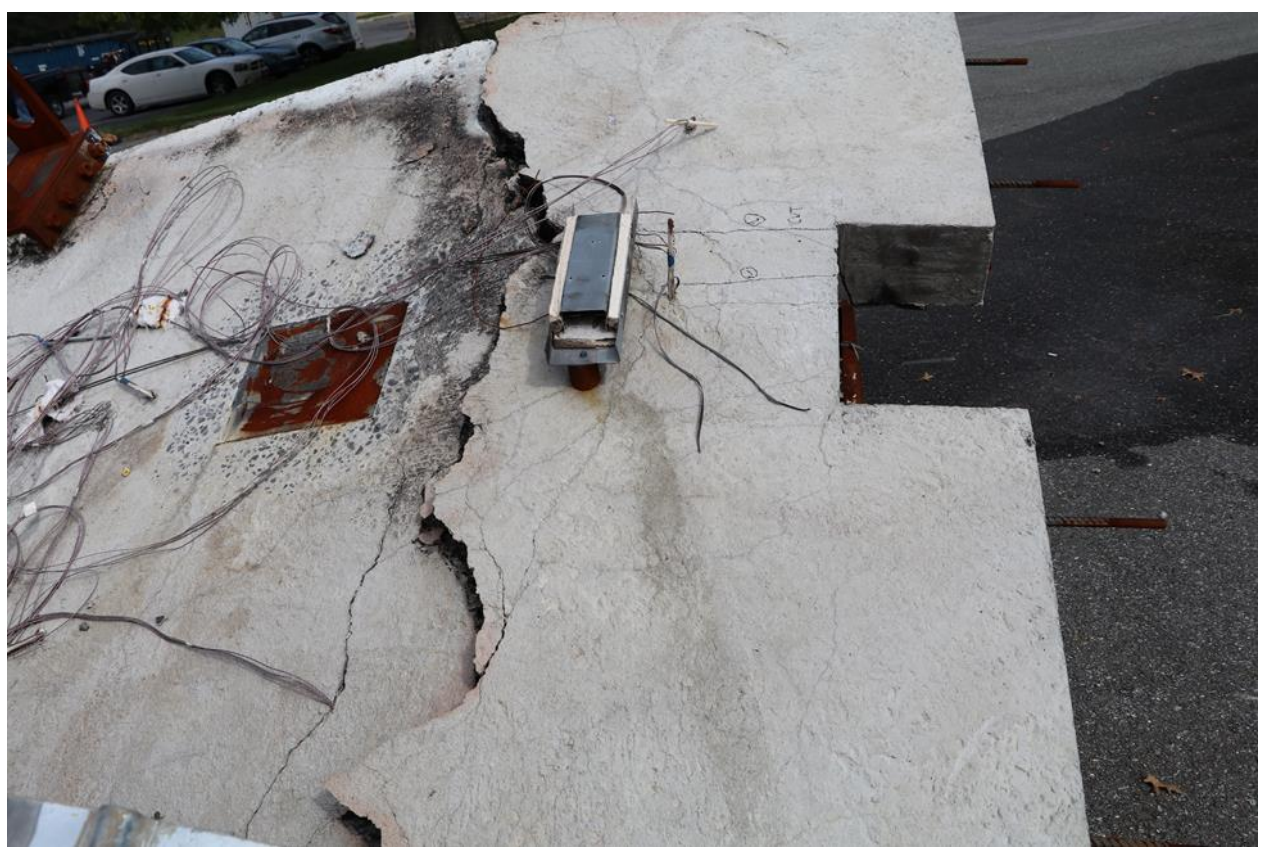

(a)

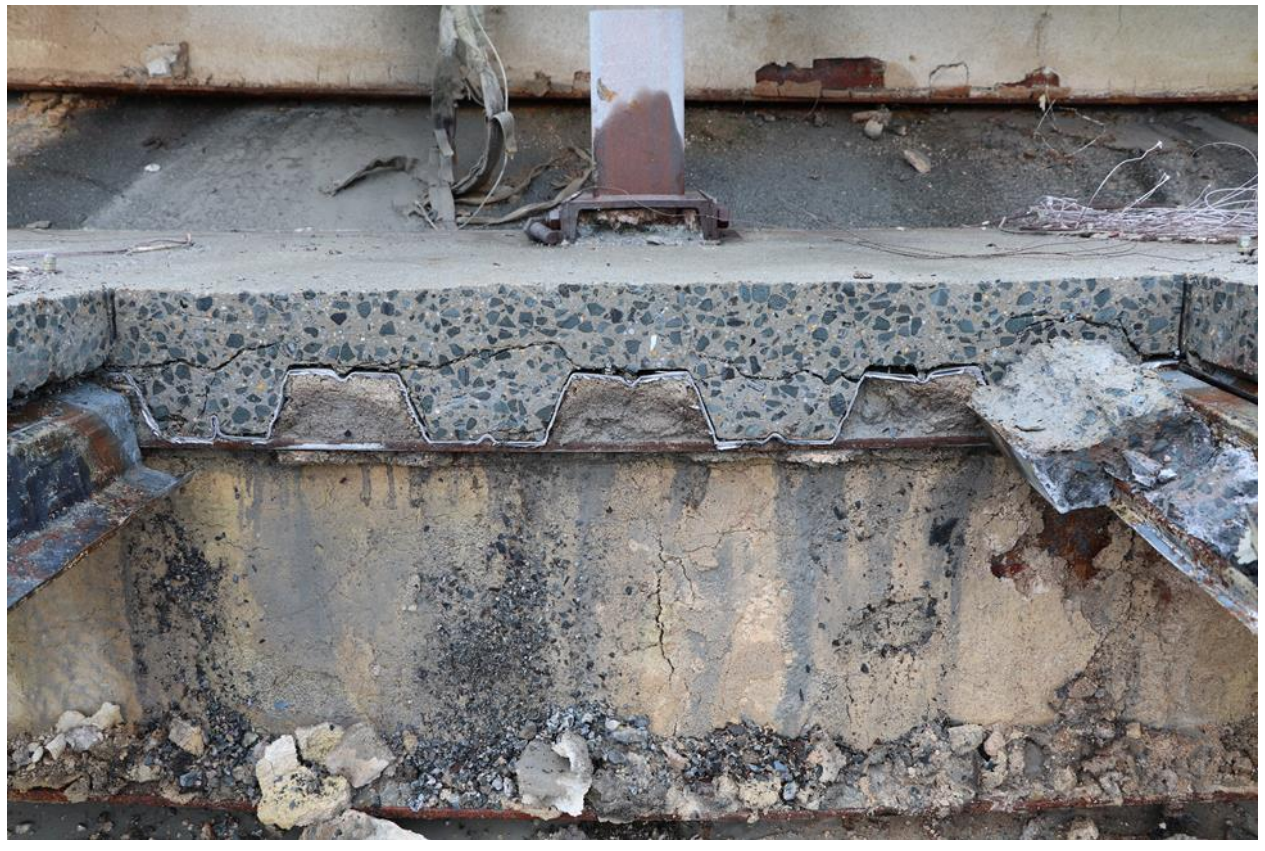

(b)

Figure 100 Photographs of CB-SP-SC after cooling: (a) concrete fracture at east end and (b) cut section of the concrete slab at midspan above the steel beam. 